Florida International University

FIU Digital Commons

FIU Electronic Theses and Dissertations

University Graduate School

6-23-2014

\title{
Simulating Everglades National Park hydrology and phosphorus transport under existing and future scenarios using numerical modeling
}

Stephanie Long

Florida International University, slong@fiu.edu

DOI: $10.25148 /$ etd.FI14071171

Follow this and additional works at: https://digitalcommons.fiu.edu/etd

\section{Recommended Citation}

Long, Stephanie, "Simulating Everglades National Park hydrology and phosphorus transport under existing and future scenarios using numerical modeling" (2014). FIU Electronic Theses and Dissertations. 1543.

https://digitalcommons.fiu.edu/etd/1543

This work is brought to you for free and open access by the University Graduate School at FIU Digital Commons. It has been accepted for inclusion in FIU Electronic Theses and Dissertations by an authorized administrator of FIU Digital Commons. For more information, please contact dcc@fiu.edu. 


\section{FLORIDA INTERNATIONAL UNIVERSITY \\ Miami, Florida}

\section{SIMULATING EVERGLADES NATIONAL PARK HYDROLOGY AND PHOSPHORUS TRANSPORT UNDER EXISTING AND FUTURE SCENARIOS USING NUMERICAL MODELING}

A dissertation submitted in partial fulfillment of the requirements for the degree of DOCTOR OF PHILOSOPHY

in

\section{GEOSCIENCES}

by

Stephanie A. Long 
To: Interim Dean Michael R. Heithaus

College of Arts and Sciences

This dissertation, written by Stephanie A. Long, and entitled Simulating Everglades National Park Hydrology and Phosphorus Transport under Existing and Future Scenarios using Numerical Modeling, having been approved in respect to style and intellectual content, is referred to you for judgment.

We have read this dissertation and recommend that it be approved.

Georgio Tachiev

Michael C. Sukop

Dean Whitman

Fernando Miralles-Wilhelm, Major Professor

Date of Defense: June 23, 2014

The dissertation of Stephanie A. Long is approved.

Interim Dean Michael R. Heithaus

College of Arts and Sciences

Dean Lakshmi N. Reddi

University Graduate School

Florida International University, 2014 
(C) Copyright 2014 by Stephanie A. Long

All rights reserved. 


\section{DEDICATION}

This dissertation is dedicated to my family. You supported me the entire time, and it was a long time. Thank you a million times over! 


\section{ACKNOWLEDGMENTS}

This work was performed in collaboration with researchers and team members from the Applied Research Center and the National Park Service who have all contributed to the development of the Mike Marsh Model of Everglades National Park (M3ENP) (Cooperative Agreement P06AC00039-MOD 0003), led by Dr. Georgio Tachiev. I would like to acknowledge Dr. Tachiev for his support and guidance with the model and the dissertation. He has always valued my work, even as an undergrad, and has helped me throughout my entire college career. Funding for the research was provided by the NASA WaterSCAPES Grant (Cooperative Agreement NNX10AQ13A), led by Dr. Fernando Miralles-Wilhelm. I am honored to have received this grant, which included internships at NASA Goddard Space Flight Center. The knowledge and experiences I have gained while working at NASA have been far beyond any other standard academic exercise. Thank you to Dr. Miralles for this amazing opportunity, I am forever grateful. Finally, the Everglades research community is recognized for their tireless efforts in understanding the complex and unique wetlands ecosystem that has served South Florida for centuries. Without their extensive data collection this research would not have been possible. It is with this data and the research which it supports, that we will discover the balance between protecting our precious natural resources and preserving our way of life. 


\title{
ABSTRACT OF THE DISSERTATION \\ SIMULATING EVERGLADES NATIONAL PARK HYDROLOGY AND PHOSPHORUS TRANSPORT UNDER EXISTING AND FUTURE SCENARIOS USING NUMERICAL MODELING \\ by
}

\author{
Stephanie A. Long \\ Florida International University, 2014 \\ Miami, Florida \\ Professor Fernando Miralles-Wilhelm, Major Professor
}

The Florida Everglades has a long history of anthropogenic changes which have impacted the quantity and quality of water entering the system. Since the construction of Tamiami Trail in the 1920's, overland flow to the Florida Everglades has decreased significantly, impacting ecosystems from the wetlands to the estuary. The MIKE Marsh Model of Everglades National Park (M3ENP) is a numerical model, which simulates Everglades National Park (ENP) hydrology using MIKE SHE/MIKE 11software. This model has been developed to determine the parameters that effect Everglades hydrology and understand the impact of specific flow changes on the hydrology of the system.

As part of the effort to return flows to the historical levels, several changes to the existing water management infrastructure have been implemented or are in the design phase. Bridge construction scenarios were programmed into the M3ENP model to review the effect of these structural changes and evaluate the potential impacts on water levels and hydroperiods in the receiving Northeast Shark Slough ecosystem. These scenarios have shown critical water level increases in an area which has been in decline due to low water levels. Results from this work may help guide future decisions for restoration designs. 
Excess phosphorus entering Everglades National Park in South Florida may promote the growth of more phosphorus-opportunistic species and alter the food chain from the bottom up. Two phosphorus transport methods were developed into the M3ENP hydrodynamic model to determine the factors affecting phosphorus transport and the impact of bridge construction on water quality. Results showed that while phosphorus concentrations in surface waters decreased overall, some areas within ENP interior may experience an increase in phosphorus loading which the addition of bridges to Tamiami Trail. Finally, phosphorus data and modeled water level data was used to evaluate the spectral response of Everglades vegetation to increasing phosphorus availability using Landsat imagery. 


\section{TABLE OF CONTENTS}

CHAPTER

PAGE

CHAPTER 1. INTRODUCTION . . . . . . . . . . . . . . . 1

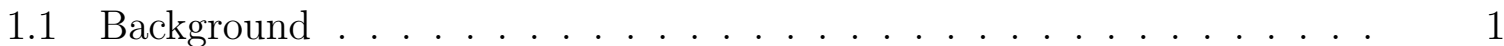

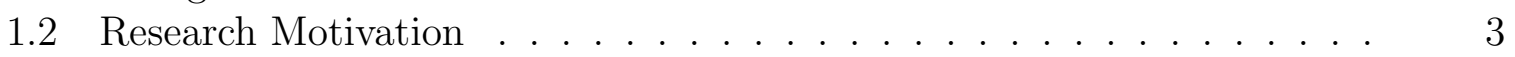

1.2.1 Previous studies . . . . . . . . . . . . . . . . . 4

1.3 Objectives . . . . . . . . . . . . . . . . . . . . . 9

1.4 Notes on Dissertation Structure . . . . . . . . . . . . . . . 9

CHAPTER 2. DEVELOPMENT OF THE MIKE MARSH MODEL OF EVERGLADES NATIONAL PARK (M3ENP) . . . . . . . . 10

2.1 Site Description . . . . . . . . . . . . . . . . . . . . 10

2.2 Methods . . . . . . . . . . . . . . . . . . . . . . . . . . . . . . . . . . .

2.2.1 Channel flow . . . . . . . . . . . . . . . . . . . . . . . . . . . . . . . . . . .

2.2.2 Evapotranspiration . . . . . . . . . . . . . . . . 14

2.2 .3 Overland flow . . . . . . . . . . . . . . . . . . . . . . . . 15

2.2.4 Unsaturated zone . . . . . . . . . . . . . . . . . . . . . . . . . . . . . . . . . . . . . .

2.2.5 Saturated Zone . . . . . . . . . . . . . . . . . 18

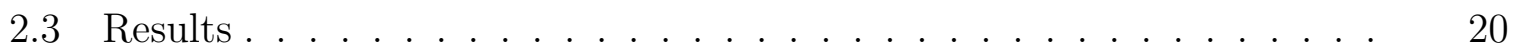

2.4 Conclusions . . . . . . . . . . . . . . . . . . . . 25

CHAPTER 3. ANALYSIS OF BRIDGE CONSTRUCTION AS A HYDROLOGICAL RESTORATION TECHNIQUE FOR EVERGLADES NATIONAL PARK, FL, USA USING HYDROLOGICAL NUMERICAL MODELING ................. 26

3.1 Abstract . . . . . . . . . . . . . . . . . 26

3.2 Introduction . . . . . . . . . . . . . . . . . . . . . . . . . . . . . . . . . . . .

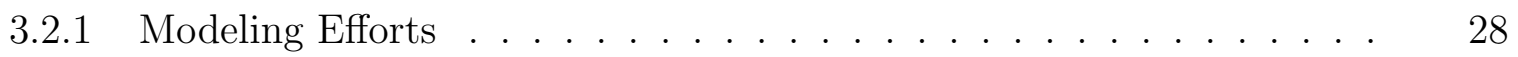

3.2.2 Restoration Plans . . . . . . . . . . . . . . . . . . . . 29

3.3 Methods . . . . . . . . . . . . . . . . . . . . . . . . . . . . . . . . . . . .

3.3 .1 Site Description . . . . . . . . . . . . . . . . . . . . . . . . . . . . . . . .

3.3.2 Model Development . . . . . . . . . . . . . . . . . . . . . . . . . . . . . . . . . . .

3.3 .3 Model Scenarios . . . . . . . . . . . . . . . . . . . . . . . . . . . . . . . . . . . . . . .

3.4 Results and Discussion . . . . . . . . . . . . . . . . . . . . . . . . 37

3.4.1 Model Calibration and Validation . . . . . . . . . . . . . 37

3.4.2 Canal Discharges . . . . . . . . . . . . . . . . . . . . . . . . . . . . . . . . . . . . . . . . . .

3.4.3 Surface Water Levels . . . . . . . . . . . . . . . . . . . . . . . . 41

3.5 Conclusions . . . . . . . . . . . . . . . . . . . . 45

3.6 Acknowledgements . . . . . . . . . . . . . . . . . 47 
CHAPTER 4. MODELING THE IMPACT OF RESTORATION EFFORTS ON PHOSPHORUS LOADING AND TRANSPORT THROUGH EVERGLADES NATIONAL PARK, FL, USA . . . . . . . 49

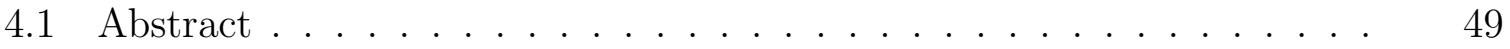

4.2 Introduction . . . . . . . . . . . . . . . . . . 50

4.2.1 Restoration efforts and their impact . . . . . . . . . . . . 51

4.2.2 Previous Modeling Studies of Phosphorus in the Everglades . . . . . 52

4.3 Methods . . . . . . . . . . . . . . . . . . 54

4.3.1 Advection-Dispersion Model Development . . . . . . . . . . . 56

4.3 .2 Phosphorus Sources . . . . . . . . . . . . . . . . . . 63

4.3 .3 Tamiami Trail Modification Scenarios . . . . . . . . . . . . . . . 66

4.4 Results and Discussion . . . . . . . . . . . . . . . . . . . . . . . 69

4.4 .1 M3ENP-AD Calibration . . . . . . . . . . . . . . . . . 69

4.4 .2 Model Sensitivity . . . . . . . . . . . . . . . . . . . . . 71

4.4 .3 Scenario Analysis . . . . . . . . . . . . . . . . . . . . . . . 73

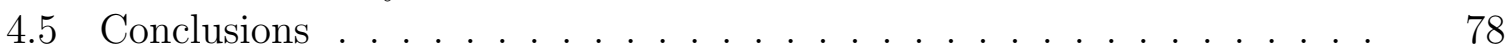

4.6 Acknowledgments . . . . . . . . . . . . . . . . . . . . . . . 79

CHAPTER 5. MODELING NUTRIENT LOADING AND TRANSPORT THROUGH EVERGLADES NATIONAL PARK, FL, USA USING A MASS BALANCE APPROACH . . . . . . . 80

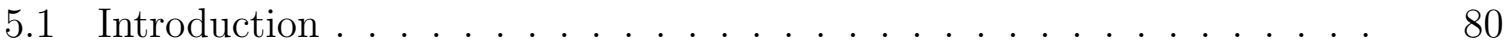

5.2 Methods . . . . . . . . . . . . . . . . . . . 81

5.2 .1 Advection-Dispersion Model Development . . . . . . . . . . . 82

5.2 .2 Mass Balance Model Development . . . . . . . . . . . . . . . . 83

5.2 .3 Phosphorus Sources . . . . . . . . . . . . . . . . . . . . 85

5.3 Results and Discussion . . . . . . . . . . . . . . . 86

$5.3 .1 \quad$ M3ENP-MB Calibration . . . . . . . . . . . . . . 86

5.3 .2 Model Mass Balance . . . . . . . . . . . . . . . . . . . . . . . 87

5.4 Conclusions . . . . . . . . . . . . . . . . . . . . . . . . 90

CHAPTER 6. REMOTE SENSING AND STATISTICAL MODELING OF PHOSPHORUS IN ENP, FL, USA . . . . . . . . . . 92

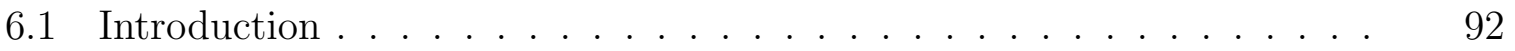

6.2 Background . . . . . . . . . . . . . . . . . . . . . . 93

6.2.1 Vegetation Reflectance . . . . . . . . . . . . . . . . . . . 93

6.2 .2 Everglades vegetation . . . . . . . . . . . . . . . . 95

6.2 .3 Landsat satellite imagery . . . . . . . . . . . . . . . . . . 96

6.3 Methods . . . . . . . . . . . . . . . . . . . . . . 97

6.3.1 Data Collection and Data Extraction . . . . . . . . . . . . . . 97

$6.3 .2 \quad$ Spectral Indices . . . . . . . . . . . . . . . . . . . . . . . . . . 99

6.3 .3 Statistical Methods . . . . . . . . . . . . . . . . . . . . . . 101

6.4 Results and Discussion . . . . . . . . . . . . . . . . . . . . . . . 104

6.4 .1 Regional Analysis . . . . . . . . . . . . . . . . . . . . . . . . . . 104 
6.5 Summary and Conclusions . . . . . . . . . . . . . . . . . . . 108

CHAPTER 7. CONCLUSIONS AND RECOMMENDATIONS . . . . . . . 110

7.1 Key Findings and Conclusions . . . . . . . . . . . . . . . . . . 110

7.2 Recommendations for Future Work . . . . . . . . . . . . . . . 112

BIBLIOGRAPHY . . . . . . . . . . . . . . . . . . . . 113

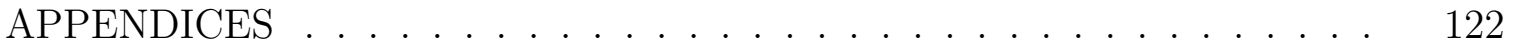

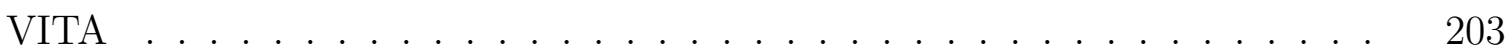




\section{LIST OF TABLES}

TABLE

PAGE

2.1 Statistical parameters for stations in the vicinity of NE1 within Northeast Shark Slough . . . . . . . . . . . . . . .

2.2 Statistical parameters for stations in the vicinity of NE3, adjacent to or within the L-31N canal. . . . . . . . . . . . . . .

2.3 Statistical parameters for stations in the vicinity of P35, in southwest Shark Slough near the mangrove boundary. . . . . . . . . . . .

2.4 Statistical parameters for stations in the vicinity of P37, in the Southern Glades and Taylor Slough. . . . . . . . . . . . . . . .

3.1 Model component overview . . . . . . . . . . . . . . . . .

3.2 Exceedance and hydroperiod analysis for the One Bridge and Two Bridge Scenarios above $0.15 \mathrm{~m}, 0.30 \mathrm{~m}$, and $0.45 \mathrm{~m}$ overland water depth.

3.3 Overland water depth increases for two ENP stations located within NESS. 44

4.1 Longitudinal dispersion coefficient values from literature. . . . . . . . . . 59

4.2 Calibrated model parameters for M3ENP-AD. . . . . . . . . . . 69

4.3 Summarized calibration statistics for the M3ENP-AD model. Statistics

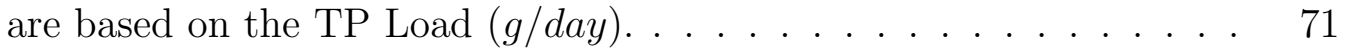

4.4 Percent change in overland TP concentration and overland TP mass for the M3ENP-AD model. . . . . . . . . . . . . . . . . .

4.5 Analysis of average daily loads and maximum cumulative loads for locations A and B along the NESS transect. . . . . . . . . . . 76

5.1 Calibrated model parameters for M3ENP-MB. . . . . . . . . . . . 87

5.2 Comparison of M3ENP-AD and M3ENP-MB model performance. . . . . 89

6.1 Landsat TM and ETM+ bands which are useful for vegetation reflectance measurements. . . . . . . . . . . . . . . .

6.2 Landsat Surface Reflectance CDR imagery acquired from the USGS. . .

6.3 List of spectral indices used to evaluate correlations between phosphorus content and vegetation reflectance. Index equations and their original developer are provided.

6.4 $\mathrm{R}$ correlation coefficients, filtered for significance (P-value $<0.05$ ), are shown for all the Landsat bands and a variety of indices. Days where water levels exceeded $15 \mathrm{~cm}$ above the ground surface were removed from the dataset prior to analysis. 


\section{LIST OF FIGURES}

FIGURE

1.1 Historical and Present-day extent of the Florida Everglades (from (Chimney and Goforth, 2006)) . . . . . . . . . . . .

2.1 The M3ENP model domain is located in South Florida and includes regions of ENP, WCA3a, and urban and agricultural areas of MiamiDade County. . . . . . . . . . . . . . . . . . . . . . .

2.2 Vegetation type for the study area (modified from (USGS, 2010)) . . . .

2.3 Leaf Area Index timeseries for Sawgrass. The LAI varies between 3 and 4 and Root Depth remains at $250 \mathrm{~mm}$. . . . . . . . . . . . . . .

2.4 Calibrated Manning's $M$ values used for friction slope calculations . . . 17

2.5 Unsaturated zone soil types (modified from NRCS; USGS (2006)) . . . 18

2.6 Horizontal hydraulic conductivity for the saturated zone layers. . . . . . 19

2.7 Monitoring station locations within the area of Northeast Shark Slough and along the L-31N canal. $\ldots \ldots \ldots$

2.8 Monitoring station locations within the area of southern Shark Slough .

2.9 Monitoring station locations within the area of southern Taylor Slough .

3.1 The M3ENP model domain (outlined in red) is located in southern Florida and includes a large portion of Everglades National Park. Tamiami Trail/US-41 marks the northern boundary for ENP. Water level monitoring stations provide the water level data for model calibration and validation.

3.2 Bridge placement along Tamiami Trail for the M3ENP models. The M3ENP-MB model scenarios include water quality simulations with no bridges (Baseline Scenario), with just the 1-mile bridge (One Bridge Scenario), and with both the 1-mile and 2.6-mile bridges (Two Bridge Scenario). . . . . . . . . . . . . . .

3.3 Averaged daily modified and observed tailwaters for structure S333. . .

3.4 Model validation from 2000 to 2010 at water level monitoring station NE1 in Northeast Shark Slough. Modeled data is shown in black and observed data is in red. . . . . . . . . . . . . . . .

3.5 Average discharge $\left(\mathrm{m}^{\mathbf{3}} / \mathbf{s}\right)$ changes along the eastern section of Tamiami Canal (L-29) for the Baseline, One Bridge, and Two Bridges Scenarios. Culverts 41 through 59 run west to east. Culverts $43,45,56$, and 58 were turned off due to the overlapping bridges and are shown as zero in the graph. . . . . . . . . . . . . . . . 
3.6 Percent probability exceedances for water levels of the One Bridge and Two Bridge scenarios. The graphs show the difference from Baseline for percent probability above $0.15 \mathrm{~m}, 0.30 \mathrm{~m}$, and $0.45 \mathrm{~m}$ overland water depth. . . . . . . . . . . . . . . .

3.7 The depth above baseline for the one bridge and two bridge scenarios over the model domain . . . . . . . . . . . . . . . 45

4.1 Model domain located in southern Florida. . . . . . . . . . . . . . 55

4.2 Comparison of the transport plume using 4 different dispersion values . 61

4.3 Schematic for the Advection-Dispersion with Reactive Transport process. 64

4.4 Observed TP concentrations (in $m g / L$ ) for critical inflow structures in the MIKE 11 model. . . . . . . . . . . . . . . . . .

4.5 Bridge placement along Tamiami Trail for the M3ENP models. The M3ENP-MB model scenarios include water quality simulations with no bridges (Baseline Scenario), with just the 1-mile bridge (One Bridge Scenario), and with both the 1-mile and 2.6-mile bridges (Two Bridges Scenario). . . . . . . . . . . . . . .

4.6 Calibrated Linear Sorption Coefficient, $k_{D}$, for the model domain. . . . . 70

4.7 Calibration results for the M3ENP-AD model at the TS/Ph2 site in Taylor Slough. . . . . . . . . . . . . . . .

4.8 Average TP load ( $g /$ day) for Observed, Baseline, One Bridge, and Two Bridge Scenarios. . . . . . . . . . . . . . . .

4.9 Overland Phosphorus Mass per Area $\left(\mathrm{g} / \mathrm{m}^{2}\right)$ for the Baseline versus Two Bridge Scenarios on 11/1/2008 . . . . . . . . . . . . . 75

4.10 Points A and B located in NESS along the flow direction. . . . . . . . 76

4.11 Daily and cumulative TP load $(\mathrm{kg})$ for Points A and B located in NESS. Daily and cumulative TP Load in A (upstream) decreases with bridge scenarios and TP Cumulative Load in B (downstream) increases with bridge scenarios. . . . . . . . . . . . . .

5.1 Model domain located in southern Florida. . . . . . . . . . . . . . . 82

5.2 Schematic for the Mass Balance process. . . . . . . . . . . . . . 84

5.3 Comparison of observed versus M3ENP-MB model results for the SRS3 water quality monitoring station. The top graph is the daily TP value (in $\mathrm{mg} / \mathrm{L}$ ) comparison for SRS3 and the bottom graph shows cumulative load for the SRS3 station. . . . . . . . . . . . . 
5.4 Schematic illustrating the movement of phosphorus between surface and subsurface flow and uptake to sorped forms. This mass balance was performed for a single modeled year, 2009, over the entire model domain. 90

6.1 Reflectance/phosphorus correlations zones on the map of the M3ENP model domain located in southern Florida. Zones include Shark Slough, the Southern Glades, and Reclaimed Agricultural. . . . . . . . . . . 105

6.2 Scatterplot of the 30-day average TP $(\mathrm{mg} / \mathrm{L})$ versus the EVIm values for the Shark Slough Zone. . . . . . . . . . . . . . . . . . 105

6.3 Scatterplot of the 90-day maximum TP $(\mathrm{mg} / \mathrm{L})$ versus the Modified EVIm values for the Reclaimed Agricultural Zone. . . . . . . . . . . . . . . 106

6.4 Scatterplot of the 30-day maximum TP $(m g / L)$ versus the Green Band values for the Southern Glades Zone. . . . . . . . . . . . . . . . . 107

A.1 Selected water level and discharge monitoring stations within the model domain. . . . . . . . . . . . . . . . . . .

B.1 Calibration results for the M3ENP-AD model at the SRS1d site in Shark Slough. . . . . . . . . . . . . . . . . . 196

B.2 Calibration results for the M3ENP-AD model at the SRS2 site in Shark Slough. . . . . . . . . . . . . . . . . . 197

B.3 Calibration results for the M3ENP-AD model at the SRS3 site in Shark Slough. . . . . . . . . . . . . . . . . . . 198

B.4 Calibration results for the M3ENP-AD model at the TS/Ph3 site in Taylor Slough. . . . . . . . . . . . . . . . 199

C.1 Comparison of observed versus M3ENP-MB model results for two stations.201

C.2 Comparison of observed versus M3ENP-MB model results for two stations.201

C.3 Comparison of observed versus M3ENP-MB model results for TS/Ph3. . 202 


\section{LIST OF ABBREVIATIONS}

$\begin{array}{ll}\text { ADRE } & \text { Advection Dispersion Reaction Equation } \\ \text { C } & \text { Carbon } \\ \text { CEPP } & \text { Climate Data Record } \\ \text { CERP } & \text { Central Everglades Planning Project } \\ \text { COR } & \text { Comprehensive Everglades Restoration Plan } \\ \text { COVAR } & \text { Correlation Coefficient } \\ \text { CS\&F } & \text { Covariance } \\ \text { DEM } & \text { Central and Southern Florida project for Flood Control } \\ \text { DHI } & \text { Digital Elevation Model } \\ \text { DMSTA } & \text { Danish Hydraulic Institute } \\ \text { ECO Lab } & \text { Dynamic Model for Storm Water Treatment Areas } \\ \text { ENP } & \text { Numerical simulation software for ecological modelling developed by } \\ \text { ENRP } & \text { DHI } \\ \text { ET } & \text { Everglades National Park } \\ \text { ETM } & \text { Everglades Nutrient Removal Project } \\ \text { Evapotranspiration } & \text { Enhanced Thematic Mapper } \\ \text { Enhanced Vegetation Index } & \text { Everglades Water Quality Model } \\ \text { ENida Coastal Everglades Long-Term Ecological Research } & \end{array}$




\begin{tabular}{|c|c|}
\hline FKAA & Florida Keys Aqueduct Authority \\
\hline HD & Hydrodynamic module \\
\hline HW & Headwater \\
\hline L-29 & Tamiami Canal \\
\hline LAI & Leaf Area Index \\
\hline M3ENP & MIKE Marsh Model of Everglades National Park \\
\hline M3ENP-AD & $\begin{array}{l}\text { MIKE Marsh Model of Everglades National Park - Advection Dis- } \\
\text { persion }\end{array}$ \\
\hline M3ENP-MB & MIKE Marsh Model of Everglades National Park - Mass Balance \\
\hline MAE & Mean Averaged Error \\
\hline $\mathrm{ME}$ & Mean Error \\
\hline MIKE 11 & One dimensional river modelling software developed by DHI \\
\hline MIKE SHE & Integrated surface water and groundwater modelling software \\
\hline NDVI & Normalized Difference Vegetation Index \\
\hline NESS & Northeast Shark Slough \\
\hline NIR & Near Infrared \\
\hline NPS & National Park Service \\
\hline NRCS & Natural Resources Conservation Service \\
\hline NS & Nash-Sutcliffe Coefficient \\
\hline $\mathrm{OL}$ & Overland Flow \\
\hline $\mathrm{P}$ & Phosphorus \\
\hline PEV & Percent Error Variance \\
\hline
\end{tabular}




$\begin{array}{ll}\text { RD } & \text { Root Depth } \\ \text { REP } & \text { Red Edge Position } \\ \text { RMSE } & \text { Root Mean Square Error } \\ \text { RSM-WQ } & \text { Regional Simulation Model for Water Quality } \\ \text { SERC } & \text { Southeast Environmental Research Council } \\ \text { SFWMD } & \text { South Florida Water Management District } \\ \text { SFWMM } & \text { South Florida Water Management Model } \\ \text { SS } & \text { Shark Slough } \\ \text { STA } & \text { Stormwater Treatment Area } \\ \text { STD } & \text { Standard Deviation } \\ \text { SWIR } & \text { Short-Wave Infrared } \\ \text { SZ } & \text { Saturated Zone } \\ \text { TIN } & \text { Triangular Irregular Network } \\ \text { TP } & \text { Total Phosphorus } \\ \text { TS } & \text { Taylor Slough } \\ \text { TW } & \text { Tailwater } \\ \text { USGS } & \text { United States Geological Survey } \\ \text { WCA } & \text { Water Conservation Area } \\ \text { WM } & \text { Water Movement } \\ \text { Wuated Zone }\end{array}$




\section{CHAPTER 1}

\section{INTRODUCTION}

A numerical model of hydrology in the Florida Everglades has been developed and utilized to determine: i) the effects of future and proposed structural changes to the water management system and ii) the fate and transport of the limiting nutrient for Everglades ecosystems - phosphorus. The model was able to simulate phosphorus loading to Everglades National Park under future water deliveries schemes. Finally, a statistical model was developed to interpret the effect of phosphorus loading to Everglades vegetation.

\subsection{Background}

Historically, the Florida Everglades ranged from south of Lake Okeechobee to Florida Bay in what was once a slow-moving sheet of water characterized by dense aquatic vegetation such as sawgrass and periphyton. The system was expansive, covering over 10,000 square kilometers of southern Florida (Stone and Legg, 2001), and the dense vegetation pulled much of the nutrients out of the water column resulting in a phosphorus-limited, oligotrophic ecosystem. Figure 1.1 shows the estimated historical and present-day extent of the Florida Everglades (Chimney and Goforth, 2006).

In the early 1900s, drainage of the Everglades began with the cutting of canals and the building of levees. In 1928, the Tamiami Trail (U.S. 41) was constructed, diving the north to south flow of Everglades waters. Since it's construction, Tamiami 
Trail been the primary physical, geographical, and hydrological barrier separating the Everglades from its water flows (NPS, 2010). By the 1970s, less than half of the original existing Everglades remained untouched; with the rest compartmentalized, channelized, dammed, gated, pumped, and drained by a highly managed system controlled by the South Florida Water Management District (SFWMD) (Stone and Legg, 2001). These hydraulic changes to the Everglades have placed stress on the native flora and fauna with the timing and distribution of water (hydroperiods) altered dramatically. With much of the Everglades drained, urban and agricultural development increased, most especially to the east. Rainfall runoff from these developed regions has increased nutrients to the naturally oligotrophic system, placing ecosystems into imbalance (Chiang et al., 2000).

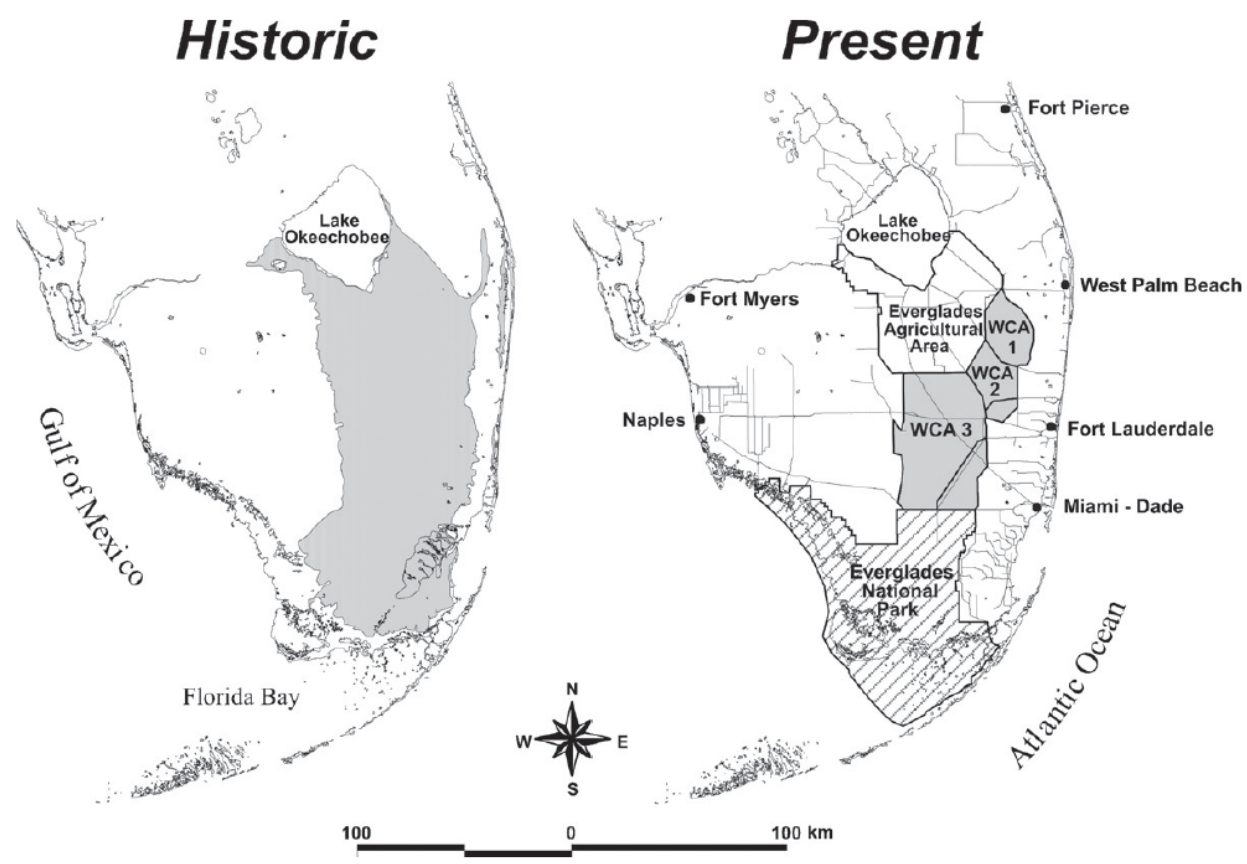

Figure 1.1: Historical and Present-day extent of the Florida Everglades (from (Chimney and Goforth, 2006))

Whereas drainage and agricultural development were the focus in the 1920s, and flood protection and water supply were the focus in the 1940s, the 1970s and 80s saw 
a refocus on water quality issues as a result of public outcry from the intense algal blooms in Lake Okeechobee (Gunderson and Light, 2006). Since then, various management efforts have sought to recover the endangered resources of the Everglades, including both water quality and water deliveries focused programs. With the acquisition of 107,000 acres in 1989, which expanded the federally protected Everglades National Park further east, plans to improve flows to Northeast Shark River Slough began (NPS, 2010). The Modified Water Deliveries Project began in 1989, with the

purpose of restoring "the natural timing, volume, and distribution of flows to Everglades National Park to the extent practicable, necessitating modification to the Tamiami Trail north of Northeast Shark River Slough" (Boler and Sikkema, 2010). However, it was not until the United States Congress authorized the 2009 Omnibus Appropriations Act that work began on bridge construction and future roadway and canal planning. In 2013, bridge construction was completed along a one-mile section of the Tamiami Trail in an attempt to improve ecosystem connectivity to the Park. An additional 2.6 mile bridge near the L-67 canal is also in the planning phase. These bridges are intended to increase ecosystem connectivity between WCA 3a (Water Conservation Area 3a) and Northeast Shark River Slough; and, in conjunction with water level increases, will promote the addition of flows into the slough and restore hydroperiods to a more natural cycle (Boler and Sikkema, 2010).

\subsection{Research Motivation}

The management of Everglades waters has been continually changing since it began a century ago, adapting to meet the social needs and objectives of the time. However, many of these changes have been largely reactive, rather than pro-active, and driven by local-scale planning issues, political interests, and governmental mandates (Gunderson and Light, 2006). The Central and Southern Florida project for Flood 
Control (CS\&F) was authorized in 1948 by Congress under the widely-accepted idea that extensive drainage and compartmentalization of the Everglades was purely beneficial. Today it is widely-accepted that the CS\&F project has caused such extensive environmental damage that what remains of the ecosystem is biologically threatened (Chimney and Goforth, 2006).

What was lacking in 1948, and may be under-emphasised by ENP decision-makers today, is scientific understanding of the large-scale and complex processes which affect the ecosystem. Extensive data collection, ecosystem monitoring, and advanced research have been ongoing for decades now, building onto that body of Everglades knowledge. It is now possible to model areas as large as ENP and determine the parameters which affect water flow and water quality. Potential Everglades restoration efforts can be simulated to provide decision-makers with the potential impacts of their plans while they finding that balance between increasing water flows to ENP and maintaining flood-control for urban and agricultural areas. It is the goal of my dissertation research to model Everglades water, in quantity and quality, and determine the effects of future restoration efforts.

\subsubsection{Previous studies}

Numerical modeling can be used to explore the hydrogeochemistry and management scenarios of the Everglades. Several previous modeling studies have been conducted to address these long-term effects of phosphorus loading to the Everglades. Buzzelli et al. (2000) created a model to simulate periphyton carbon (C) and phosphorus (P) growth as a tool to explore potential effects of external $\mathrm{P}$ loading on the pristine ENP. The model utilized the in-situ flume P-enrichment study results (Childers et al., 1999; Gaiser et al., 2004) and focused on responses of periphyton, soils, macrophytes, and consumer biogeochemical properties to $\mathrm{P}$ inputs. The $\mathrm{C}$ and $\mathrm{P}$ growth 
model by Buzzelli et al. was used to identify factors that regulate periphyton growth and examine the role of periphyton in TP cycling under input scenarios. The model calculated average daily periphyton biomass for a period of 365 days. They found that periphyton biomass did not follow the seasonal cycle; it followed the horizontal TP loading profile, reinforcing the understanding that phosphorus is the most influential factor for Everglades periphyton communities (Buzzelli et al., 2000). The C and $\mathrm{P}$ growth model, by Buzzelli et al., was limited by the simplification of the $\mathrm{P}$ cycling; phosphorus was only able to enter the system, be consumed or recycled by periphyton, settle out, or exit the system. The interaction of phosphorus with other chemicals, oxygen, benthic vegetation, or the movement of phosphorus through the system as detritus or floc was not considered. Suspended sediments were not used as a phosphorus transport mechanism. Additionally, the model was applied on a small scale and did not account for surface water/groundwater interactions. While the model was able to successfully illustrate the importance of phosphorus in periphyton communities, it was not able to reliably estimate the timing of maximum periphyton biomass. Results from the $\mathrm{C}$ and $\mathrm{P}$ growth model, by Buzzelli et al., may have improved by integrating the periphyton model with a more complete hydrological model which included overland flow, subsurface flow, evapotranspiration, rainfall, and soil properties as factors influencing water flow and phosphorus transport.

The Everglades Water Quality Model (EWQM) was developed by Raghunathan et al. in 2001 to determine the external loads that would lead to "no imbalance" phosphorus levels for biota in the everglades. The EWQM uses an empirical approach by creating an apparent net settling rate coefficient (aggregate of multiple biogeochemical processes in one term) which is then used in a mass balance equation. A net loss term represented the sum of all the physical, biological, and chemical processes that act to change the $\mathrm{P}$ concentration within a cell. Each cell is $3.2 \times 3.2 \mathrm{~km}$ and the 
study area is the entirety of the remaining Florida Everglades from the Water Conservation Areas to the edge of Everglades National Park (ENP) ending in Florida Bay. The EWQM is useful in achieving a general understanding of the rates of transport and accretion of phosphorus over the entire Everglades. However, the biogeochemical and physical processes which determine phosphorus movement are not explored individually and the low spatial resolution does not allow for much detail within each basin. For ecosystem assessment and management needs at a smaller scale (i.e. at the basin scale), it is important to have fine spatial and temporal resolution to gain the ability to simulate hydrologically controlled releases on daily and hourly basis and at finer spatial scales of interest. For instance, EWQM model averages all the timesteps over a monthly time scale, which tends to remove any critical nutrient spikes in the data. The model raised some serious mechanistic warnings as well. The model cannot account for cells which experience completely dry conditions. It will skip any dry cells for the duration of the dry months and resume the phosphorus concentrations from the previous wet months. While the South Florida Water Management Model (SFWMM) (SFWMD, 2005) in conjunction with the EWQM have been able to describe regional overland water flows and depths as well as phosphorus levels, the models are limited by their large cell size which generalizes many of the unique wetlands features as well as any water control structural changes.

A spatio-temporal phosphorus transport and cycling model was developed to evaluate the Everglades Nutrient Removal Project (ENRP) in Stormwater Treatment Area 1 (STA1) by Paudel et al. (2010). The hydrological model develops the information necessary to simulate $\mathrm{P}$ transport; which is divided into advection-dispersion transport and a flexible biogeochemical reaction module. However, separate processes affecting $\mathrm{P}$ dynamics, such as resuspension and chemical precipitation, are not independently calculated. The model focuses on a Stormwater Treatment Area, which is 
designed as a buffer for high nutrient loading from the agricultural areas which drain into the Everglades. Using a similar model on a more natural, or less designed, region of the Florida Everglades would provide more insight to the immediate and long-term effects of P loading. In addition, Paudels hydrodynamic model includes overland flow coupled with groundwater flow (Paudel et al., 2010). However, the water quality is only calculated for overland flow and ignores the critical interaction with subsurface flow. Harvey et al. (2006) modeled the spatial distribution of tritium measurements and concluded that the interaction between surface water and groundwater in the Everglades is relatively small but significant, especially when considering its effect on solute fate and transport and storage (Harvey et al., 2006).

Remote sensing is becoming a useful tool for monitoring the health and productivity of large remote areas of the world as a consequence of the availability of repeating data acquisition from multiple satellites. Historical imagery can now trace changes in vegetation coverage over multiple decades. Rivero et al. (2009) attempted to address the long-term effects of P loading to the Everglades using remote sensing modeling. The study by Rivero et al. was limited by the single image acquisition and the types of indices used for correlation. Once the relationships between the spectral reflectance of the vegetation and the vegetation type and productivity are established, information about the nutrient content in the surrounding area can be inferred. Some ecosystem components such as vegetation and water can be directly measured with remote sensing; however, information such as total phosphorus content in soils and floc must be inferred via statistical relationships to spectral data (Rivero et al., 2009).

The Mike Marsh Model of Everglades National Park (M3ENP), developed in 2011 by the Applied Research Center at Florida International University and the National Park Service in Homestead, FL, is a physically defined numerical model which has successfully simulated surface and groundwater flows and levels within ENP (Cook, 
2012). In Chapter 3 of the present research, the M3ENP model is used to explore the effects of bridge construction and canal water level increases on ENP water levels and flows.

Hydrology provides the mechanism by which phosphorus moves and is considered the most important factor in the phosphorus transport regime (Haygarth and S. C., 1999). By adding a water quality module to the hydrodynamic results of the M3ENP baseline and bridge addition simulations, phosphorus loading to ENP is spatially and temporally quantified. Chapter 4 demonstrates the water quality model development and validation and quantifies phosphorus loading to ENP using the simulations representing the construction of the 1-mile and 2.6-mile bridges. Chapter 5 develops the water quality model further by introducing phosphorus uptake and release kinetics into a mass balance model.

Chapter 6 of this research utilizes statistical modeling to develop relationships between phosphorus content of the Everglades and the spectral reflectance of vegetation measured from space. Modeled phosphorus data from the M3ENP Water Quality model was used to develop statistical relationships between phosphorus (in selected media such as soils, periphyton, vegetation, water, etc.) and spectral bands and indices from Landsat images. The statistical correlations established through this investigation provide a quick-look tool for ecosystem stakeholders to determine Everglades nutrient levels and ecosystem health with every new satellite image obtained. In addition, the indices can provide ENP managers and stakeholders with a simple and efficient monitoring tool which also provides remote sensing visuals for communication to the public about the effects of phosphorus. 


\subsection{Objectives}

The work completed and described in this doctoral dissertation was driven by the primary goal of determining phosphorus fate and transport in Everglades National Park. To complete this work, three specific objectives were identified:

1. Model water flows and levels throughout the domain with both current and future conditions.

2. Using the water movement results, determine the phosphorus transport through ENP with both current and future conditions.

3. Determine the long-term effects of phosphorus loading to ENP by combining remote sensing techniques with modeled results.

\subsection{Notes on Dissertation Structure}

The present dissertation is arranged according to how the watershed model was developed. The work begins with the model development in Chapter 2, then moves on to how that model was utilized in simulations in Chapter 3. The dissertation then advances to the development of advection-dispersion-reaction module in Chapter 4, and then an even more complex user-designed phosphorus mass balance module in Chapter 5. The paper ends with a look into the potential for using remote sensing to determine critical understanding of how phosphorus can change an ecosystem Chapter 6. Chapters 3 and 4 were prepared for publication in separate peer-reviewed

journals; consequently, some of the main ideas of the paper (including the the cost of anthropogenic changes on Everglades wetland ecosystems and the impact of restoration efforts) may be reiterated so that each of the papers could stand alone. 


\section{CHAPTER 2}

\section{DEVELOPMENT OF THE MIKE MARSH MODEL OF EVERGLADES NATIONAL PARK (M3ENP)}

Crucial to the completion of the objectives was the development of the numerical model for determining water flow in the surface and subsurface of the model domain. Chapter 2 provides a detailed description of the processes and equations describing water movement, which are developed into the Mike Marsh Model of Everglades National Park (M3ENP) numerical model. Chapter 3 refers directly to hydrodynamic results calculated using this model, and water quality Chapters 4 and 5 refer to processes which are calculated using the hydrodynamic results of this model. Therefore, this chapter may serve as the mathematical basis of the dissertation. Calibration results of the M3ENP are shown in Appendix A.

\subsection{Site Description}

The M3ENP model domain, shown in Figure 3.1, is approximately 2,720 sq $\mathrm{km}$ and includes parts of Everglades National Park (ENP), WCA 3a and 3b (Water Conservation Areas just north of ENP), and urban and agricultural areas of Miami-Dade County in South Florida. Figure 2.1 shows the model domain location in South Florida. The focal region encompasses a range of ecosystems including ridge and slough, wet prairies, tree islands, pine forests, cypress forests, upland pine forests, mangrove forests in estuarine regions, and agricultural areas (Stone and Legg, 2001). 
Hydroperiods can vary widely in these ecosystems and include permanent inundation in sloughs and mangrove forests, seasonal inundation in the wet prairies and cypress forests, daily inundation in tidal zones, and permanently dry in the upland pine forests (Boler and Sikkema, 2010). Seasons in South Florida are driven by changes in rainfall and evapotranspiration. The wet season in South Florida is from June to October, during which two thirds of the annual precipitation falls (Abtew, 1996).

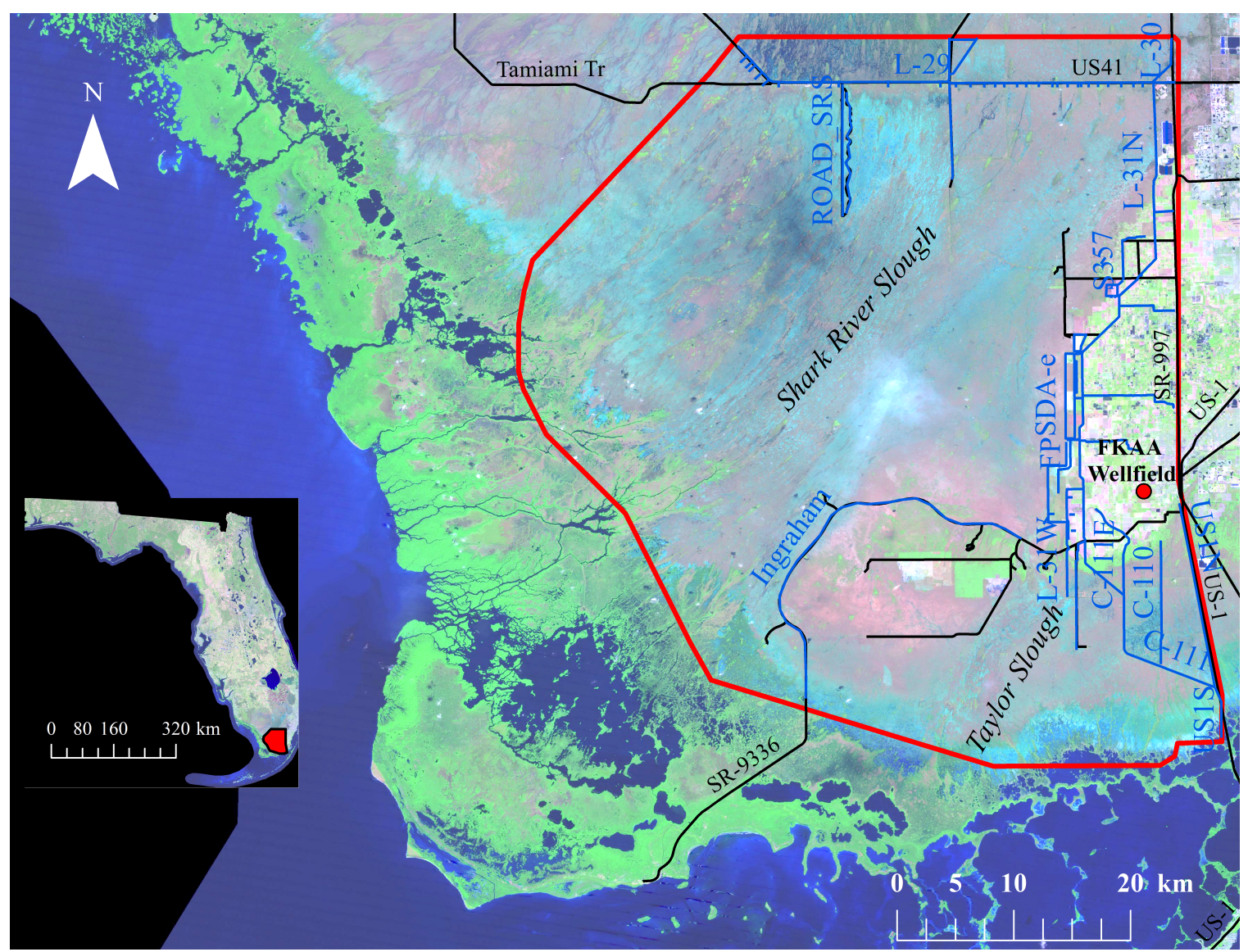

Figure 2.1: The M3ENP model domain is located in South Florida and includes regions of ENP, WCA3a, and urban and agricultural areas of Miami-Dade County.

Soils in this system range from calcitic marl to organic peat (Zhou and Li, 2001). Peat in the Everglades plays a crucial role in landscape and ecosystem development, and is sensitive to hydroperiods and drainage (Boler and Sikkema, 2010). Underlying the soils is the surficial aquifer system, which is comprised of everything from the land 
surface down to the top of the intermediate confining unit and is the source of most of the potable water used in southeastern Florida. Within the surficial aquifer system is the Biscayne aquifer which is a highly transmissive system composed of several rock layers including the thin Miami Oolite formation and the Fort Thompson formation (Fish and Stewart, 1991). Cut through the soils and rock are the canals and levees which control water flow to and away from ENP. The main channels are the L-29 canal which runs west to east and the L31N canal which runs south to the C-111 and then southeast out to the Atlantic Ocean.

\subsection{Methods}

The numerical model calculates the physical processes of the hydrological cycle using well-established equations. The two-dimensional diffusive wave Saint Venant equations describe overland flow (OL), the Kristensen and Jensen methods (Kristensen and Jensen, 1975) are used for evapotranspiration (ET), the one-dimensional Richards's equation for unsaturated zone flow (UZ), and a three-dimensional Boussinesq equation for saturated zone flow (SZ) (Christiaens and Feyen, 2002). The partial differential equations are solved by implicit finite difference methods, while other methods (i.e., evapotranspiration) in the model are empirical equations obtained from independent experimental research (Refsgaard and Storm, 1995; Havnø et al., 1995). The equations are built into the commercially available software MIKE SHE/MIKE 11 by DHI Group, LLC, which is used to develop the M3ENP model. Details on these numerical modeling methods are provided in the following sub-sections.

\subsubsection{Channel flow}

The model computes water levels, discharges and flow velocities at all nodes on the basis of the one-dimensional Saint Venant equations. The differential equations are 
solved using a 6-point implicit finite difference scheme with alternating flow and stage points along the channel which can be applied to both subcritical and supercritical flows (Havnø et al., 1995). The channel flow component was built from USGS river delineations. Channel cross sections were determined from topography data and design as-builts. Channel structures such as culverts, weirs, gates and pumps were developed based on designs obtained from SFWMD and DERM as described in Cook (2012). Canal water level inputs were obtained from NPS, SFWMD, or USGS.

During normal flow regimes, river flow in MIKE 11 is allowed seep into the MIKE SHE saturated zone (SZ). Flow from the channel to the SZ is calculated as $Q=C \cdot \Delta h$, where $C$ is conductance and $\Delta h$ is the head difference between the river and the model grid cell (DHI, 2012). The conductance (in $\mathrm{m}^{2} / \mathrm{s}$ ) represents the exchange between surface water and groundwater per unit head difference.

Conductance is calculated differently depending on the type of river bed lining. If the material which lines the river bed is sufficiently thick in comparison to the aquifer material, or the head loss from the river is much larger than that in the aquifer, the conductance is calculated using the river bed leakage rate only. If there is no permeable river bed lining and the river is in full contact with the saturated zone, the conductance is calculated using the saturated zone horizontal hydraulic conductivity. If there the river bed lining is sufficiently permeable, both the river bed leakage rate and the saturated zone horizontal conductivity can be used to calculate the conductance (DHI, 2012).

To simulate inundation of the flood plain, the option for Direct Overbank Spilling to and from MIKE 11 was used. The flood plain is defined as part of the MIKE SHE topography. Since the bank elevation is used to define when a cell floods, a special emphasis was placed on ensuring that that the cross-sections are consistent with the topography, especially in the areas where flooding was simulated. The table in the 
simulation log file was used to locate any inconsistencies and the elevation data of the cross section was revised. The availability of fine grid and detailed DEM has reduced the inconsistencies and the amount of interpolation and averaging when creating the model topography.

\subsubsection{Evapotranspiration}

The actual ET and the actual soil moisture status in the root zone were calculated from the potential evaporation rate, the maximum root depth (RD), and the leaf area index (LAI) for each vegetation classification. In MIKE SHE, the ET process proceeds as follows: i) a portion of rainfall is intercepted by the canopy (at a storage capacity of $0.05 \mathrm{~mm}$ ) and evaporates, ii) the remainder reaches the soil and adds to runoff or percolates into the upper soil layer, iii) part of the infiltrating water is either transpired by plant roots or evaporated, iv) and the remaining water recharges the groundwater. When the saturated zone rises to a level that is within the UZ (as is common in the wet prairies of the Everglades), transpiration is calculated as a distributed loss from both the SZ and UZ.

Figure 2.2 shows the vegetation types defined from the USGS GAP survey (USGS, 2010). Vegetation types were aggregated from the survey on the basis of parameter similarity and spatial connectivity. Each vegetation type has specified LAI and RD values which are used in the calculation of transpiration. The LAI varies seasonally, increasing in the months of the wet season, but RD is considered unchanging with time. Figure 2.3 is an example of the variable LAI and RD approximation for Sawgrass.

The SFWMM gridded daily rainfall data was acquired for this model. These data is interpolated from hundreds of rainfall stations over south Florida using a Triangular Irregular Network (TIN) and gridded with a 4 square mile cell size (SFWMD, 2005). 


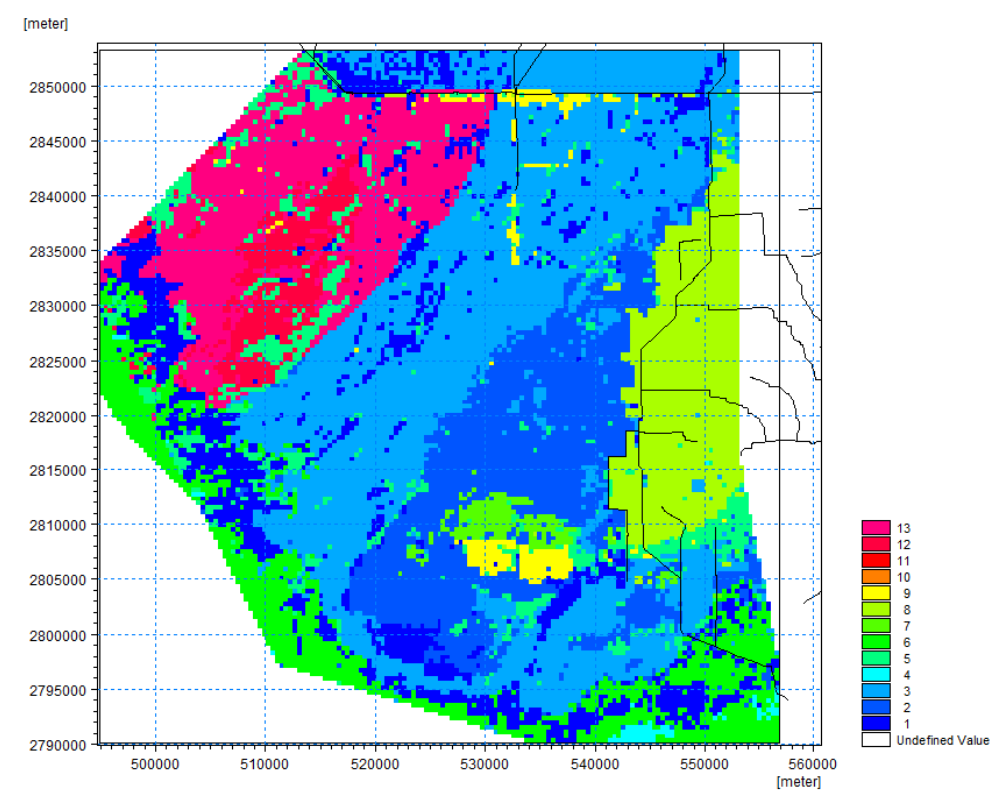

Figure 2.2: Vegetation type for the study area (modified from (USGS, 2010))

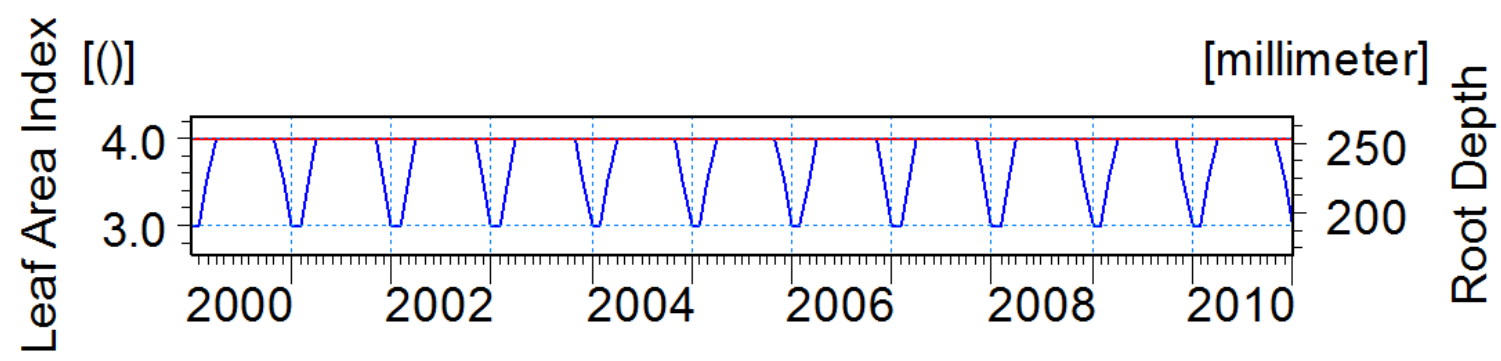

Figure 2.3: Leaf Area Index timeseries for Sawgrass. The LAI varies between 3 and 4 and Root Depth remains at $250 \mathrm{~mm}$.

\subsubsection{Overland flow}

When the net rainfall rate exceeds the infiltration capacity of the soil, the model allows water to accumulate on the ground surface. The accumulated water is then available as surface runoff and is routed downhill towards the river system. The exact route and quantity is determined by the topography and flow resistance, as well as the losses due to evaporation and infiltration along the flow path (Refsgaard and Storm, 
1995). Overland flow is calculated using the diffusive wave approximation for the Saint Venant equations and the friction slope is solved using the Manning's equation.

Manning's values were initialized on the basis of vegetation friction and calibrated for each subdomain in the model, the resulting values are shown in Figure 2.4. Manning's $M$ is the inverse of Manning's $n(M=1 / n)$; higher values describe areas with lower surface roughness including paved areas and bare soil, while lower $M$ values are associated with densely vegetated areas which increase surface roughness. For a planar surface of infinite width with uniform rainfall; precipitation falls on the plane, builds on the surface in response to the surface roughness, and flows down the slope in the positive x-direction. Flow is adjusted for surface friction using Manning's equation is as follows:

$$
u(x, y)=\frac{1}{n} S_{f} x^{1 / 2} R^{2 / 3}
$$

where $R$ is the hydraulic radius, $S_{f}$ is the friction slope of the water surface, and $n$ is Manning's number. Assumed values for Manning n (Chow, 1959) range between 0.01-0.10 (i.e., range between concrete and vegetated area, heavily vegetated areas can have $n$ as high as 0.20).

\subsubsection{Unsaturated zone}

Transport of water in the unsaturated zone is driven by the gradient of the hydraulic head, $\Delta h$, which has both a gravity component, $z$, and pressure component, $\Psi$, such that $h=z+\Psi$. While the reference value for the pressure head is the atmospheric pressure, unsaturated conditions can produce negative pressures as a result of interstitial capillary forces and adsorptive forces between the water molecules and soil

matrix. The pressure head component $\Psi$ is therefore considered negative while above the water table (unsaturated) and positive while below (saturated). The MIKE SHE model utilizes the Richards Equation and an iterative coupling procedure between 


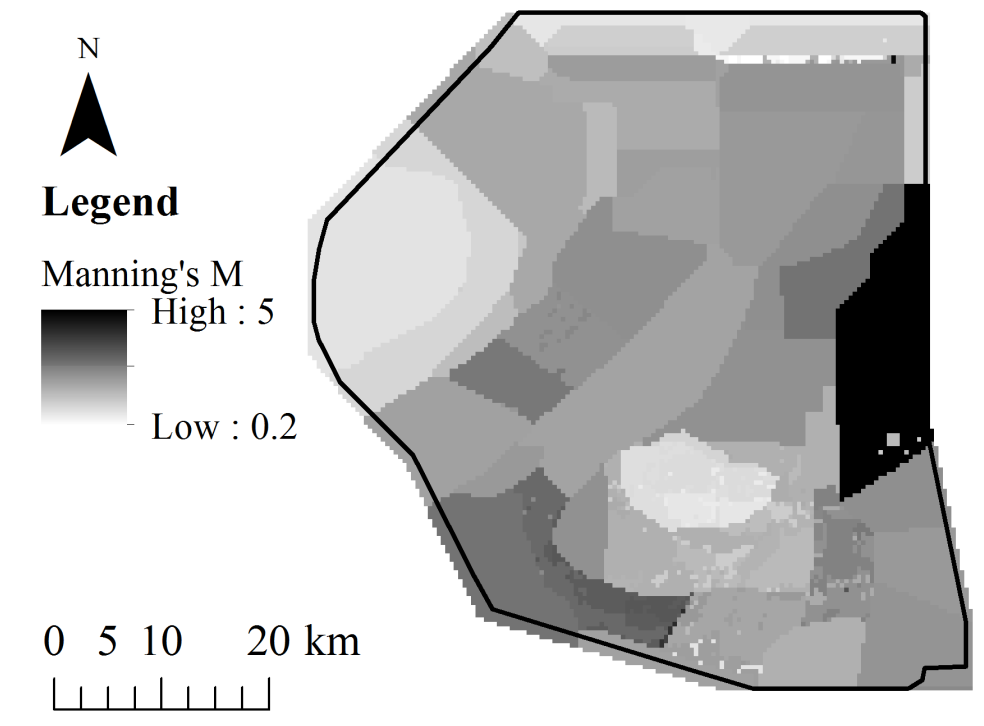

Figure 2.4: Calibrated Manning's $M$ values used for friction slope calculations

the unsaturated zone and the saturated zone to calculate the correct soil moisture and water table dynamics.

Incorporating the hydraulic conductivity $K(\theta)$ from Darcys Law, the volumetric soil moisture $\theta$, the root extraction sink term $S$, the pressure head $\Psi$, and the soil water capacity $C$; Richards equation is derived:

$$
C \frac{\partial \Psi}{\partial t}=\frac{\partial}{\partial t}\left(K(\theta) \frac{\partial \Psi}{\partial z}\right)+\frac{\partial K(\theta)}{\partial z}-S
$$

Parameters for the soil moisture equation were obtained from the Carsel and Parrish (1988) database. Values of saturated hydraulic conductivities and van Genuchten water retention parameters were identified for each of the soil texture types in the study area.

Soil types vary widely, from marl to a variety of peat soils as shown in Figure 2.5. Areas which maintain standing water throughout most of the year typically accumulate a layer of organic peat which is formed during the deposition of sawgrass and other emergent plants (Harvey et al., 2006). In other regions, the soils may be a calcitic mud called marl (Stone and Legg, 2001). Soil type data was modified from 
(NRCS; USGS, 2006). Many of the soil types were aggregated on the basis of soil parameter similarity and spatial connectivity.

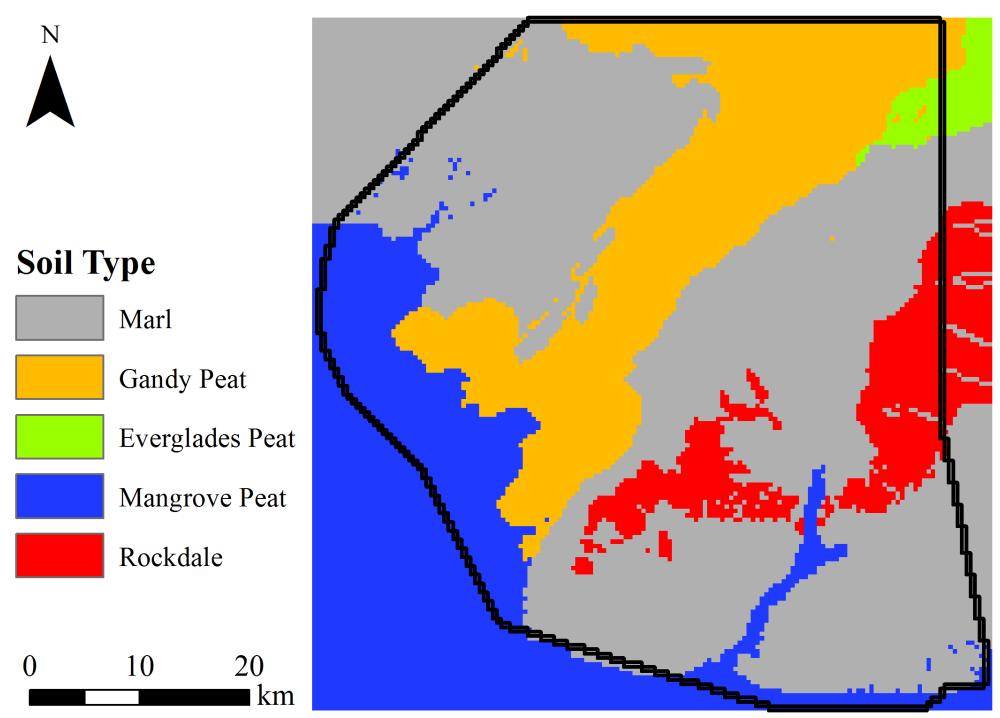

Figure 2.5: Unsaturated zone soil types (modified from NRCS; USGS (2006))

Unsaturated zone exchange with the saturated zone is solved using an iterative mass balance method which conserves mass in the water column by considering outflows and source and sinks to the SZ. Recharge to the groundwater is calculated based on the actual soil moisture distribution within the UZ and is affected by groundwater levels, UZ storage, and soil properties.

\subsubsection{Saturated Zone}

Hydrogeologic sections of the study area reveal several formations, aquifers, and confining units (Fish and Stewart, 1991). However, it was necessary to simplify the system into a 2-layer saturated zone. The first layer is the thin Miami Oolite layer from the land surface down to the top of the Fort Thompson Formation. The Oolite layer can be as deep as 6 meters below the surface in the south east to less than a meter below the surface in the northwestern section of ENP. The second layer is the 
remaining section of the Biscayne aquifer which ranges from 40 to 70 meters below the surface. It is comprised of several semi-confining and aquifer layers including the Fort Thompson Formation, Key Largo Limestone, and the Tamiami Formation (Fish and Stewart, 1991). At the base of the second layer is a confining unit through which all fluxes are considered zero.

Horizontal and vertical hydraulic conductivity measure the capacity of the aquifer material to transmit water in each direction. Values for horizontal hydraulic conductivity in the SZ Layer 1 were calculated and interpolated from transmissivity and aquifer thickness data provided in Fish and Stewart (1991). Horizontal hydraulic conductivity in SZ Layer 2 was calibrated in subbasin sections. Figure 2.6 shows the horizontal hydraulic conductivity for both SZ layers.
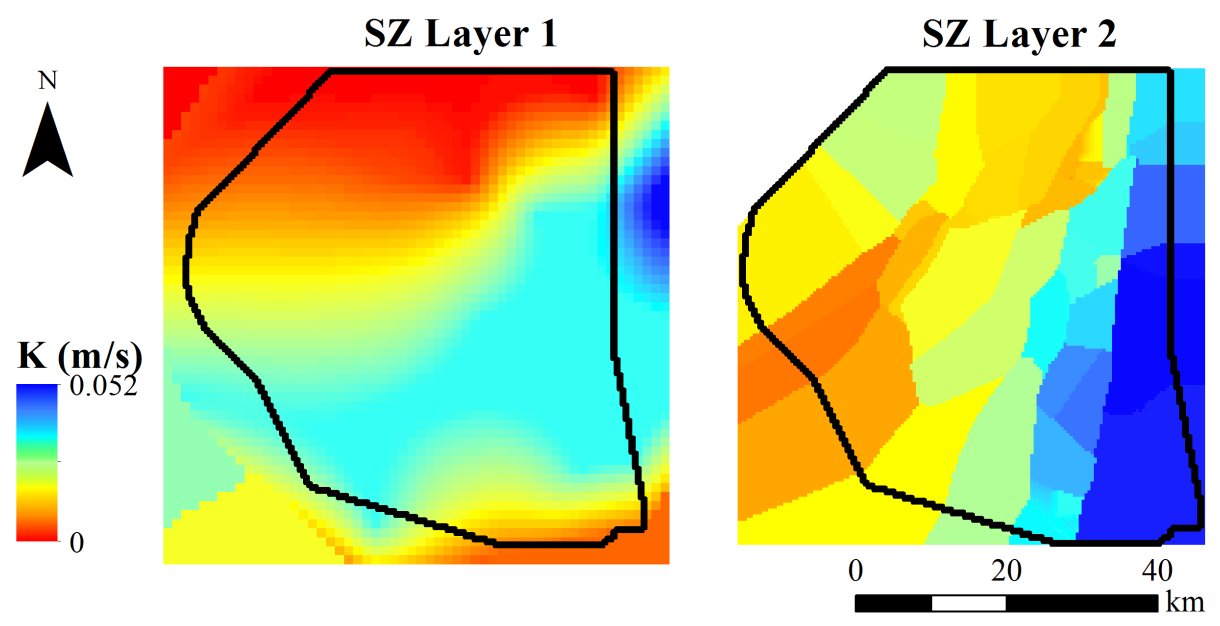

Figure 2.6: Horizontal hydraulic conductivity for the saturated zone layers.

The hydraulic head in the saturated zone is calculated using the three-dimensional groundwater flow equation. Exchange from the saturated zone with other hydrological components, such as the channel flow and unsaturated zone modules, is calculated along the boundaries of these other components and solved implicitly or explicitly as sources and sinks to the groundwater flow equation. The governing flow equation for 
the 3-D saturated flow in saturated porous media is as follows:

$$
\frac{\partial}{\partial x}\left(K_{x x} \frac{\partial h}{\partial x}\right)+\frac{\partial}{\partial y}\left(K_{y y} \frac{\partial h}{\partial y}\right)+\frac{\partial}{\partial z}\left(K_{z z} \frac{\partial h}{\partial z}\right)-Q=S \frac{\partial h}{\partial t}
$$

where $K_{x x}, K_{y y}, K_{z z}$, are the hydraulic conductivities in three dimensions, $h$ is the hydraulic head, $Q$ represents the source/sink terms, and $S$ is the specific storage coefficient. Specific storage is defined as the volume of water released per volume of aquifer per unit decline in head. For this study, both SZ layers used specific storage coefficient of $0.0001 \mathrm{~m}^{-1}$.

\section{Pumping}

One pumping well was incorporated into the model to account for SZ losses in this region. The well is at 21.95 meters below the ground surface and is into the SZ Layer 2. The theoretical well represents the FKAA (Florida Keys Aqueduct Authority) wellfield just outside of the ENP boundary, but included in the M3ENP domain as shown in Figure 2.1. Pumping was set to a constant rate of $0.9345 \mathrm{~m}^{3} / \mathrm{s}\left(33 \mathrm{ft}^{3} / \mathrm{s}\right)$ for the simulation period.

\section{$2.3 \quad$ Results}

Calibration for the M3ENP was performed for several subdomains within the model domain to determine sensitive parameters such as Manning's number and hydraulic conductivity (Cook, 2012). Model best fit was evaluated using stage and discharge observed data at over 100 sites within the model domain for the 2000 to 2010 period. For each monitoring station with observed data a set of statistical parameters was calculated, including:

1. ME: mean error equal to the sum of the difference observed minus calculated divided by the total number of samples 
2. MAE: sum of the absolute difference of observed minus calculated divided by the total number of samples

3. RMSE: root mean square of the observed minus computed

4. STD: standard deviation of the residual

5. NS: fraction of the error relative to the measured fluctuation

6. COVAR: standard deviation of the residual

7. COR: covariance of the observed and modeled stage divided by the product of the standard deviations

8. PEV: a measure of how much two variables change with respect to each other (in this report the PEV factor is provided as fraction rather than a percent).

The Nash-Sutcliffe Coefficient yields a percentage of the error relative to the measured fluctuation. The NS is sensitive to mean differences in measured and computed, which can yield large negative values. The Nash-Sutcliffe model efficiency coefficient $(N S)$ compares the residual squared to the measured variance as shown in Equation 2.4 .

$$
N S=1-\frac{\sum_{t=1}^{T}\left(h_{m}^{t}-h_{o}^{t}\right)^{2}}{\sum_{t=1}^{T}\left(h_{o}^{t}-\overline{h_{o}}\right)^{2}}
$$

The following tables provide all of the calculated statistical parameters for several key areas within the model domain. These areas include the Northeast Shark Slough region (NESS) and the L-31N canal (Figure 2.7),downstream Shark Slough (SS) near the mangrove boundary (Figure 2.8), and the Taylor Slough (TS) and Southern Glades region (Figure 2.9).

Figure 2.7 shows locations for the monitoring sites listed in both Table 2.1 and Table 2.2. The statistics show that the model performs well in this region (NS above 0.75 on average). 
Table 2.1: Statistical parameters for stations in the vicinity of NE1 within Northeast Shark Slough

\begin{tabular}{lcccccccc}
\hline Station & N & MAE & RMSE & STD & NS & COVARCOR & PEV \\
\hline NE2 & 3743 & 0.16 & 0.00 & 0.00 & 0.87 & 0.34 & 0.94 & 0.88 \\
NE4 & 3667 & 0.20 & 0.01 & 0.01 & 0.75 & 0.37 & 0.88 & 0.75 \\
NE5 & 3864 & 0.19 & 0.00 & 0.00 & 0.72 & 0.32 & 0.89 & 0.72 \\
BRDG53 & 4368 & 0.18 & 0.00 & 0.00 & 0.75 & 0.24 & 0.91 & 0.75 \\
L67XW & 3784 & 0.25 & 0.00 & 0.00 & 0.84 & 0.45 & 0.95 & 0.88 \\
L67XE & 3824 & 0.18 & 0.00 & 0.00 & 0.86 & 0.32 & 0.93 & 0.87 \\
\hline
\end{tabular}

Table 2.2: Statistical parameters for stations in the vicinity of NE3, adjacent to or within the L-31N canal.

\begin{tabular}{lcccccccc}
\hline Station & N & MAE & RMSE & STD & NS & \multicolumn{2}{c}{ COVARCOR } & PEV \\
\hline NE3 & 3707 & 0.51 & 0.01 & 0.01 & 0.66 & 0.55 & 0.93 & 0.80 \\
G3576 & 3914 & 0.18 & 0.00 & 0.00 & 0.87 & 0.49 & 0.96 & 0.90 \\
G3578 & 3912 & 0.24 & 0.01 & 0.00 & 0.86 & 0.69 & 0.95 & 0.90 \\
G3576 & 3914 & 0.18 & 0.00 & 0.00 & 0.87 & 0.49 & 0.96 & 0.90 \\
L31NMILE1 & 3929 & 0.23 & 0.00 & 0.00 & 0.74 & 0.24 & 0.87 & 0.74 \\
L31NMILE3 & 3941 & 0.23 & 0.00 & 0.00 & 0.73 & 0.23 & 0.86 & 0.73 \\
L31NMILE4 & 3955 & 0.25 & 0.01 & 0.00 & 0.71 & 0.23 & 0.86 & 0.72 \\
L31NMILE5 & 3921 & 0.23 & 0.00 & 0.00 & 0.73 & 0.23 & 0.86 & 0.73 \\
L31NMILE7 & 3928 & 0.22 & 0.01 & 0.01 & 0.69 & 0.22 & 0.84 & 0.69 \\
G3272 & 3951 & 0.38 & 0.01 & 0.01 & 0.77 & 0.89 & 0.90 & 0.79 \\
S334_HW & 3972 & 0.12 & 0.00 & 0.00 & 0.91 & 0.24 & 0.98 & 0.96 \\
S334_TW & 3972 & 0.20 & 0.01 & 0.00 & 0.70 & 0.24 & 0.87 & 0.75 \\
S336_HW & 3950 & 0.21 & 0.01 & 0.00 & 0.71 & 0.24 & 0.86 & 0.73 \\
G211_HW & 3785 & 0.22 & 0.01 & 0.01 & 0.67 & 0.22 & 0.84 & 0.70 \\
\hline
\end{tabular}




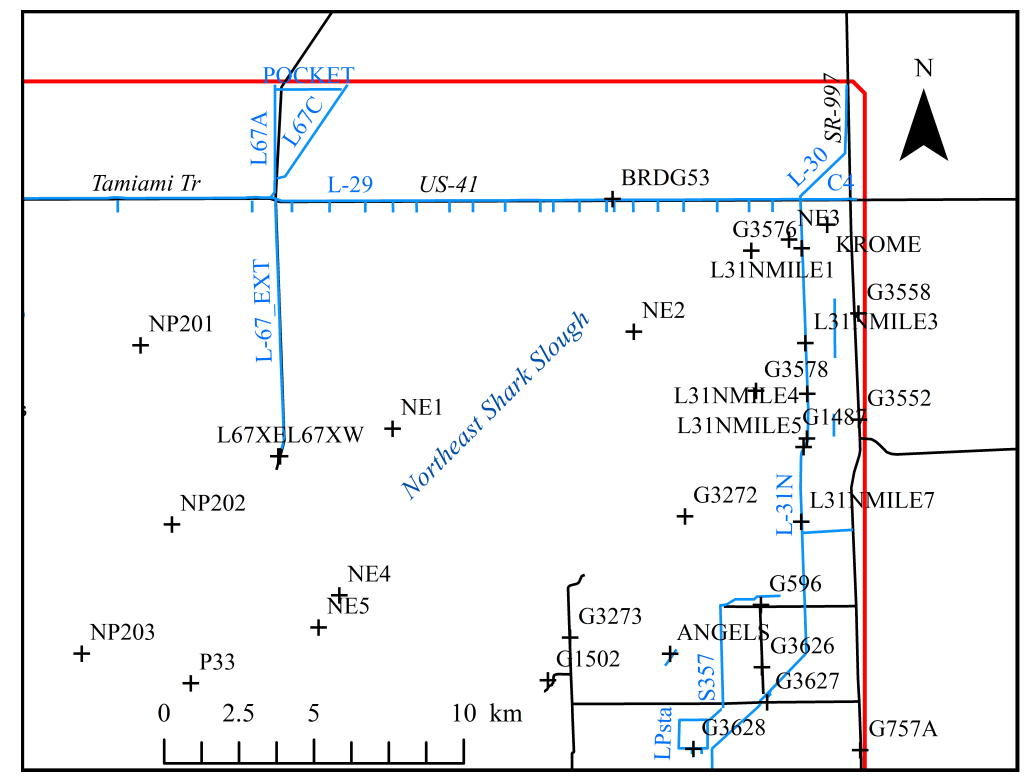

Figure 2.7: Monitoring station locations within the area of Northeast Shark Slough and along the L-31N canal.

Table 2.3: Statistical parameters for stations in the vicinity of P35, in southwest Shark Slough near the mangrove boundary.

\begin{tabular}{lcccccccc}
\hline Station & N & MAE & RMSE & STD & NS & COVAR COR & PEV \\
\hline P35 & 3943 & 0.51 & 0.01 & 0.01 & -0.10 & 0.31 & 0.77 & 0.34 \\
CN & 4220 & 0.16 & 0.00 & 0.00 & 0.82 & 0.18 & 0.92 & 0.84 \\
SH1 & 3788 & 0.34 & 0.01 & 0.01 & 0.65 & 0.40 & 0.83 & 0.66 \\
\hline
\end{tabular}

Figure 2.7 shows locations for the monitoring sites listed in both Table 2.1 and Table 2.2. The statistics show that the model performs well in this region (NS above 0.75 on average). Figure 2.8 shows locations for the monitoring sites listed in Table 2.3. The statistics show that the model correlates well with the observed data, with a correlation coefficient of $84 \%$.

Figure 2.9 shows locations for the monitoring sites listed in Table 2.4, and includes monitoring stations within Taylor Slough and along canals such as the C-111. Not shown in Figure 2.9 is the FROGPOND site which is farther north of station R158 along the C-111 Canal. The statistics show that the model performs well in this region (NS above 0.74 on average). 


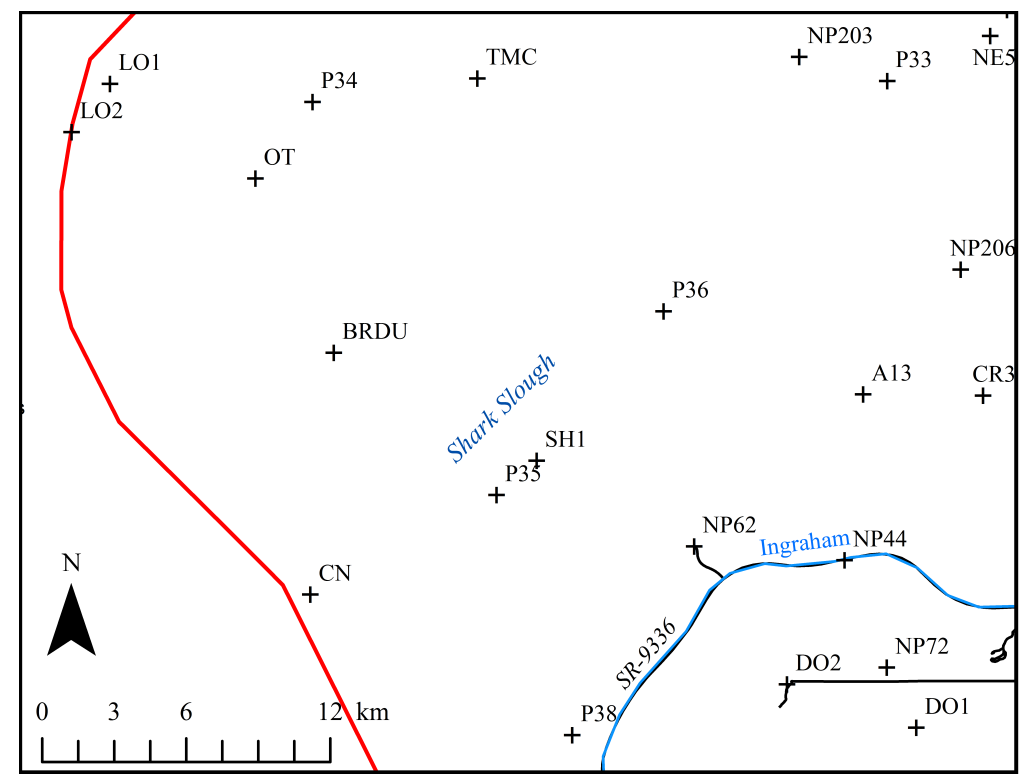

Figure 2.8: Monitoring station locations within the area of southern Shark Slough

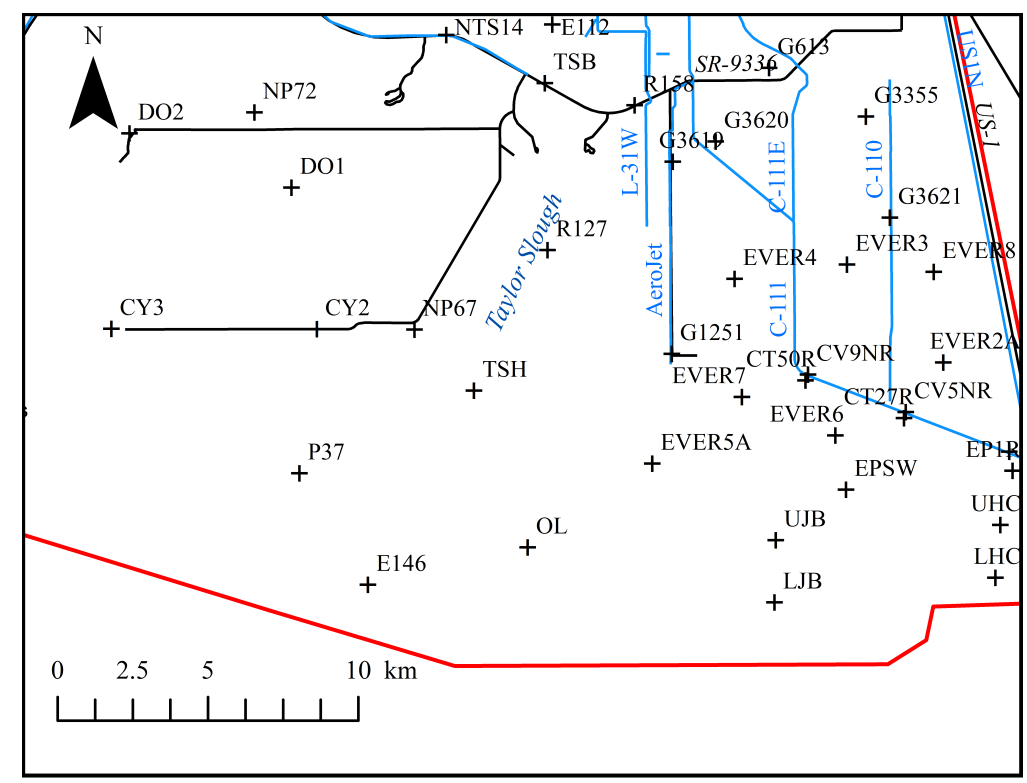

Figure 2.9: Monitoring station locations within the area of southern Taylor Slough

Additional calibration results are provided in Appendix A, which provides figures for observed versus modeled data and exceedance probability curves at each of the monitoring sites. 
Table 2.4: Statistical parameters for stations in the vicinity of P37, in the Southern Glades and Taylor Slough.

\begin{tabular}{lcccccccc}
\hline Station & N & MAE & \multicolumn{2}{c}{ RMSE STD } & NS & \multicolumn{2}{c}{ COVAROR } & PEV \\
\hline FROGPOND & 3520 & 0.51 & 0.01 & 0.01 & 0.52 & 0.91 & 0.80 & 0.52 \\
R158 & 3938 & 0.37 & 0.01 & 0.01 & 0.71 & 0.58 & 0.87 & 0.74 \\
EVER4 & 3859 & 0.20 & 0.00 & 0.00 & 0.69 & 0.28 & 0.89 & 0.69 \\
G1251 & 3581 & 0.22 & 0.01 & 0.00 & 0.73 & 0.36 & 0.92 & 0.83 \\
G3619 & 3945 & 0.22 & 0.01 & 0.01 & 0.61 & 0.27 & 0.84 & 0.64 \\
P37 & 3972 & 0.14 & 0.00 & 0.00 & 0.87 & 0.40 & 0.96 & 0.88 \\
OL & 3968 & 0.13 & 0.00 & 0.00 & 0.87 & 0.30 & 0.95 & 0.90 \\
E146 & 3919 & 0.11 & 0.00 & 0.00 & 0.95 & 0.30 & 0.99 & 0.96 \\
\hline
\end{tabular}

\subsection{Conclusions}

The M3ENP was developed to simulate water flows and levels of Everglades National Park. The model uses physical-based equations for the entire hydrological cycle; including rainfall and evapotranspiration, channel flow, overland flow, and flow in the subsurface. The M3ENP model is capable of simulating water levels in ENP with greater accuracy than any other existing model with a comparable scale. Such a model is necessary to provide insight into ENP hydrodynamics and to simulate the effects of external forcings or anthropogenic changes.

The following chapters describe how this calibrated model was used to i) simulate water movement under a variety of future conditions, ii) simulate the transport and fate of phosphorus through ENP under current and future conditions. Water level data from the M3ENP model were also used to help filter spectral data in Chapter 6 . 


\section{CHAPTER 3}

\section{ANALYSIS OF BRIDGE CONSTRUCTION AS A HYDROLOGICAL RESTORATION TECHNIQUE FOR EVERGLADES NATIONAL PARK, FL, USA USING HYDROLOGICAL NUMERICAL MODELING}

\subsection{Abstract}

Since the construction of Tamiami Trail in the 1920's, overland flow to the Florida Everglades has decreased significantly, impacting ecosystems from the wetlands to the estuary. As part of the effort to return flows to the historical levels, several changes to the existing water management infrastructure have been implemented or are in the design phase. These changes include the construction of two bridges (a 1- mile and a 2.6 mile bridge) and the removal of Tamiami Trail roadway as well as increasing canal water levels to increase head elevations north of Everglades National Park (ENP). A numerical model of ENP hydrology was developed using MIKE SHE/MIKE

11 software to review the effect of these structure changes and evaluate the potential impact of bridge construction. Model simulations show that the newly constructed 1-mile bridge along Tamiami Trail will increase water delivery to Northeast Shark Slough (NESS) by about 5.6\%. The 1-mile bridge plus the proposed 2.6-mile bridge will increase flows by $10.4 \%$ from the baseline flow. These simulations also show an increase of flow to the eastern canals by less than $1 \%$ for each scenario, demon- 
strating that bridge implementation along Tamiami Trail will have a minimal impact on eastern canal operations and flood management. Hydroperiod analysis demonstrated that bridge construction alone can increase water levels in large areas of ENP by an additional $0.3 \mathrm{~m}$ above Baseline conditions for an additional 7 days annually. Additional simulations were conducted to demonstrate the effect of proposed water level increases for canals north of the Park. Raising water levels in the canal by up to one foot (0.3 meters) increased overland water levels up to $21 \mathrm{~cm}$ in some areas within ENP. These simulations demonstrate that a general increase in water levels and hydroperiods within ENP will be achieved by adding bridges to the Tamiami Trail roadway and by increasing water levels in the canal.

\subsection{Introduction}

The Everglades of southern Florida is a unique wetland that once flowed in a slowmoving sheet of water from the southern rim of Lake Okeechobee out to the Gulf of Mexico and Florida Bay. The Everglades is now a highly managed system controlled by a series of canals, levees, pumps, and compartmentalized Water Conservation Areas (WCAs), completed in the 1960's and 70's. Water levels throughout the region are controlled to provide flood protection to urban and agricultural areas, regulate Lake Okeechobee water levels, and provide irrigation for the Everglades Agricultural areas south of Lake Okeechobee (Stone and Legg, 2001). After over a century of changes to the hydrology of the system, the remaining natural Florida Everglades are currently limited to a protected area in the southern portion of the original Everglades, its original size reduced by half (Chimney and Goforth, 2006). Changes to the natural Everglades, including drainage, urbanization, and agricultural development, have caused spatial and temporal alterations of the wetlands and have led to a decline in the quality and quantity of water that enters Everglades National Park (ENP). 
These changes in the hydrology of southern Florida have had profound impacts on the Everglades ecosystems, which have been widely recognized as unique, important and worthy of protection (Chimney and Goforth, 2006). The Comprehensive Everglades Restoration Plan (CERP), initiated in the late 90's, represents the political and cultural recognition of the importance of this ecosystem, the past declines in environmental quality, and the continued threats to the natural character of the remaining Everglades (NRC, 2012). Prolonged or altered hydroperiods in coordination with high nutrient loading has led to the increase of cattail communities and decline of sawgrass and periphyton, placing historical ecosystems and food webs into imbalance (Chiang et al., 2000). Reduced hydroperiods and water depths, specifically in Shark Slough, have shown to cause peat oxidation and tree island reduction; however, conservation area decompartmentalization and hydrologic restoration may offer a means to recover tree island habitats (NRC, 2012). Water management choices now have a direct and measurable impact on Everglades habitat and species diversity (Armentano et al., 2006).

\subsubsection{Modeling Efforts}

The validity and reliability of distributed model results is often a matter of the accuracy and availability of model parameters; however, even simplified models can provide insight into flow patterns, improve knowledge of the hydrology of the area, and identify areas where more information is needed and lacking (Refsgaard and Storm, 1995).

Numerical modeling of Everglades hydrology has been ongoing since the development of the South Florida Water Management Model (SFWMM) in the 1980's, a water balance model with an extensive spatial domain (SFWMD, 2005). Other Ev-

erglades modeling efforts focus on improved spatial and temporal resolution (Bolster 
and Saiers, 2002; Langevin et al., 2005), increased vertical discretization for detailed subsurface studies (Chui et al., 2011), and enhanced parameter estimations such as hydraulic resistance (Bolster and Saiers, 2002; Min et al., 2010). However, there remained the need for a hydrological model of ENP with finer resolution and more accurate results in the wetlands and the associated canal system.

The MIKE Marsh Model of Everglades National Park (M3ENP), a hydrological model built through the collaborative efforts of the Applied Research Center at Florida International University and the National Park Service, began development in 2011. This surface water/ground water numerical model uses the commercial modeling software MIKE SHE/MIKE 11 by DHI to evaluate hydroperiods and hydropatterns in the wetlands (Cook, 2012) and to better understand the impacts of historical and proposed structural operations. The domain for the M3ENP model is shown in Figure 3.1.

\subsubsection{Restoration Plans}

Tamiami Trail, a U.S. highway which connects Tampa and Miami, was constructed in 1928 with little to no concern or understanding of the impacts it might have on the surrounding marshland. The Trail cuts directly across the Florida Everglades and created one of the first structural impediments to the natural water flows into the southern Everglades. The L-29 canal runs parallel to Tamiami Trail, conveying water from west to east. Water from the canal is allowed to flow southward under the roadway impediment at regularly spaced structures and gated culverts; however, flows at these points are inadequate to restore water flow to ENP and Northeast Shark

Slough without adverse impacts to the roadway or tree islands (Boler and Sikkema, 2010) 


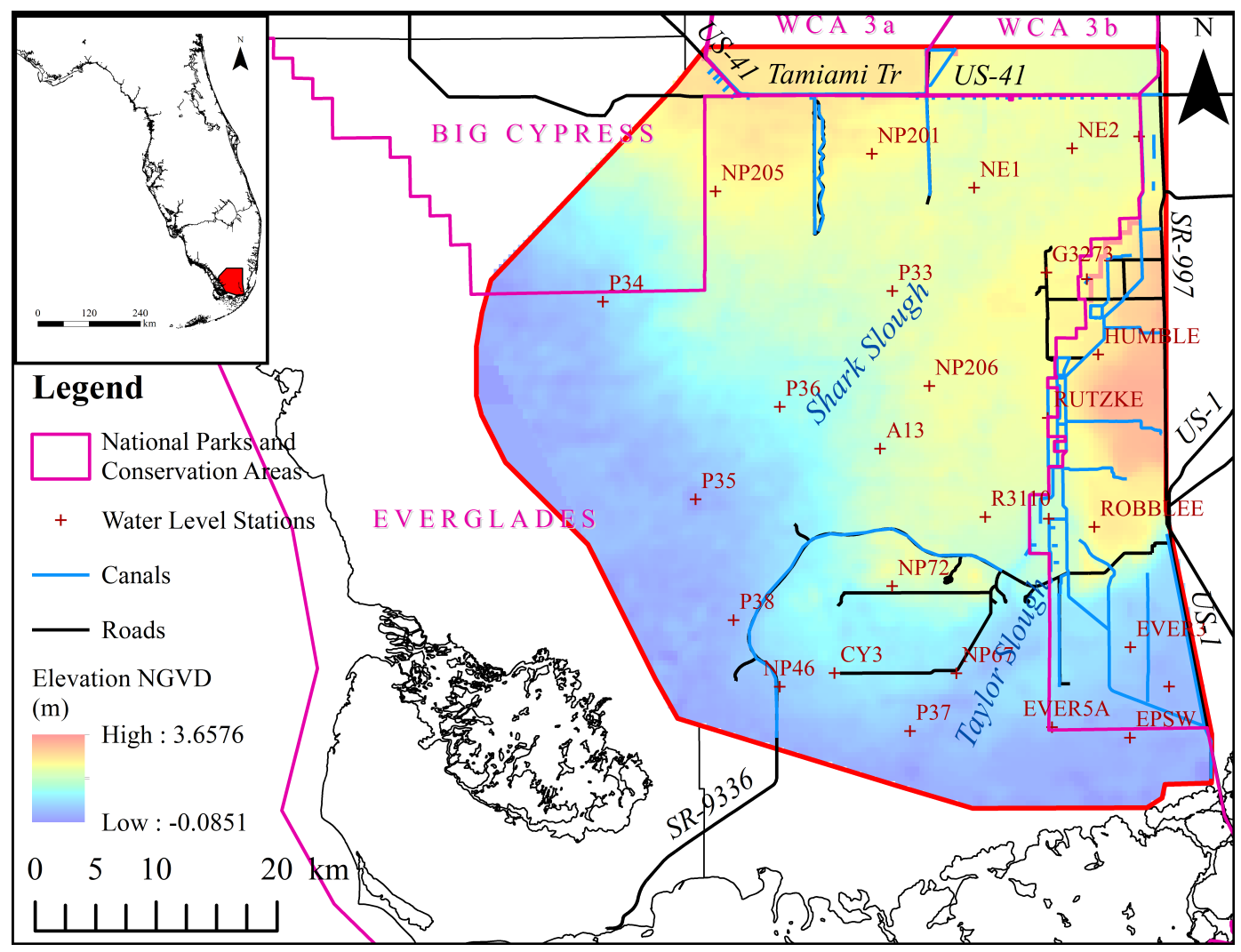

Figure 3.1: The M3ENP model domain (outlined in red) is located in southern Florida and includes a large portion of Everglades National Park. Tamiami Trail/US-41 marks the northern boundary for ENP. Water level monitoring stations provide the water level data for model calibration and validation.

Congress directed the National Park Service (NPS) to evaluate the efficacy of converting some of Tamiami Trail into bridges for the purpose of restoring water flow and promoting ecological connectivity in the 2009 Omnibus Appropriations Act. As a result, the Modified Water Deliveries (MWD) plan to convert a 1-mile section of the Trail to bridgeway was approved and construction on the first Everglades bridge began in late 2009 (Boler and Sikkema, 2010).

In 2010, the Department of Interior and the National Park Service endorsed a plan to construct an additional 2.6 miles of bridgeway on Tamiami Trail to increase water deliveries to Northeast Shark Slough (NESS). The plan will also raise the water levels 
in L-29 canal up to $8.5 \mathrm{ft}$ NGVD (USACE, 2013) to provide a water level gradient to promote north-south water flow; consequently, the roadbed must be raised up to a foot higher to prevent flooding the road (Boler and Sikkema, 2010). To date, construction of the 1-mile bridge has been completed; no other proposed construction efforts have broken ground.

The purpose of this work is to evaluate any changes in the hydrology that may be induced by future restoration efforts (including bridge construction and water level increases). Using calibrated results from the M3ENP model, this paper evaluates water flow to ENP from 2000-2010 in three initial scenarios: 1) the current (or Baseline) operations, 2) post-construction of the 1-mile bridge on Tamiami Trail (One Bridge Scenario), and 3) simulated effects of both the planned 2.6-mile bridge and the constructed 1-mile bridge (Two Bridges Scenario). In addition, proposed canal water level increases are evaluated in coordination with the bridge scenarios.

\subsection{Methods}

\subsubsection{Site Description}

Figure 3.1 shows the model domain location in South Florida. This region encompasses a range of Everglades ecosystems including ridge and slough, wet prairies, tree islands, pine forests, cypress forests, upland pine forests, mangrove forests in estuarine regions, and agricultural areas (Stone and Legg, 2001). Hydroperiods can vary widely in these ecosystems and include permanent inundation in sloughs and mangrove forests, seasonal inundation in the wet prairies and cypress forests, daily inundation in tidal zones, and can be permanently dry in the upland pine forests. Seasons in South Florida are driven by changes in rainfall and evapotranspiration. The wet season in South Florida is from June to October, during which two thirds of the annual precipitation falls (Abtew, 1996). 
Soils in this system range from calcitic marl to organic peat (Fish and Stewart, 1991; Zhou and Li, 2001). Peat in the Everglades plays a crucial role in landscape and ecosystem development, and is sensitive to hydroperiods and drainage (USACE, 2013). Underlying the soils is the surficial aquifer system, which is comprised of everything from the land surface down to the top of the intermediate confining unit and is the source of most of the potable water used in southeastern Florida. Within the surficial aquifer system is the Biscayne aquifer which is a highly transmissive system composed of several rock layers including the thin Miami Oolite formation and the Fort Thompson formation (Fish and Stewart, 1991). Canals and levees control water flow to and away from ENP. The main channels are the L-29 canal which runs west to east and the L31N canal which runs south to the C-111 and then southeast out to the Atlantic Ocean.

\subsubsection{Model Development}

The M3ENP modeling system consists of a 3-dimensional saturated and unsaturated groundwater flow and 2-dimensional overland flow model (MIKE SHE) coupled with a 1-dimensional river flow model (MIKE 11). The hydrological processes are described by physical laws of conservation of mass, momentum and energy. The MIKE 11 model is a one-dimensional modeling tool for the detailed analysis, design, management and operation of both simple and complex river and channel systems. The MIKE $11 \mathrm{Hy}-$ drodynamic (HD) module solves the one-dimensional vertically integrated equations for the conservation of continuity and momentum, i.e., the Saint Venant equations (Havnø et al., 1995).

The equations and methods developed into the MIKE SHE/MIKE 11 software are

well documented (Refsgaard and Storm, 1995; Havnø et al., 1995) and the use of this software has been established as a viable method for wetlands research (Rahim et al., 
2012), karst aquifers (Doummar et al., 2012), and Everglades communities (Michot et al., 2011). Therefore, only minimal technical details of the model development will be included in this paper. For a more detailed technical description of the M3ENP model, please refer to Cook (2012).

The M3ENP model domain, shown in Figure 3.1, is approximately 2,720 sq km and includes parts of Everglades National Park (ENP), WCA 3a and 3b, and urban and agricultural areas of Miami-Dade County in South Florida. For these simulations, the model spatial resolution was $400 \mathrm{~m}$ and the water levels and flows are simulated with a daily timestep.

In the M3ENP model, the two-dimensional diffusive wave Saint Venant equations describe overland flow (OL), the Kristensen and Jensen methods (Kristensen and Jensen, 1975) are used for evapotranspiration (ET), the one-dimensional Richards's equation for unsaturated zone flow (UZ), and a three-dimensional Boussinesq equation for saturated zone flow (SZ) (Christiaens and Feyen, 2002). Table 3.1 lists the model components and their solutions and interactions with the other model components, i.e., Channel Flow interacts with the Saturated Zone by infiltration and with the Overland Flow by overbank spilling. The partial differential equations are solved by implicit finite difference methods, while other methods (i.e., evapotranspiration) in the model are empirical equations obtained from independent experimental research (Refsgaard and Storm, 1995; Havnø et al., 1995).

\subsubsection{Model Scenarios}

Canal and structural changes were implemented into the MIKE 11 files and topographical changes were implemented into the MIKE SHE model to simulate water flows in ENP using pre-construction, the construction of the 1-mile bridge, and the 
Table 3.1: Model component overview

\begin{tabular}{clc} 
Model Component & Solution Scheme & Interactions \\
\hline Channel Flow (Rivers) & 1-D Saint Venant equations & SZ, OL \\
Evapotranspiration (ET) & $\begin{array}{l}\text { Kristensen and Jensen } \\
\text { method }\end{array}$ & UZ, OL \\
Overland Flow (OL) & $\begin{array}{l}\text { 2-D Saint Venant equa- UZ, SZ, Rivers, ET } \\
\text { tions/Manning's law for fric- }\end{array}$ & \\
& tion slope & OL, SZ \\
Unsaturated Flow (UZ) & $\begin{array}{l}\text { Richard's Equation, van } \\
\text { Genuchten for soil moisture } \\
\text { Saturated Flow (SZ) }\end{array}$ & $\begin{array}{l}\text { 3-D groundwater flow equa- } \\
\text { tion }\end{array}$ \\
\end{tabular}

proposed 2.6-mile Tamiami Trail bridge. These three scenarios (illustrated in Figure 3.2) use observed water level data from 2000 to 2010.

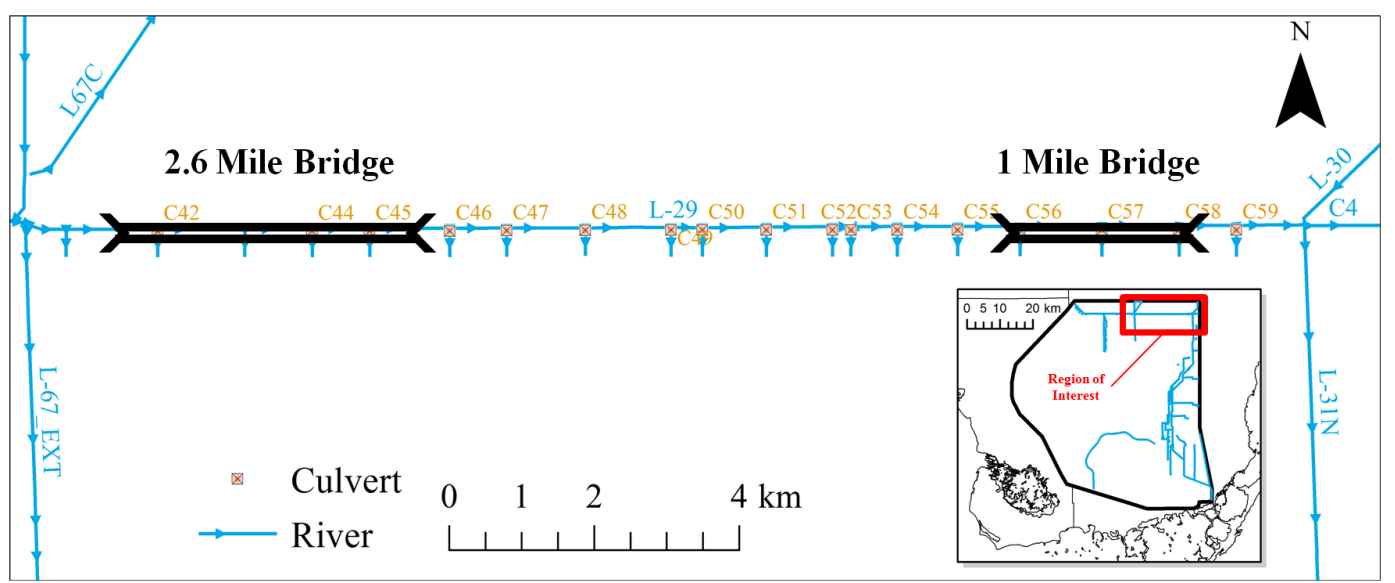

Figure 3.2: Bridge placement along Tamiami Trail for the M3ENP models. The M3ENP-MB model scenarios include water quality simulations with no bridges (Baseline Scenario), with just the 1-mile bridge (One Bridge Scenario), and with both the 1-mile and 2.6-mile bridges (Two Bridge Scenario).

\section{Baseline}

The Baseline scenario considers structures and operations that existed from 1999 to 2010. Water level data after the completion of the 1-mile bridge construction were not obtained. The MIKE 11 canal network includes canal reaches, water control 
structures (with gate operations), weirs, culverts, and leakage pathways between the river and the saturated zone (SZ). Cross sections of the canal reach were determined from topography and design data. Each canal reach boundary point is assigned conditions such as daily flow or water level.

Northeast Shark Slough (NESS) receives water input from the eastern section of the Tamiami Canal (L-29 Canal) which is bounded by water control structures S333 to the west and S334 to the east. This segment of the Tamiami Trail has a series of 19 outlets which convey water from the L-29 canal into NESS, each outlet has three culverts ranging from 42 to 60 inches in diameter (NPS, 2010).

\section{One Bridge}

The One Bridge model scenario includes the construction of the 1-mile Tamiami Trail bridge with the section of roadway under the bridge removed. The 1-mile bridge was implemented into the model by changing the three culvert outlet at Culvert 57 to a mile-wide broad crested weir and increasing the cross section from $100 \mathrm{ft}$ wide (30.48 m) to 1 mile wide $(1.6 \mathrm{~km})$. All flow through neighboring Culvert 56 and Culvert 58 was shut off due to the overlapping cross section of the new bridge. This One Bridge Scenario setup is illustrated in Figure 3.2.

\section{Two Bridges}

The Two Bridges model scenario is simulated as if the 1-mile and proposed 2.6-mile Tamiami Trail bridges were built and the section of roadway under the bridges were removed. The 2.6-mile bridge was implemented into the model in two parts. First, the three culvert outlet at Culvert 42 was changed to a mile-wide broad crested weir and the cross section was increased to 1 mile wide $(1.6 \mathrm{~km})$. Second, the three culvert outlet at Culvert 44 was changed to a 1.6 mile-wide broad crested weir and the cross 
section was increased to 1.6 miles wide $(2.6 \mathrm{~km})$. Flow through the surrounding Culvert 43 and Culvert 45 was shut off due to the overlapping cross section of the new bridge sections. This Two Bridge Scenario setup is illustrated in Figure 3.2.

\section{Canal water level increase}

In an effort to increase head elevations within NESS, USACE (2013) has proposed to increase the water levels in the L-29 canal by raising tailwaters at key structures. Canal water levels are currently controlled via a series of gated structures which allow water to enter the canal and which allow water to flow out toward the Atlantic Ocean. To simulate the proposed increase in water levels within the L-29 canal, the tailwater (TW) head at structure S333 was increased for water levels greater than $2.134 \mathrm{~m}$ (7.0

feet). Canal structure S333 (shown in blue in Figure 3.2) is the primary structure providing flows to L-29 to maintain and regulate water levels. The following set of control parameters were used at S333 to create a gradual increase in the canal water levels above $2.134 \mathrm{~m}$ :

$$
\begin{array}{ll}
H^{*}=H+1.5(H-2.134) & (\text { For } H \geq 2.134 m) \\
H^{*}=2.591 & \left(\text { For } H^{*}>2.591 m\right)
\end{array}
$$

Where $H$ is the observed tailwaters at S333 and $H^{*}$ is the adjusted water head levels. The control parameters do not allow for water flow above $2.591 \mathrm{~m}(8.5 \mathrm{ft})$, in accordance with the proposed stage changes. The maximum stage level creates a minimum embankment below the proposed roadbed to prevent washout and flooding, a crucial component of the Army Corps proposal (USACE, 2013).

Figure 3.3 illustrates the average observed and modified tailwater levels for the simulation period (2000-2010). The modification provides a realistic interpretation of the proposed canal water level increases. The increase in canal water levels will facilitate the flow of water southward into NESS by creating a gradient in the surface water 


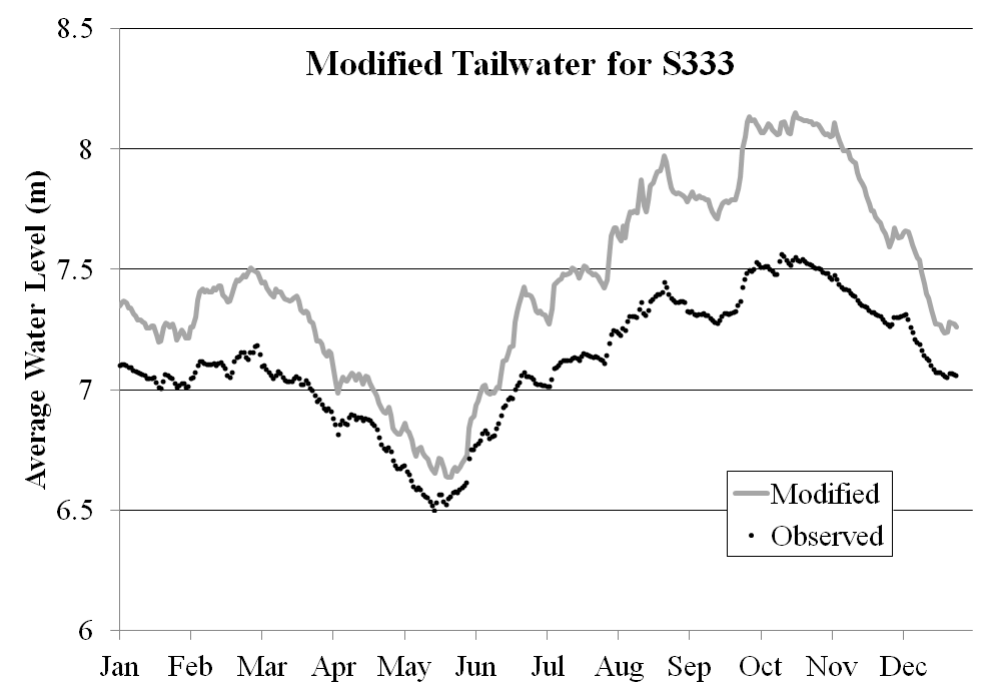

Figure 3.3: Averaged daily modified and observed tailwaters for structure S333.

potential head. However, before the water level can be raised, the existing roadway must also be raised to protect the roadbed from washout. Therefore the implementation of the raised water levels will be postponed until the roadway requirements are met (USACE, 2013).

\subsection{Results and Discussion}

\subsubsection{Model Calibration and Validation}

Cook (2012) documented the model calibration for the baseline model, which was performed for several subdomains within the model domain to determine sensitive parameters such as Manning's number and hydraulic conductivity. Model calibration was performed using stage and discharge observed data at over 100 sites within the model domain for the 1987 to 1997 period. Parameters such as UZ van Genuchten values, UZ hydraulic conductivities, Manning's M values, canal leakage coefficients to SZ, and SZ hydraulic conductivities were optimized using exploratory and statistical 
analysis to calibrate the model. The model was then validated for the 1999-2010 period, which includes the construction of detention areas.
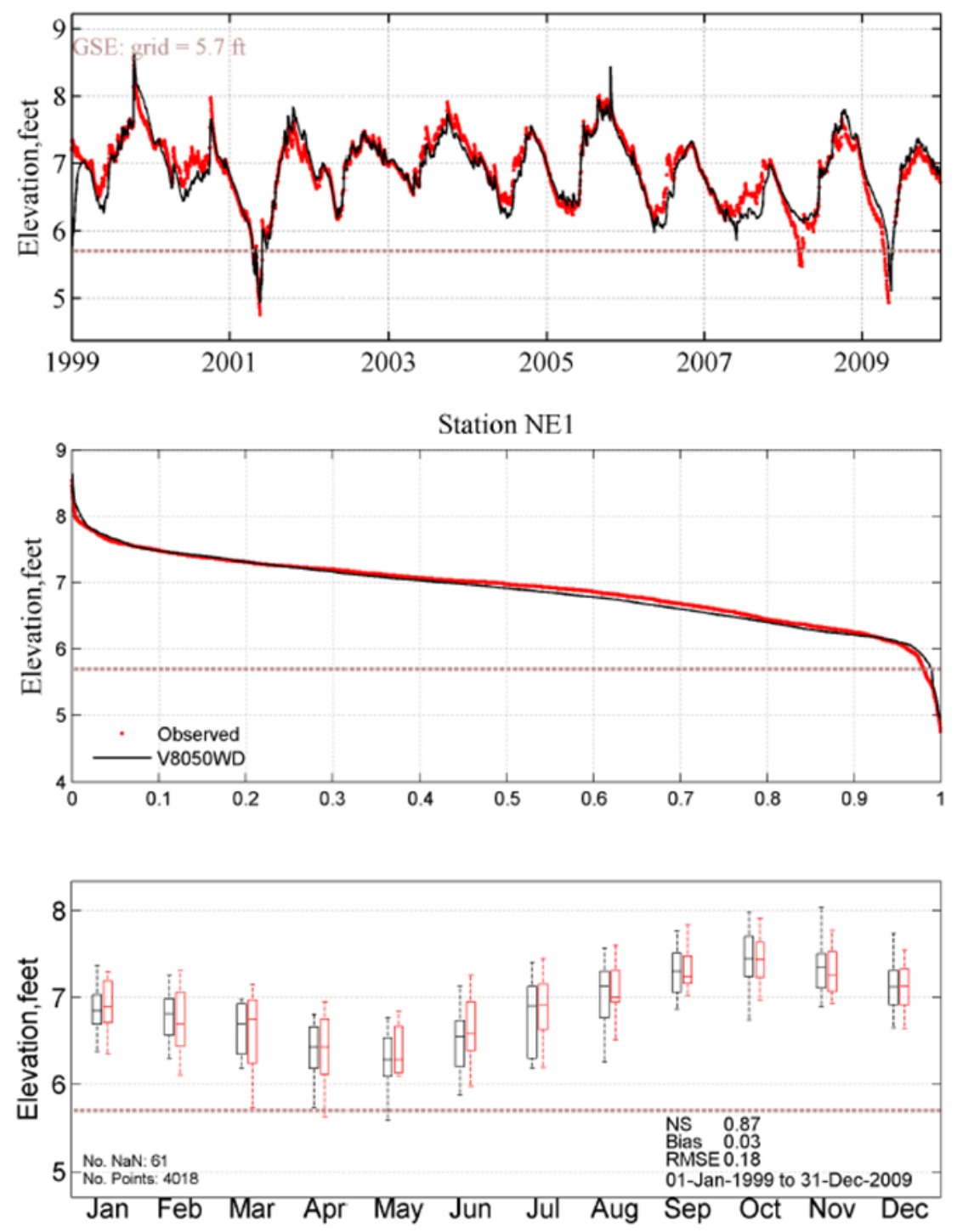

Figure 3.4: Model validation from 2000 to 2010 at water level monitoring station NE1 in Northeast Shark Slough. Modeled data is shown in black and observed data is in red.

Figure 3.4 shows an example of the model performance at one location within NESS for the 2000 to 2010 time period. Water elevation (and ground surface elevation, GSE, at $1.74 \mathrm{~m}$ or $5.7 \mathrm{ft}$ ) is shown in the top graph, probability of exceedance of water 
level is shown in the middle graph, and averaged monthly water levels are shown in the bottom graph. Simulated water elevations for the base condition are compared with observed water elevations from NE1, a station located within the discharge area of the proposed 2.6 mile bridge (NE1 location is shown in Figure 3.1). The NS value for this location is 0.87 , which indicates that the modeled water levels correspond closely with the observed data.

The probability that the water level elevation will exceed $7 \mathrm{ft}(2.1 \mathrm{~m})$ during the evaluation period is around 0.5 for both the observed and modeled data; however, there is a much lower probability $(<0.1)$ that the water level elevation will exceed 7.5 $\mathrm{ft}(2.3 \mathrm{~m})$. The probability of exceedance metric illustrates that the model is capable of simulating the extreme water levels with the same frequency as the model. The entire model performs well statistically, with minimal error $(\mathrm{RMSE}=0.18-0.24)$. Additional M3ENP model validation can be found in Cook (2012).

\subsubsection{Canal Discharges}

Compared with the baseline modeled cumulative discharge, there was an increase in discharge of $5.59 \%$ with the addition of the 1-mile bridge from the eastern Tamiami Trail section which provides flows to NESS. Figure 3.5 shows the breakdown of these changes in flow for each Culvert along Tamiami Trail. Culverts 43, 45, 56, and 58 were turned off due to the overlapping bridges and are shown as zero in the graph. For the One Bridge Scenario, flows increase to the NESS region by $116 \%$ and specifically through Culvert 57 by 407\%. Flows decrease at all remaining operational culverts by 6\%. Despite these decreases, the total flow to Northeast Shark Slough increases by $5.6 \%$ with the One Bridge Scenario. An additional $4.4 \mathrm{cu}$. km (or 35,827.5 kAF) of water entered the park annually during this simulation period. 


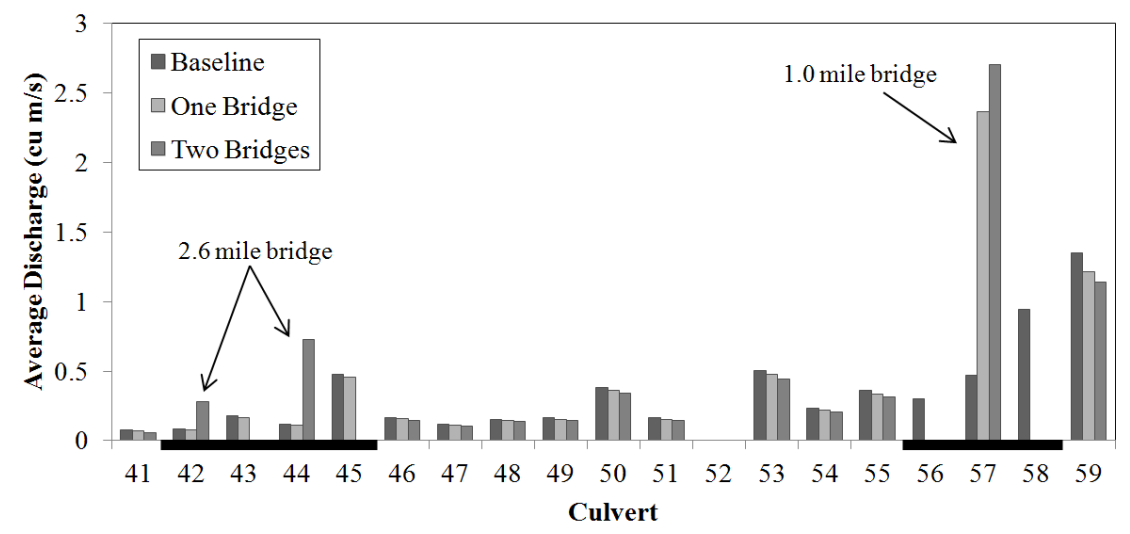

Figure 3.5: Average discharge $\left(\mathrm{m}^{3} / \mathbf{s}\right)$ changes along the eastern section of Tamiami Canal (L-29) for the Baseline, One Bridge, and Two Bridges Scenarios. Culverts 41 through 59 run west to east. Culverts $43,45,56$, and 58 were turned off due to the overlapping bridges and are shown as zero in the graph.

Compared with the baseline modeled cumulative discharge, there was an overall increase in discharge of $10.4 \%$ with the Two Bridge Scenario. Flows increase from the baseline flow to the NESS region by $695 \%$. Flows through Culvert 42 increase by $233 \%$ and through Culvert 44 by about $532 \%$. Flows decrease at all remaining operational culverts by $14 \%$ because of the release of flow at both of the bridges. Despite these decreases, the total flow to NESS increases by $10.4 \%$. An additional $8.2 \mathrm{cu} . \mathrm{km}$ (or $66,354.8 \mathrm{kAF}$ ) of water entered the park annually during this simulation period. While adding the 1-mile bridge to the model increased discharges to the park by $5.6 \%$, the addition of the second and larger bridge increased flows by $4.5 \%$. The almost double increase in flows shows the importance and impact of the additional bridge length. However, an increase in infrastructure of $260 \%$ does not equally increase discharge; therefore, there are diminished returns when using bridge infrastructure as a restoration technique.

With the additions of the bridges, flows increase to the NESS region by $5.6 \%$ $10.4 \%$ and much of that water remains within the park and discharges through the historical flow path and into Shark Slough. Discharge through the canal structures 
along the eastern boundary of the ENP increased by less than one percent for both bridge additions. The modeled result may alleviate some concerns that increasing flow under Tamiami Trail will increase flooding risk in the agricultural areas east of ENP. Increasing flows to NESS while keeping the flows contained within the park has the potential to increase water levels where they had been low and return hydroperiods to a more natural cycle for this region.

\subsubsection{Surface Water Levels}

Figure 3.6 illustrates the difference from Baseline surface water probability exceedance percentage for the One Bridge (1-mile bridge) and Two Bridges (1-mile and 2.6-mile bridges) scenarios. The probability exceedance is calculated for each cell within the model domain as the percent probability that water levels will be above a specified value within the 2000-2010 simulation period. Explored here are $0.15 \mathrm{~m}$ (half a foot), $0.30 \mathrm{~m}$ (one foot), and $0.45 \mathrm{~m}$ (one and a half feet) depth of overland flow values (measured from the ground surface to the top of the water surface). To better illustrate the effects of the bridges on surface water levels, the percent probability exceedances for the One Bridge and Two Bridge scenarios were subtracted from that of the Baseline. The Two Bridges scenario (with the 1-mile and the 2.6-mile bridge) showed the greatest effect on surface water depth. While the largest increase in water depth exceedance occurs near the bridge locations, the impact is seen throughout Shark Slough and in some areas of Taylor Slough.

Hydroperiod analysis showed that in the Two Bridge scenario, compared to Baseline conditions, over $160 \mathrm{sq}$. $\mathrm{km}$ of the model domain was flooded above $0.30 \mathrm{~m}$ for an additional 7 days annually. Table 3.2 provides a numerical summary for Figure 3.6 and quantifies the impact of these scenarios at exceedance thresholds of $0.15 \mathrm{~m}, 0.30$ $\mathrm{m}$, and $0.45 \mathrm{~m}$. In Table 3.2, the total area within the model domain that exceeded 

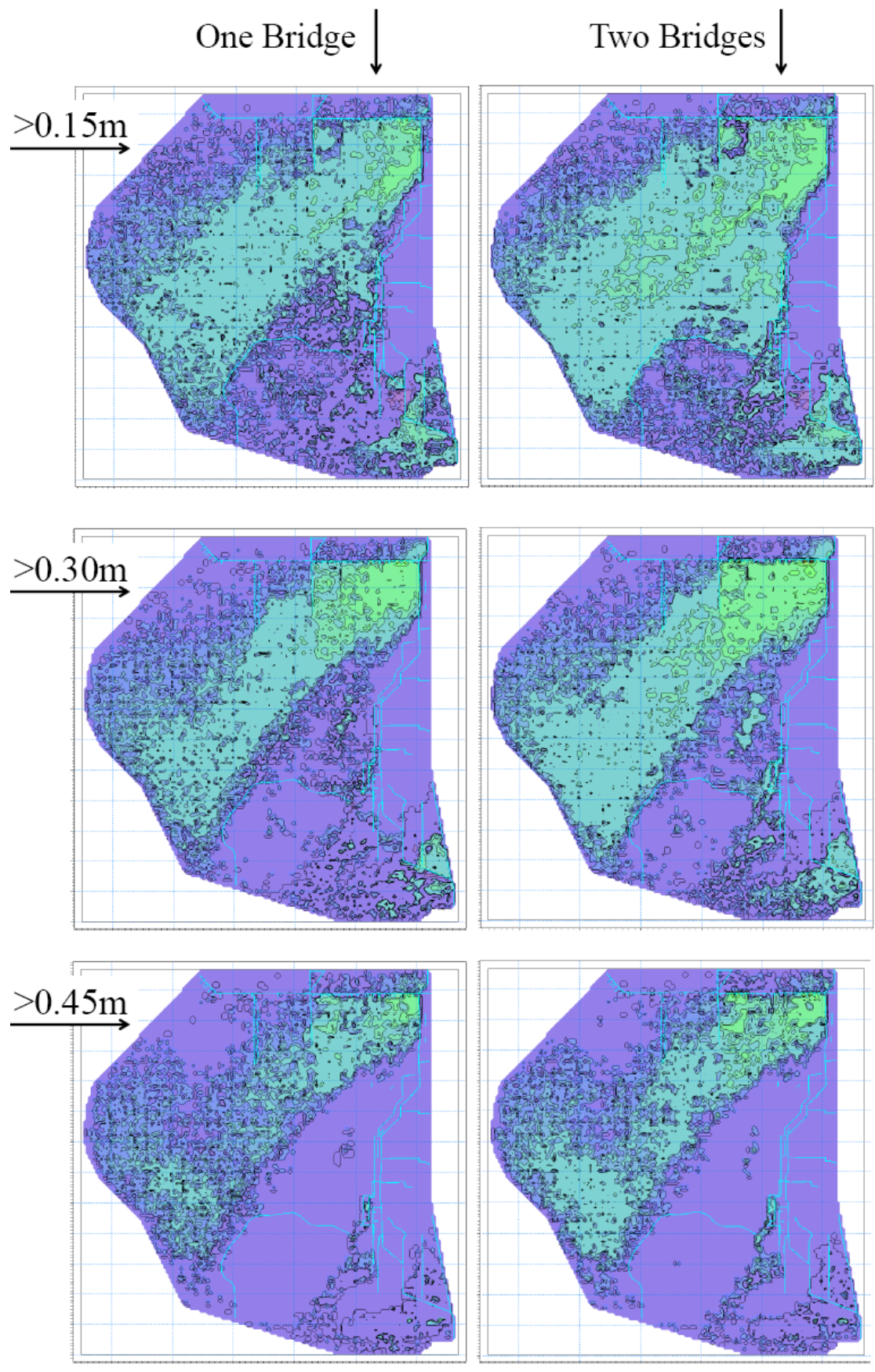

Above $15.00 \%$

$13.00-15.00$

$11.00-13.00$

$9.00-11.00$

$7.00-9.00$

$5.00-7.00$

$3.00-5.00$

$1.00-3.00$

$0.50-1.00$

$0.10-0.50$

$0.05-0.10$

$0.01-0.05$

$0.00-0.01$

$-0.50-0.00$

$-1.00--0.50$

Below -1.00

Undefined Value

Figure 3.6: Percent probability exceedances for water levels of the One Bridge and Two Bridge scenarios. The graphs show the difference from Baseline for percent probability above $0.15 \mathrm{~m}, 0.30 \mathrm{~m}$, and $0.45 \mathrm{~m}$ overland water depth. 
Table 3.2: Exceedance and hydroperiod analysis for the One Bridge and Two Bridge Scenarios above $0.15 \mathrm{~m}, 0.30 \mathrm{~m}$, and $0.45 \mathrm{~m}$ overland water depth.

\begin{tabular}{cccc}
\hline $\begin{array}{c}\text { Exceedance } \\
\text { Threshold }\end{array}$ & Scenario & Area (sq km) & $\begin{array}{c}\text { Average } \\
\text { Number of } \\
\text { Days Exceeded } \\
\text { Annually }\end{array}$ \\
\hline$>\mathbf{0 . 1 5} \mathbf{m}$ & One Bridge & 31.2 & 5.0 \\
& Two Bridges & 82.2 & 5.8 \\
\hline$>\mathbf{0 . 3 0} \mathbf{~ m}$ & One Bridge & 89.8 & 5.7 \\
& Two Bridges & 160.5 & 7.6 \\
\hline$>\mathbf{0 . 4 5} \mathbf{m}$ & One Bridge & 15.5 & 5.2 \\
& Two Bridges & 38.1 & 6.8 \\
\hline
\end{tabular}

the thresholds determined calculated by multiplying the cell count by the cell area (400m x 400m). This value indicates indicates that both Bridge Scenarios had higher water levels than the Baseline. The Average Number of Days Exceeded Annually demonstrates that the hydroperiods were longer in both Bridge Scenarios than in the Baseline Scenario.

Despite the increase in discharge to NESS with the inclusion of both bridges, the depth of surface water within NESS increases very little. The small increase is primarily a consequence of to two factors: 1) the water disperses quickly and evenly through the relatively flat terrain and 2) the water level gradient is not steep enough to push water out of the L-29 and into the slough given the current L-29 water levels.

The USACE (2013) proposed to increase L29 canal water levels to increase the head elevation north of NESS. To implement this plan, tailwater levels at the control structure S333 were raised using Equation 3.1 for the One Bridge and Two Bridge scenarios as described in Section 3.3.3.

Simulation results (Table 3.3) show an increase in depth of overland water in NESS with the forced increase in tailwater at S333. The addition of the 1-mile bridge increased water levels at station NE1 in NESS by $4.08 \mathrm{~cm}$ on average. The addition 
Table 3.3: Overland water depth increases for two ENP stations located within NESS.

\begin{tabular}{ccc}
\hline Model Simulation & $\begin{array}{c}\text { NE1 Overland Depth } \\
(\mathbf{c m})\end{array}$ & $\begin{array}{c}\text { NE2 Overland Depth } \\
(\mathbf{c m})\end{array}$ \\
\hline One Bridge & 0.20 & 0.40 \\
Two Bridges & 0.37 & 0.63 \\
One Bridge (with raised & 4.08 & 5.15 \\
$\begin{array}{c}\text { canal levels) } \\
\text { Two Bridges (with raised } \\
\text { canal levels) }\end{array}$ & 4.35 & 5.46 \\
\hline
\end{tabular}

of the 1-mile and 2.6-mile bridge increased water levels at NE1 by $4.35 \mathrm{~cm}$ on average. Water level increases were more pronounced during peak water levels for both bridges.

Figure 3.7 shows the overland water level increases compared to baseline water levels (in meters) for the entire domain. The top figures show the surface water increases for simulations which used the observed tailwater (TW) levels for S333. The bottom figures show the surface water increases for the simulations which used the tailwater levels modified for S333 using Equation 3.1. A typical wet season date $(8 / 26 / 2005)$ was chosen to illustrate the largest change in water levels. Little to no change in surface water was observed for the dry season, this may a result of the disconnectivity of the water flow during days with low surface water level. All scenes show increased water levels in NESS and Shark Slough, and the two bridge scenario shows the largest increase. The largest increase in surface water levels occurs with the Two Bridges scenario using the modified TW levels for S333. The increase in canal water levels will develop the water level gradient to help promote the southwest flow of water from L-29 into NESS. The bridge scenarios show surface water level increases and extended hydroperiods which are a primary goal of the restoration efforts for ENP. 


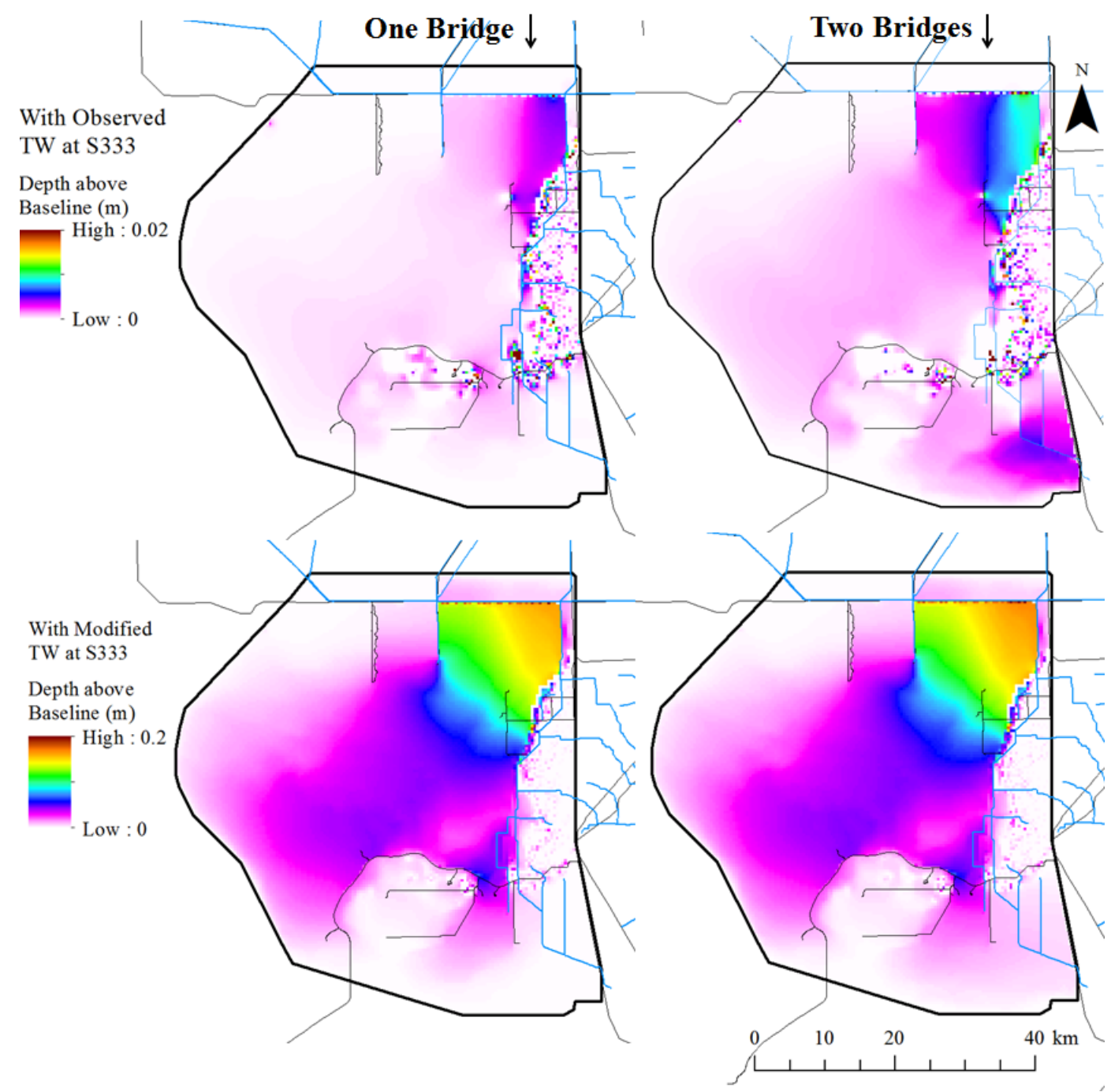

Figure 3.7: The depth above baseline for the one bridge and two bridge scenarios over the model domain on a wet season day (8/26/2005). The images on the top represent the increase in surface water for the observed tailwater in S333. The images on the bottom represent the increase in surface water using the modified tailwater conditions for S333.

\subsection{Conclusions}

An integrated surface/subsurface hydrological model (M3ENP) was developed for Everglades National Park in South Florida using MIKE SHE/MIKE 11 software. The M3ENP model was calibrated using water level elevations at monitoring stations 
throughout the park and showed good performance with the observed data. The M3ENP model was used to determine changes in flow to ENP which are a result of proposed bridges construction and canal water level increases. Bridges are being planned and constructed with the intention of increasing ecosystem connectivity and water flow into Northeast Shark Slough and moving towards a more natural hydroperiod for the region. Modeling the increase in flow to NESS given certain restoration scenarios is important for planners to gain confidence in project goals and results.

Several conclusions can be made from the simulation of these restoration efforts: i) simulated construction of the 1-mile and 2.6-mile bridges will increase discharges under Tamiami Trail by $5.6 \%$ and $10.4 \%$, ii) discharge did not increase significantly through eastern structures near the agricultural areas ( $<1 \%$ total discharge increase), iii) bridge implementation increased hydroperiods in large areas of ENP, including NESS, iv) and increasing water levels in the L-29 canal provided a hydraulic head which increase water levels in ENP much higher than with bridge construction scenarios alone.

With the 1-mile bridge implemented into the model, discharge to NESS increased by $0.35 \mathrm{~m}^{3} / \mathrm{s}$ on average. Implementing both the 1 -mile and the 2.6 -mile bridge into the model increased flows (from the baseline conditions) to NESS by $0.65 \mathrm{~m}^{3} / \mathrm{s}$ on average. The eastern section of the model includes an elaborate network of canals and detention storage areas used to provide flood control to developed areas and supply water to agricultural areas. With the implementation of the 1-mile and 2.6mile bridges, flow increased to these canals by less than $1 \%$ in total. Therefore, restoration efforts centered around increasing flows under Tamiami Trail will have minimal impact on flood control operations to the east.

Hydroperiods, a critical factor in maintaining the health of peat soils, ridge and slough landscapes, and tree islands, were extended for large areas of the model do- 
main. About $90 \mathrm{sq}$. $\mathrm{km}$ of ENP were flooded above $30 \mathrm{~cm}$ for an additional 5.7 days with construction of the 1-mile bridge, and about $160 \mathrm{sq} \mathrm{km}$ were flooded above 30 $\mathrm{cm}$ for an additional 7.6 days with the construction of both the 1-mile and 2.6 mile bridges.

The proposed increase in canal levels was simulated by raising tailwater levels at control structure S333 which feeds into the L-29 canal. Results of this simulation showed that the raised water levels created a hydraulic gradient which increased water levels in ENP up to $21 \mathrm{~cm}$ in some regions with this forced tailwater scenario. Implementation of the increased canal water levels will have a large impact on NESS water levels and hydroperiods. It is recommended that additional evaluation should be conducted to determine the appropriate stage elevations in the canals which provide sustainable hydroperiods and water levels for marsh and tree island ecosystems.

Future structural and operational changes can be implemented in the model to simulate the possible effects on flows and stages within the Park, including proposed additional bridges (Boler and Sikkema, 2010) and levee and water level changes proposed in the Central Everglades Planning Project (CEPP) (USACE, 2013). Water level data obtained after the final completion of the 1-mile Tamiami Trail bridge can be evaluated to validate model performance and adjust model parameters, if needed. Advection-dispersion and reactive transport modules can also be implemented to simulate the fate and transport of nutrients into ENP under actual conditions as well as scenario-based conditions given hydrological changes as a result of restoration efforts.

\subsection{Acknowledgements}

This work is a collaborative effort between the National Park Service and Florida International University's Applied Research Center (Cooperative Agreement P06AC00039MOD 0003). We would like to thank the Everglades research community at large for 
their tireless data collection and willingness to extend access to that data to their fellow researchers. Data has been accessed from NPS, USGS, SFWMD, U.S. ACE, Everglades Foundation, FCE LTER, CERP, NASA, and NOAA. Partial funding support for this investigation was provided through the NASA WaterSCAPES University Research Center (Cooperative Agreement NNX10AQ13A). 


\section{CHAPTER 4}

\section{MODELING THE IMPACT OF RESTORATION EFFORTS ON PHOSPHORUS LOADING AND TRANSPORT THROUGH EVERGLADES NATIONAL PARK, FL, USA}

\subsection{Abstract}

Ecosystems of the Florida Everglades are highly sensitive to phosphorus loading. Future restoration efforts, which focus on restoring Everglades water flows, may pose a threat to the health of these ecosystems. To determine the fate and transport of total phosphorus and evaluate proposed Everglades restoration, a water quality model has been developed using the hydrodynamic results from the M3ENP (Mike Marsh Model of Everglades National Park) - a physically-based hydrological numerical model which uses MIKE SHE/MIKE 11 software. Using Advection-Dispersion with reactive transport for the model, parameters were optimized and phosphorus loading in the overland water column was modeled with good accuracy (60\%). The calibrated M3ENP-AD model was then modified to include future bridge construction and canal water level changes, which have shown to increase flows into ENP. These bridge additions increased total phosphorus (TP) load downstream in Shark Slough and decreased TP load in downstream Taylor Slough. However, there was a general decrease in TP concentration and TP mass per area over the entire model domain. The M3ENP-AD model has determined the mechanisms for TP transport and quan- 
tified the impacts of ENP restoration efforts on the spatial-temporal distribution of phosphorus transport. This tool can be used to guide future Everglades restoration decisions.

\subsection{Introduction}

The Everglades of southern Florida is a unique wetland that once flowed in a slowmoving sheet of water from the southern rim of Lake Okeechobee out to the Gulf of Mexico and Florida Bay. After decades of changes to the hydrology of the system, the remaining Florida Everglades are currently limited to a protected area in the southernmost portion of the original Everglades, and east of the urban zone. Changes to the natural Everglades include drainage, urbanization, and agricultural development which have led to a decline in the quality and quantity of water that enters the Everglades.

Ecosystems in the Florida Everglades are considered ultra-oligotrophic because of their low dissolved phosphorus $(\mathrm{P})$ concentrations in surface waters, ranging from 5 to $15 \mu \mathrm{g} \mathrm{L}^{-1}$. Large spikes of phosphorus entering these areas are removed by the periphyton community, which act as a short-term nutrient absorber or buffer. However, this removal is not sustainable over long periods of time as the periphyton communities die and return the majority of the phosphorus back to its soluble form, with only a small fraction precipitating as sediments (Reddy et al., 2006). Aquatic species in the Florida Everglades have adapted to low phosphorus conditions. Therefore, the timing, distribution, quantity, and quality of the water entering the Everglades have a strong influence on the wetlands ecosystem (Chimney and Goforth, 2006).

When $\mathrm{P}$ concentrations are high, opportunistic species such as cattail (Typha domingensis Pers.) tend to dominate over sawgrass (Cladium jamaicense Crantz) by using the additional phosphorus for growth and production, this increases biomass 
and photosynthesis in the ridge ecosystems. In the slough ecosystems, periphyton has been shown to decline with added P, allowing other macroalgae to take over and change the very basis of the food web (Chiang et al., 2000). Phosphorus loading has shown to be a more influential factor for periphyton biomass productivity than the seasonal water cycle (Buzzelli et al., 2000). Phosphorus loading can accumulate in these ecosystems over time and have significant implications for the health of traditional ecosystems by placing food webs into imbalance; therefore, it is important to evaluate long-term cumulative effects of P loading (Chiang et al., 2000).

\subsubsection{Restoration efforts and their impact}

The Florida Everglades has been subjected to a series of water management changes which have focused on either urban/agricultural flood protection or on environmental issues arising from hydrological changes and water quality degradation. However, the management practices have been consistently reactive rather than proactive, resulting in changes which have resulted in further environmental issues; for example, flooding protection initiated in the 1940s led to the construction of Water Conservation Areas (WCAs), canals, and levees, which have negatively impacted Park water levels and flows (Gunderson and Light, 2006).

In recent years, restoration plans have focused on returning flows to Northeast Shark Slough (NESS) in ENP and restoring hydroperiods to pre-drainage conditions. In an effort to jump-start this process, a 1-mile bridge has been constructed along one of the most significant hydrological barriers to ENP, the Tamiami Trail (Boler and Sikkema, 2010). In 2010, the Department of Interior and the National Park Service endorsed a plan to construct an additional 2.6 miles of bridgeway on Tamiami Trail to increase water deliveries to NESS. In addition, the Central Everglades Planning Project (CEPP) will increase discharge into the L-29 canal, adjacent to Tamiami 
Trail, to raise the water levels from the maximum operational limit of 7.5 to $8.5 \mathrm{ft}$ NGVD (USACE, 2013). Raising L-29 water levels will provide a water level gradient to promote southwest water flow, but will require that the roadbed be raised up to a foot higher to prevent flooding the road (Boler and Sikkema, 2010).

While these restoration efforts intend to return hydrological performance in ENP to pre-drainage conditions, it is important to quantify the changes that will occur and identify any negative impacts. Currently, discharges at culverts and spillways through Tamiami Trail have been reported to have higher average concentrations of TP than the ecologically significant threshold of $10 \mathrm{ppb}$ (NPS, 2010). Increasing discharges may increase total phosphorus (TP) mass flux into ENP, which could lead to further ecosystem degradation. An evaluation of water quality is crucial to determining the effects of Tamiami Trail bridge construction on sensitive ENP ecosystems.

\subsubsection{Previous Modeling Studies of Phosphorus in the Everglades}

Several modeling studies have been conducted to address the long-term effects of phosphorus loading to the Everglades (Walker, 1995; Buzzelli et al., 2000; Raghunathan et al., 2001; Paudel et al., 2010; Wang et al., 2012). The Dynamic Model for Storm Water Treatment (DMSTA) (Walker, 1995) and the Everglades Water Quality Model (EWQM) (Raghunathan et al., 2001) utilize the mass balance approach which formulates the idea that phosphorus entering the system will either settle out or leave the system downstream. These methods aggregate the phosphorus settling and uptake rates into an apparent net settling rate which simplifies the various phosphorus removal pathways. Wang et al. (2012) used the DMSTA aggregated phosphorus settling rates and incorporated them into the physical-based dispersive mass flux equation. Similarly, the Regional Simulation Model - Water Quality (RSM-WQ) uses the advection-dispersion equation for the physical transport of phosphorus through 
the system, yet includes a biological cycling equation with aggregated settling and uptake mechanisms for changes within the system (James and Jawitz, 2007; Paudel et al., 2010). In contrast, Buzzelli et al. (2000) applied a more mechanistic approach with the use of the gross primary production equation which evaluates the biological processes that occur during the uptake of phosphorus by periphyton.

Harvey et al. (2006) modeled the spatial distribution of tritium measurements, and concluded that the interaction between surface water and groundwater in the Everglades is relatively small but significant, especially when considering its effect on solute fate and transport. The EWQM and the RSM-WQ use hydrodynamic results from the South Florida Water Management Model (SFWMM), which includes surface water and groundwater flow equations (SFWMD, 2005), to model P transport. However, this model sacrifices resolution for complexity and scale, as the grid size is $2 \times 2$ miles yet it covers the entire Everglades system from Lake Okeechobee to Florida Bay.

The ecosystems of Everglades National Park are shown to be sensitive to nutrient inputs, most especially the inflow of phosphorus via surface water and groundwater media. While many studies have been conducted in order to determine the appropriate water quality limits for the ENP, the system has not been fully modeled and the water quality standards have been generalized (Walker, 1995; Buzzelli et al., 2000; Raghunathan et al., 2001; Paudel et al., 2010). The present paper will address limitations and gaps in these studies by modeling phosphorus fate and transport in the ENP system with improved spatial and temporal resolution, an integrated surface water/groundwater hydrological model, and a quantitative biophysical and chemical characterization of how phosphorus interacts with the environment.

The Mike Marsh Model of Everglades National Park (M3ENP) was developed by Florida International University's Applied Research Center in coordination with the 
National Park Service in 2011 (Cook, 2012). The model was used to evaluate the effect of restoration efforts on water deliveries to ENP including the construction of bridges along Tamiami Trail, which are intended to restore hydroperiods and hydropatterns to pre-drainage conditions (Long et al., Submitted 2014). The model was built using MIKE SHE/MIKE 11 (DHI Group) modeling software, which uses hydrodynamic equations for overland, unsaturated and saturated flow. Using the hydrodynamic results (such as water fluxes and depths) from the M3ENP, transport equations can estimate the movement of phosphorus through the system.

The present paper evaluates phosphorus fate and transport in ENP by incorporating advection-dispersion-reaction equations into the M3ENP hydrodynamic model (M3ENP-AD). The M3ENP-AD model was calibrated at several stations within ENP for the 2007 to 2010 period. The model was then used to evaluate the impact of pro-

posed bridge additions on the transport of phosphorus into ENP by incorporating two bridge construction scenarios. The aim of this paper is to i) develop, calibrate, and validate a phosphorus transport model for ENP waters and ii) to quantify the effects of Tamiami Trail bridges (including the 1-mile and 2.6-mile bridges) on ENP water quality.

\subsection{Methods}

The M3ENP model domain, shown in Figure 5.1, is approximately 2,720 sq km and includes parts of Everglades National Park (ENP), WCA 3a and 3b, and agricultural areas of Miami-Dade County in South Florida (Cook, 2012; Long et al., Submitted 2014). The region encompasses a range of ecosystems including ridge and slough, wet prairies, tree islands, pine forests, cypress forests, upland pine forests, mangrove forests in estuarine regions, and agricultural areas (Stone and Legg, 2001). 


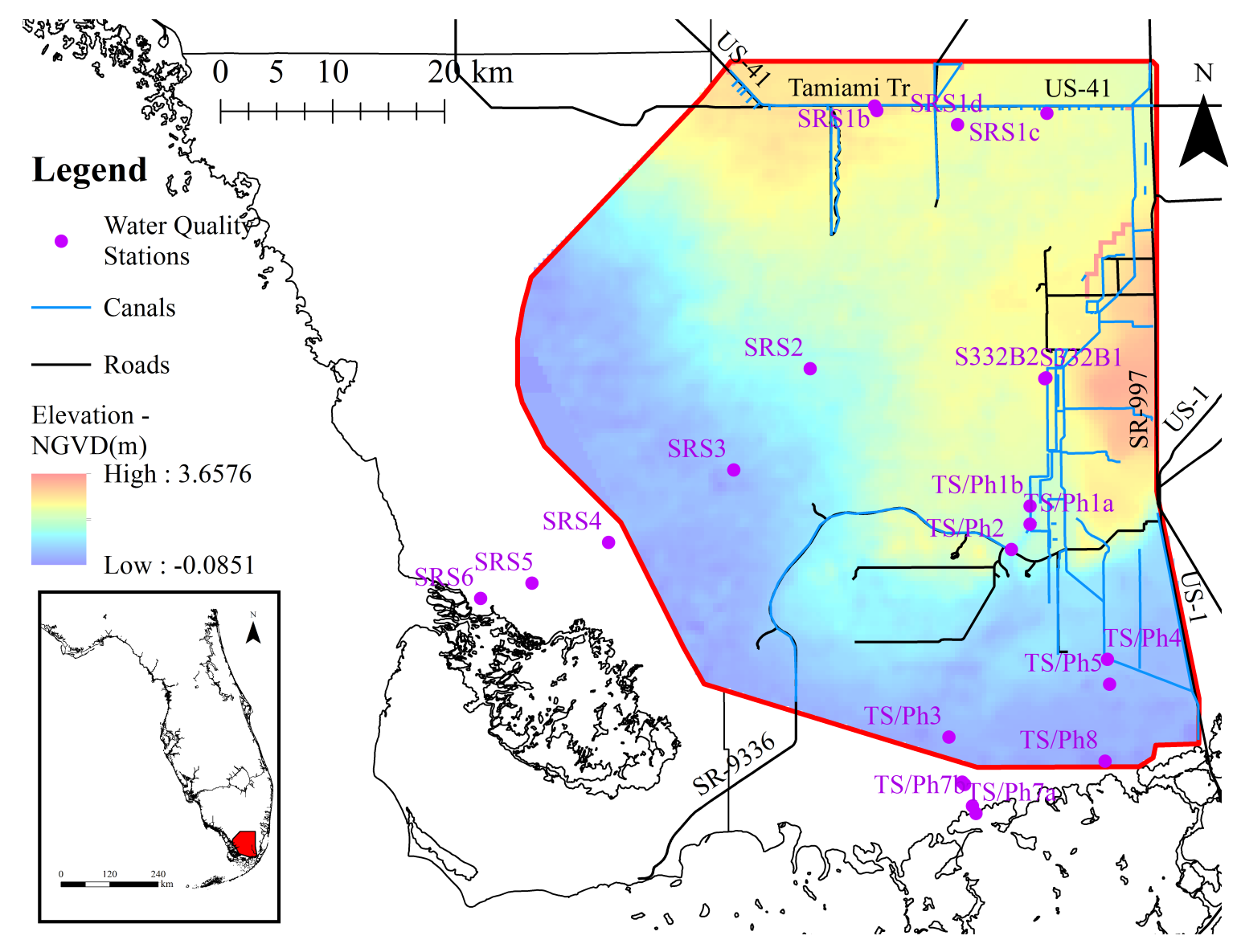

Figure 4.1: Model domain (outlined in red) located in southern Florida. Water Quality stations (in purple) were used to calibrate AD model parameters with observed TP concentrations.

The fate and transport of phosphorus in Everglades National Park was modeled using a 3-D finite-difference approach. The M3ENP hydrodynamic results for water levels and velocities were used to calculate the transport of phosphorus in the M3ENPAD model using the advection-dispersion-reaction equation (ADRE). The ADRE is a numerical technique which has been successfully applied across many spatial and temporal scales to simulate the mechanisms of solute transport and reaction (James and Jawitz, 2007). The method evaluates how phosphorus is transported in the system via advection (moves with the water) and dispersion (moves down a 
concentration gradient), as well as how it interacts with the soil and rocks of the unsaturated and saturated zones (sorption and desorption).

\subsubsection{Advection-Dispersion Model Development}

The MIKE SHE water movement module supports the calculation of solute trans-

port in the different parts of the hydrological cycle, including overland flow (OL), unsaturate zone flow (UZ), and saturated zone flow (SZ). Water flow, water contents, hydraulic heads and water levels estimated in the water movement simulation are used to compute the solute transport (Refsgaard and Storm, 1995). Solute transport is calculated in MIKE SHE using the Advection-Dispersion equation, shown in Equation 5.1.

$$
\frac{\partial c}{\partial t}=-\frac{\partial}{\partial x_{i}}\left(c v_{i}\right)+\frac{\partial}{\partial x_{i}}\left(D_{i j} \frac{\partial c}{\partial x_{j}}\right)+R_{c}
$$

Where $c$ is the concentration of the solute, $v_{i}$ is the velocity tensor (calculated from the WM simulation), $D_{i j}$ is the dispersion tensor (from user-specified longitudinal and transverse dispersion coefficients), and $R_{c}$ is the sum of the sources and sinks.

The Advection-Dispersion equation is used to calculate the solute concentration in the Overland Flow for horizontal transport (where $i, j=1,2$ for two-dimensional), in the Unsaturated Zone for vertical transport (only calculated in the $\mathrm{z}$ direction), and in the Saturated Zone for transport in three dimensions $(i, j=1,2,3)$. The numerical solution to the advection-dispersion equation in MIKE SHE AD employs the QUICKEST (Quadratic Upstream Interpolation for Convective Kinematics with Estimated Streaming Terms) method originally introduced by Leonard (1979). This method uses a upstream differencing for the advection term and central differencing for the dispersion term (DHI, 2007). 
For solute transport in the rivers and canals, the AD equation is modified for one-dimensional flow as shown in Equation 4.2.

$$
\frac{\partial A c}{\partial t}=-q \frac{\partial c}{\partial x}+A D \frac{\partial^{2} c}{\partial^{2} x^{2}}-A K C+c_{s} q
$$

Where $q$ is the lateral inflow, $A$ is the river cross-sectional area, $D$ is the dispersion coefficient, $K$ is the linear decay coefficient, and $c_{s}$ is the source/sink concentration. The equation assumes that $i$ ) the solute is completely mixed over the cross-sectional area $A, i i)$ the solute is conservative and undergoes a first-order reaction, and iii) that the dispersive transport is proportional to the concentration gradient (DHI, 2012).

Two species were specified for the Advection-Dispersion transport: TP (dissolved total phosphorus in the water column) and $T P_{S}$ (sorbed total phosphorus). The dissolved species, $T P$, is mobile in the subsurface and surface water zones of the model. The sorbed species, $T P_{S}$, is only available in the subsurface and does not move with the water as it is fixed to the soil matrix. Total phosphorus is computed using the $\mathrm{AD}$ equation and is sorbed to the subsurface material and transformed to $T P_{S}$ using sorption processes and solubility maxima.

\section{Dispersion}

Modeling of solute transport and dispersion is a useful engineering tool for predicting the movement of contaminants. Dispersion has been described as the physical phenomena that govern the change in the transition zone between two miscible fluids in a porous medium (Davis, 1986). A change in concentration results from a combination of non-uniform velocity distribution and diffusion (DHI, 2012).

In canals, dispersion is largely controlled by the spatial-temporal velocity distribution. The dispersion coefficient, $D$ in Equation 4.3, is determined as a function of 
the mean flow velocity, $V$, multiplied by a dispersivity factor, $a$, which is calibrated for the model.

$$
D=a V^{b}
$$

For simplicity of calibration, the dispersion exponent $b$ was set to zero so that the dispersion coefficient can be directly specified by the user as the dispersion factor, $a$. Typically, the dispersion coefficient in rivers is 5 to $10 \mathrm{~m}^{2} / \mathrm{s}$ but can be as high as 30 to $100 \mathrm{~m}^{2} / \mathrm{s}$ when secondary processes dominate, such as cross-currents and wind turbulence (DHI, 2012).

For overland flow, the 2-dimensional $D_{i j}$ is calculated from the longitudinal and transverse dispersion coefficients $\left(D_{L}\right.$ and $\left.D_{T}\right)$ which are user-specified. The dispersion coefficient $D_{i j}$ is calculated using the following relationships:

$$
\begin{aligned}
& D_{x x}=D_{11}=D_{L} \frac{V_{x}^{2}}{U^{2}}+D_{T} \frac{V_{y}^{2}}{U^{2}} \\
& D_{y y}=D_{22}=D_{T} \frac{V_{x}^{2}}{U^{2}}+D_{L} \frac{V_{y}^{2}}{U^{2}} \\
& D_{x y}=D_{y x}=D_{12}=\left(D_{L}-D_{T}\right) \frac{V_{x} V_{y}}{U^{2}}
\end{aligned}
$$

Where $V_{x}$ and $V_{y}$ are the velocity components and $U$ is the magnitude of the velocity vector. These components were calculated in the water movement module of MIKE SHE/11.

Ho et al. (2009) determined Everglades dispersion coefficients from a tracer study performed in a well-preserved ridge and slough environment in WCA-3A. The results of their tracer study gave a longitudinal (in the direction of flow) dispersion coefficient that varied with time from 0.037 to $0.26 \mathrm{~m}^{2} \mathrm{~s}^{-1}$ and a constant transverse (perpendicular to the direction of flow) dispersion coefficient of $0.012\left(\mathrm{~m}^{2} \mathrm{~s}^{-1}\right)$ (Ho et al., 2009). Similarly, (Saiers et al., 2003) performed a tracer study in a 100-m long channel in Shark Slough and determined longitudinal dispersion to be $4.167 \times 10^{-5} \mathrm{~m}^{2} \mathrm{~s}^{-1}$. While other studies have determined the longitudinal dispersion coefficient to be much 
Table 4.1: Longitudinal dispersion coefficient values from literature.

\begin{tabular}{ccc}
\hline $\begin{array}{c}\text { Longitudinal } \\
\text { Dispersion Coefficient } \\
\left(\mathrm{m}^{2} \mathrm{~s}^{-1}\right)\end{array}$ & Location & Source \\
$4.167 \times 10^{-5}$ & & \\
$5 \times 10^{-5}$ & ENP & (Saiers et al., 2003) \\
0.01 & ENP & (Harvey et al., 2005) \\
$2.1 \times 10^{-5}$ & WCA 2A & (Harvey et al., 2006) \\
$0.037-0.26$ & WCA 3A & (Ho et al., 2009) \\
0.5 & WCA 3A & (Wang et al., 2012) \\
\hline
\end{tabular}

lower $\left(2.1 e^{-5}\right.$ for (Huang et al., 2008), and $5 e^{-5} m^{2} s^{-1}$ for (Harvey et al., 2005)), the study by Ho et al. (2009) is based on a larger, landscape-scale experiment. Harvey et al. (2006) used a longitudinal dispersion coefficient of $0.01 \mathrm{~m}^{2} \mathrm{~s}^{-1}$ for their model of surface water/groundwater interactions calibrated with tritium data. Wang et al. (2012) used a constant dispersion coefficient of $0.5\left(\mathrm{~m}^{2} \mathrm{~s}^{-1}\right)$, but suggest that a spatially varying coefficient may be more accurate. Several modeling studies suggest that $\mathrm{TP}$ is not sensitive to the dispersion coefficient in marsh surface water flow (Harvey et al., 2006; Paudel et al., 2010; Wang et al., 2012). Table 4.1 lists the longitudinal dispersion coefficients found in the literature.

In Overland Flow, the dispersion coefficient is user-specified, but for the Unsaturated Zone the vertical dispersion of solutes is determined from the following equation:

$$
D=\alpha_{L} v_{z}
$$

where $D$ is the Unsaturated Zone dispersion coefficient (units of $m^{2} / s$ ), $\alpha_{L}$ is the longitudinal dispersivity of the porous medium (with units of $m$ ) and $v_{z}$ is the vertical velocity (units of $\mathrm{m} / \mathrm{s}$ ), determined by dividing the flux by the moisture content $v_{z}=q / \theta$. The longitudinal dispersivity is specified by the user for each soil type and can vary vertically to account for layered inhomogeneities. 


\section{Overland Dispersion Test}

Using a simple model setup in MIKE SHE, a test was performed to determine the effects of dispersion on the transport plume in surface waters. The Overland Dispersion Test had a model cell resolution of $400 \mathrm{~m}$ square and the domain was a square with 10,000 cells. The hydrodynamic portion of the model was setup such that water moved from north to south at a constant rate of $2.5 \mathrm{~m}^{2} \mathrm{~s}^{-1}$. A single source cell was included to provide a pulse of $1,000 \mathrm{~g}$ of solute daily at the northern end of the domain. Several different dispersion values were tested; however, the dispersion values that had the most effect on the chemical transport were from 0.001 to 1.0 $m^{2} s^{-1}$. Transverse dispersion was input as 10 times less than longitudinal dispersion (Davis, 1986). Figure 4.2 shows how the plume became much wider with increasing dispersion.

Field experiments in the Florida Everglades have found that transport plumes in overland waters are long and thin, with plume widths not exceeding the source width (Ho et al., 2009). In the Overland Dispersion Test, the minimum width of the plume did not exceed the width of the source for dispersion values less than $0.01 \mathrm{~m}^{2} \mathrm{~s}^{-1}$. However, for the calibration of the M3ENP model, a range of values from literature and testing were evaluated.

The Péclet number is typically used to determine whether a hydrological system experiences the effects of both advection and dispersion (Huysmans and Dassargues, 2005) and can be used as a model constraint for preventing numerical dispersion and instabilities (DHI, 2007). For the Overland Dispersion Test, the Péclet number (calculated as $P e=v * L / D$ ) was determined to be 0.625 , which is within the model constraint for numerical stability.

The MIKE SHE model calculates the maximum allowable timestep for water qual-

ity simulations by limiting the advective Courant number $\left(\sigma_{x}=\frac{v_{x} \Delta t}{\Delta x}\right)$ and dispersive 
Figure 4.2: Comparison of the transport plume using 4 different dispersion values

(a) Long. Disp. $0.001 \mathrm{~m}^{2} \mathrm{~s}^{-1}$

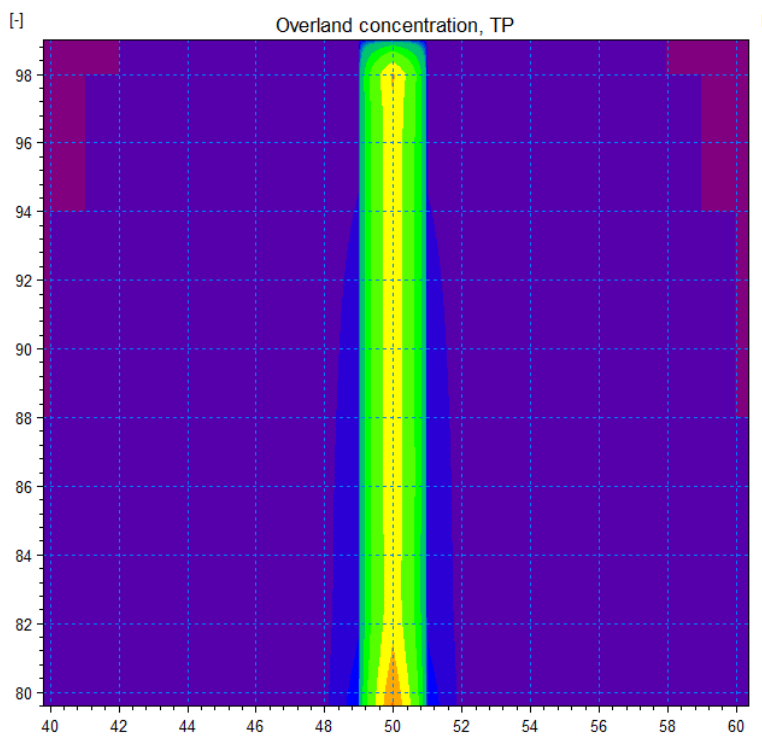

(c) Long. Disp. $0.1 \mathrm{~m}^{2} \mathrm{~s}^{-1}$

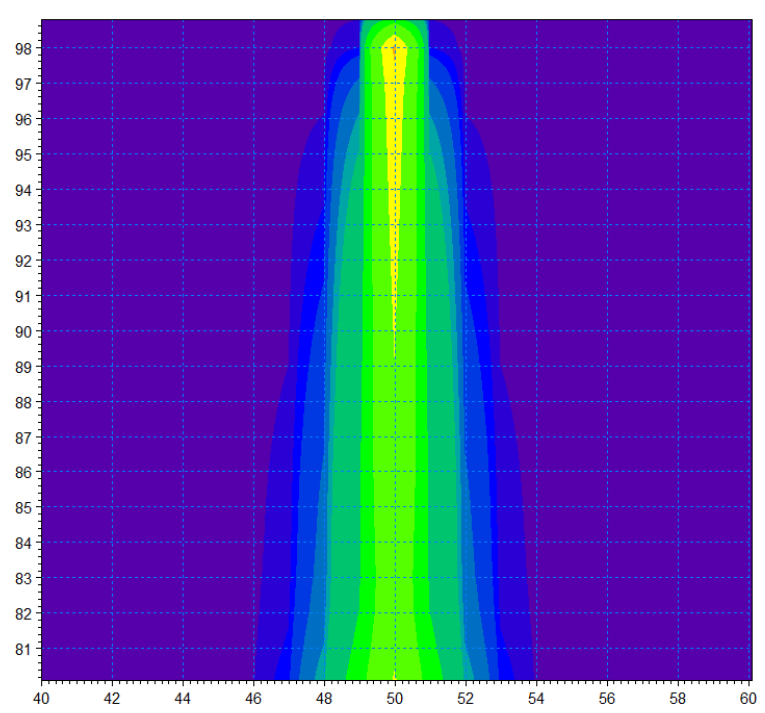

(b) Long. Disp. $0.01 \mathrm{~m}^{2} \mathrm{~s}^{-1}$

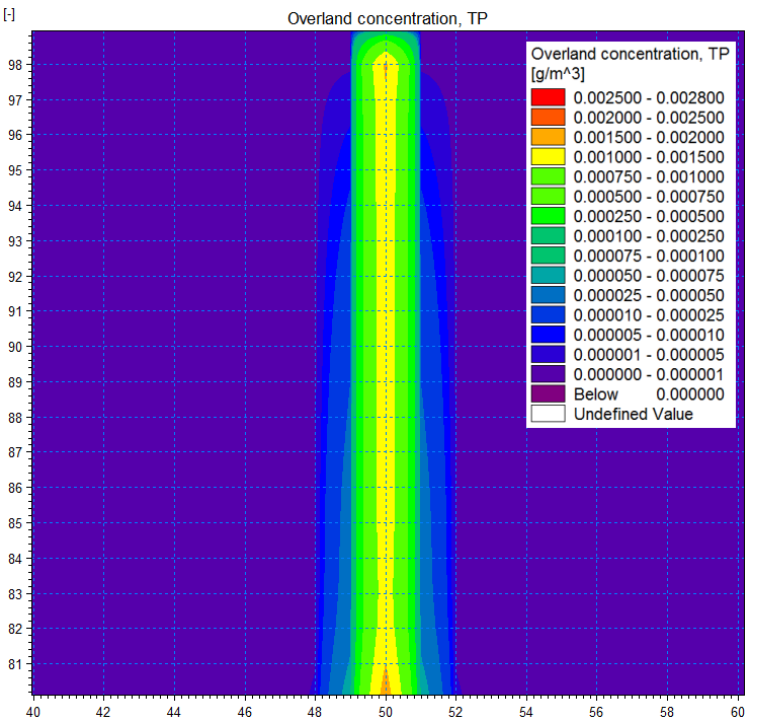

(d) Long. Disp. $1.0 \mathrm{~m}^{2} \mathrm{~s}^{-1}$

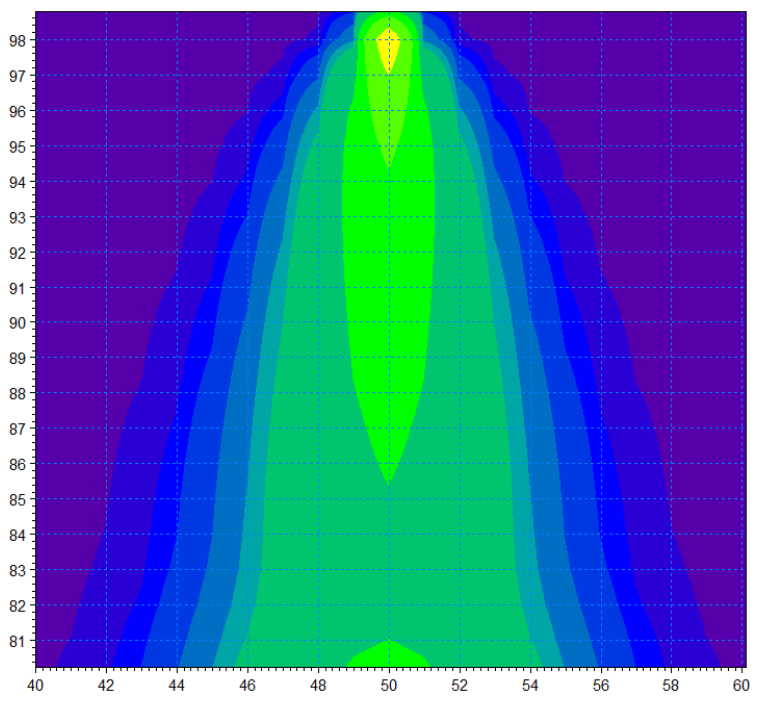


Courant number $\left(\Gamma=\frac{D_{x}}{\Delta x^{2}} \Delta t\right)$ for Overland, Unsaturated, and Saturated Zones (DHI, 2007). In this respect, numerical dispersion and instabilities are avoided. In MIKE 11, the computational scheme used for the AD model is stable for large Péclet numbers $(>2)(\mathrm{DHI}, 2012)$.

\section{Reactive Transport}

The "Sorption and Decay" module in MIKE SHE allows the calculation of reactive processes such as the sorption and decay of solutes in the Unsaturated Zone and Saturated Zone. The model extends the advection-dispersion equation to the following:

$$
\frac{\partial c}{\partial t}=-\frac{\partial}{\partial x_{i}}\left(c v_{i}\right)+\frac{\partial}{\partial x_{i}}\left(D_{i j} \frac{\partial c}{\partial x_{j}}\right)+\frac{\rho_{b}}{\theta} \frac{\partial c^{*}}{\partial t}+\left(\frac{\partial c}{\partial t}\right)_{\text {reac }}
$$

where the bulk density $\rho_{b}$ and porosity $\theta$ of the porous medium are included, $c^{*}$ is the mass of solutes sorbed per dry unit weight of solid, and the $\left(\frac{\partial c}{\partial t}\right)_{\text {reac }}$ term is referring to a biological or chemical reaction of the solute. The first term on the right hand side of the equation represents the advection of solutes, the second term represents dispersion, the third term represents sorption processes, and the last term represents decay rates.

Equilibrium sorption isotherms can be used to describe the sorption processes in Equation 4.6. The Freundlich isotherm provides the best fit for Everglades wetlands sediments (Wang and Li, 2010) and bedrock (Zhou and Li, 2001). However, TP uptake by macrophytes and periphyton may be the dominant form of removal (Gaiser et al., 2005; Lai and Lam, 2009). For numerical analysis simplicity, the linear sorption isotherm was used in the model, and the calibrated value represents a generalized combination of physical sorption and biological uptake. 
The linear sorption isotherm can be described as a linear relationship between the amount of solute sorbed onto the soil material and the aqueous concentration of the solute, shown in Equation 4.7.

$$
c^{*}=K_{D} c
$$

where $K_{D}$ is the sorption coefficient, which is related to the organic content of the soils and which determines the amount of $T P$ that can be sorbed from the total solute.

Bulk densities of the UZ soils also play a role in the reactive transport. In 2005 a survey of the Florida Everglades was performed. Soil type was determined by visual inspection and soil bulk density was analyzed by FIU SERC (Olsen, 2005). Averaged values give a bulk density of $120 \mathrm{~kg} / \mathrm{m}^{3}$ for peat and $380 \mathrm{~kg} / \mathrm{m}^{3}$ for marl.

The entire Advection-Dispersion with Reactive Transport process is illustrated in Figure 4.3. In the Overland Flow and Saturated Zone components, $T P_{\text {in }}$ and $T P_{\text {out }}$ represent the total phosphorus entering and exiting (respectively) the calculation cell at each time step, $D_{T}$ and $D_{L}$ are the transverse and longitudinal dispersion coefficients which are used in Equation 4.4 with the corresponding velocity components. In the Unsaturated Zone, $D_{V}$ is the vertical dispersion coefficient (determined from Equation 4.5) and $K_{D}$ is the sorption coefficient (used in Equation 4.7) which is specified for all sub-surface components.

\subsubsection{Phosphorus Sources}

Phosphorus loading was applied to the M3ENP-AD model in two ways: $i$ ) as ob-

served and constant concentration inflows at canal boundaries and $i i$ ) as atmospheric deposition. 


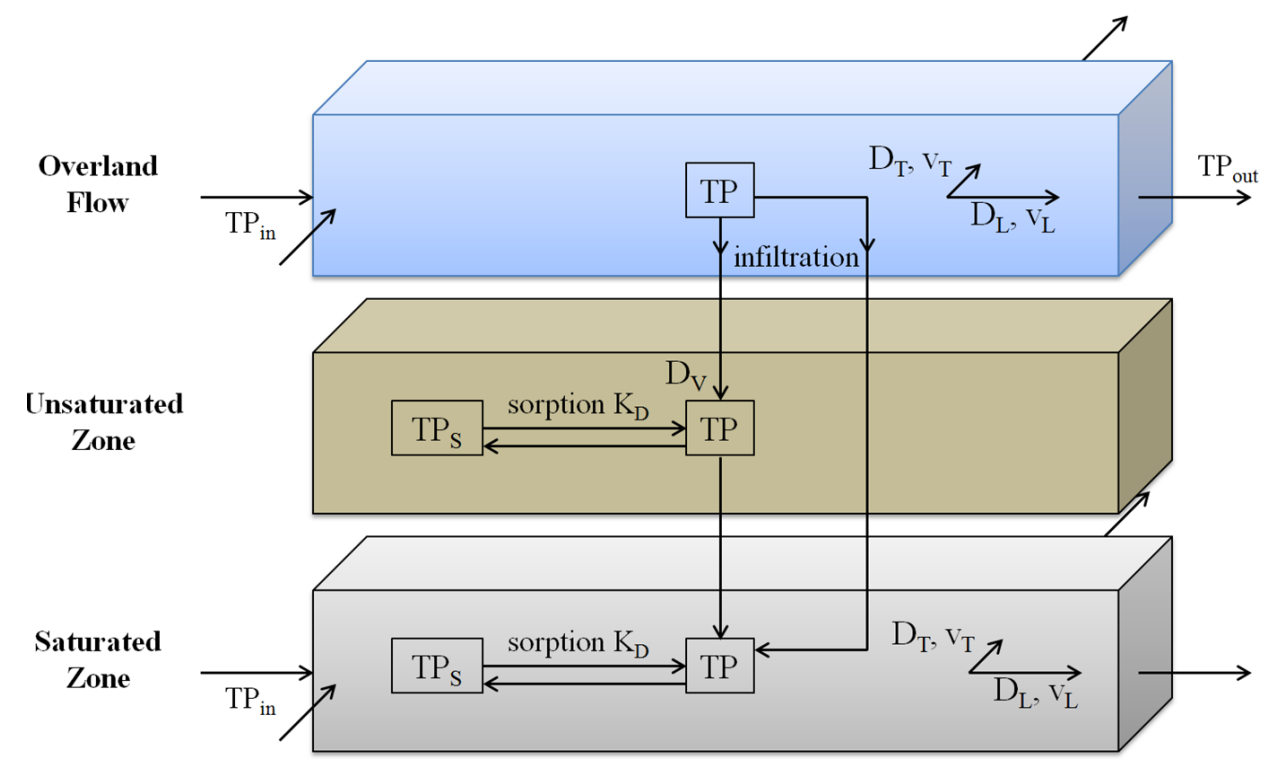

Figure 4.3: Schematic for the Advection-Dispersion with Reactive Transport process.

\section{Canal Inflows}

Phosphorus concentrations are input at all MIKE 11 boundaries as inflow concentrations. A background constant concentration of $0.001 \mathrm{mg} / \mathrm{L}$ was used for all boundary locations as a continuous point source. Observed TP concentration timeseries were used at critical inflow points such as the S333, S335 and S178 structures where ENP inflows are controlled with gated structures and flow operations. Modeled canal water levels and inflows from the M3ENP hydrodynamic model were used to determine the total loading. Figure 4.4 shows the observed values for each structure on a logarithmic scale.

The dataset included data from $7 / 20 / 2006$ to $12 / 1 / 2010$ and was the limiting factor for the selection of the simulation period. All model simulations were performed using these dates. 


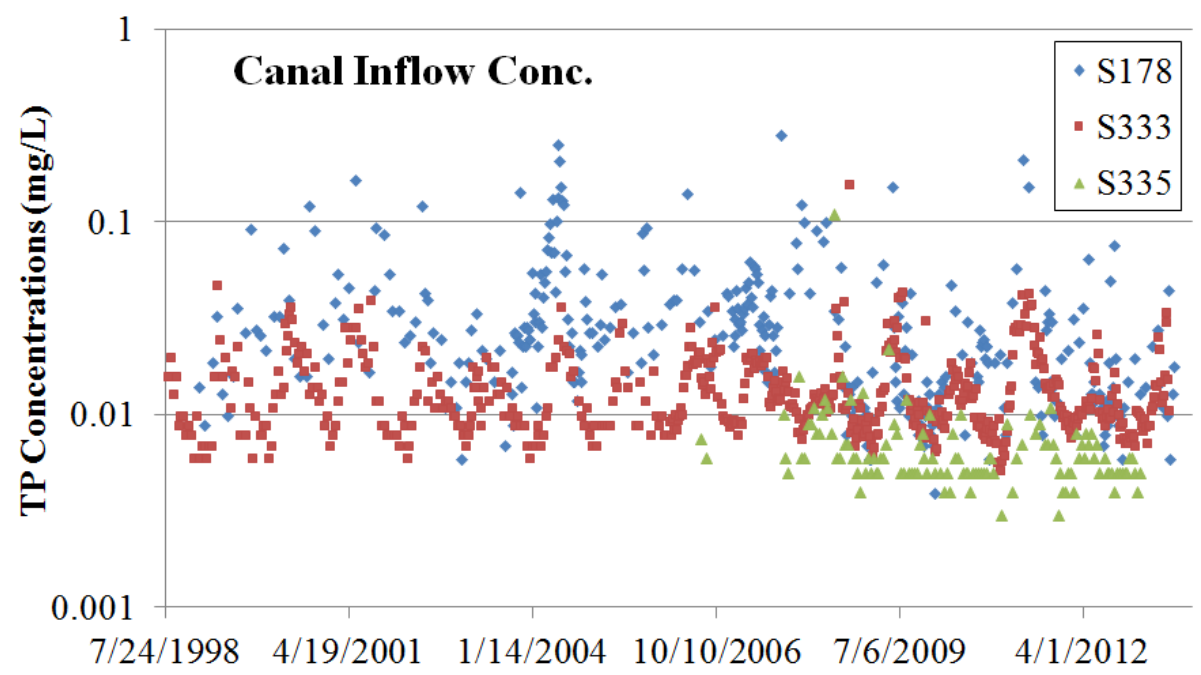

Figure 4.4: Observed TP concentrations (in $m g / L$ ) for critical inflow structures in the MIKE 11 model.

\section{Atmospheric Deposition}

Historically, wet and dry atmospheric loading was the primary source of phosphorus for the Florida Everglades (Sklar et al., 2005). Because ambient surface water phosphorus levels are so low, it is important to establish the background loading from atmospheric deposition. However, many factors influence the calculation of rate of deposition of phosphorus in the Everglades, including seasonal trends, proximity to anthropogenic activity, sample contamination, and sampling method (Redfield, 2002; Walker, 1999).

Redfield (2002) aggregated a range of published atmospheric deposition rates and determined the average value from locally calculated rates to be $30.1 \frac{\mathrm{mg}}{\mathrm{m}^{2} \text { year }}$ (or 13.2 g/day for the model cell size of 400m) (Redfield, 2002). Ahn and James (2001) measured atmospheric deposition from April 1992 to December 1996 and calculated a volume-weighted average of $0.0066 \mathrm{mg} / \mathrm{L}$ wet deposition and $18.5 \mathrm{mg} / \mathrm{L}$ dry deposition for stations within the model domain (Ahn and James, 2001). Walker (1999) evaluated P deposition rate in the Loxahatchee National Wildlife Refuge and showed 
that contaminants such as animal material and ash can alter the values dramatically. The estimated volume-weighted mean ranged from 4.6 to $39.5 \mathrm{ppb}$ wet deposition annually (Walker, 1999). By measuring $\mathrm{P}$ concentrations in weekly composite rainfall samples, Grimshaw and Dolske (2002) found the volume-weighted annual mean P concentration to be around $1.7 \mu \mathrm{g} P / L(0.0017 \mathrm{mg} / \mathrm{L})$ for Everglades National Park.

A constant concentration was applied to the precipitation rate over the entire domain to represent the Wet Deposition of phosphorus. The precipitation rate for the model is a daily rainfall map which was interpolated from rainfall gauge stations over a 1200 m gridded domain. By multiplying the phosphorus wet atmospheric deposition concentration $T P_{a t m}$ with the daily rainfall maps, a continuous 2-dimensional source of TP loading is applied to the models. The rainfall mean $\mathrm{P}$ concentration $0.0017 \mathrm{mg} / \mathrm{L}$, determined from Grimshaw and Dolske (2002), was used. A constant loading of $13.2 \mathrm{~g} /$ day of $T P_{\text {drydep }}$ (taken from (Redfield, 2002)) was applied over the entire domain as a daily uniform overland loading, representing the Dry Deposition of phosphorus and is included in the source term of the AD equation.

\subsubsection{Tamiami Trail Modification Scenarios}

Recent Everglades restoration efforts have focused on increasing the quantity of water that enters ENP. One focus has been on the construction of bridges along Tamiami Trail, which is currently acting as a levee and water impediment for north-south flow into ENP. In addition, USACE (2013) has proposed to increase the water levels in the L-29 canal by raising tailwaters at key structures as part of an effort to create a greater head elevation north of ENP. Canal water levels are currently controlled via a series of gated structures that allow water to enter the canal and flow out toward the Atlantic Ocean. To simulate the proposed increase in canal stages, the tailwater (TW) head at structure S333 was increased for water levels greater than $2.134 \mathrm{~m}$ (7.0 
feet) (Long et al., Submitted 2014). Three proposed bridge construction scenarios were evaluated using the M3ENP-AD model: a Baseline scenario, the One Bridge Scenario (includes the 1-mile bridge and raised canal stages), and The Two Bridges Scenario (includes both the 1-mile and 2.6 mile bridges and raised canal stages). The scenarios are explained in Chapter 3 and are revisited in the following sections.

\section{Baseline}

The Baseline scenario includes structures and operations that existed from 2007 to 2010. The MIKE 11 canal network includes canal reaches, water control structures (with gate operations), weirs, culverts, and leakage pathways between the river and the saturated zone. Cross sections of the canal reach were determined from topography and design data. Each canal reach boundary point is assigned conditions such as daily flow or water level.

Northeast Shark Slough (NESS) receives water input from the eastern section of the Tamiami Canal (L-29 Canal) which is bounded by water control structures S333 to the west and S334 to the east. This portion of the Tamiami Trail has a series of 19 outlets which convey water from the L-29 canal into NESS, each outlet has three culverts ranging from 42 to 60 inches in diameter (NPS, 2010).

\section{One Bridge}

The One Bridge scenario includes the construction of the 1-mile Tamiami Trail bridge with the section of roadway under the bridge removed. The One Bridge scenario includes an elevated canal stage as controlled by structure S333. The 1-mile bridge was implemented into the model by changing the three culvert outlet at Culvert 57 to a mile-wide broad crested weir and increasing the cross section from $100 \mathrm{ft}$ wide $(30.48 \mathrm{~m})$ to 1 -mile wide $(1.6 \mathrm{~km})$. All flow through neighboring Culvert 56 and 
Culvert 58 was shut off because of the overlapping cross section of the new bridge.

Figure 4.5 shows the 1-mile bridge placement over Culvert 57 (C57).

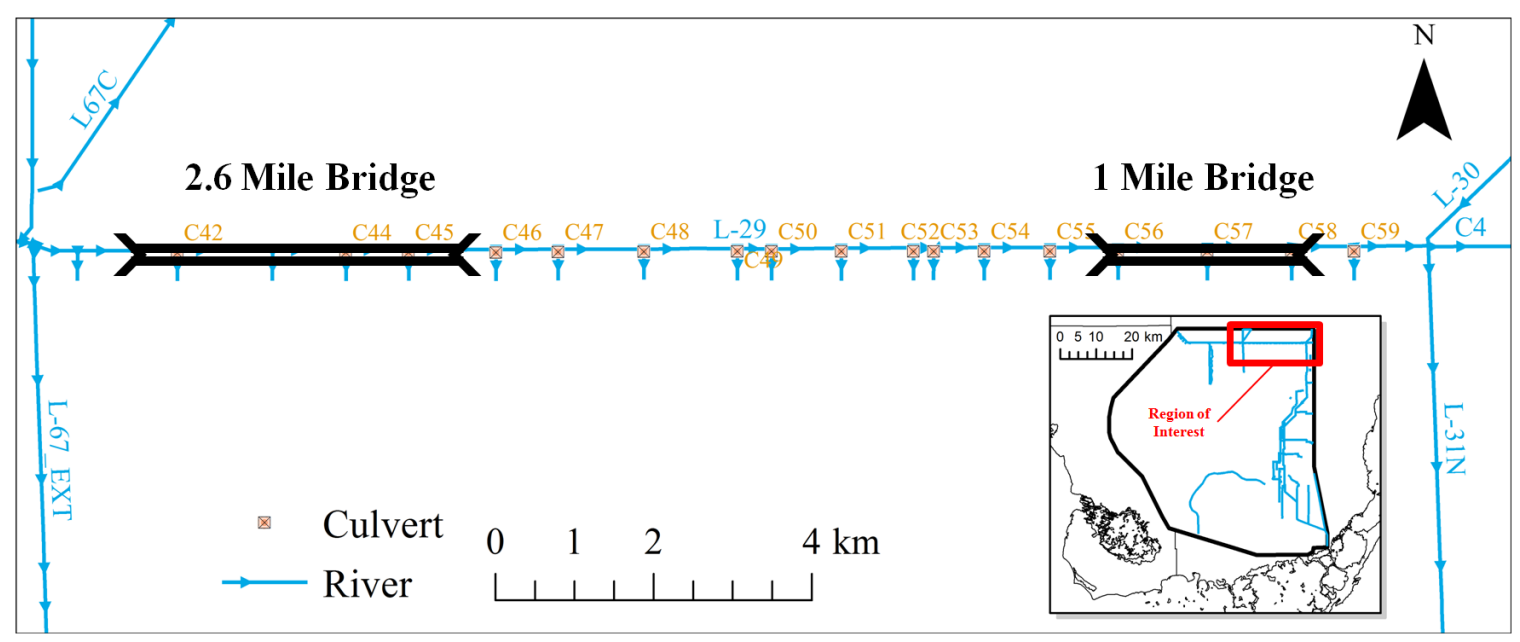

Figure 4.5: Bridge placement along Tamiami Trail for the M3ENP models. The M3ENP-MB model scenarios include water quality simulations with no bridges (Baseline Scenario), with just the 1-mile bridge (One Bridge Scenario), and with both the 1-mile and 2.6-mile bridges (Two Bridges Scenario).

\section{Two Bridges}

The Two Bridges scenario is simulated as if the 1-mile and proposed 2.6-mile Tamiami Trail bridges were built and the section of roadway under the bridges was removed. The Two Bridges scenario includes an elevated canal stage as controlled by structure S333. The 2.6-mile bridge was implemented into the model in two parts. First, the three culvert outlet at Culvert 42 was changed to a mile-wide broad crested weir and the cross section was increased to 1-mile wide $(1.6 \mathrm{~km})$. Second, the three culvert outlet at Culvert 44 was changed to a 1.6 mile-wide broad crested weir and the cross section was increased to 1.6 miles wide $(2.6 \mathrm{~km})$. Flow through the surrounding Culvert 43 and Culvert 45 was shut off due to the overlapping cross section of the new bridge sections. Figure 4.5 shows the 2.6-mile bridge placement over Culvert 42 and 44 (C42 and $\mathrm{C} 44)$. 
Table 4.2: Calibrated model parameters for M3ENP-AD.

\begin{tabular}{lcc}
\hline Parameter & Units & Value \\
\hline Canal Dispersivity, $a$ & $\mathrm{~m}^{2} / \mathrm{s}$ & 15.0 \\
OL Longitudinal Dispersion Coefficient, $D_{L}$ & $\mathrm{~m}^{2} / \mathrm{s}$ & 0.0001 \\
OL Transverse Dispersion Coefficient, $D_{T}$ & $\mathrm{~m}^{2} / \mathrm{s}$ & $10^{-5}$ \\
Linear Sorption Coefficient, $k_{D}$ & $\mathrm{~m}^{3} / \mathrm{g}$ & Figure 4.6 \\
Wet Atmospheric Deposition, $T P_{\text {rain }}$ & $\mathrm{mg} / \mathrm{L}$ & 0.0017 \\
Dry Atmospheric Deposition, $T P_{\text {drydep }}$ & $\mathrm{g} /$ day & 13.2 \\
\hline
\end{tabular}

\subsection{Results and Discussion}

\subsubsection{M3ENP-AD Calibration}

The M3ENP-AD model was first run with the Baseline scenario. All model results were compared with the observed values obtained from the Florida Coastal Everglades Long-Term Ecological Research (FCE LTER) Core Data (Childers and Troxler, 2013a,b, 2008, 2013c,d,e). A linear interpolation was performed on the observed datasets to fill the date range. Observed and Modeled TP loading through the calibration points was calculated using the $\mathrm{x}$ - and $\mathrm{y}$-directional Overland Flow values $\left(Q_{x}\right.$ and $Q_{y}$ in $\left.m^{3} / s\right)$ obtained from the M3ENP water movement simulation and the observed and modeled TP concentrations.

$$
\begin{aligned}
\operatorname{Load}_{T P} & =\text { Flux } \times \text { Concentration } \\
& =\sqrt{Q_{x}^{2}+Q_{y}^{2}} \times C_{T P}
\end{aligned}
$$

Model performance measures such as the Correlation Coefficient (Corr), Root Mean Squared Error (RMSE), and the Nash-Sutcliff model efficiency coefficient (NS) were calculated for each observed dataset and used for exploratory model parameter optimization.

The M3ENP soil map (developed in (Cook, 2012) using aggregated soil types from (NRCS; USGS, 2006)) was used to define distinct zones for Linear Sorption Coefficient values. Values were calibrated for each soil type (Marl, Everglades Peat, Gandy Peat, 


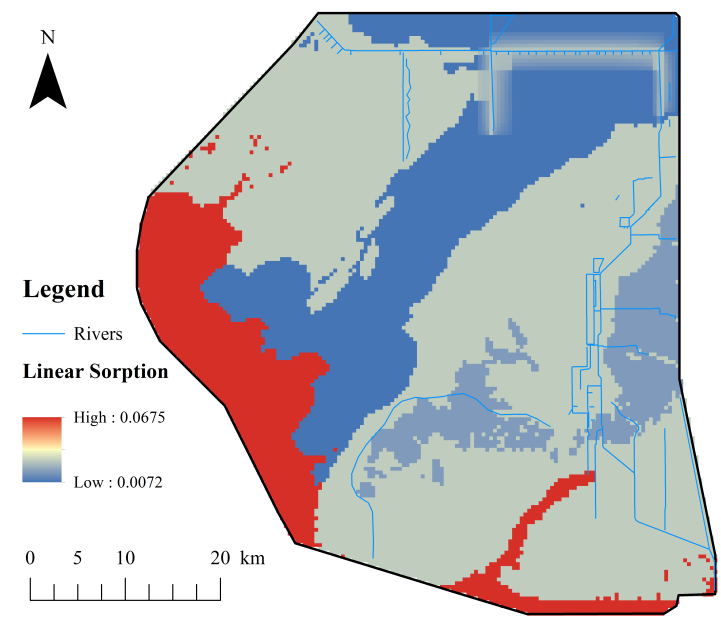

Figure 4.6: Calibrated Linear Sorption Coefficient, $k_{D}$, for the model domain.

Mangrove Peat, and Rockdale). Observed phosphorus values from locations within each soil type zone were used to calibrate the modeled results, shown in Figure 4.6. While the Everglades Peat was calibrated to be very low at an interior station (SRS2), stations near the canals required a much higher sorption coefficient. Studies have reported higher linear sorption coefficients for soils near Everglades canals compared with interior wetlands (Wang and Li, 2010). Vegetation found near canals, such as cattail (Typha domingensis Pers.), have been found to be much more efficient at utilizing dissolved phosphorus in the water column than interior species such as sawgrass (Cladium jamaicense Crantz) which is more adapted to using phosphorus bound in the soils (Chiang et al., 2000; Brix et al., 2010). To account for these factors, a higher linear sorption coefficient was used for cells along the L-29 canal and a linear interpolation was used to gradually decrease the values into the lower sorption coefficient of the Everglades Peat as shown in Figure 4.6.

Table 4.3 provides an overview of the model performance which was calibrated using 1,304 observed values at 6 interior TP monitoring sites. In general the M3ENPAD model performed well, with a correlation coefficient of about $60 \%$. The TP load 
Table 4.3: Summarized calibration statistics for the M3ENP-AD model. Statistics are based on the TP Load $(g / d a y)$.

\begin{tabular}{c|ccccc}
\hline $\begin{array}{c}\text { Calibration } \\
\text { Site }\end{array}$ & $\begin{array}{c}\text { \# of } \\
\text { Observed } \\
\text { Values }\end{array}$ & $\begin{array}{c}\text { Max Load } \\
(g / \text { day })\end{array}$ & $\begin{array}{c}\text { RMSE } \\
(g / d a y)\end{array}$ & $\begin{array}{c}\text { Nash- } \\
\text { Sutcliff }\end{array}$ & $\begin{array}{c}\text { Correlation } \\
\text { Coeffi- } \\
\text { cient }\end{array}$ \\
\hline SRS1d & 303 & 2866.47 & 185.99 & -0.56 & 0.34 \\
SRS2 & 275 & 1091.08 & 350.04 & 0.08 & 0.38 \\
SRS3 & 263 & 2527.91 & 496.54 & 0.04 & 0.34 \\
TS/Ph2 & 205 & 1093.32 & 207.21 & 0.54 & 0.76 \\
TS/Ph3 & 209 & 611.54 & 71.60 & 0.66 & 0.85 \\
TS/Ph5 & 49 & 1047.07 & 66.93 & 0.70 & 0.88 \\
\hline Summary & 1304 & 2866.47 & 229.72 & 0.24 & 0.59 \\
\hline
\end{tabular}

ranged from 0 to 2,867 $\mathrm{g} /$ day and had an average Root Mean Squared Error (RMSE) of $230 \mathrm{~g} /$ day. The Nash-Sutcliff coefficient, which is another way to determine the correlation between modeled results and observed values, was 0.24 for the entire region. Negative Nash-Sutcliff values indicate that the observed mean is a better predictor than the modeled data.

The M3ENP-AD model performed better in areas near the canals, such as the Taylor Slough region, than in open and more pristine areas, such as the Shark River Slough region. This indicates that TP transport in the Shark River Slough region may be driven by different processes than in the canal-fed areas where advection is dominant. Figure 4.7 shows the calibration results for the TS/Ph2 site within Taylor Slough. The majority of the flows through this location are controlled upstream via gates and weirs, and the advection process may be the dominant form of TP transport. Additional calibration results for the M3ENP-AD model are shown in Table 4.3 and the detailed calibration figures are available in Appendix B.

\subsubsection{Model Sensitivity}

The M3ENP model showed sensitivity to all of the parameters listed in Table 5.1. The model was sensitive to Canal Dispersivity and OL Dispersion Coefficients at a certain 


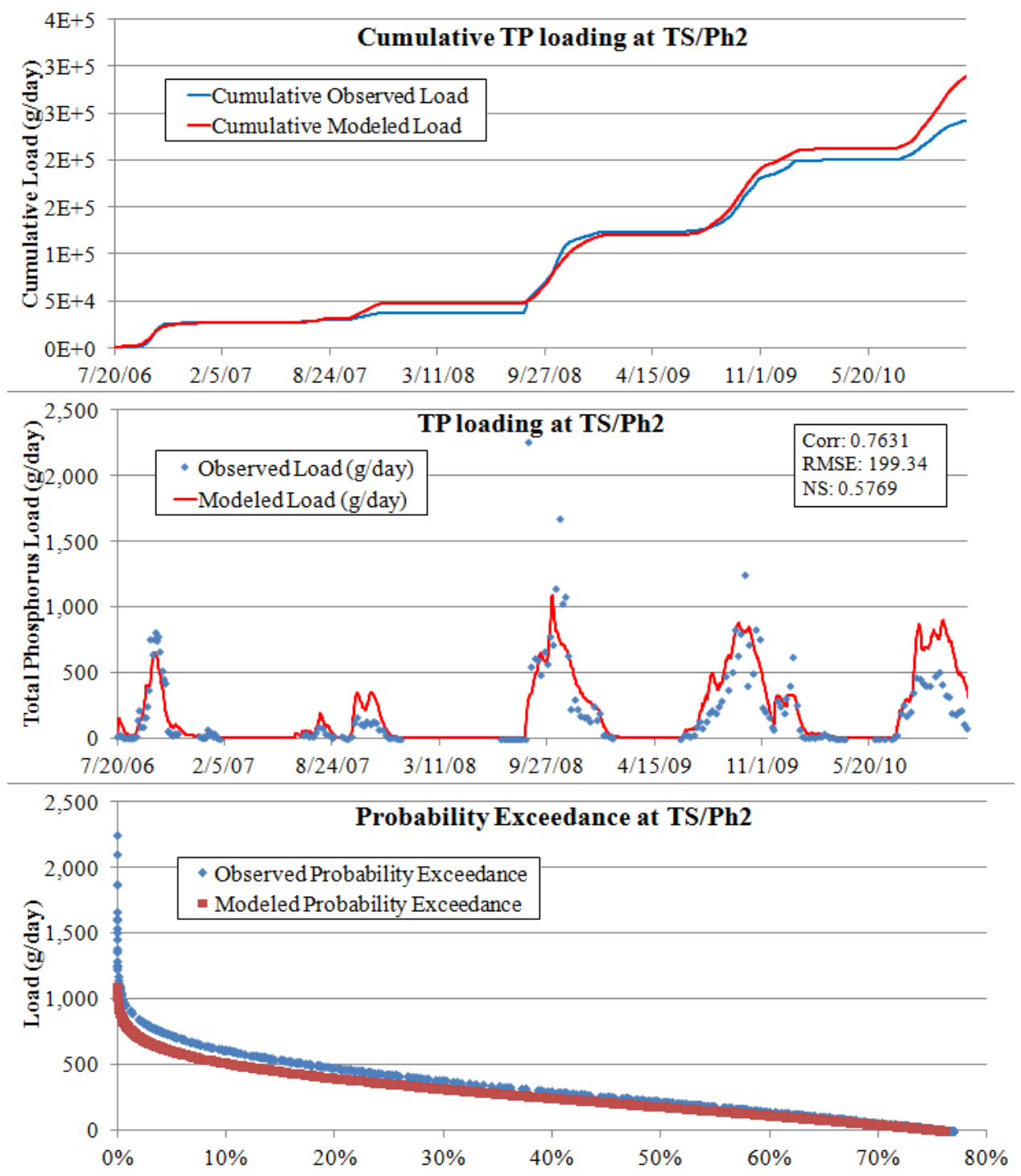

Figure 4.7: Calibration results for the M3ENP-AD model at the TS/Ph2 site in Taylor Slough.

threshold, beyond which the model would produce instabilities $\left(<15 \mathrm{~m}^{2} / \mathrm{s}\right.$ for canals, and $>0.0001 \mathrm{~m}^{2} / \mathrm{s}$ for overland). Wang et al. (2012) also showed model sensitivity to canal dispersion. However, both Wang et al. (2012) and Paudel et al. (2010) showed that the marsh models were not sensitive to Overland Dispersion Coefficients. This discrepancy may arise from the scaling issue associated with dispersion coefficients (Schulze-Makuch, 2005). 
The model was highly sensitive to the Saturated Zone Sorption Coefficient. Decreasing the SZ Sorption Coefficient by a third increased water column TP values by an average of about 14\%. In addition, the total TP sorbed to the Saturated Zone accounted for about $83 \%$ of the total TP input to the SZ. These results indicate that sorbtion, as a phosphorus transport mechanism, dominates over advection-dispersion transport in the SZ. The model did not show sensitivity to the Unsaturated Zone Sorption Coefficient.

The M3ENP-AD model was highly sensitive to phosphorus loading from atmospheric deposition. Raghunathan et al. (2001) also found their numerical model sensitive to atmospheric deposition and showed that this parameter has a strong influence on areas with typically low TP. Sorption values were calibrated based on the observed total phosphorus; therefore, any sources of phosphorus added to the model must be accurate. Values for wet and dry atmospheric deposition were taken from the literature. A rainfall concentration of $0.0017 \mathrm{mg} / \mathrm{L}$ (Grimshaw and Dolske, 2002) and a general dry loading from the atmosphere of $13.2 \mathrm{~g} /$ day (Ahn and James, 2001; Redfield, 2002) was used uniformly over the entire domain.

\subsubsection{Scenario Analysis}

The Tamiami Trail Modification Scenarios were simulated using parameters from the calibrated Baseline scenario, which are summarized in Table 5.1). Very minimal changes in TP load occurred in the model domain for the simulation period using the bridge scenarios. The average TP load $(g / d a y)$, shown in Figure 4.8, increased with the addition of bridges for the Shark Slough data points (SRS2 and SRS3). Average load decreased with the addition of bridges at the site closest to the bridge area (SRS1d) and at downstream Taylor Slough sites (TS/Ph3 and TS/Ph5). 


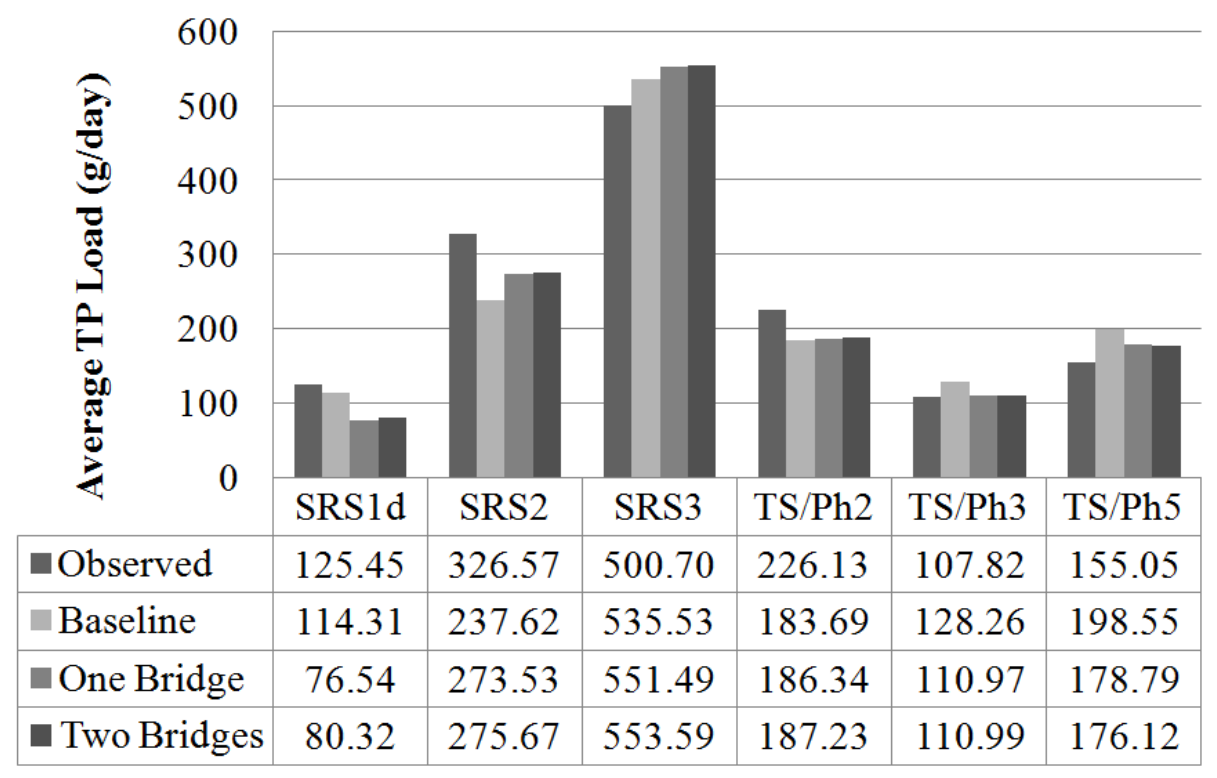

Figure 4.8: Average TP load $(g / d a y)$ for Observed, Baseline, One Bridge, and Two Bridge Scenarios.

While site-specific increases in TP load occurred with the addition of bridges, in general, the model domain experienced a decrease in dissolved TP concentrations as shown in Table 4.4. The Overland TP Mass decreased an average of 14.4-14.8\% for the entire simulation period $(7 / 20 / 2006$ - 12/1/2010). The Everglades wet season ranges from about mid-May to November (May 15 to Nov. 1) and the dry season is the remainder of the year (Nov. 2 to May 14). The wet seasons which were within the simulation period were from 2007 to 2010. These wet season domain average values were then averaged again to get a mean wet season value for the entire model domain and simulation period. The same was done for the dry season. In general the water column TP concentration decreased during the dry season by $2.8-3.6 \%$ and in the wet season by 4.1-4.6\%. The Overland TP Mass decreased during the dry season by $11.2-11.8 \%$ and in the wet season by $13.6-14.1 \%$. It is interesting to note that the percent change in overland TP mass is significantly greater, this is because it includes the depth of the overland water column 
Table 4.4: Percent change in overland TP concentration and overland TP mass for the M3ENP-AD model.

\begin{tabular}{|c|cc|cc|}
\cline { 2 - 5 } \multicolumn{1}{c|}{} & \multicolumn{2}{l|}{$\begin{array}{l}\text { Overland Concen- } \\
\text { tration }(\mathrm{mg} / \mathrm{L})\end{array}$} & $\begin{array}{l}\text { Overland } \\
\left(\mathrm{g} / \mathrm{m}^{2}\right)\end{array}$ & Mass \\
\cline { 2 - 5 } \multicolumn{1}{c|}{} & One Bridge & Two Bridges & One Bridge & Two Bridges \\
\hline Total Change & $-4.62 \%$ & $-3.95 \%$ & $-14.35 \%$ & $-14.80 \%$ \\
Avg. Dry Season & $-3.59 \%$ & $-2.76 \%$ & $-11.20 \%$ & $-11.75 \%$ \\
Avg. Wet Season & $-4.58 \%$ & $-4.10 \%$ & $-13.59 \%$ & $-14.11 \%$ \\
\hline
\end{tabular}

Figure 4.9 compares the Overland TP mass per area $\left(\mathrm{g} / \mathrm{m}^{2}\right)$ for the Baseline and the Two Bridges Scenario on a late-wet season day when TP spiked unusually high. The date of comparison, $11 / 1 / 2008$, was chosen because it is during the Everglades wet season and it demonstrates a spike in the phosphorus which came from a high measurement at the S333 structure on 10/1/2008. This figure illustrates the change in the TP mass transport over the entire domain. The change is specifically visible in the NESS region. The One Bridge simulation was omitted from the figure because there is minimal difference between the One Bridge and Two Bridge Scenarios.
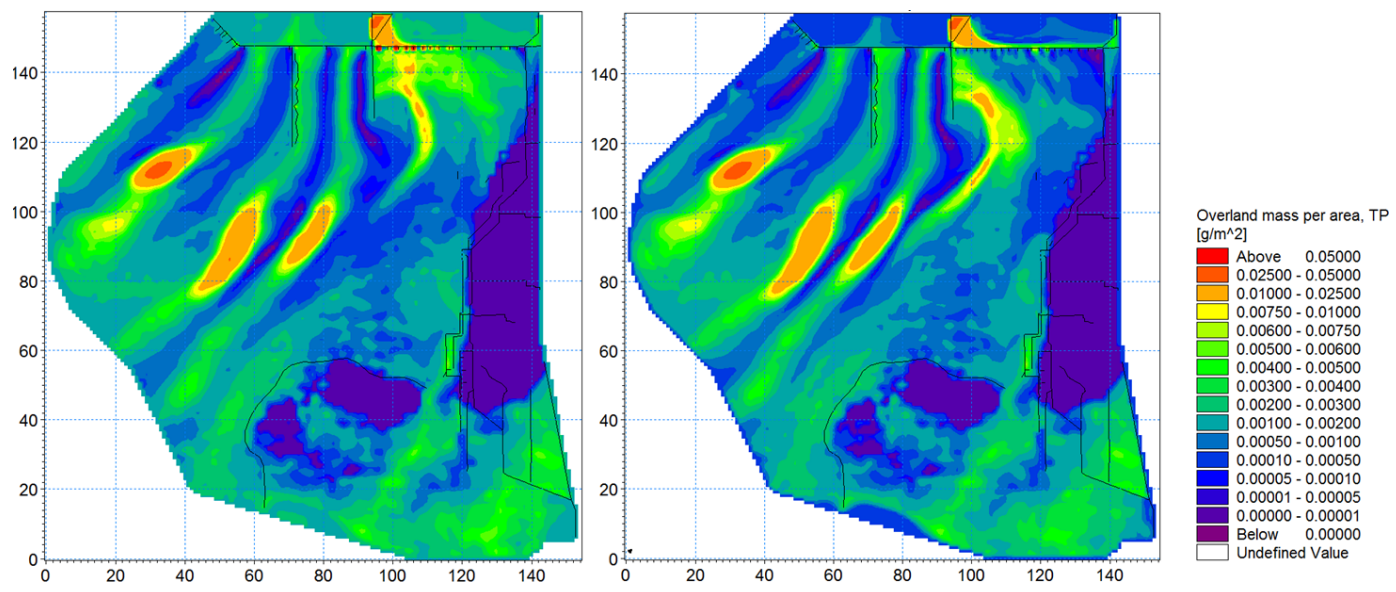

Figure 4.9: Overland Phosphorus Mass per Area $\left(\mathrm{g} / \mathrm{m}^{2}\right)$ for the Baseline versus Two Bridge Scenarios on 11/1/2008

The Overland Flow velocity is driving TP mass transport for both scenarios in Figure 4.9. The average Péclet numbers for the entire region are around 58, indicating 
Table 4.5: Analysis of average daily loads and maximum cumulative loads for locations $\mathrm{A}$ and $\mathrm{B}$ along the NESS transect.

\begin{tabular}{lcccc} 
& Transect & Baseline & One Bridge & Two Bridges \\
\hline Average Daily & A & 0.104 & 0.060 & 0.057 \\
Load (kg/d) & B & 0.188 & 0.242 & 0.235 \\
\hline Max Cumulative & A & 165.23 & 95.56 & 90.74 \\
Load (kg) & B & 299.82 & 386.24 & 375.69 \\
\hline
\end{tabular}

that phosphorus transport is primarily an advective process within the model domain on the $11 / 1 / 2008$ analysis day.

The primary goal of the Tamiami Trail modifications is to increase water levels and flows to Northeast Shark Slough (NESS) (Boler and Sikkema, 2010). To observe how the implementation of bridges and raised canal stages impact this region, two points were selected along within NESS along the flow direction (illustrated as point $\mathrm{A}$ and $\mathrm{B}$ in Figure 4.10). Point $\mathrm{A}$ is $6.8 \mathrm{~km}$ south of the L-29 canal and $9.2 \mathrm{~km}$ west of the L-31N canal. Point B is located $9.63 \mathrm{~km}$ southwest (downstream NESS) of Point A.

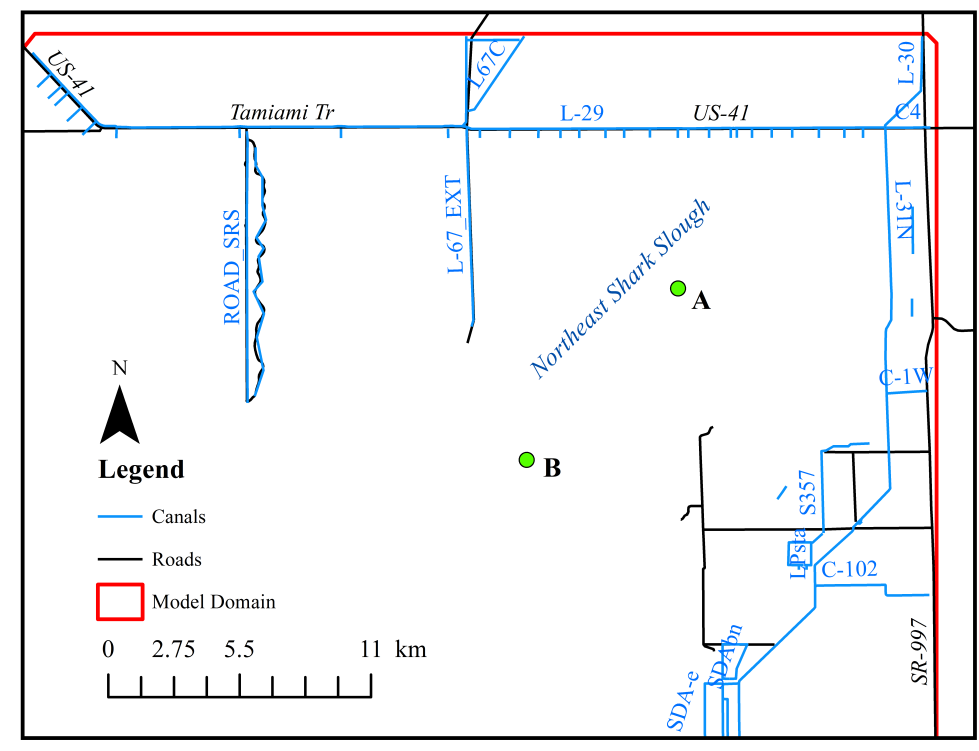

Figure 4.10: Points A and B located in NESS along the flow direction. 

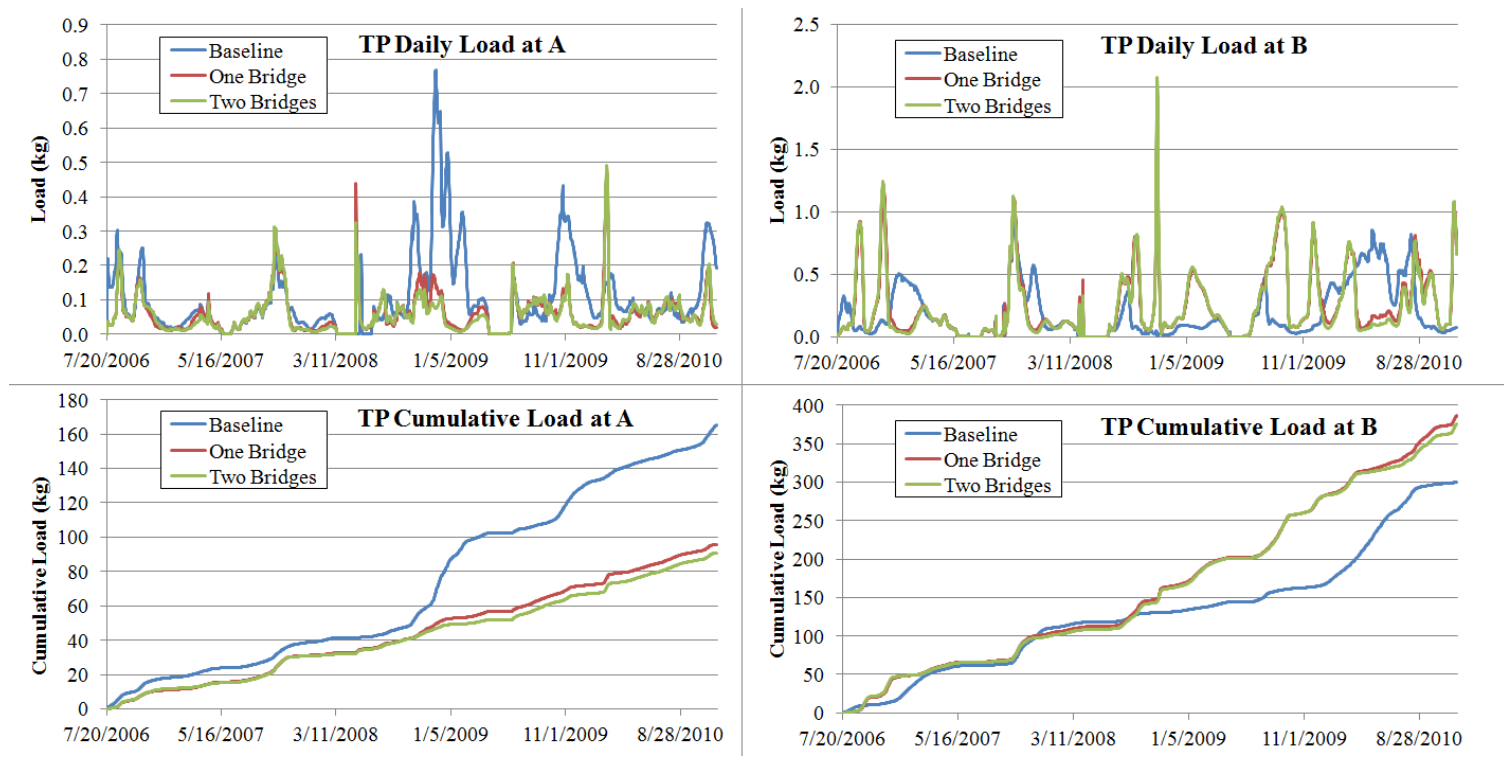

Figure 4.11: Daily and cumulative TP load $(\mathrm{kg})$ for Points A and B located in NESS. Daily and cumulative TP Load in A (upstream) decreases with bridge scenarios and TP Cumulative Load in B (downstream) increases with bridge scenarios.

Figure 4.11 shows the daily and cumulative load (in $\mathrm{kg}$ of $\mathrm{TP}$ ) at A and B and Table 4.5 provides the average daily load and max cumulative loads for each scenario. The TP load for all scenarios is larger downstream. Cumulative TP load decreases upstream and increases downstream with the One Bridge and Two Bridges scenarios. Daily TP load tends to decrease at A with bridge scenarios and increase at B with bridge scenarios. In addition, the shape of the daily load curves change with the bridge scenarios at the downstream location B. This change may be caused by the switching of the dominant form of transport in that area. Higher flows caused by the addition of bridges may change the transport mechanism from dispersion-dominant to advection-dominant.

The increase in loading is due to the increase in flow velocities downstream (as the water flux is a multiplier for load). Long et al. (Submitted 2014) demonstrated that the addition of bridges and elevated canal stages as modeling scenarios created higher water levels and flows within ENP. Because the advection-dispersion calculation relies 
on these parameters, it is intuitive that phosphorus load will increase within the model domain with increasing flows.

\subsection{Conclusions}

Everglades ecosystem restoration efforts are driven by infrastructure changes which may change Everglades hydrology and hydrochemistry. It is important to estimate the effects of these infrastructure changes, such that restoration decisions can be guided by comprehensive scientific analysis. The M3ENP model simulates the entire hydrological cycle of the Everglades, and includes water flow calculations for overland, channels, the unsaturated zone soil layers, and saturated zone aquifer layers (Cook, 2012; Long et al., Submitted 2014). A phosphorus transport model was developed using results from the M3ENP water model to calculate the advection-dispersion of phosphorus in ENP from July 2006 to December 2010. The model (termed M3ENPAD) was calibrated with observed phosphorus values (in water $m g / L$ ) at ENP interior locations using model parameter optimization. The model showed sensitivity to overland dispersion, the linear sorption coefficient, and the atmospheric deposition (wet

and dry). The model performed well with a correlation coefficient of $60 \%$ for the 6 observation points within the domain.

The M3ENP-AD model was used to simulate the effects of raising the Tamiami Trail roadway with proposed bridges and increasing L-29 canal stages. The One Bridge Scenario (which simulated the newly-constructed 1-mile Tamiami Trail bridge and an increase in canal stage) and Two Bridge Scenario (which added an additional proposed 2.6-mile bridge to the One Bridge Scenario) were evaluated with the M3ENP-AD model calibrated parameters. The average TP concentration decreased by 4 to $4.6 \%$ and the average TP mass per area decreased by $14.4-14.8 \%$ in all cells within the model domain with the Tamiami Trail modifications. 
Many interior locations within the model domain experienced a general increase in the Daily TP Load with the addition of bridges, most especially during highflow periods. However, Taylor Slough experienced a decrease in TP Load with the addition of bridges. Northeast Shark Slough (NESS), a target ecosystem for many recent restoration efforts, experienced an increase in cumulative TP load of about $30 \%$ over the simulation period with the inclusion of the 1-mile bridge and raised canal stages.

This study was limited by the availability of a complete long-term phosphorus data record. In addition, the model simplified and aggregated the complex sorption and uptake mechanisms which control phosphorus transport in the ENP. However, the M3ENP-AD model provides a tool which can simulate the transport of a key nutrient in the Everglades system and provide insight toward the effects of future restoration efforts.

\subsection{Acknowledgments}

This work is a collaborative effort between the National Park Service and Florida International University's Applied Research Center (Cooperative Agreement P06AC00039MOD 0003). Funding support for this research was provided through the NASA WaterSCAPES University Research Center (Cooperative Agreement NNX10AQ13A). This material is based upon work supported by the National Science Foundation under Grant No. EAR-1204762. 


\section{CHAPTER 5}

\section{MODELING NUTRIENT LOADING AND TRANSPORT THROUGH EVERGLADES NATIONAL PARK, FL, USA USING A MASS BALANCE APPROACH}

\section{$5.1 \quad$ Introduction}

The M3ENP-AD model (explored in Chapter 4) uses hydrodynamic results from the calibrated M3ENP (Mike Marsh Model of Everglades National Park) to model phosphorus fate and transport using the advection-dispersion-reaction equation (ADRE). Reactive transport using a linear sorption coefficient provides a mechanism for phosphorus removal from the water column via sorption to an immobile phase. In this chapter, the sorption isotherm used in the reactive transport equations are substituted for uptake and release kinetics formulated via mass balance. The resulting M3ENP-MB model was developed using the ECO Lab module from DHI Group.

The success of mass balance equations for determining TP transport in the Everglades is well documented. Walker (1995) developed a mass balance model for total phosphorus in the Stormwater Treatment Areas south of Lake Okeechobee and the agricultural areas. The Dynamic Model for Storm Water Treatment (DMSTA2) includes differential equations to describe steady-state water and phosphorus balances in each wetland segment (Walker, 1995). This includes an effective settling velocity and a correction factor for the percentage of dry days in the average year. Further 
development of this model included the uptake and release of phosphorus to the soil or UZ, as well as a burial term for the permanent storage of stable forms of $\mathrm{P}$ to the accreting peat layer (Walker and Kadlec, 2011). However, Walker's model was developed to determine annual $T P$ budget over an entire wetlands.

Wang et al. (2012) simulated TP transport in a compartmentalized portion of the Everglades using the dispersive mass balance equation. The reactive loss of TP was estimated based on the DMSTA2 model developed by Walker (1995); Walker and Kadlec (2011).

Paudel et al. (2010) follows the work of Walker and Kadlec (2011) yet his model differentiates concentrations over time rather than for the wetland area (Paudel et al., 2010).

\subsection{Methods}

The M3ENP model domain, shown in Figure 5.1, is approximately 2,720 sq $\mathrm{km}$ and includes parts of Everglades National Park (ENP), WCA 3a and 3b, and agricultural areas of Miami-Dade County in South Florida (Cook, 2012; Long et al., Submitted 2014). This region encompasses a range of ecosystems including ridge and slough, wet prairies, tree islands, pine forests, cypress forests, upland pine forests, mangrove forests in estuarine regions, and agricultural areas (Stone and Legg, 2001).

The fate and transport of phosphorus in Everglades National Park was modeled using a 3-D finite-difference approach. Two methods for determining phosphorus transport were evaluated in conjunction with the M3ENP hydrodynamic results. Both methods were used to examine restoration efforts for ENP, including the effects of bridge additions on nutrient transport. The first method evaluates how the chemical transports in the system via advection (moves with the water) and dispersion (moves down a concentration gradient), as well as how it interacts with the soil and rocks of 


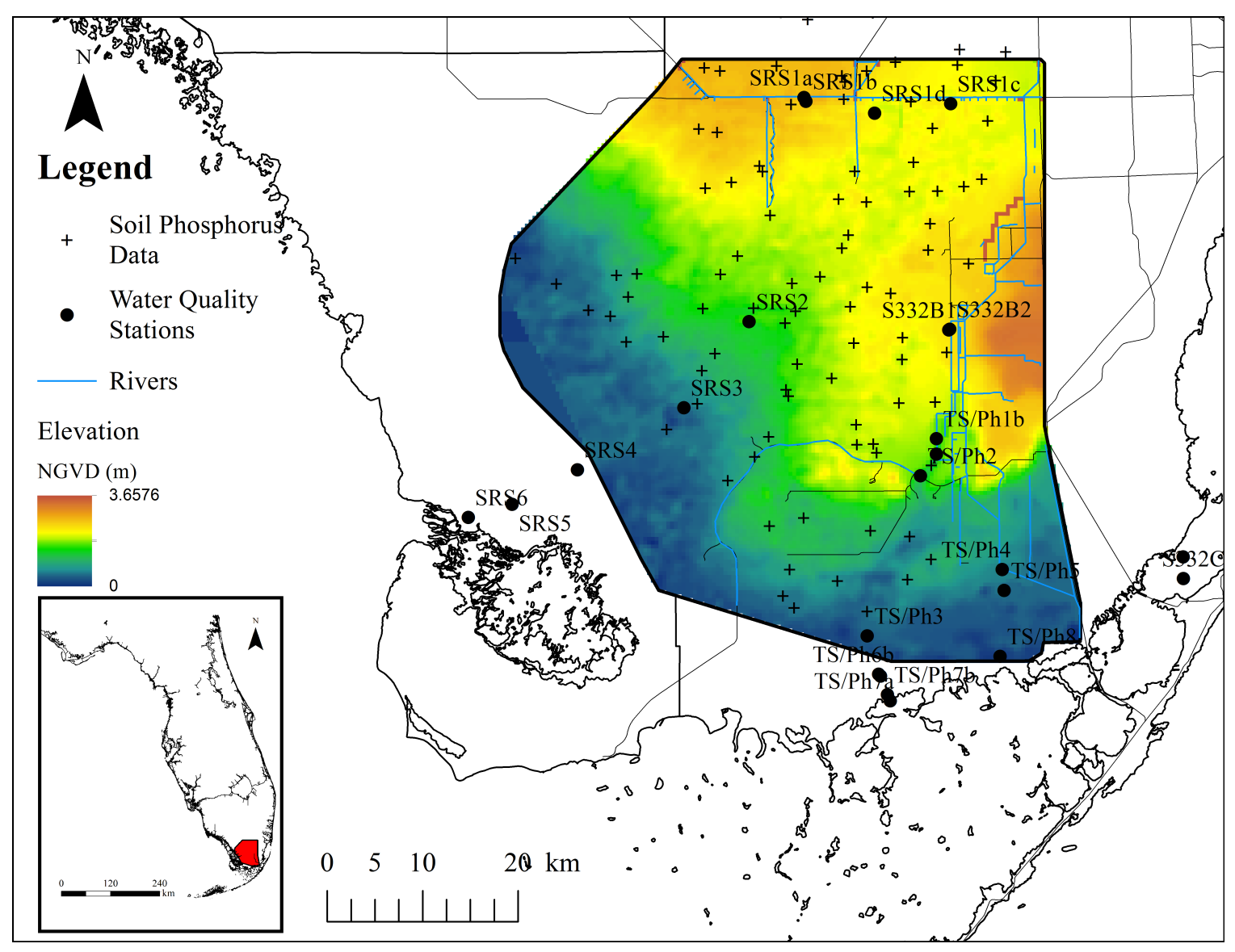

Figure 5.1: Model domain located in southern Florida.

the unsaturated and saturated zones (sorption and desorption). The second method utilizes the ECOLab module to develop a set of mass balance equations for sorbed and dissolved phosphorus.

\subsubsection{Advection-Dispersion Model Development}

The MIKE SHE water movement module supports the calculation of solute transport in the different parts of the hydrological cycle, including overland flow (OL), unsaturate zone flow (UZ), and saturated zone flow (SZ). Water flow, water contents, hydraulic heads and water levels calculated in the water movement simulation are used to calculate the solute transport (Refsgaard and Storm, 1995). 
Two species were specified for the Advection-Dispersion transport: TP (total phosphorus in the water column) and $T P_{S}$ (total phosphorus sorbed). The two were linked via sorption processes and solubility maximums. A linear sorption coefficient controlled the rate of sorption/desorption between the two species and any TP that reached maximum solubility would precipitate out of the water column into the sorbed species.

Solute transport is calculated in MIKE SHE using the Advection-Dispersion equation:

$$
\frac{\partial c}{\partial t}=-\frac{\partial}{\partial x_{i}}\left(c v_{i}\right)+\frac{\partial}{\partial x_{i}}\left(D_{i j} \frac{\partial c}{\partial x_{j}}\right)+R_{c}
$$

Where $c$ is the concentration of the solute, $v_{i}$ is the velocity tensor (calculated from the WM simulation), $D_{i j}$ is the dispersion tensor (from user-specified longitudinal and transverse dispersion coefficients), and $R_{c}$ is the sum of the sources and sinks.

The Advection-Dispersion equation is used to calculate the solute concentration in the Overland Flow for horizontal transport (where $i, j=1,2$ for two-dimensional), in the Unsaturated Zone for vertical transport (only calculated in the z direction), and in the Saturated Zone for transport in three dimensions $(i, j=1,2,3)$ depending on the WM setup. The entire Advection-Dispersion with Reactive Transport process is illustrated in Chapter 4.

\subsubsection{Mass Balance Model Development}

Based on the work of Walker and Kadlec (2011) and Paudel et al. (2010), a mass balance equation was developed using DHI's ECOLAB module for use with the M3ENP model. ECOLab is an add-on component which allows user-specified processes to be programmed in addition to the Advection-Dispersion processes which are inherent in 
the MIKE SHE model. Figure 5.2 illustrates the process used for determining the change in $T P$ and $T P_{S}$ in the cell for each time step.

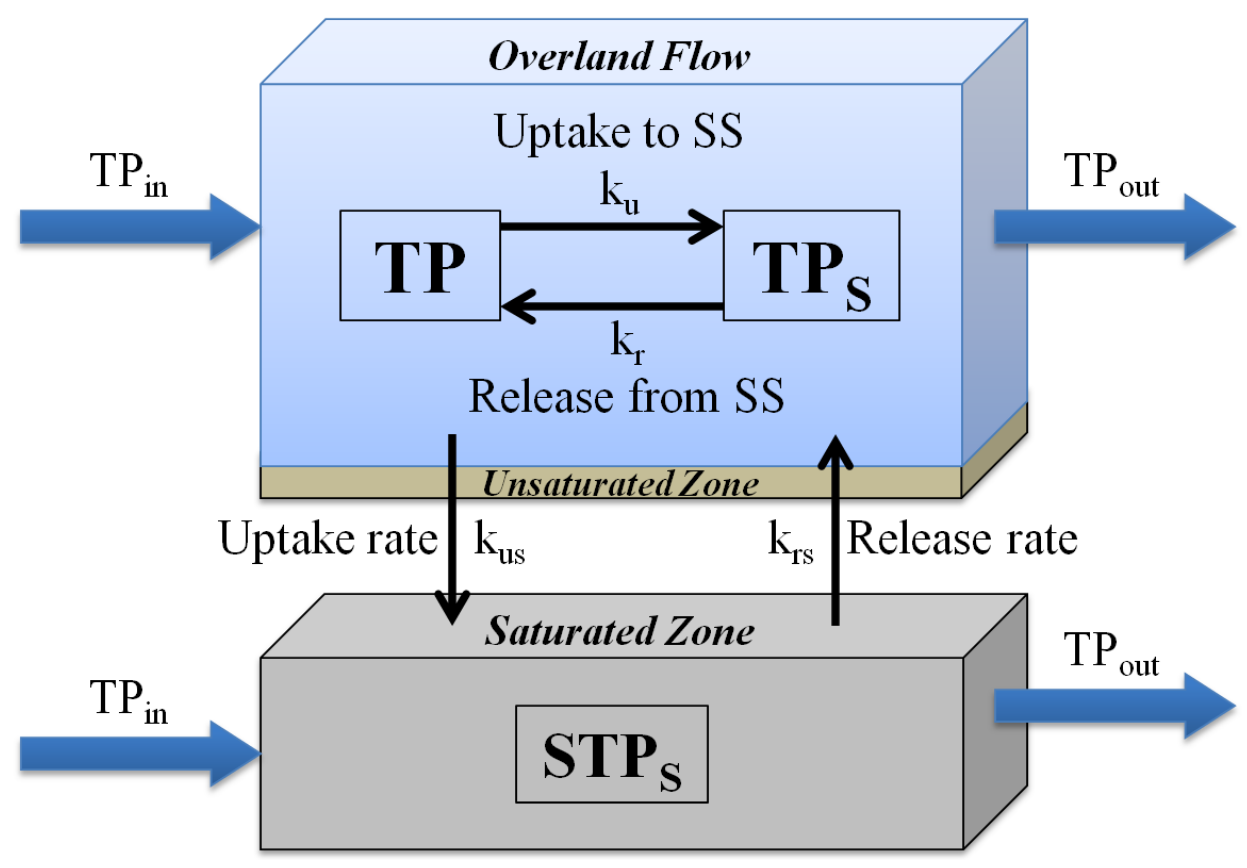

Figure 5.2: Schematic for the Mass Balance process.

The Saturated Zone layer was included in the Mass Balance formulation because analysis of the Advection-Dispersion study showed that the model was highly sensitive to the SZ sorption coefficient. In addition, in many regions of ENP, the overland water is indistinguishable from the groundwater. The following set of equations were developed using the mass balance method. They include the transformation of phosphorus from the dissolved $T P$ to the suspended $T P_{S}$ species and from the dissolved $T P$ to the sorbed $S T P_{S}$ species.

$$
\begin{aligned}
\frac{d(T P)}{d t} & =\frac{k_{r} T P_{S}}{\left(1+k_{u}\right)} \\
\frac{d\left(T P_{S}\right)}{d t} & =\frac{k_{u} T P}{\left(1+k_{r}\right)}
\end{aligned}
$$


In the Overland Flow component, $k_{u}$ is the uptake rate from the dissolved form to suspended solids (SS) in the water column and $k_{r}$ is the release rate from $\mathrm{SS}$ to the dissolved species.

$$
\begin{aligned}
\frac{d(T P)}{d t} & =\frac{k_{r s}}{d\left(1+k_{u s}\right)} S T P_{S} \\
\frac{d\left(S T P_{S}\right)}{d t} & =\frac{d k_{u s}}{\left(1+k_{r s}\right)} T P
\end{aligned}
$$

For the Saturated Zone, $k_{u s}$ is the uptake rate to $\mathrm{SZ}$ aquifer materials and $k_{r s}$ represents the release rate of $\mathrm{SZ}$ materials back into the dissolved component. The overland water depth $d$ is used to convert back and forth from the the volume-based concentration to the dry-mass concentration. These mass balance equations were then coded within the ECOLab module in separate calculations for Overland Flow (including 1-D Channel Flow) and Saturated Zone.

\subsubsection{Phosphorus Sources}

Phosphorus loading was applied to the M3ENP-MB model as it was applied to the M3ENP-AD model in Chapter 4: i) as observed and constant concentration inflows at canal boundaries and $i$ ) as atmospheric deposition.

\section{Canal Inflows}

Phosphorus concentrations are input at all MIKE 11 boundaries as inflow concentrations. A background constant concentration of $0.001 \mathrm{mg} / \mathrm{L}$ was used for all boundary locations as a continuous point source. Observed TP concentration timeseries are used at critical inflow points such as the S333, S335 and S178 structures where ENP inflows are controlled with gated structures and flow operations. Modeled canal water levels and inflows from the M3ENP hydrodynamic model are used to determine the total loading. 


\section{Atmospheric Deposition}

A constant concentration was applied to the precipitation rate over the entire domain to represent the Wet Deposition of phosphorus. The precipitation rate for the model is a daily rainfall map which was interpolated from rainfall gauge stations over a 1200 $\mathrm{m}$ gridded domain. By multiplying the phosphorus wet atmospheric deposition concentration $T P_{a t m}$ with the daily rainfall maps, a continuous 2-dimensional source of $T P$ loading is applied to the models. A constant loading of $13.2 \mathrm{~g} /$ day of $T P_{\text {drydep }}$ was applied over the entire domain as a daily uniform overland loading. This represents the Dry Deposition of phosphorus.

\subsection{Results and Discussion}

\subsubsection{M3ENP-MB Calibration}

The M3ENP-AD model was run with the Baseline scenario. All model results were compared with the observed values obtained from the Florida Coastal Everglades Long-Term Ecological Research (FCE LTER) Core Data (Childers and Troxler, 2013a,b, 2008, 2013c,d,e). A linear interpolation was performed on the observed datasets to fill the date range. Observed and Modeled TP loading through the calibration points was calculated using the x- and y-directional Overland Flow values $\left(Q_{x}\right.$ and $Q_{y}$ in $\mathrm{m}^{3} / \mathrm{s}$ ) obtained from the M3ENP water movement simulation and the observed and modeled TP concentrations.

$$
\begin{aligned}
\operatorname{Load}_{T P} & =\text { Flux } \times \text { Concentration } \\
& =\sqrt{Q_{x}^{2}+Q_{y}^{2}} \times C_{T P}
\end{aligned}
$$

Model performance measures such as the Correlation Coefficient (Corr), Root Mean Squared Error (RMSE), and the Nash-Sutcliff model efficiency coefficient (NS) 
Table 5.1: Calibrated model parameters for M3ENP-MB.

\begin{tabular}{lcc}
\hline Parameter & Units & Value \\
\hline Canal Dispersivity, $a$ & $\mathrm{~m}^{2} / \mathrm{s}$ & 15.0 \\
OL Longitudinal Dispersion Coefficient, $D_{L}$ & $\mathrm{~m}^{2} / \mathrm{s}$ & 0.0001 \\
OL Transverse Dispersion Coefficient, $D_{T}$ & $\mathrm{~m}^{2} / \mathrm{s}$ & $10^{-5}$ \\
Wet Atmospheric Deposition, $T P_{\text {rain }}$ & $\mathrm{mg} / \mathrm{L}$ & 0.0017 \\
Dry Atmospheric Deposition, $T P_{d r y d e p}$ & $g / d a y$ & 13.2 \\
Uptake rate in surface waters, $k_{u}$ & $d^{-1}$ & 0.01 \\
Release rate in surface waters, $k_{r}$ & $d^{-1}$ & 0.011 \\
Uptake rate in groundwater, $k_{u s}$ & $d^{-1}$ & 0.001 \\
Release rate in groundwater, $k_{r s}$ & $d^{-1}$ & 0.0025 \\
\hline
\end{tabular}

were calculated for each observed dataset and used to for exploratory model parameter calibration.

Figure C.3 shows the M3ENP-MB model results versus the observed values of TP daily load and cumulative load over the simulation period from $7 / 20 / 2006$ to 12/31/2010 for stations SRS3 and TS/Ph3. All of the M3ENP-MB results can be found in Appendix C

The M3ENP-MB model under-performed in comparison to the M3ENP-AD model for certain stations. This indicates that i) the Everglades ecosystem may follow the Advection-Dispersion with linear sorption reaction equation and that ii) the M3ENPMB model parameters may require further calibration in the future. Table 5.2 compares the statistical performance of the M3ENP-AD and M3ENP-MB models with observed data.

\subsubsection{Model Mass Balance}

Total Phosphorus undergoes transformations and transports between the surface and subsurface components before leaving the system. To illustrate the movement within the system, a mass balance was performed for for a single full modeled year $(1 / 1 / 2009$ 
Figure 5.3: Comparison of observed versus M3ENP-MB model results for the SRS3 water quality monitoring station. The top graph is the daily TP value (in $m g / L$ ) comparison for SRS3 and the bottom graph shows cumulative load for the SRS3 station.
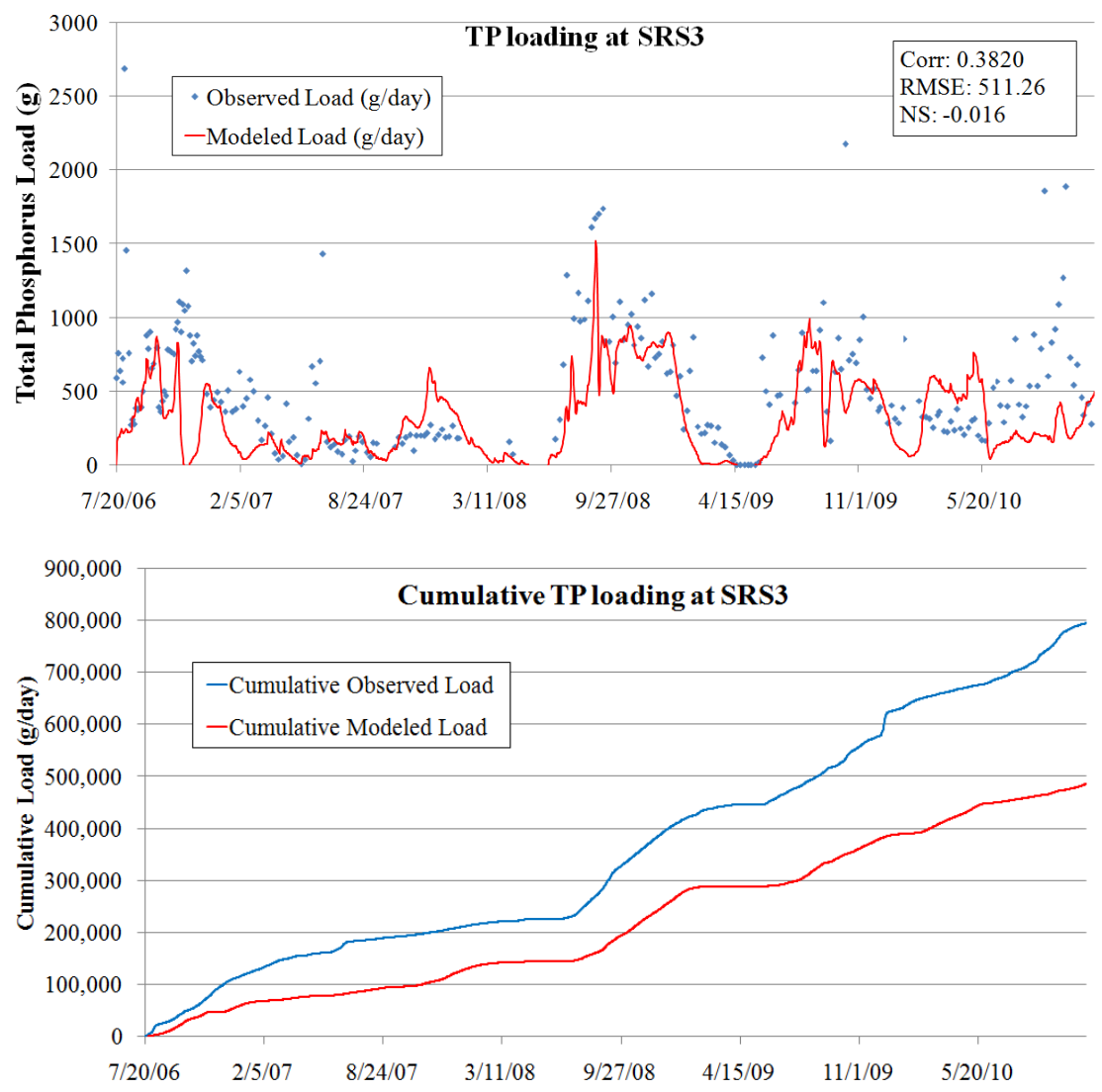
Table 5.2: Comparison of M3ENP-AD and M3ENP-MB model performance.

\begin{tabular}{llcc} 
& & M3ENP-AD & M3ENP-MB \\
\hline \multirow{3}{*}{ SRS1d } & RMSE & 185.99 & 240.00 \\
& Correlation Coef & 0.3353 & 0.1515 \\
& NS & -0.5603 & -1.5981 \\
\hline \multirow{3}{*}{ SRS2 } & RMSE & 350.04 & 376.71 \\
& Correlation Coef & 0.3787 & 0.3660 \\
\hline \multirow{2}{*}{ SRS3 } & NS & 0.0776 & -0.0683 \\
& RMSE & 496.54 & 511.26 \\
\hline \multirow{3}{*}{ TS/Ph2 } & Correlation Coef & 0.3440 & 0.3820 \\
& NS & 0.0417 & -0.0160 \\
\hline \multirow{2}{*}{ TS/Ph3 } & RMSE & 207.21 & 361.48 \\
& Correlation Coef & 0.7631 & 0.4175 \\
& NS & 0.5429 & -0.3912 \\
\hline \multirow{2}{*}{ TS/Ph5 } & RMSE & 71.60 & 166.23 \\
& Correlation Coef & 0.8461 & 0.5899 \\
& NS & 0.6550 & -0.8595 \\
\hline
\end{tabular}

to $12 / 31 / 2009)$ over the entire model domain. Figure 5.4 shows the movement of TP between the OL, UZ, and SZ, as well as uptake to and release from sorped forms.

The mass balance of the M3ENP-MB model shows that much of the transport of TP occurred as uptake to sorped $S T P_{S}$ and release to soluble $T P$ SZ. To ensure that the values for mass of $T P$ were realistic, a water balance was performed for the hydrodynamic results. This provided the volume of water moving within the model for 2009. The average concentration of $T P$ within the system was then calculated, and remained within a reasonable range of about $3 \times 10^{-3} \mathrm{mg} / \mathrm{L}$ for subsurface flow and $3 \times 10^{-3} \mathrm{mg} / \mathrm{L}$ for OL flow. The TP concentration from atmospheric deposition was $1.19 \times 10^{-3} \mathrm{mg} / \mathrm{L}$, slightly less than the input of $1.7 \times 10^{-3} \mathrm{mg} / \mathrm{L}$. 


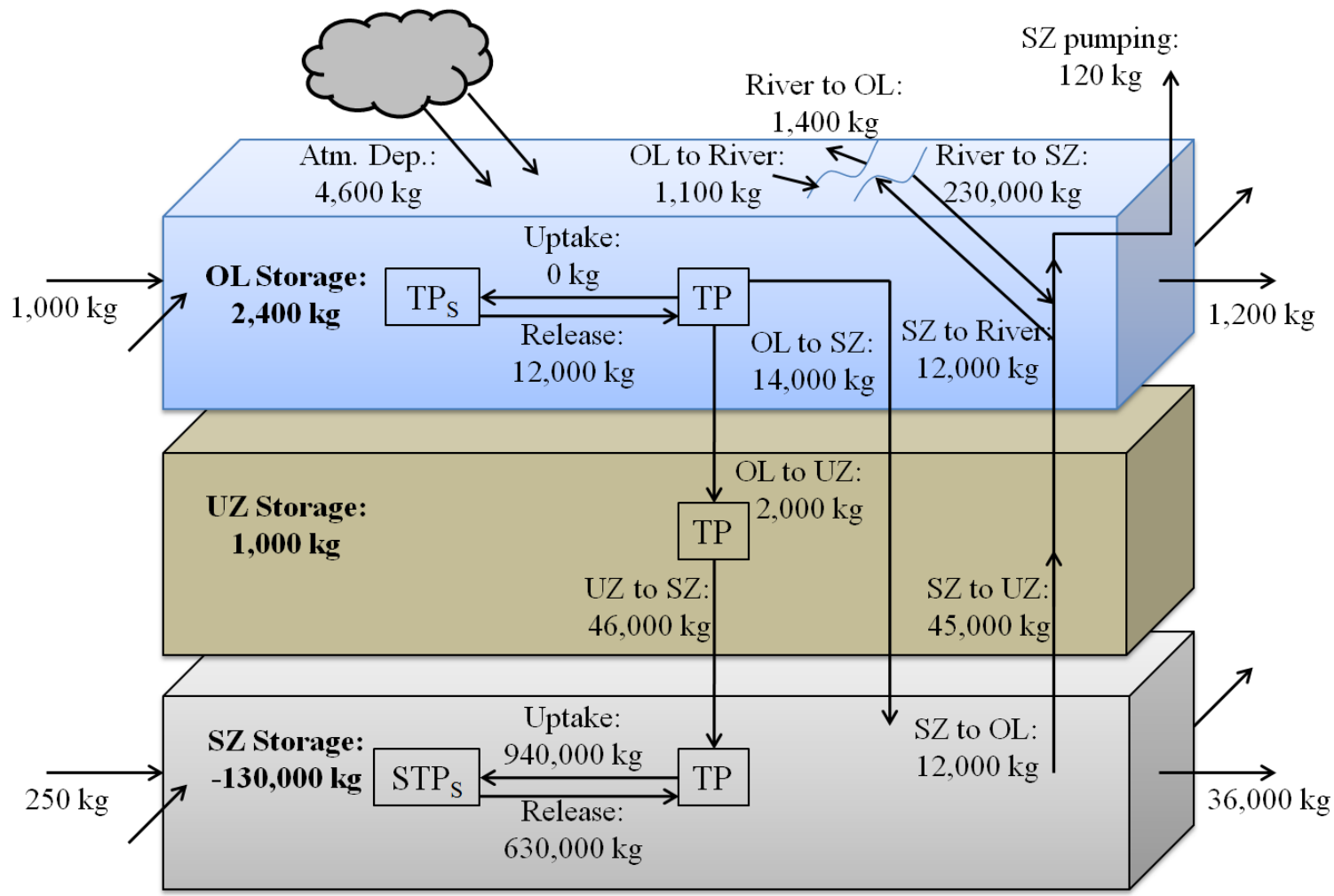

Figure 5.4: Schematic illustrating the movement of phosphorus between surface and subsurface flow and uptake to sorped forms. This mass balance was performed for a single modeled year, 2009, over the entire model domain.

\subsection{Conclusions}

A mass-balance based phosphorus fate and transport model was developed (M3ENPMB) using Advection-Dispersion equations, which describe physical movement of TP, and uptake/release equations, which describe lumped biophysical exchanges with the TP in the water column, suspended sediments, and sorbed material. The mass balance equations were developed into the ECOLab module, which works in coordination with the MIKE SHE/MIKE 11 water movement and AD water quality models.

A variety of rate constants which describe the uptake and release of phosphorus were used in the equations and were calibrated using exploratory statistical analysis with observed data. These rate constants are generalized for all TP uptake and release 
processes. TP uptake to the water column suspended sediments, $k_{u}$, and the release from these sediments, $k_{r}$, were calibrated to be 0.01 and 0.011 , respectively. TP uptake to the groundwater fixed material, $k_{u s}$, and the release from these sediments, $k_{r s}$, were calibrated to be 0.001 and 0.0025 , respectively.

The M3ENP-MB model has the potential to characterize phosphorus transport and biogeochemical uptake and release processes in the Everglades. However, further parameter optimization is required to better represent the spatial inhomogeneity of nutirent/ecosystem interactions. 


\section{CHAPTER 6}

\section{REMOTE SENSING AND STATISTICAL MODELING OF PHOSPHORUS IN ENP, FL, USA}

\subsection{Introduction}

Phosphorus increases the biomass of Everglades ecosystems; including sawgrass, periphyton, and cattail communities (Chiang et al., 2000). This increase in biomass is a measure of the productivity of the system, which can be monitored from satellite remote sensing. NDVI (Normalized Difference Vegetation Index) uses the relative spectral reflectance of vegetation in the red and near infrared (NIR) to monitor plant productivity, photosynthetic activity, and leaf area, as well as land use and land cover (LULC) (Griffith et al., 2002). Biosynthetic properties determined from spectral indices can be used to relate spectral reflectance to the total nutrient content in a system in a nutrient-limited system (Rivero et al., 2009; Pimstein et al., 2011). Alternatively, direct correlations between image band data and nutrient content can be established using statistical techniques such as partial least squares regression (PLSR), multiple linear regression (MLR) and stepwise multiple linear regression (SMLR), principle components regression, and committee trees (Ryu et al., 2011; Pimstein et al., 2011; Ramoelo et al., 2011; Vasques et al., 2008).

Remote sensing is useful as a cost-effective tool for extensive monitoring of areas from which data acquisition may be considered challenging, such as the extensive 
Florida Everglades. Landsat, MODIS (MODerate Resolution Imaging Spectroradiometer), and ASTER (Advanced Spaceborne Thermal Emission and Reflection Radiometer) are multispectral scanners which have previously been used in wetlands mapping with some success and accuracy, including vegetation and land cover classification as well as monitoring stress and changes in biomass (Rivero et al., 2009). In addition, Earth-observing satellites such as Landsat have been collecting images for 40 years, providing the data necessary for evaluating the long-term effects of phosphorus loading on the Everglades.

This chapter evaluates the spectral response of Everglades vegetation to increasing soluble phosphorus availability using Landsat imagery and observed phosphorus values. Zones of similar spectral correlation to phosphorus were discovered using $\mathrm{R}$ correlation coefficients and a variety of bands, band combinations, and spectral indices.

\subsection{Background}

\subsubsection{Vegetation Reflectance}

Incoming solar radiation will reflect off the leaf surface, enter the leaf and be either used for photosynthesis (absorped) or undergo refraction and scattering when it encounters air spaces and water in the cells. Light that is not absorped is either reflected back to through the leaf surface or transmitted through the bottom of the leaf (Kumar et al., 2002).

Vegetation reflects in the visible region of the electromagnetic spectrum due to strong adsorbtions by foliar pigments. Plant pigments such as chlorophyll and carotene use violet-blue and red wavelengths for photosynthesis but do not use wavelengths in the green range; creating the characteristic green coloration of leaves as it reflects back at that wavelength (Kumar et al., 2002). 
Plants have a high transmittance and reflectance in the near-infrared region (700$1300 \mathrm{~nm}$ ), regardless of pigmentation. Leaf structure, such as distribution of air spaces and the size, shape and arrangement of cells, contribute to how near-infrared radiation entering the leaf is reflected, whether through scattering or transmittance. Since vegetation absorbs strongly in the red (due to the presence of chlorophyll) and then reflects strongly in the neighboring near-infrared, this region is of interest to vegetation spectroscopy and may be useful for determining chlorophyll content (Kumar et al., 2002). The Normalized Difference Vegetation Index (NDVI) developed by Rouse and Deering (1973) takes into account this red/near-infrared phenomenon with the following equation:

$$
N D V I=\frac{\rho_{800-900}-\rho_{650-700}}{\rho_{800-900}+\rho_{650-700}}
$$

Guyot et al. (1992) explored the red to near-infrared region of the electromagnetic spectrum with a vegetation index called the Red Edge Position (REP) (Guyot et al.).

$$
R E P=700+40 * \frac{\rho_{\text {rededge }}-\rho_{700}}{\rho_{740}+\rho_{700}}
$$

In the mid-infrared region of the electromagnetic spectrum (1300-2500nm), vegetation can reveal water content of the leaves due to vibrational and rotational states of water molecules. In addition, some leaf biochemicals may absorb in the mid-infrared, including cellulose, starch, proteins and nutrients (Kumar et al., 2002).

\section{Vegetation reflectance and phosphorus}

Pimstein et al. (2011) showed that the $N_{1645-1715}$ waveband combination and the REP (Eq. 6.2) could accurately predict plant nutrient concentration (specifically developed for phosphorus and potassium) in a wide variety of agricultural fields. They identified mineral and nutrient stresses on vegetation using both narrow-band spectral indices and regression modeling of individual spectral bands (Pimstein et al., 2011). 
Because there are no currently known adsorbtion features associated with foliar P, Ramoelo et al. (2013) used all of the adsorption features associated with chlorophyll, protein, sugar, and starch to determine plant P levels. Starch, sugar, lignin, or protein are often associated with the adsorption of light in the Short-wave infrared range. Starch is biosynthesized via the use of adenosine diphosphate (ADP) and the enzyme glucose-1-phosphate adenylyltransferase with energy in the form of adenosine triphosphate (ATP), the entire biosynthesis process is dependent on the availability of phosphates (Smith, 2001). Burauel et al. (1990) determined that the amount of carbohydrates in a plant (sucrose, glucose, and fructose) was related to the phosphate availability. Therefore, starch (bonded glucose units) and other related compounds may indirectly indicate phosphorus content (Zhang et al., 2013).

Relationships between NVDI temporal and value metrics and water quality parameters of nearby streams have been found. Specifically, the NDVI-derived date of onset greenness is correlated to the amount of stream total phosphorus (Griffith et al., 2002).

\subsubsection{Everglades vegetation}

The Florida Everglades is a diverse freshwater wetlands dominated by ridges and sloughs, wet prairies, and streaked with tree islands covered with hammock communities. Cyprus swamps can also be found throughout the Everglades and the Everglades coast is covered in mangroves, forming a lush estuarine community. However, the majority of the Everglades landscape is dominated by sawgrass (Cladium jamaicense Crantz), covering 65-70\% of the marsh (Davis, 1990). The reason for the success of sawgrass in the Everglades is largely due to the sedges low nutrient requirements, an adaptation that proved beneficial in the historically oligotrophic surface water (5-15 $\mu g \mathrm{P} / L$ ) (Davis, 1990; Chiang et al., 2000). However, with the 
increase in nutrient inflow to the Everglades via agricultural and urban runoff, sawgrass communities are being replaced by cattail (Typha domingensis Pers.), which is able to utilize soluble reactive phosphorus for growth more aggressively.

Chiang et al. (2000) studied the effects of additional $\mathrm{N}$ and $\mathrm{P}$ to experimental plots in WCA 2B of the central Everglades. They showed that the addition of phosphorus to the study plots significantly increases LAI, ground area photosynthesis, and leaf tissue P. While a significant relationship between leaf area photosynthesis and foliar $\mathrm{P}$ concentrations was found for cattail $\left(r^{2}=0.22\right)$, no statistical relationship was found for sawgrass $\left(r^{2}=0.01\right)$ (Chiang et al., 2000).

\section{Everglades vegetation reflectance}

Anderson et al. (1997) showed that there is a strong correlation between sawgrass community biomass densities and spectral reflectance as obtained from a field spectroradiometer at around $770 \mathrm{~nm}$. This correlation was strongest during a period of low water level. They used a modified NDVI to represent vegetation abundance in sawgrass communities (shown in Equation 6.3) (Anderson et al., 1997).

$$
[N D V I]_{A M}=\frac{(770 n m-650 n m)}{(770 n m+650 n m)}
$$

The study also showed that a greater amount of sawgrass biomass is detectable (20-60\%) during the dry season when the water levels are at their lowest (below 0.5m) (Anderson et al., 1997).

\subsubsection{Landsat satellite imagery}

Landsat Thematic Mapper and Landsat Enhanced Thematic Mapper Plus (ETM+) have similar spectral bands. With the exception of the resolution of the thermal band and the panchromatic band in the ETM+, data from the two sensors are the same 
and can be used for analysis without noticeable issues. Bands 1, 2, and 3 are within the visible spectrum and represent blue, green, and red, respectively.

Table 6.1: Landsat TM and ETM+ bands which are useful for vegetation reflectance measurements.

\begin{tabular}{lcc}
\hline Band & Wavelength range (nm) & Resolution (meters) \\
\hline Band 1 - Blue & $450-520$ & 30 \\
Band 2 - Green & $520-600$ & 30 \\
Band 3 - Red & $630-690$ & 30 \\
Band 4 - Near Infrared & $770-900$ & 30 \\
Band 5 - Short-Wave Infrared & $1550-1750$ & 30 \\
Band 7 - Short-Wave Infrared & $2090-2350$ & 30 \\
\hline
\end{tabular}

\subsection{Methods}

This paper seeks to determine correlations between reflectance of vegetation and phosphorus content in ENP waters. A method involving data extraction and filtering followed by statistical analysis and evaluation was developed.

\subsubsection{Data Collection and Data Extraction}

In order to perform correlations between reflectance and phosphorus content of vegetation, these two datasets must be obtained.

\section{Reflectance Data}

Landsat spectral data for the Florida Everglades (Path 15, Row 42) is available to search, filter, select, request, and download in the EarthExplorer online database (USGS, 2014). The Landsat Surface Reflectance CDR (Climate Data Record) imagery is a high-level dataset which has undergone geometric and atmospheric correction routines to reduce the effects of water vapor, ozone, incoming radiation, land surface elevation, and other image-distorting phenomena (USGS, 2013; Masek et al., 
2006). Images from this dataset were selected based on the clarity of the scene, i.e. minimal cloud cover, from 1999 to present. No additional pre-processing was required for the selected Landsat Surface Reflectance scenes. Twenty five images in total were selected; Table 6.2 shows all of the downloaded Landsat Surface Reflectance CDR imagery with the date the image was taken and the Landsat satellite which was used. Landsat Surface Reflectance imagery was used to extract Band values at each phosTable 6.2: Landsat Surface Reflectance CDR imagery acquired from the USGS.

\begin{tabular}{|c|c|c|c|}
\hline Satellite & Date & Satellite & Date \\
\hline Landsat 5 TM & $1 / 25 / 1999$ & Landsat 7 ETM+ & $1 / 17 / 2005$ \\
\hline at $5 \mathrm{TM}$ & 2/26/1999 & Landsat 7 ETM+ & $2 / 18 / 2005$ \\
\hline Landsat 5 TM & 12/19/1999 & Landsat 7 ETM+ & $4 / 23 / 2005$ \\
\hline ETM+ & $2 / 5 / 2000$ & Landsat 7 ETM+ & $5 / 9 / 2005$ \\
\hline Landsat 7 ETM+ & $2 / 21 / 2000$ & Landsat 7 ETM+ & $12 / 3 / 2005$ \\
\hline Landsat 7 ETM+ & $11 / 6 / 2001$ & sat 7 ETM+ & $1 / 4 / 2006$ \\
\hline & $1 / 9 /$ & 7 ETM+ & $3 / 25 / 2006$ \\
\hline at 7 ETM+ & $6 / 2 / 2002$ & at 7 ETM+ & $5 / 28 / 2006$ \\
\hline t 7 ETM+ & $11 / 9 / 2002$ & 7 ETM+ & $2 / 8 / 2007$ \\
\hline t 7 ETM+ & $2 / 13 / 2003$ & at 7 ETM+ & $11 / 7 / 2007$ \\
\hline Landsat 7 ETM+ & $12 / 30 / 2003$ & lsat 7 ETM+ & $3 / 14 / 2008$ \\
\hline Landsat 7 ETM+ & $1 / 15 / 2004$ & Landsat 7 ETM+ & $5 / 1 / 2008$ \\
\hline Landsat 7 ETM+ & $6 / 23 / 2004$ & & \\
\hline
\end{tabular}

phorus sampling site. To ensure that the values are not just reflectance anomalies, a 3x3 Low-Pass Gaussian Convolution was first applied to each image. This process interpolates values with those around it in a $3 \times 3$ cell square. The cell values corresponding to the phosphorus sampling sites were then extracted. Indices such as NDVI and REP were calculated directly from the band values for each sampling location.

\section{Phosphorus Data}

Observed TP values (in $m g / L$ ) were obtained from the Florida Coastal Everglades Long-Term Ecological Research (FCE LTER) Core Data (Childers and Troxler, 2013a,b, 2008, 2013c,d,e). Phosphorus data from the sampling sites were obtained as a time 
series and data was selected on or near the Landsat image date of acquisition. P data was extracted using 4 different methods: i) 30-day average of the TP data prior to the Landsat image date, ii) 30-day maximum value of the TP data prior to the Landsat image date, iii) 90-day average of the TP data prior to the Landsat image date, and iv) 90-day maximum value of the TP data prior to the Landsat image date. Averages were used to remove the effect of minor fluctuations in the water column, and maximum values were used to emphasize water column $\mathrm{P}$ variability. The 90day averages and maximums were used to test for any long-term trends or delays in vegetation response to $\mathrm{P}$.

\section{Additional Data}

Other factors may play a role in the spectral signature as it relates to phosphorus content; including vegetation type, water level, soil moisture content, etc. This data is available using the M3ENP model results ((Long et al., Submitted 2014) or Chapter 3) for depth of overland water and soil moisture. Data was selected at the P sampling locations and values associated with the dates for the Landsat images were extracted.

\subsubsection{Spectral Indices}

The Landsat Band data was extracted and a variety of spectral indices were calculated and evaluated for potential correlation with phosphorus data. Spectral indices were selected from literature based on their usefulness in obtaining biophysical information such as Leaf Area Index (LAI), biomass coverage, or plant productivity. These indices and their equations are provided in Table 6.3. 
Table 6.3: List of spectral indices used to evaluate correlations between phosphorus content and vegetation reflectance. Index equations and their original developer are provided.

\begin{tabular}{|c|c|c|c|}
\hline Index & Full Name & Equation & Author \\
\hline \multirow[t]{2}{*}{ SIPI } & Structure Independent & $\frac{\text { NIR-Blue }}{\text { NIR-Red }}$ & (Penuelas et al., 1995) \\
\hline & Pigment Index & & \\
\hline \multirow[t]{2}{*}{ PSRI } & Plant Senescence & $\frac{\text { Red-Blue }}{\text { NIR }}$ & (Merzlyak et al., 1999) \\
\hline & Reflectance Index & & \\
\hline TM3/TM1 & TM3/TM1 & $\frac{\text { Red }}{\text { Blue }}$ & \\
\hline TM5/TM4 & TM5/TM4 & $\frac{S W I R}{N I R}$ & \\
\hline TM4/TM1 & TM4/TM1 & $\frac{N I R}{B l u e}$ & (Datt, 1998) \\
\hline \multirow[t]{2}{*}{ ARI } & Anthocyanin & $\frac{1}{\text { Green }}-\frac{1}{N I R}$ & (Gitelson et al., 2001) \\
\hline & Reflectance Index & & \\
\hline TM2/TM3 & Greeness Index & $\frac{\text { Green }}{\text { Red }}$ & (Smith et al., 1995) \\
\hline \multirow[t]{2}{*}{ EVIm } & Enhanced Vegetation & $2.5 \frac{N I R-R e d}{\text { NIR }+6 \text { Red }-7.5 \text { Blue }+1}$ & (Huete et al., 1994) \\
\hline & Index (MODIS) & & \\
\hline \multirow[t]{2}{*}{ TVI } & Transformed & $\sqrt{\frac{N I R-R e d}{N I R+R e d}}+0.5$ & (Deering et al., 1975) \\
\hline & Vegetation Index & & \\
\hline \multirow[t]{2}{*}{ OSAVI } & Optimized Soil & $1.16 \frac{N I R-R e d}{N I R+R e d+0.16}$ & (Rondeaux et al., 1996) \\
\hline & Adjusted Veg Index & & \\
\hline \multirow[t]{2}{*}{ EVI2 } & Enhanced Vegetation & $2.5 \frac{N I R-R e d}{N I R+6 * \operatorname{Red}+1}$ & (Huete et al., 2002) \\
\hline & Index (2 Band) & & \\
\hline \multirow[t]{2}{*}{ MTVI2 } & Modified Triangular & $\frac{1.5[1.2(\text { NIR-Green })-2.5(\text { Red }- \text { Green })]}{\sqrt{2 N I R+1^{2}-(6 N I R-5 \sqrt{R e d})-0.5}}$ & (Haboudane et al., 2004) \\
\hline & Vegetation Index & & \\
\hline \multirow[t]{3}{*}{ MCARI a } & Modified Chlorophyll & $((N I R-R e d)-0.2 *(N I R-$ Green $) *$ & (Daughtry et al., 2000) \\
\hline & Absorption Ratio & $(N I R / R e d))$ & \\
\hline & Index (Chl a) & & \\
\hline RVI & Ratio Vegetation Index & $\frac{R e d}{N I R}$ & (Richardson and Wiegand, 1977) \\
\hline \multirow[t]{2}{*}{ NRVI } & Normalized Ratio & $\frac{R V I-1}{R V I+1}$ & (Baret and Guyot, 1991) \\
\hline & Vegetation Index & & \\
\hline
\end{tabular}


Table 6.3 - Continued

\begin{tabular}{lccc}
\hline \hline Index & Full Name & Equation & Author \\
\hline CTVI & Corrected Transformed & $\frac{N D V I+0.5}{|N D V I+0.5|} * \sqrt{|N D V I+0.5|}$ & (Perry and Lautenschlager, 1984) \\
& Vegetation Index & & \\
\hline
\end{tabular}

\subsubsection{Statistical Methods}

It is notoriously difficult to detect wetland vegetation type and other vegetation parameters due to several factors that are unique to wetlands habitats; including submerged and emergent vegetation in standing water (Dahl, 2006), high spatial complexity and temporal variability (Klemas, 2011), and the difficulty of performing ground-truthing in remote wetlands regions (Zomer et al., 2009).

The $\mathrm{R}$ correlation coefficient is related to the covariance of two variables. In order to determine if there is a correlation between two variables, the $\mathrm{R}$ correlation coefficient was determined for a matrix of values including several different observed values (TP 30-day Avg, TP 30-day Max, etc.), the observed Band Values (for Bands $1-5$, and Band 7), and a range of Band-derived indices (including NDVI, EVI, etc.). The $\mathrm{R}$ correlation coefficient was filtered using the $\mathrm{P}$ value, which is the probability of getting a correlation as large as the observed value by random chance, when the true correlation is zero. If the $\mathrm{P}$-value is small $(<0.05)$, then the $\mathrm{R}$ correlation is significant. Any R correlations which have a $\mathrm{P}$-value above 0.05 were removed and the remaining correlations are considered significant.

Initial $\mathrm{R}$ correlation coefficient screening on the entire dataset showed almost no significant correlations between observed TP values and Landsat Band data or indices. However, many of the indices and bands showed correlation to the depth of the overland water. Overland water depth is cyclical in the Everglades and follows a 
wet season to dry season pattern which may have been correlating to the reflectance.

To remove this effect, the dataset was filtered for water levels less than $15 \mathrm{~cm}$. The remaining 43 data points are spread throughout Shark and Taylor Sloughs and are mostly within the dry season, with some points into the early wet season. The P-value filtered R correlation coefficients are shown in Table 6.4.

Table 6.4: $\mathrm{R}$ correlation coefficients, filtered for significance (P-value $<0.05)$, are shown for all the Landsat bands and a variety of indices. Days where water levels exceeded $15 \mathrm{~cm}$ above the ground surface were removed from the dataset prior to analysis.

\begin{tabular}{|c|c|c|c|c|c|}
\hline & $\begin{array}{l}\text { TP } 30- \\
\text { day Avg }\end{array}$ & $\begin{array}{l}\text { TP } 30- \\
\text { day Max }\end{array}$ & $\begin{array}{l}\text { TP 90- } \\
\text { day Avg }\end{array}$ & $\begin{array}{l}\text { TP 90- } \\
\text { day Max }\end{array}$ & $\begin{array}{l}\text { Water } \\
\text { Depth }\end{array}$ \\
\hline B1 (Blue) & Not Sig & Not Sig & Not Sig & Not Sig & Not Sig \\
\hline B2 (Green) & Not Sig & Not Sig & Not Sig & Not Sig & Not Sig \\
\hline B3 (Red) & Not Sig & Not Sig & Not Sig & Not Sig & Not Sig \\
\hline B4 (NIR) & Not Sig & Not Sig & Not Sig & Not Sig & Not Sig \\
\hline B5 & Not Sig & Not Sig & Not Sig & Not Sig & -0.3022 \\
\hline B7 & Not Sig & Not Sig & Not Sig & Not Sig & -0.3070 \\
\hline NDVI & Not Sig & Not Sig & Not Sig & Not Sig & Not Sig \\
\hline SIPI & -0.3354 & -0.3147 & Not Sig & -0.3433 & Not Sig \\
\hline PSRI & -0.3784 & -0.3570 & Not Sig & -0.3664 & Not Sig \\
\hline TM3/TM1 & -0.4014 & -0.3787 & Not Sig & -0.3592 & Not Sig \\
\hline TM5/TM4 & Not Sig & Not Sig & -0.3154 & Not Sig & Not Sig \\
\hline TM4/TM1 & Not Sig & Not Sig & Not Sig & Not Sig & Not Sig \\
\hline ARI & Not Sig & Not Sig & Not Sig & Not Sig & Not Sig \\
\hline TM2/TM3 & 0.3988 & 0.4268 & 0.4010 & 0.4185 & Not Sig \\
\hline EVIm & 0.4483 & 0.4279 & 0.3289 & 0.4118 & Not Sig \\
\hline TVI & Not Sig & Not Sig & Not Sig & Not Sig & Not Sig \\
\hline OSAVI & Not Sig & Not Sig & Not Sig & Not Sig & Not Sig \\
\hline EVI2 & Not Sig & Not Sig & Not Sig & Not Sig & Not Sig \\
\hline MTVI2 & Not Sig & Not Sig & Not Sig & Not Sig & Not Sig \\
\hline MCARI a & -0.3022 & -0.3486 & -0.3231 & -0.3511 & Not Sig \\
\hline RVI & Not Sig & Not Sig & Not Sig & Not Sig & Not Sig \\
\hline NRVI & Not Sig & Not Sig & Not Sig & Not Sig & Not Sig \\
\hline CTVI & Not Sig & Not Sig & Not Sig & Not Sig & Not Sig \\
\hline
\end{tabular}

While no Bands showed a direct correlation to TP, several indices showed significance to TP values, many of which include Bands 1, 3 and 4 in their calculation. 
EVIm showed the greatest significance and, of those which showed significance, EVIm had the greatest linear relationship to the observed data.

\section{Enhanced Vegetation Index}

The Enhanced Vegetation Index was developed by Huete et al. (1997) to optimize the vegetation signal with improved sensitivity in high biomass regions. The EVI decouples the influence of canopy background signal (or soil signal return) and atmospheric resistance (Huete et al., 2002). The EVIm was then calibrated using MODIS and coefficients were established as shown in Equation 6.4 (Huete et al., 1997, 2002).

$$
E V I m=2.5 * \frac{N I R-R e d}{1+N I R+6 \operatorname{Red}-7.5 \text { Blue }}
$$

The EVI has shown to provide better vegetation classifications over NDVI due to an extended linear response over a wider range of vegetation conditions (Huete et al., 1997). This vegetation index is useful for providing radiometric and biophysical information for land surface characterization (Huete et al., 1997, 2002).

A modification to the EVIm was performed in order to take into account the moisture signal shown the spectral reflectance of vegetation. In Table 6.4, the Shortwave infrared bands showed statistical correlation to the water depth. This may be due to the wet-dry signal of vegetation; i.e. if the region is dry the plant health or vigor will decline. A modification to include this band was added to the EVIm equation. A weighting coefficient for Band 7, herein termed the wetlands coefficient $\gamma$, was calibrated using the dataset to $\gamma=-0.45$. The MODEVIm is shown in Equation 6.5. This modification increased the $\mathrm{R}$ correlation coefficient for all data points by $11 \%$ for the 30-day averaged TP.

$$
M O D E V I m=2.5 * \frac{N I R-\text { Red }}{1+N I R+6 \text { Red }-7.5 \text { Blue }-0.45 S W I R}
$$


To further explore the correlations between specific indices and phosphorus, the data points were separated into zones of similar reflectance. This was done using exploratory analysis of the dataset and the $\mathrm{R}$ correlation coefficients. Stronger relationships which explain a regional variation were placed into separate zones.

\subsection{Results and Discussion}

\subsubsection{Regional Analysis}

Regions of reflectance correlation were discovered during statistical exploration of the data with the $\mathrm{R}$ correlation coefficient. While all Shark Slough data points are at sites described as "Sawgrass dominated marsh interspersed with Eleocharis/Panicum slough" and all Taylor Slough data points are at sites described as "Sparse sawgrass marsh", separating the analysis into Shark Slough and Taylor Slough did not produce the best $\mathrm{R}$ correlation coefficients for each. Instead, three distinct reflectance/phosphorus correlation zones were identified: i) Shark Slough, ii) the Southern Glades, and iii) Reclaimed Agricultural. These zones are shown in Figure 6.1 over the M3ENP model domain.

\section{Shark Slough Zone}

Isolating the Shark Slough data points increased the $\mathrm{R}$ correlation coefficients with many of the spectral indices, all of which included some combination of the Red and NIR bands in their calculation. The $\mathrm{R}$ correlation between the EVIm increased by about $81 \%$. A scatterplot of the 30-day average TP values versus the EVIm values for this zone shows a linear correlation of 0.66 in Figure 6.2.

The EVIm index has been used to derive vegetation biophysical parameters such as leaf area index, biomass, and percentage green cover (Huete et al., 1997). An increasing EVIm value indicates an increase in plant productivity. Chiang et al. (2000) 


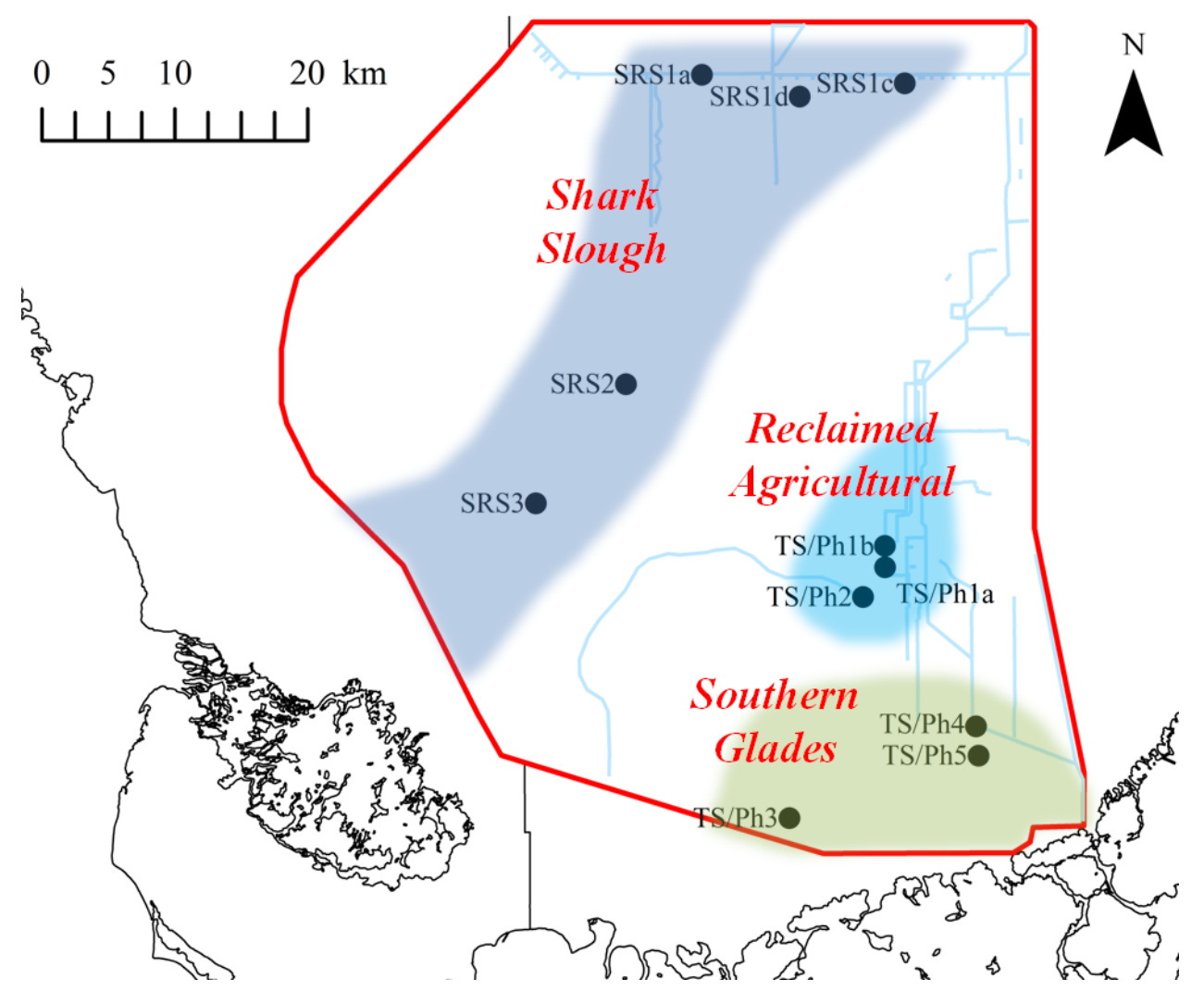

Figure 6.1: Reflectance/phosphorus correlations zones on the map of the M3ENP model domain located in southern Florida. Zones include Shark Slough, the Southern Glades, and Reclaimed Agricultural.

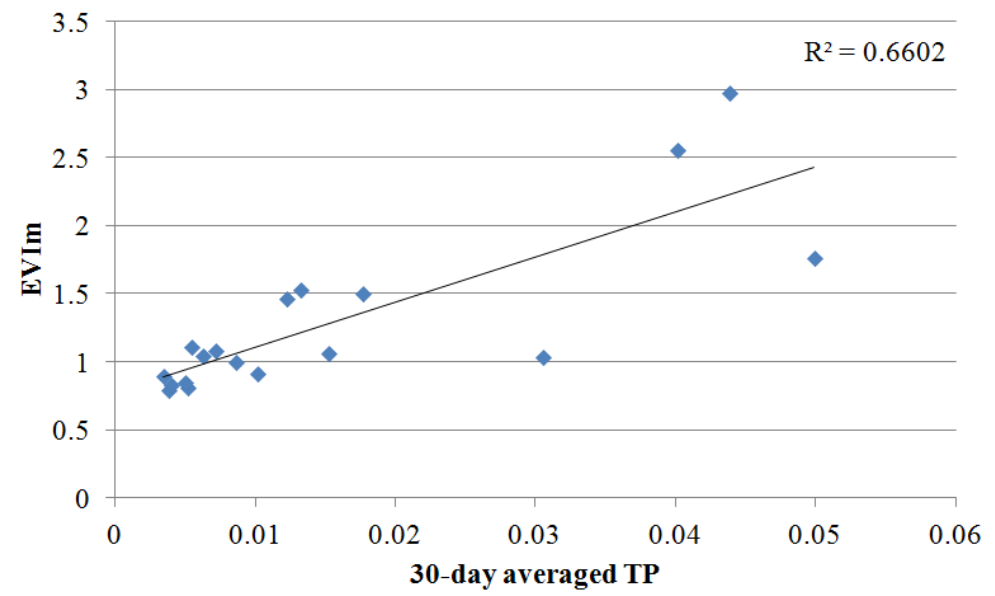

Figure 6.2: Scatterplot of the 30-day average TP $(\mathrm{mg} / L)$ versus the EVIm values for the Shark Slough Zone. 
has shown that increasing phosphorus may increase leaf area index and plant photosynthesis, an metric for plant productivity. The correlation of EVIm with phosphorus data indicates that increasing phosphorus levels increases vegetation productivity in the Shark Slough Zone.

\section{Reclaimed Agricultural Zone}

Areas near the detention areas and reclaimed agricultural areas of south MiamiDade county have experienced generations of anthropogenically altered hydrology and water quality. Increased TP loading can cause changes in the vegetation species and biomass that can alter the response of the reflectance, creating a unique signature for the region.

The Reclaimed Agricultural Zone showed almost no correlation between phosphorus and reflectance with the exception of the MODEVIm. This modified EVIm takes into account the relationships between the water level of the area and reflectance in Band 7 (shown in Equation 6.5). Figure 6.3 shows the scatterplot for the 90-day maximum TP versus the MODEVIm values.

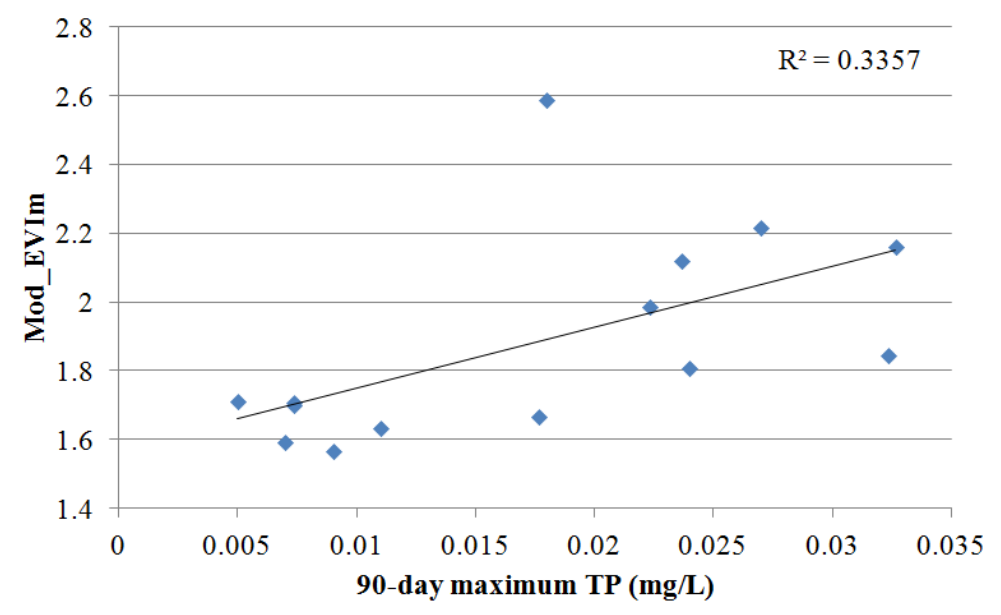

Figure 6.3: Scatterplot of the 90-day maximum TP $(\mathrm{mg} / \mathrm{L})$ versus the Modified EVIm values for the Reclaimed Agricultural Zone. 
A correlation with the 90-day maximum TP values could suggest that the vegetation reflectance response in this region has a longer lag-time and is affected mostly by the larger maximum inputs. This is explained by the regions long history of phosphorus loading due to urban and agricultural runoff. Vegetation in this region may be adjusted to the presence of elevated phosphorus levels.

\section{Southern Glades Zone}

The Southern Glades Zone encompasses much of the remaining pristine Taylor Slough wetlands. This dataset produced statistical correlations between the 30-day average or maximum TP values and the three visible bands, Blue, Green and Red. The greatest statistical correlation was between the 30-day maximum TP and the Green Band and the scatterplot for these is shown in Figure 6.4.

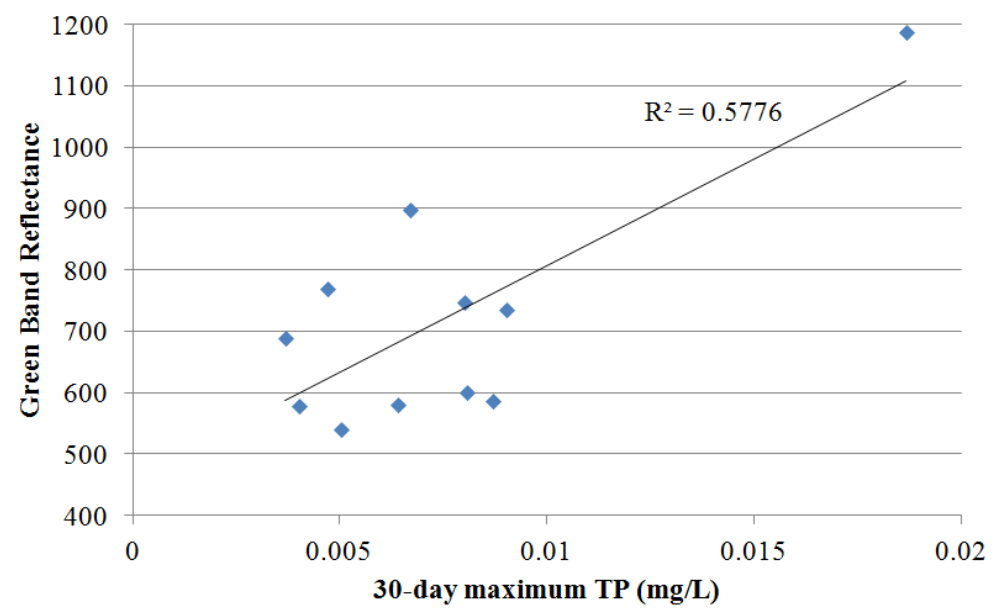

Figure 6.4: Scatterplot of the 30-day maximum TP $(m g / L)$ versus the Green Band values for the Southern Glades Zone.

Chlorophyll in plants typically absorb visible light in the blue and red spectrum ( $\mathrm{R}$ correlations with $\mathrm{TP}$ of 0.692 and 0.694 respectively) and reflect in the green spectrum (R correlation with TP of 0.760). When plants die and the leaf turns brown, chlorophylls and carotenes in the leaf have stopped absorbing light and are reflecting 
light in the 400 to $750 \mathrm{~nm}$ range (Kumar et al., 2002). That the TP concentration is positively correlated to all three of these bands indicates that increasing phosphorus in the Southern Glades region may contribute to leaf senescence and death.

Chiang et al. (2000) showed that periphyton declines quickly when phosphorus levels are high. The death and decline of periphyton with added phosphorus may be the cause of the spectral correlation with all three bands.

\subsection{Summary and Conclusions}

Phosphorus data from water quality stations throughout Everglades National Park were gathered for the 1999 to 2010 period. At these stations spectral data was extracted from selected Landsat data, which had already been ortho-rectified and atmospherically corrected. The dataset was filtered to remove data points that were taken during periods of inundation (water levels greater than $15 \mathrm{~cm}$ ), which may cause unrealistic reflectance values in the Landsat data.

The R correlation coefficients between these two datasets were examined. Several zones of similar spectral response to phosphorus content were discovered. In the Shark Slough zone, phosphorus was highly correlated to EVIm, the Enhanced Vegetation Index that includes the NIR, Red and Blue bands. In the Reclaimed Agricultural Zone, phosphorus was highly correlated to a modified EVIm, which adds the SWIR Band 7 to take into account the effect of moisture on the reflectance signature. In the Southern Glades Zone, phosphorus was highly correlated to each of the Blue, Green and Red bands.

These correlations should be explored further to understand the precise cause of the spectral response. In situ experiments and ground truthing would greatly increase the accuracy of this data. In addition, phosphorus water column data does not accurately represent the total loading of phosphorus available to vegetation for 
use. Local spikes in phosphorus data could be a result of nearby decaying material or evaporation in hydrological disconnected ponds. If these spikes occur during a dry season day when the vegetation is in decline, the correlations can be off. A more accurate assessment of the amount of phosphorus affecting a zone would be the load (or mass), which takes is calculated using the water flux and the phosphorus concentration. This data can be acquired from numerical modeling results or data collection at the site. 


\section{CHAPTER 7}

\section{CONCLUSIONS AND RECOMMENDATIONS}

\subsection{Key Findings and Conclusions}

This body of research has used numerical modeling of the physical and process-based equations that describe water movement and chemical transport to understand anthropogenic changes to the Florida Everglades. Chapter 2 provided the technical description of the development of Mike Marsh Model of Everglades National Park (M3ENP). This model provided the hydrodynamic results, upon which further simulations and modules could be developed. In Chapter 3, proposed bridge construction and water level increases were examined using the M3ENP model and alterations to key structures along the L-29 Canal and Tamiami Trail. The Baseline scenario was calibrated using observed water level and discharges at locations throughout the domain (calibration results can be found in Chapter 2 and Appendix A). Results from the addition of bridges showed that the addition of the proposed 2.6-mile bridge will increase discharges through L-29 canal culverts by 10.4\%, that's an additional 66,354.8 kAF entering ENP annually. Analysis of the changes to overland flow showed that over $160 \mathrm{sq}$. $\mathrm{km}$ would have an additional $30 \mathrm{~cm}$ of water for 7 extra days a year with the construction of the 2.6-mile bridge. This indicates that restoration of hydroperiods, in areas which have been low for decades, may be partly achieved with the construction of the 2.6-mile bridge. Raising water levels in the L-29 canal will also 
create a greater hydraulic gradient and will have a greater impact on ENP surface water levels than with bridge construction alone.

Chapter 4 of this research applied the advection-dispersion equation with sorption kinetics to the hydrodynamic results obtained in Chapter 3 to determine phosphorus fate and transport in ENP. The model, called M3ENP-AD, was calibrated using observed data from water quality stations throughout ENP (Appendix B). The addition of bridges to Tamiami Trail caused a overall decrease in the total phosphorus concentration of about 4 to $4.6 \%$ yet many location within the domain showed a general increase in TP load $(\mathrm{kg})$. While TP concentrations decreased due to the dilution effect from the additional water, the mass of TP entering the domain increased. Parts of Northeast Shark Slough (NESS), a key component in recent ENP restoration efforts, experienced an increase in total TP load of up to $30 \%$ over the simulation period with the inclusion of the 1-mile bridge and L-29 canal stage increases.

Chapter 5 of this research further develops the Advection-Dispersion model by programming a mass-balance based biogeochemical transport module using ECO Lab with MIKE SHE/MIKE 11. The resulting model, called the M3ENP-MB model, used the $\mathrm{AD}$ equation for physical transport and incorporated uptake and release parameters for channel flow, overland flow, and saturated zone flow. The model under-performed in comparison to the M3ENP-AD model calibrated in Chapter 4, indicating that further calibration may be needed.

Chapter 6 of this research explores the use of satellite remote sensing to characterize how vegetation responds to phosphorus changes in the water column. Using Landsat bands and a variety of calculated spectral indices, $\mathrm{R}$ correlation coefficients were used to determine statistical relationships between phosphorus in the water column and spectral reflectance. Three unique regions of spectral response were identified using this method. The Shark Slough, Reclaimed Agricultural, and South Glades 
Zones all correlated differently to phosphorus levels. These correlations indicated unique spectral properties of the vegetation in each zone.

\subsection{Recommendations for Future Work}

Chapters 3 and 4 of this dissertation provide critical scientific insight into key questions for ENP decision makers. How will proposed bridge additions to Tamiami Trail impact the water levels, flows, and phosphorus transport to ENP? It is recommended that future actions regarding structural or hydraulic changes to ENP examine simulations such as these, before actions are taken that may adversely impact the ecosystem.

The 1-mile bridge along Tamiami Trail has been completed, the roadbed has been removed, and water level and phosphorus data has been collected since the completion of this infrastructure. It is recommended that the current model be validated using this more recent data when it becomes available. Model refinement and further calibration can proceed from there. All future infrastructure simulations will be guided by the lessons learned from this initial effort.

The M3ENP-MB model explored in Chapter 5 must undergo further calibration to better parameterize the phosphorus uptake and release components of the canals, overland water, and groundwater. After calibration, it is recommended that the future conditions scenarios developed in Chapters 3 and 4 be implemented into the M3ENP-MB model. 


\section{BIBLIOGRAPHY}

Abtew, W. Evapotranspiration measurements and modeling for three wetland systems in south florida. Journal of American Water Resources Association, 32(3):465-473, 1996.

Ahn, H. and T. James. Variability, uncertainty, and sensitivity of phosphorus deposition load estimates in South Florida. Water, Air, and Soil Pollution, 126:37-51, 2001.

Anderson, J., D. Morgan, and G. Desmond. Mapping sawgrass densities in the florida everglades using spectral data and digital multispectral video. 1997.

Armentano, T., J. Sah, M. Ross, D. Jones, H. Cooley, and C. Smith. Rapid responses of vegetation to hydrological changes in taylor slough, everglades national park, florida, usa. Hydrobiologia, 569(1):293-309, 2006.

Baret, F. and G. Guyot. Potentials and limits of vegetation indices for LAI and APAR assessment. Remote Sensing of Environment, 35(23):161 - 173, 1991. ISSN 0034-4257. doi: http://dx.doi.org/10.1016/0034-4257(91)90009-U.

Boler, R. and D. Sikkema. Tamiami Trail modifications: Next steps project summary of findings and draft environmental impact statement, project evaluation report, SFNRC Technical Series 2010:1. Technical report, South Florida Natural Resources Center, Everglades National Park, Homestead, FL, 2010.

Bolster, C. and J. Saiers. Development and evaluation of a mathematical model for surface-water flow within the Shark River Slough of the Florida Everglades. Journal of Hydrology, 259:221-235, 2002.

Brix, H., B. Lorenzen, I. Mendelssohn, K. McKee, and S. Miao. Can differences in phosphorus uptake kinetics explain the distribution of cattail and sawgrass in the Florida Everglades? BMC Plant Biology, 10(23), 2010.

Burauel, P., J. Wieneke, and F. Führ. Carbohydrate status in roots of two soybean cultivars: A possible parameter to explain different efficiencies concerning phosphate uptake. Plant and Soil, 123:169-174, 1990. 
Buzzelli, C., D. Childers, Q. Dong, and R. Jones. Simulation of periphyton phosphorus dynamics in everglades national park. Ecological Modelling, 134:103-115, 2000.

Carsel, R. and R. Parrish. Developing joint probability distributions of soil water retention characteristics. Water Resources Research, 24(5):755-769, 1988.

Chiang, C., C. Craft, D. Rogers, and C. Richardson. Effects of 4 years of nitrogen and phosphorus additions on everglades plant communities. Aquatic Botany, 68(1): 61-78, 2000.

Childers, D. and T. Troxler. Water Quality Data (Extensive) from the Taylor Slough, just outside Everglades National Park (FCE), from August 1998 to December 2006. Technical report, Long Term Ecological Research Network, 2008. Data sets were provided by the Florida Coastal Everglades Long-Term Ecological Research (LTER) Program. This material is based upon work supported by the National Science Foundation under Grant No. DEB-1237517, DBI-0620409, and Grant No. DEB9910514.

Childers, D. and T. Troxler. Water Quality Data (Extensive) from the Shark River Slough, Everglades National Park (FCE), from October 2000 to Present. Technical report, Long Term Ecological Research Network, 2013a. Data sets were provided by the Florida Coastal Everglades Long-Term Ecological Research (LTER) Program. This material is based upon work supported by the National Science Foundation under Grant No. DEB-1237517, DBI-0620409, and Grant No. DEB-9910514.

Childers, D. and T. Troxler. Water Quality Data (Grab Samples) from the Shark River Slough, Everglades National Park (FCE), from May 2001 to Present. Technical report, Long Term Ecological Research Network, 2013b. Data sets were provided by the Florida Coastal Everglades Long-Term Ecological Research (LTER) Program. This material is based upon work supported by the National Science Foundation under Grant No. DEB-1237517, DBI-0620409, and Grant No. DEB-9910514.

Childers, D. and T. Troxler. Water Quality Data (Grab Samples) from the Taylor Slough, Everglades National Park (FCE), for August 1998 to November 2006. Technical report, Long Term Ecological Research Network, 2013c. Data sets were provided by the Florida Coastal Everglades Long-Term Ecological Research (LTER) Program. This material is based upon work supported by the National Science Foundation under Grant No. DEB-1237517, DBI-0620409, and Grant No. DEB9910514.

Childers, D. and T. Troxler. Water Quality Data (Extensive) from the Taylor Slough, Everglades National Park (FCE), South Florida from July 1999 to Present. Technical report, Long Term Ecological Research Network, 2013d. Data sets were provided by the Florida Coastal Everglades Long-Term Ecological Research (LTER) 
Program. This material is based upon work supported by the National Science Foundation under Grant No. DEB-1237517, DBI-0620409, and Grant No. DEB9910514.

Childers, D. and T. Troxler. Water Quality Data (Grab Samples) from the Taylor Slough, Everglades National Park (FCE), South Florida from July 1999 to Present. Technical report, Long Term Ecological Research Network, 2013e. Data sets were provided by the Florida Coastal Everglades Long-Term Ecological Research (LTER) Program. This material is based upon work supported by the National Science Foundation under Grant No. DEB-1237517, DBI-0620409, and Grant No. DEB9910514.

Childers, D., R. Jones, J. Trexler, C. Buzzelli, S. Dailey, A. Edwards, and et al. Quantifying the effects of low level phosphorus enrichment on unenriched Everglades wetlands with in situ flumes and phosphorus dosing. In: Porter, K., Porter, J. (Eds.), The Everglades Hydroscape. St. Lucie Press, 1999.

Chimney, M. and G. Goforth. History and description of the everglades nutrient removal project, a subtropical constructed wetland in south florida (usa). Ecological Engineering, 27:268-278, 2006.

Chow, V. Open-Channel Hydraulics. McGraw-Hill, New York, NY, 1959.

Christiaens, K. and J. Feyen. Use of sensitivity and uncertainty measures in distributed hydrological modeling with an application to the mike she model. Water Resources Research, 38(9):1169, 2002. doi: 10.1029/2001WR000478.

Chui, T., S. Low, and S.-Y. Liong. An ecohydrological model for studying groundwater-vegetation interactions in wetlands. Journal of Hydrology, 409:291$304,2011$.

Cook, A. Development of an integrated surface and subsurface model of everglades national park. ProQuest ETD Collection for FIU, art. AAI1514727, 2012.

Dahl, T. E. Remote sensing as a tool for monitoring wetland habitat change. Technical report, U.S. Fish and Wildlife Servie, 2006.

Datt, B. Remote sensing of chlorophyll a, chlorophyll b, chlorophyll $a+b$, and total carotenoid content in eucalyptus leaves. Remote Sensing of Environment, 66(2): 111 - 121, 1998. ISSN 0034-4257. doi: http://dx.doi.org/10.1016/S0034-4257(98) 00046-7.

Daughtry, C. S. T., C. L. Walthall, M. S. Kim, E. B. de Colstoun, and I. J. E. McMurtrey. Estimating corn leaf chlorophyll concentration from leaf and canopy re- 
flectance. Remote Sensing of Environment, 74(2):229 - 239, 2000. ISSN 0034-4257. doi: http://dx.doi.org/10.1016/S0034-4257(00)00113-9.

Davis, A. Deterministic modeling of dispersion in heterogeneous permeable media. Groundwater, 24(5):609-615, 1986. doi: 10.1111/j.1745-6584.1986.tb03709.x.

Davis, S. M. Growth, decomposition, and nutrient retention of sawgrass and cattail in the everglades. technical publication 90-30. Technical report, Environmental Sciences Division, Research and Evaluation Department, South Florida Water Management District, 1990.

Deering, D., J. Rouse, R. Haas, and J. Schell. Measuring "forage production" of grazing units from Landsat MSS data. In Proceedings of the 10th International Symposium on Remote Sensing of Environment, volume II, pages 1169-1178, 1975.

DHI. MIKE SHE User Manual Vol 2: Reference Guide, 2007.

DHI. MIKE 11, A Modelling System for Rivers and Channels, Reference Manual, 2012.

Doummar, J., M. Sauter, and T. Geyer. Simulation of flow processes in a large scale karst system with and integrated catchment model (Mike She) - identification of relevant parameters influencing spring discharge. Journal of Hydrology, 426-427: 112-123, 2012. doi: 10.1016/j.jhydrol.2012.01.021.

Fish, J. and M. Stewart. Hydrogeology of the surficial aquifer system, dade county, florida: U.s. geological survey water-resources investigations report 90-4108. Technical report, U.S. Geological Survey, 1991.

Gaiser, E., L. Scinto, J. Richards, K. Jayachandran, D. Childers, J. Trexler, and R. Jones. Phosphorus in periphyton mats provides the best metric for detecting low-level p enrichment in an oligotrophic wetland. Water Research, 38:507-516, 2004.

Gaiser, E., J. Trexler, J. Richards, D. Childers, D. Lee, A. Edwards, L. Scinto, K. Jayachandran, G. Noe, and R. Jones. Cascading ecological effects of low-level phosphorus enrichment in the florida everglades. Journal of Environmental Quality, 34: 717-723, 2005.

Gitelson, A. A., M. N. Merzlyak, and O. B. Chivkunova. Optical properties and nondestructive estimation of anthocyanin content in plant leaves. Photochemistry and Photobiology, 74(1):38-45, 2001. ISSN 1751-1097. doi: 10.1562/0031-8655(2001) 0740038OPANEO2.0.CO2. 
Griffith, J., E. Martinko, J. Whistler, and K. Price. Interraltionships among landscapes, ndvi, and stream water quality in the u.s. central plains. Ecological Applications, 12(6):1702-1718, 2002.

Grimshaw, H. J. and D. A. Dolske. Rainfall concentrations and wet atmospheric deposition of phosphorus and other constituents in florida, u.s.a. Water, Air, and Soil Pollution, 137:117-140, 2002.

Gunderson, L. and S. Light. Adaptive management and adaptive governance in the everglades ecosystem. Policy Science, 39:323-334, 2006. doi: 10.1007/ s11077-006-9027-2.

Guyot, G., F. Baret, and S. Jacquemoud. Imaging spectroscopy for vegetation studies. In: Imaging Spectroscopy: Fundamentals and Prospective Applications.

Haboudane, D., J. R. Miller, E. Pattey, P. J. Zarco-Tejada, and I. B. Strachan. Hyperspectral vegetation indices and novel algorithms for predicting green $\{\mathrm{LAI}\}$ of crop canopies: Modeling and validation in the context of precision agriculture. Remote Sensing of Environment, 90(3):337 - 352, 2004. ISSN 0034-4257. doi: http://dx.doi.org/10.1016/j.rse.2003.12.013.

Harvey, J., J. Saiers, and J. Newlin. Solute transport and storage mechanisms in wetlands of the everglades, south florida. Water Resources Research, 41, 2005.

Harvey, J., J. Newlin, and S. Krupa. Modeling decadal timescale interactions between surface water and groundwater in the central everglades, florida, usa. Journal of Hydrology, 320:400-420, 2006.

Havnø, K., M. Madsen, and J. Dørge. Computer Models of Watershed Hydrology, chapter MIKE 11, pages 733-782. Water Resources Publication, Colorado, USA, 1995.

Haygarth, P. M. and J. S. C. Transfer of phosphorus from agricultural soils. Advances in Agronomy, 66:195-249, 1999.

Ho, D., V. Engel, E. Variano, P. Schmieder, and M. Condon. Tracer studies of sheet flow in the florida everglades. Geophysical Research Letters, 36, 2009.

Huang, Y. H., J. E. Saiers, J. W. Harvey, G. B. Noe, and S. Mylon. Advection, dispersion, and filtration of fine particles within emergent vegetation of the florida everglades. Water Resources Research, 44, 2008. doi: 10.1029/2007WR006290.

Huete, A., C. Justice, and H. Liu. Development of vegetation and soil indices for MODIS-EOS. Remote Sensing of the Environment, 49:224 - 234, 1994. 
Huete, A., H. Liu, K. Batchily, and W. van Leeuwen. A comparison of vegetation indices over a global set of TM images for EOS-MODIS. Remote Sensing of the Environment, 59:440 - 451, 1997.

Huete, A., K. Didan, T. Miura, E. P. Rodriguez, X. Gao, and L. G. Ferreira. Overview of the radiometric and biophysical performance of the modis vegetation indices. Remote Sensing of the Environment, 83:195 - 213, 2002.

Huysmans, M. and A. Dassargues. Review of the use of pclet numbers to determine the relative importance of advection and diffusion in low permeability environments. Hydrogeology, 13(5-6):895-904, 2005.

James, A. I. and J. W. Jawitz. Modeling two-dimensional reactive transport using a Godunov-mixed finite element method. Journal of Hydrology, 338(12):28 - 41, 2007. ISSN 0022-1694. doi: (http://dx.doi.org/10.1016/j.jhydrol.2007.02.007).

Klemas, V. Remote sensing of wetlands: Case studies comparing practical techniques. Journal of Coastal Research, 27(3):418-427, 2011.

Kristensen, K. J. and S. Jensen. A model for estimating actual evapotranspiration from potential evapotranspiration. Nordic Hydrology 6, pages 170-188, 1975.

Kumar, L., K. Schmidt, S. Dury, and A. Skidmore. Imaging spectrometry: Basic principles and prospective applications, chapter Imaging spectroscopy and vegetation science, pages 111-155. Springer, 2002.

Lai, D. and K. Lam. Phosphorus sorption by sediments in a subtropical constructed wetland receiving stormwater runoff. Ecological Engineering, 35:735-743, 2009.

Langevin, C., E. Swain, and M. Wolfert. Simulation of integrated surfacewater/ground-water flow and salinity for a coastal wetland and adjacent estuary. Journal of Hydrology, 314:212-234, 2005.

Leonard, B. A stable and accurate convective modelling procedure based on quadratic upstream interpolation. Computer Methods in Applied Mechanics and Engineering, 19(1):59 - 98, 1979. ISSN 0045-7825. doi: http://dx.doi.org/10. 1016/0045-7825(79)90034-3. URL http://www.sciencedirect.com/science/article/ pii/0045782579900343.

Long, S., A. Cook, G. Tachiev, V. Villamizar, R. Fennema, K. Kotun, and F. MirallesWilhelm. Analysis of bridge construction as a hydrological restoration technique for Everglades National Park, FL, USA using hydrological numerical modeling. Submitted 2014. 
Masek, J., E. Vermote, N. Saleous, R. Wolfe, F. Hall, F. Huemmrich, F. Gao, J. Kutler, and T. Lim. A Landsat surface reflectance data set for North America, 19902000. IEEE Geoscience and Remote Sensing Letters, 3(1):66-72, 2006.

Merzlyak, M. N., A. A. Gitelson, O. B. Chivkunova, and V. Y. Rakitin. Nondestructive optical detection of pigment changes during leaf senescence and fruit ripening. Physiologia Plantarum, 106(1):135-141, 1999. ISSN 1399-3054. doi: 10.1034/j.1399-3054.1999.106119.x.

Michot, B., E. Meselhe, V. Rivera-Monroy, C. Coronado-Molina, and R. Twilley. A tidal creek water budget: Estimation of groundwater discharge and overland flow using hydrologic modeling in the Southern Everglades. Estuarine, Coastal and Shelf Science, 93:438-448, 2011. doi: 10.1016/j.ecss.2011.05.018.

Min, J.-H., R. Paudel, and J. Jawitz. Spatially distributed modeling of surface water flow dynamics in the Everglades ridge and slough landscape. Journal of Hydrology, 390:1-12, 2010.

NPS. Tamiami Trail Modifications: Next Steps Draft Environmental Impact Statement. Technical report, National Park Service, Department of the Interior, 2010.

NRC. Progress Toward Restoring the Everglades: The Fourth Biennial Review - 2012. The National Academies Press, Washington, D.C., 2012.

NRCS. United States Department of Agriculture. U.S. General Soil Map (STATSGO2). URL http://soildatamart.nrcs.usda.gov.

Olsen, T. Florida everglades 2005-6 survey design. Technical report, U.S. Environmental Protection Agency NHEERL, 2005.

Paudel, R., J. Min, and J. W. Jawitz. Management scenario evaluation for a large treatment wetland using a spatio-temporal phosphorus transport and cycling model. Ecological Engineering, 36(12):1627-1638, 2010.

Penuelas, J., I. Filella, and G. J. A. Assessment of photosynthetic radiation-use efficiency with spectral reflectance. New Phytol., 131:291-296, 1995.

Perry, C. R., Jr. and L. F. Lautenschlager. Functional equivalence of spectral vegetation indices. Remote Sensing of Environment, 14(13):169 - 182, 1984. ISSN 0034-4257. doi: http://dx.doi.org/10.1016/0034-4257(84)90013-0.

Pimstein, A., A. Karnieli, S. Bansal, and D. Bonfil. Exploring remotely sensed technologies for monitoring wheat potassium and phosphorus using field spectroscopy. Field Crops Research, 121:125-135, 2011. 
Raghunathan, R., T. Slawecki, T. Fontaine, Z. Chen, D. Dilks, V. B. Jr, and S. Wade. Exploring the dynamics and fate of total phosphorus in the Florida Everglades using a calibrated mass balance model. Ecological Modelling, 142:247-259, 2001.

Rahim, B., I. Yusoff, A. Jafri, Z. Othman, and A. Ghani. Application of MIKE SHE modelling system to set up a detailed water balance computation. Water and Environment Journal, 26:490-503, 2012. doi: 10.1111/j.1747-6593.2012.00309.x.

Ramoelo, A., A. Skidmore, M. Schlerf, R. Mathieu, and I. Heitkönig. Water-removed spectra increase the retrieval accuracy when estimating savanna grass nitrogen and phosphorus concentrations. ISPRS Journal of Photogrammetry and Remote Sensing, 66:408-417, 2011.

Ramoelo, A., A. K. Skidmore, M. A. Cho, R. Mathieu, I. M. A. Heitkönig, N. DudeniTlhone, M. Schlerf, and H. H. T. Prins. Non-linear partial least square regression increases the estimation accuracy of grass nitrogen and phosphorus using in situ hyperspectral and environmental data. ISPRS Journal of Photogrammetry and Remote Sensing, 82:27-40, 2013.

Reddy, K. R., M. J. Chimney, and R. H. Kadlec. The everglades nutrient removal project. Ecological Engineering, 27(4):265-267, 2006.

Redfield, G. Atmospheric deposition of phosphorus to the Everglades: Concepts, constraints, and published deposition rates for ecosystem management. The Scientific World, 2:1843-1873, 2002.

Refsgaard, J. and B. Storm. Computer Models of Watershed Hydrology, chapter MIKE SHE, pages 809-846. Water Resources Publication, Colorado, USA, 1995.

Richardson, A. and C. Wiegand. Distinguishing vegetation from soil background information. Photogramnetric Engineering and Remote Sensing, 43(12):1541 - 1552, 1977.

Rivero, R., S. Grunwald, M. Binford, and T. Osborne. Integrating spectral indices into prediction models of soil phosphorus in a subtropical wetland. Ecological Engineering, 113:2389-2402, 2009.

Rondeaux, G., M. Steven, and F. Baret. Optimization of soil-adjusted vegetation indices. Remote Sensing of Environment, 55(2):95 - 107, 1996. ISSN 0034-4257. doi: http://dx.doi.org/10.1016/0034-4257(95)00186-7.

Rouse, R. H. H. J. A. S., J. W. and D. W. Deering. Monitoring vegetation systems in the Great Plains with ERTS. In Third ERTS Symposium, NASA SP-351 I, pages 309-317, 1973. 
Ryu, C., M. Suguri, and M. Umeda. Multivariate analysis of nitrogen content for rice at the heading stage using reflectance of airborne hyperspectral remote sensing. Field Crops Research, 122:214-224, 2011.

Saiers, J. E., J. W. Harvey, and S. E. Mylon. Surface water transport of suspended matter through wetland vegetation of the Florida everglades. Geophysical Research Letters, 30(19):1987, 2003.

Schulze-Makuch, D. Longitudinal dispersivity data and implications for scaling behavior. Ground Water, 43(3):443-456, 2005.

SFWMD. Documentation of the South Florida Water Management Model, Version 5.5. Technical report, South Florida Water Management District, 2005.

Sklar, F. H., M. J. Chimney, S. Newman, P. McCormick, D. Gawlik, S. Miao, C. McVoy, W. Said, J. Newman, C. Coronado, G. Crozier, M. Korvela, and K. Rutchey. The ecologicalsocietal underpinnings of Everglades restoration. Frontiers in Ecology and the Environment, 3(3):161-169, 2005.

Smith, A. The biosynthesis of starch granules. Biomacromolecules, 2(2):335-341, 2001.

Smith, R. C. G., J. Adams, D. J. Stephens, and P. T. Hick. Forecasting wheat yield in a Mediterranean-type environment from the NOAA satellite. Australian Journal of Agricultural Research, 46(1):113 - 125, 1995.

Stone, J. and D. Legg. Agriculture and the Everglades. Journal of Soil and Water Conservation, 47(3):207-215, 2001.

USACE. Central Everglades Planning Project: Draft integrated project implementation report and environmental impact statement. Draft rep., U.S. Army Corps of Engineers, Jacksonville, FL, 2013.

USGS. Eastern Geographic Science Center, Miami-Dade County FL Soil Map, 2006. URL http://sofia.usgs.gov/exchange/jjones/jjones.html.

USGS. Gap Analysis Program (GAP), National Land Cover Survey. Technical report, U.S. Geological Survey, 2010.

USGS. Product Guide: Landsat Surface Reflectance CDR, Version 3.4, December 2013.

USGS. Earthexplorer, 2014. URL (http://earthexplorer.usgs.gov/). 
Vasques, G., S. Grunwald, and J. Sickman. Comparison of multivariate methods for inferential modeling of soil carbon using visible/near-infrared spectra. Geoderma, 146:14-25, 2008.

Walker, W. W. Analysis of Water Quality Data from ARM Loxahatchee National Wildlife Refuge. Technical report, U.S. Dept. of Interior, 1999.

Walker, W. Design basis for Everglades stormwater treatment areas. Water Resources Bulletin, 31(4):671-685, 1995.

Walker, W. and R. Kadlec. Modeling phosphorus dynamics in Everglades wetlands and stormwater treatment areas. Critical Reviews in Environmental Science and Technology, 41:430-446, 2011.

Wang, H., E. Meselhe, M. Waldon, M. Harwell, and C. Chen. Compartment-based hydrodynamics and water quality modeling of a northern everglades wetland, florida, usa. Ecological Modelling, 247:273-285, 2012.

Wang, Q. and Y. Li. Phosphorus adsorption and desorption behavior on sediments of different origins. Journal of Soils Sediments, 10:1159-1173, 2010.

Zhang, X., F. L., Y. He, and X. Gong. Detecting macronutrients content and distribution in oilseed rape leaves based on hyperspectral imaging. Biosystems Engineering, 115:56-65, 2013.

Zhou, M. and Y. Li. Phosphorus-sorption characteristics of calcareous soils and limestone from the southern Everglades and adjacent farmlands. Soil Science Society of America Journal, 65:1404-1412, 2001.

Zomer, R., A. Trabucco, and S. Ustin. Building spectral libraries for wetlands land cover classification and hyperspectral remote sensing. Journal of Environmental Management, 90:2170-2177, 2009. 


\section{Appendix A}

\section{M3ENP Calibration}

The following figures compare modeled (black) and observed (red) discharge and water level data for the Baseline scenario at a variety of water monitoring stations. The figures also provide the $[\mathrm{X}, \mathrm{Y}]$ location of the station in meters for a NAD 1983 UTM Zone $17 \mathrm{~N}$ map projection, the "Z Grid" interpolated elevation of the model cell, and the "Z Survey" elevation of the monitoring station. The monitoring stations are scattered throughout ENP as indicated in Figure A.1. Graphs of exceedance probability for each of the points are also included. The exceedance probability figures illustrate the probability that the water level at that station will exceed a certain elevation for both the Observed data (red) and Baseline data (black). The ground level is also indicated with a green line. The default for all figures is water level data on the y-axis in NGDV feet. Station names followed by "HW" indicate the headwater elevation (or elevation just upstream of a water control structure), station names followed by "-TW" indicate the tailwater elevation (or elevation just

downstream of a water control structure), station names followed by “_Q” indicate discharge data in $f t^{3} / s$. 


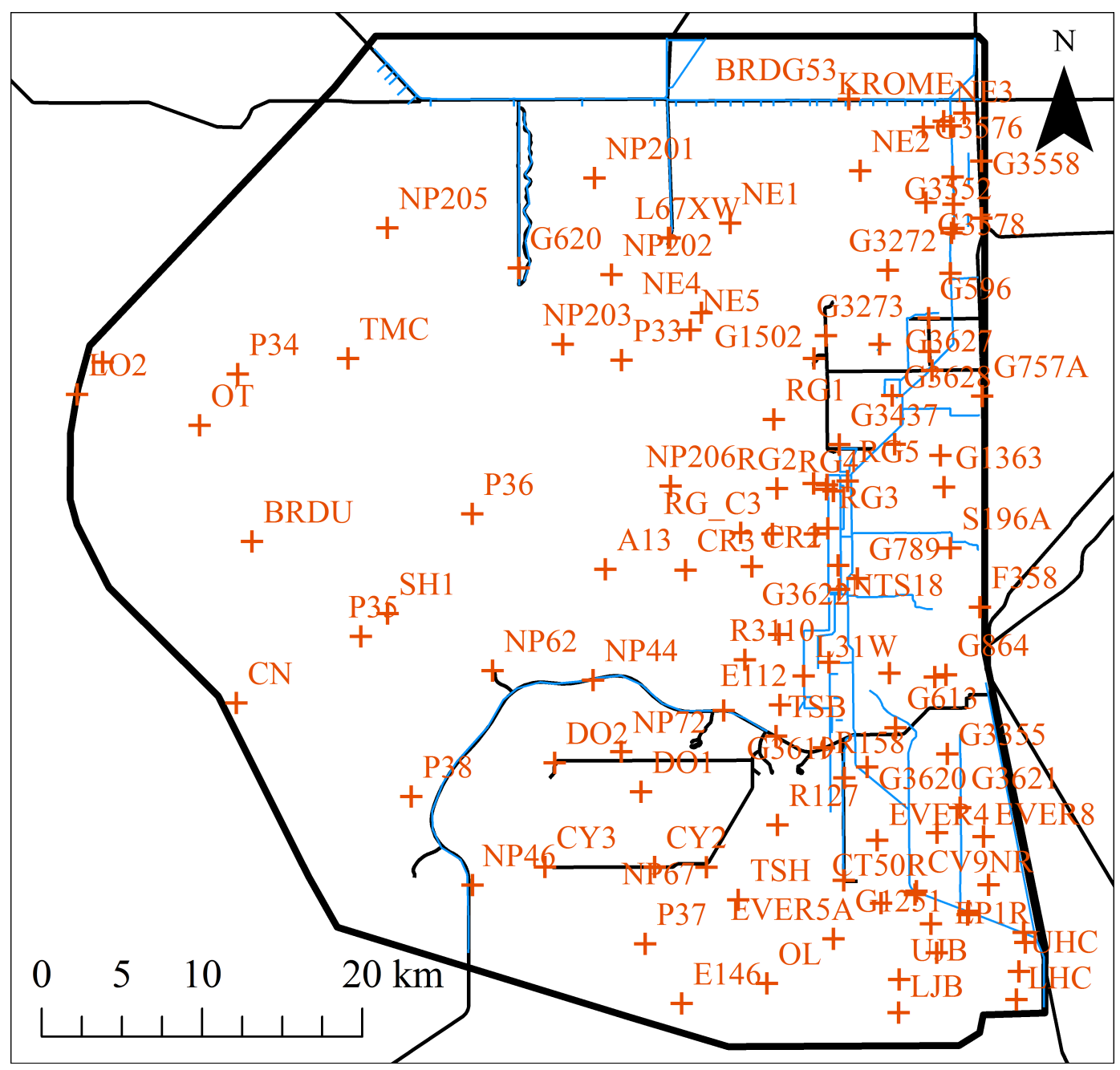

Figure A.1: Selected water level and discharge monitoring stations within the model domain. Observed data obtained from these stations were used for model calibration and validation. 

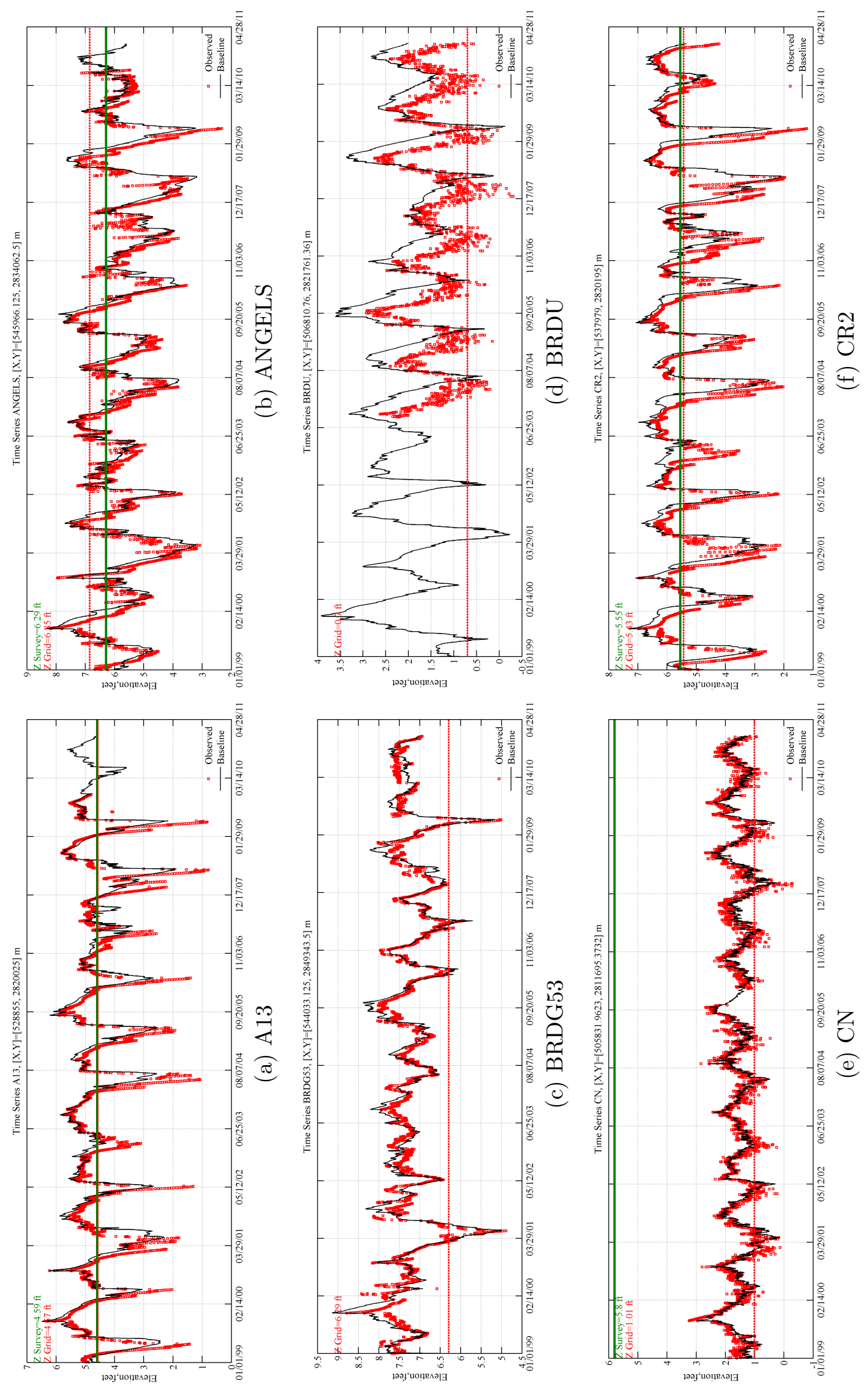

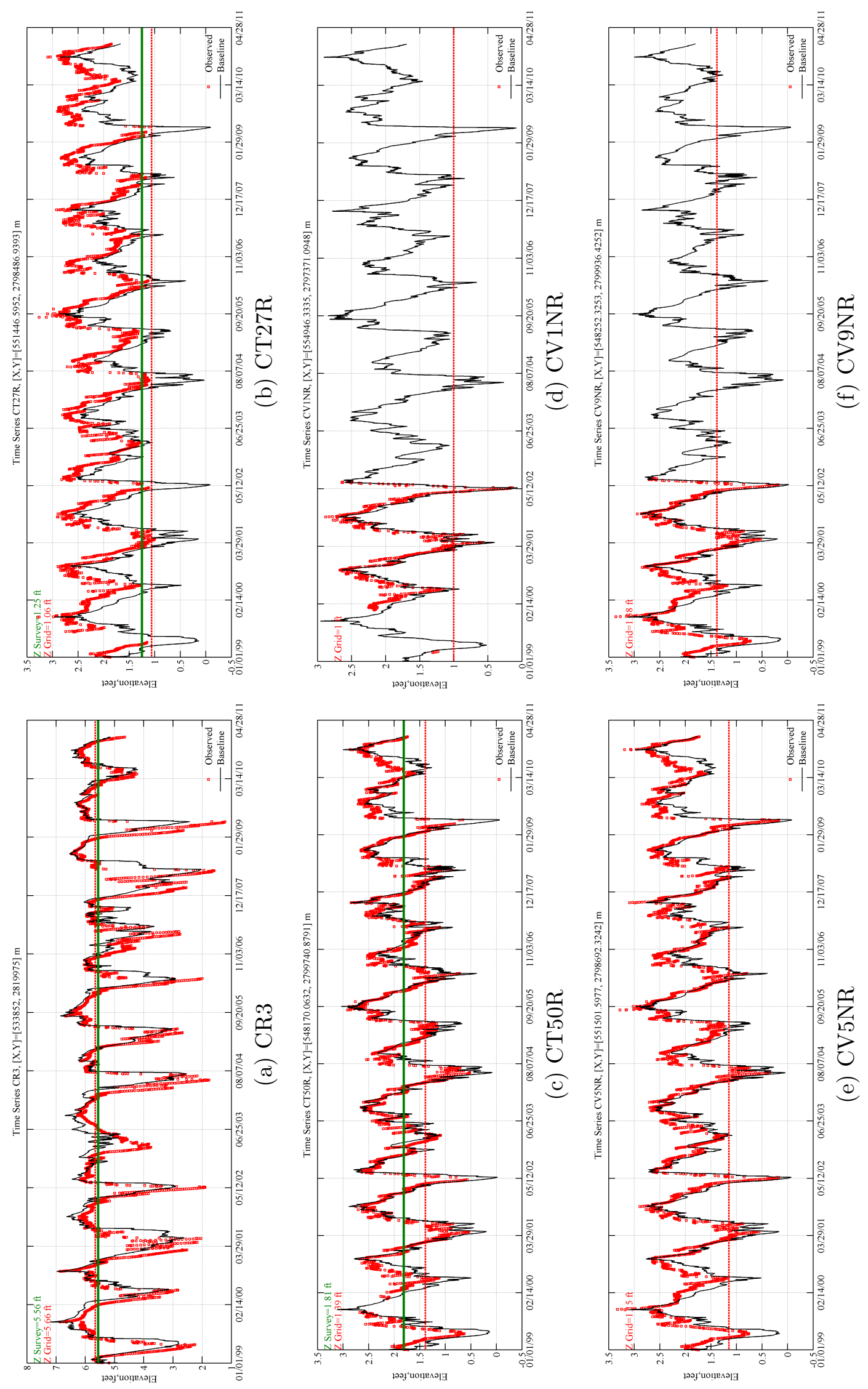

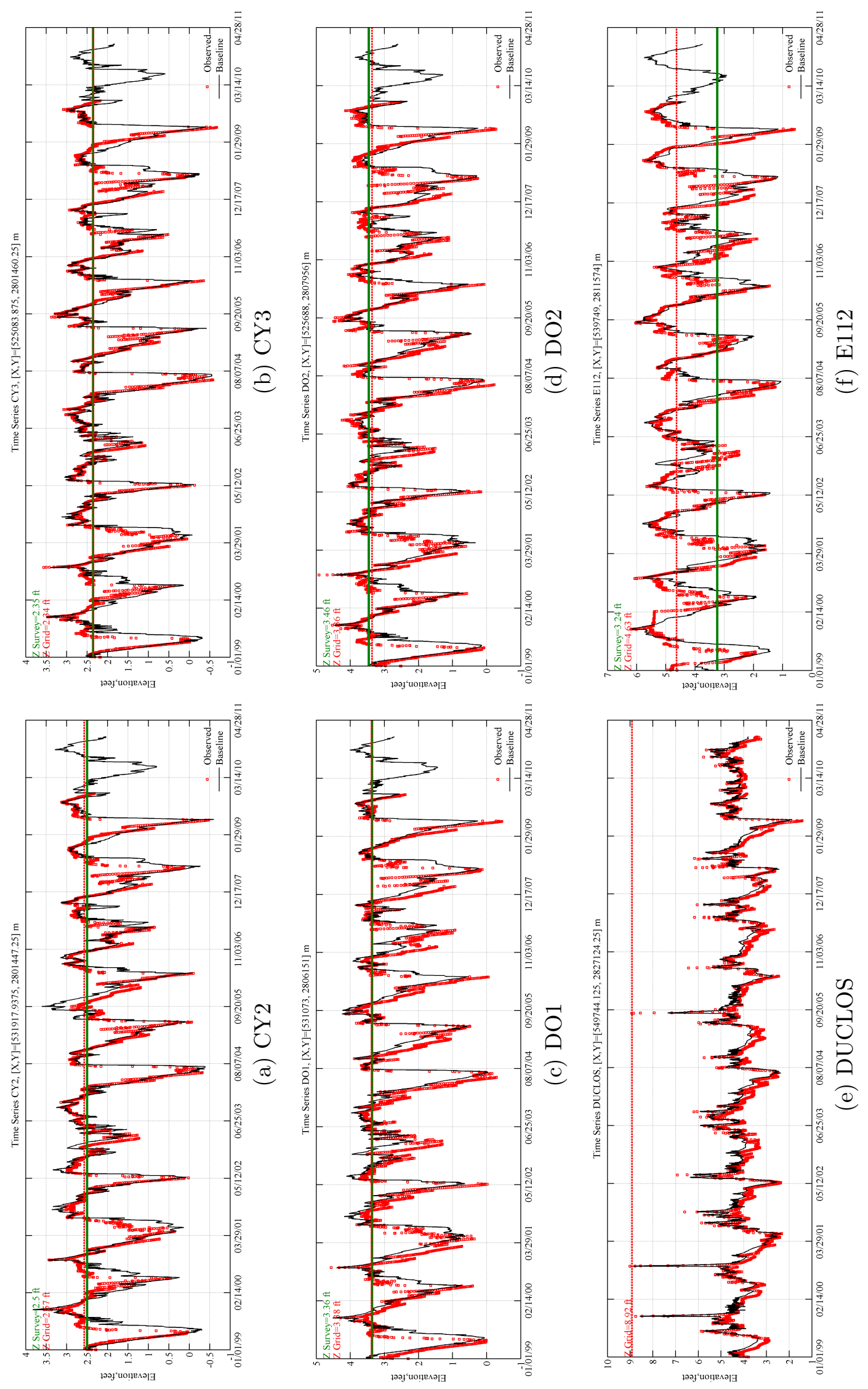

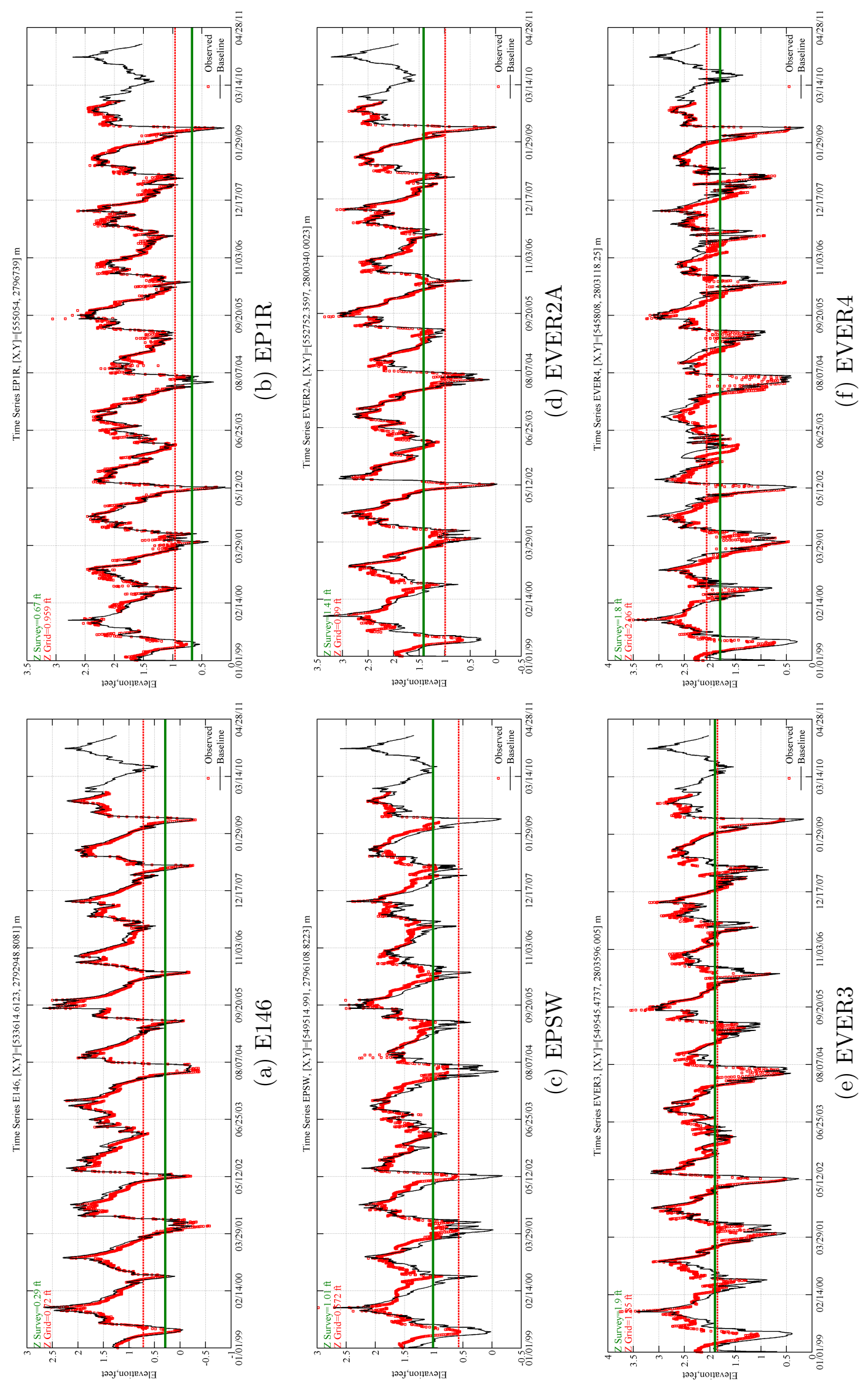

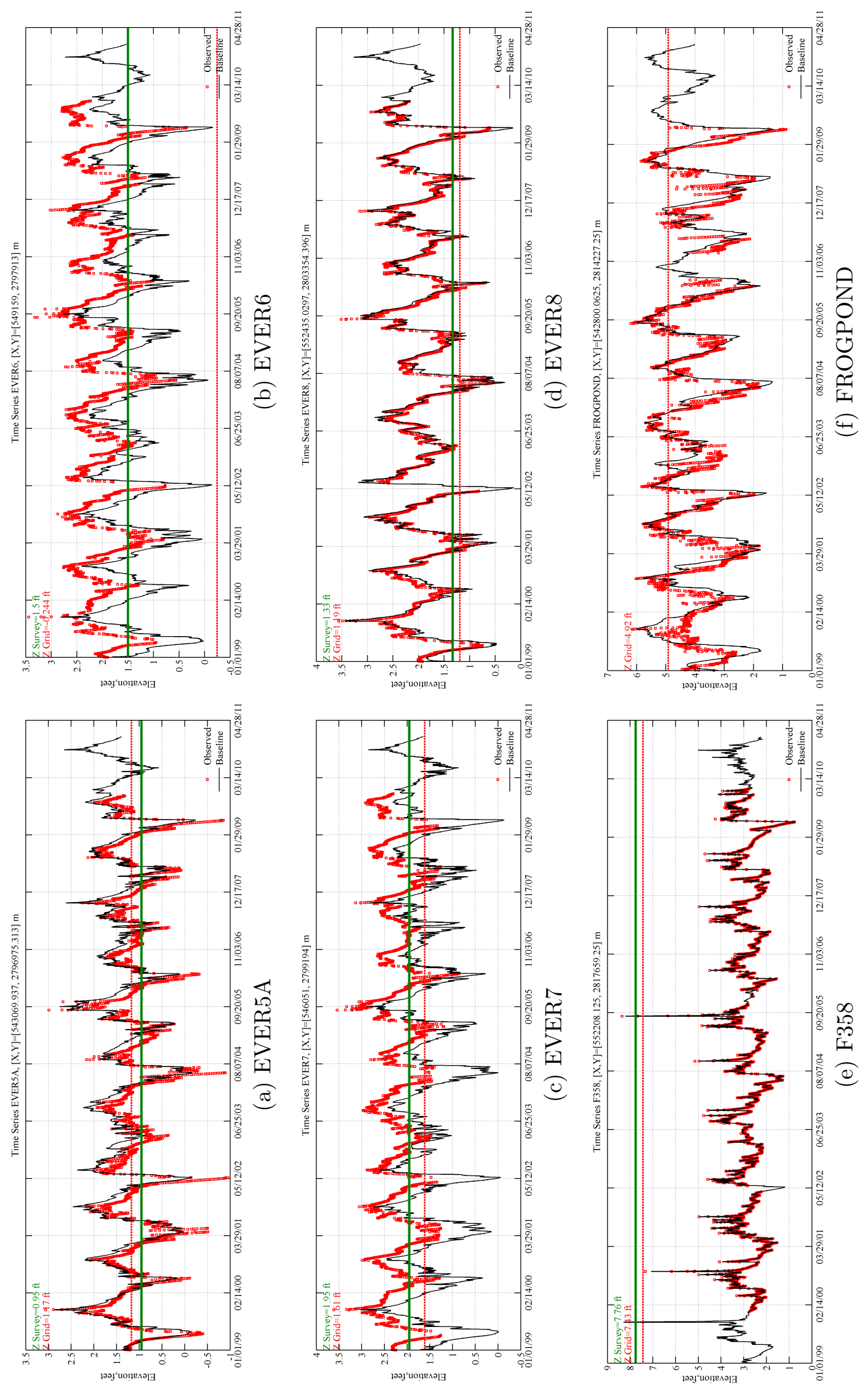

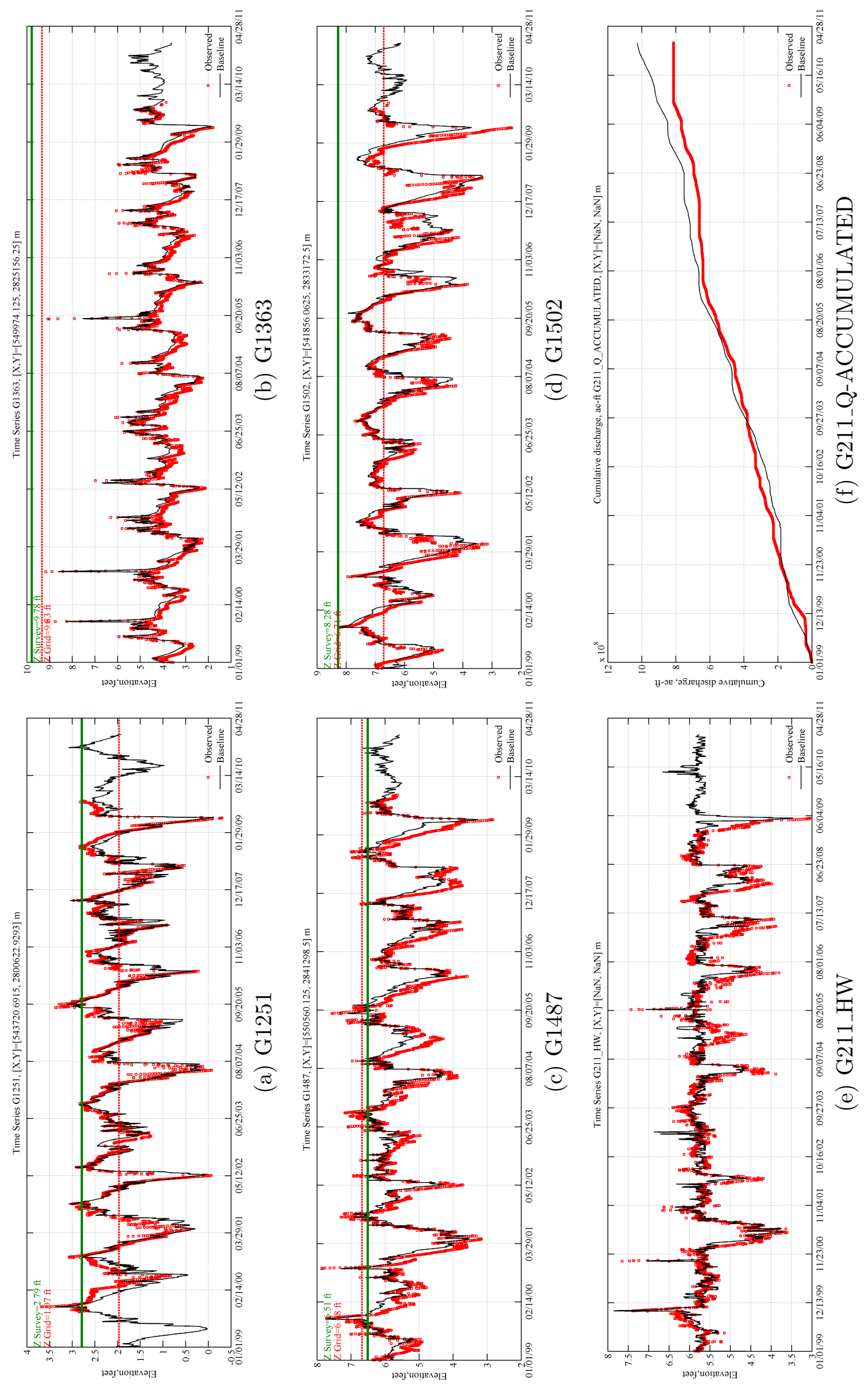

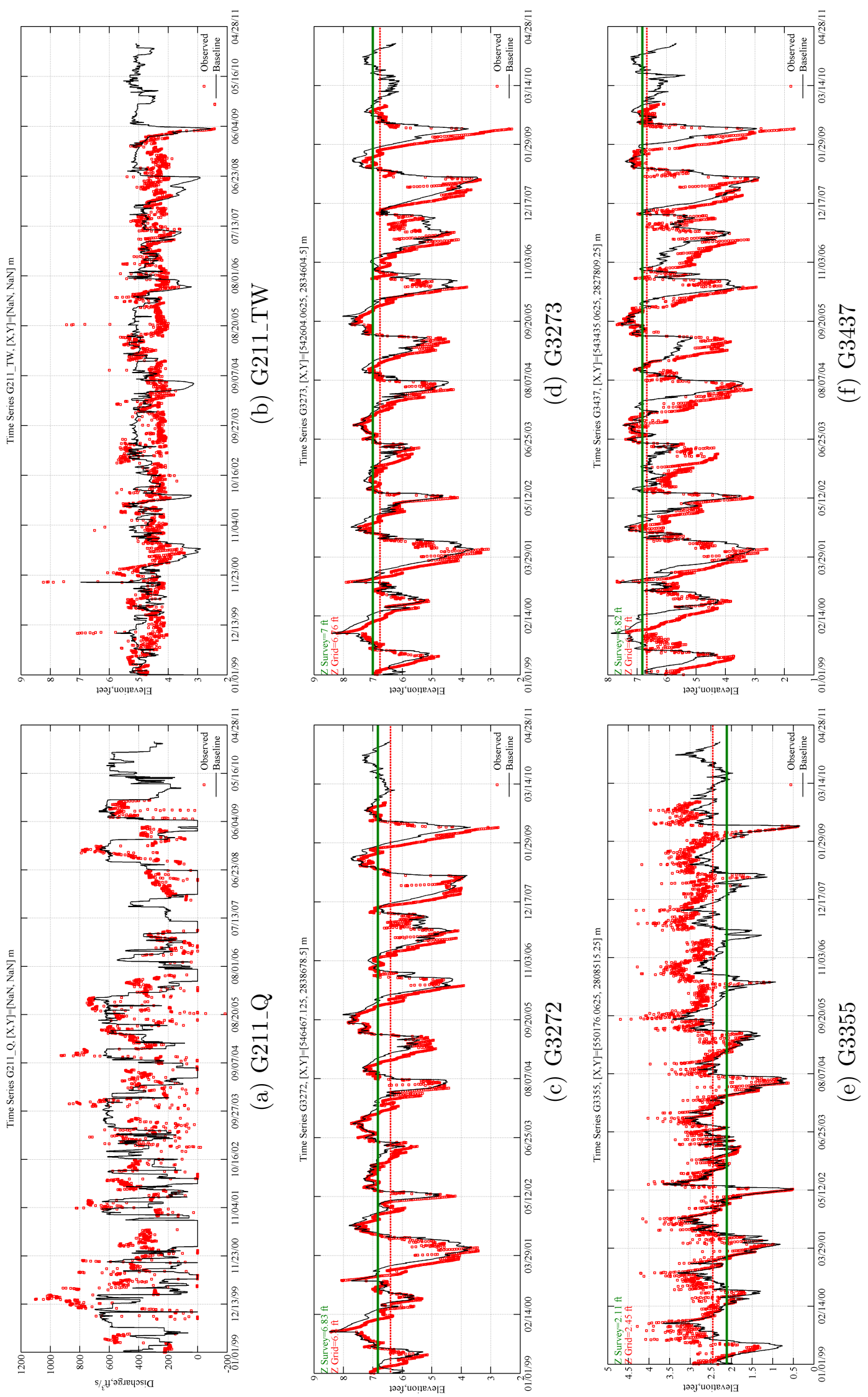

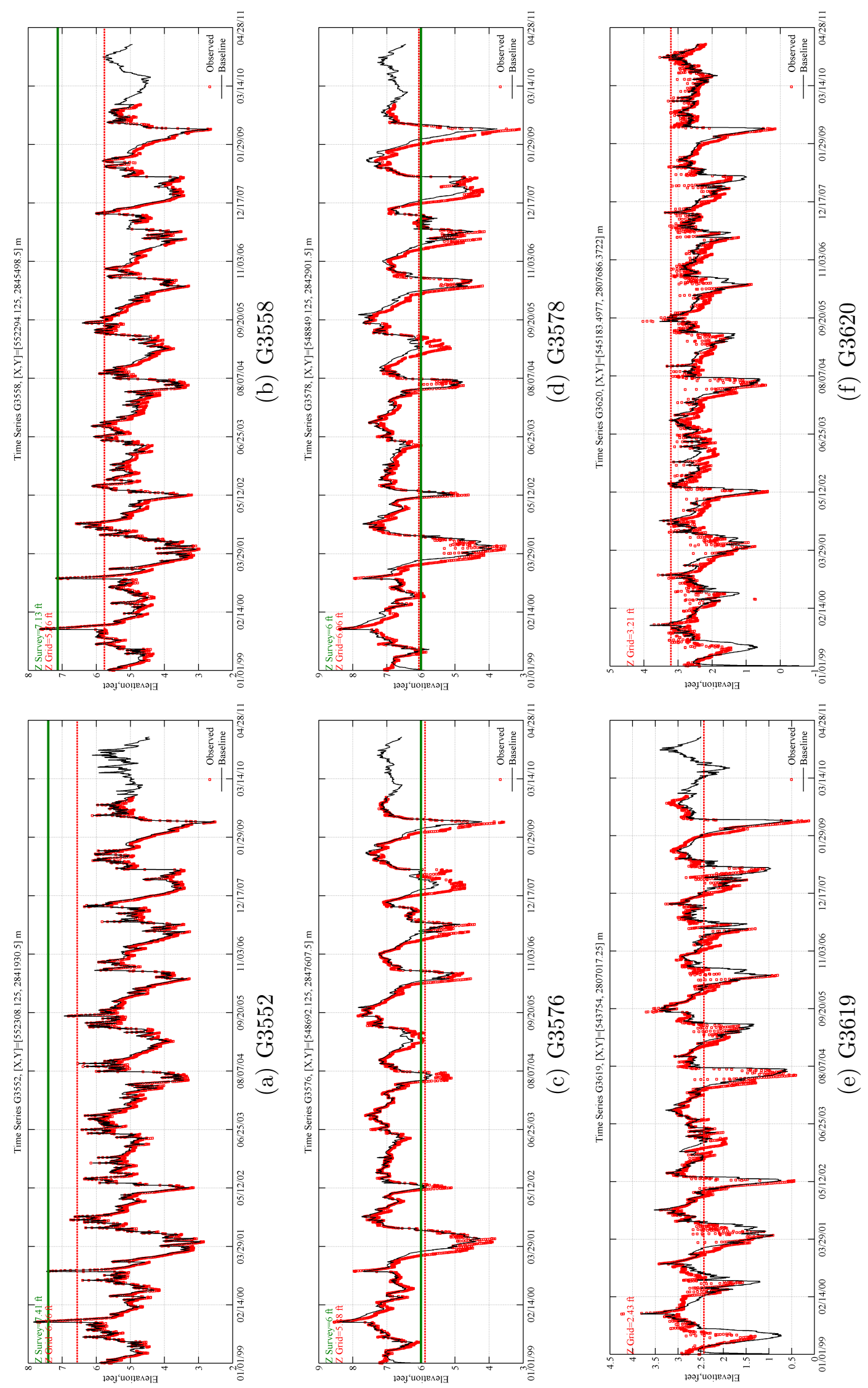

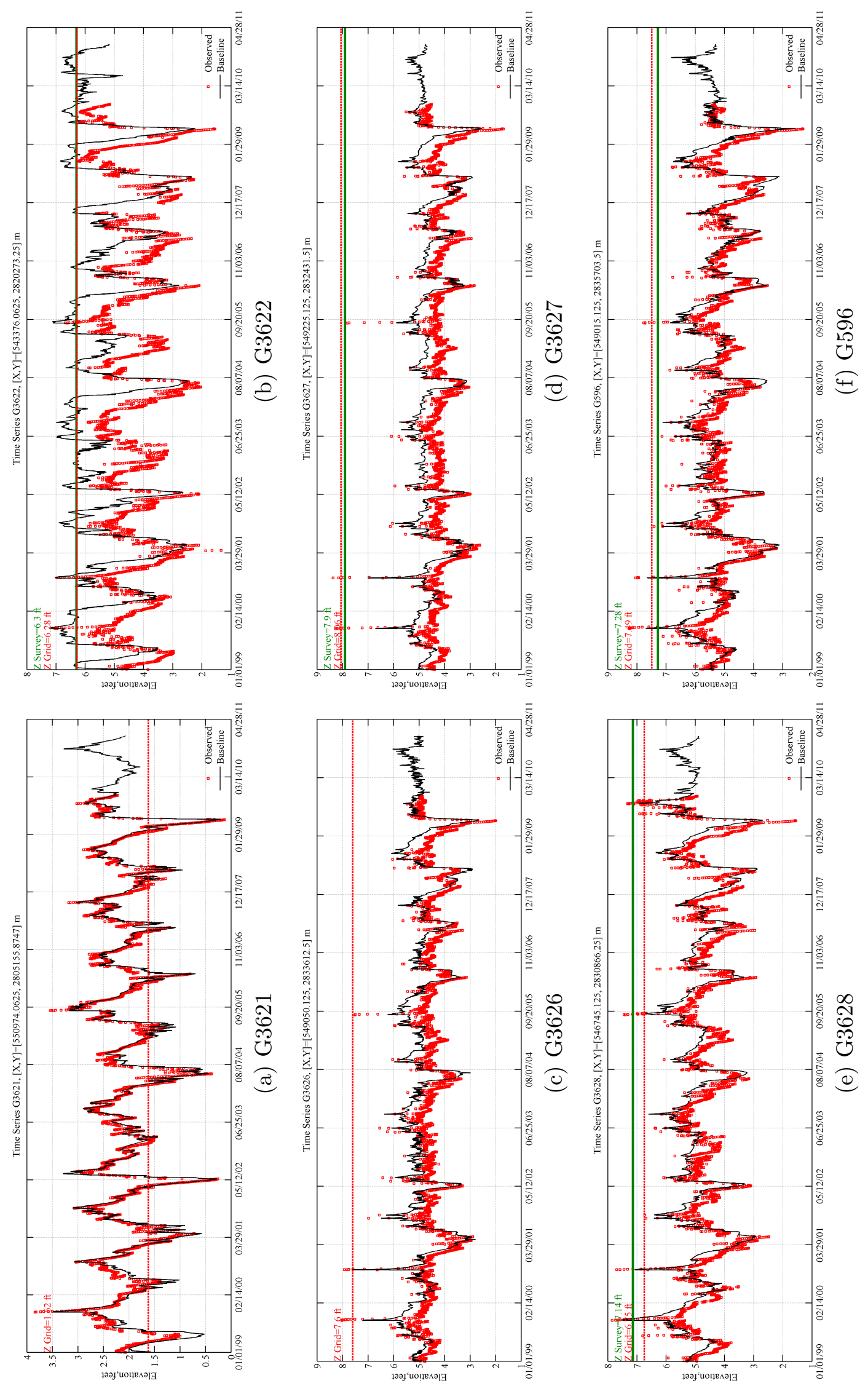

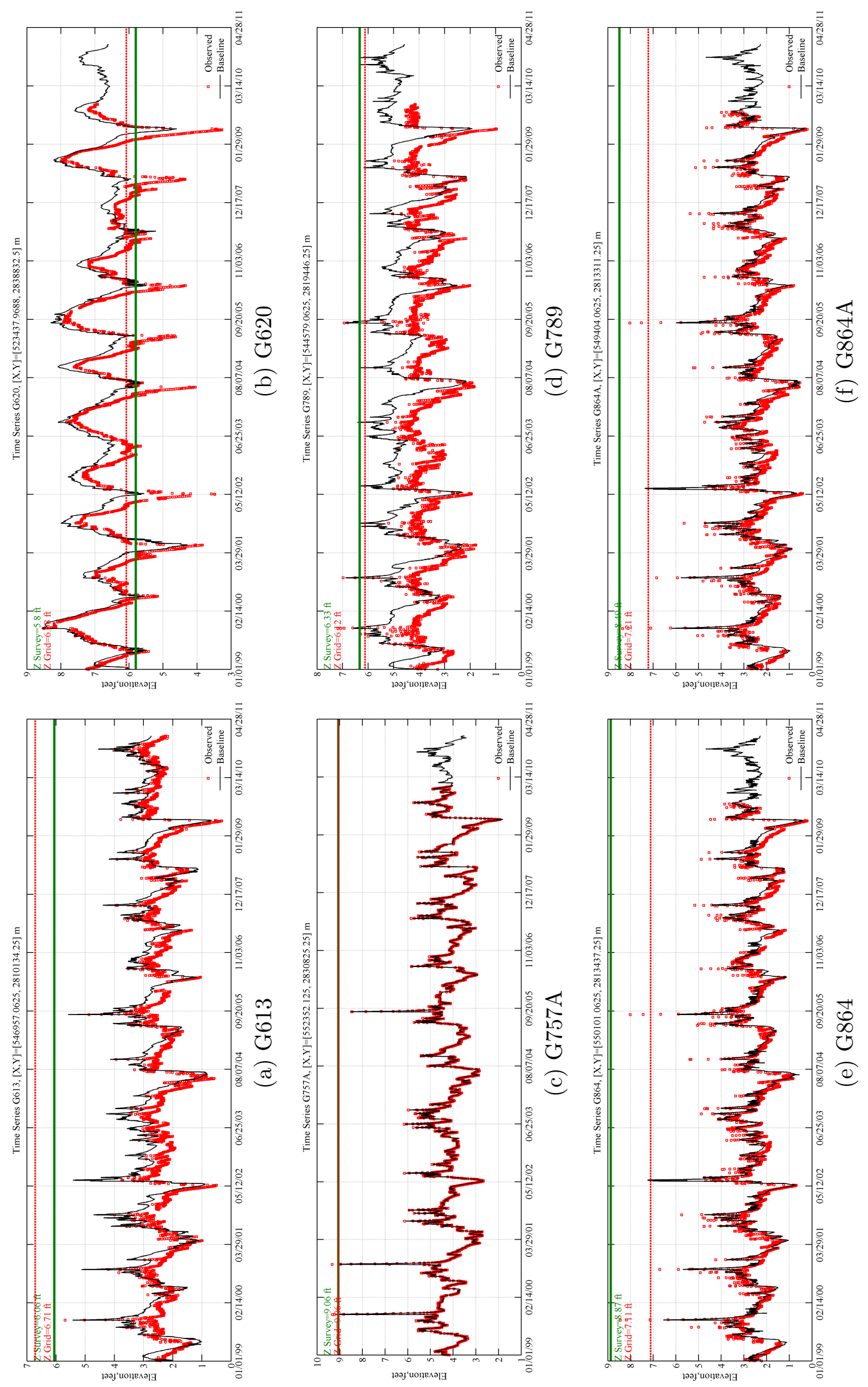

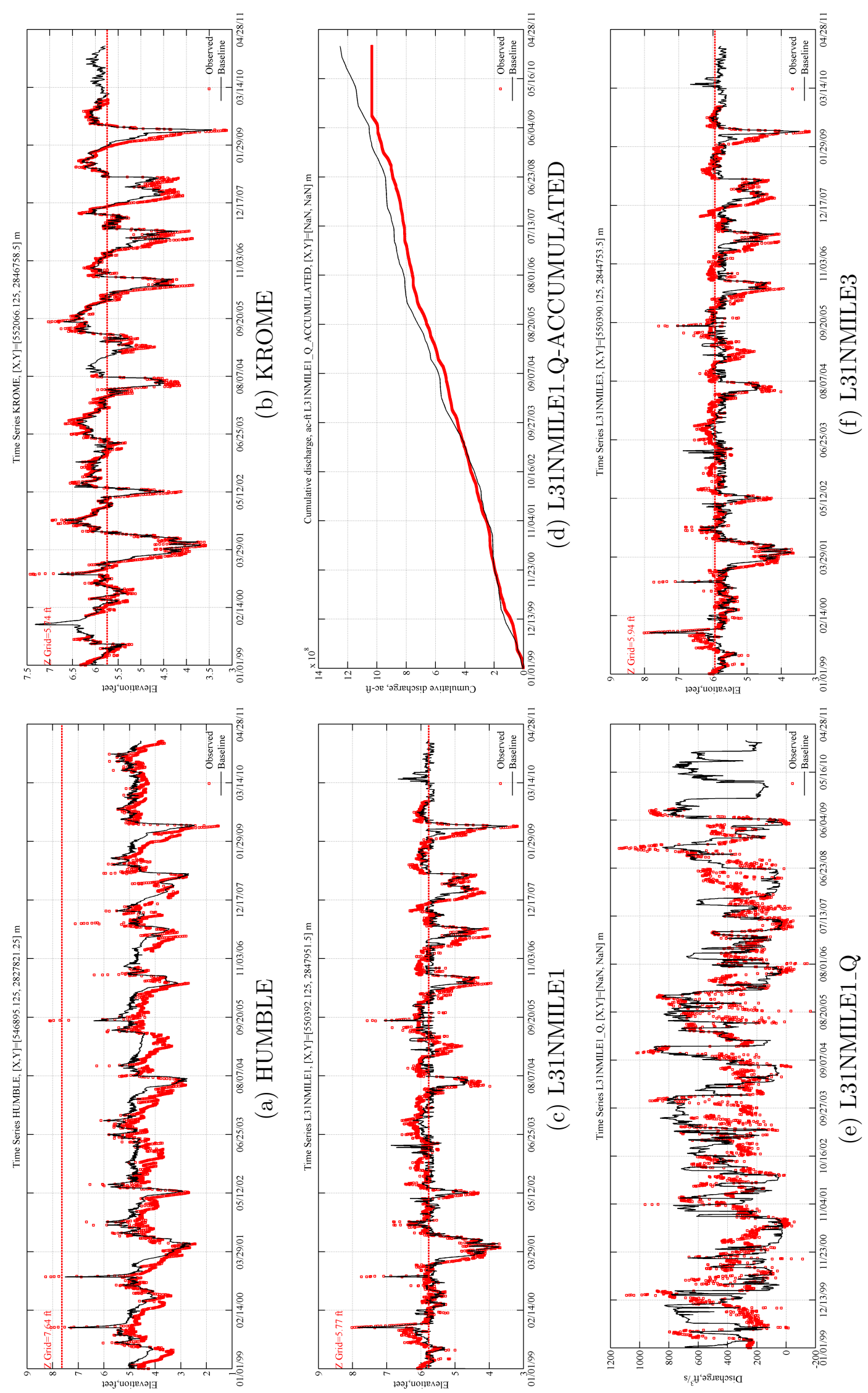

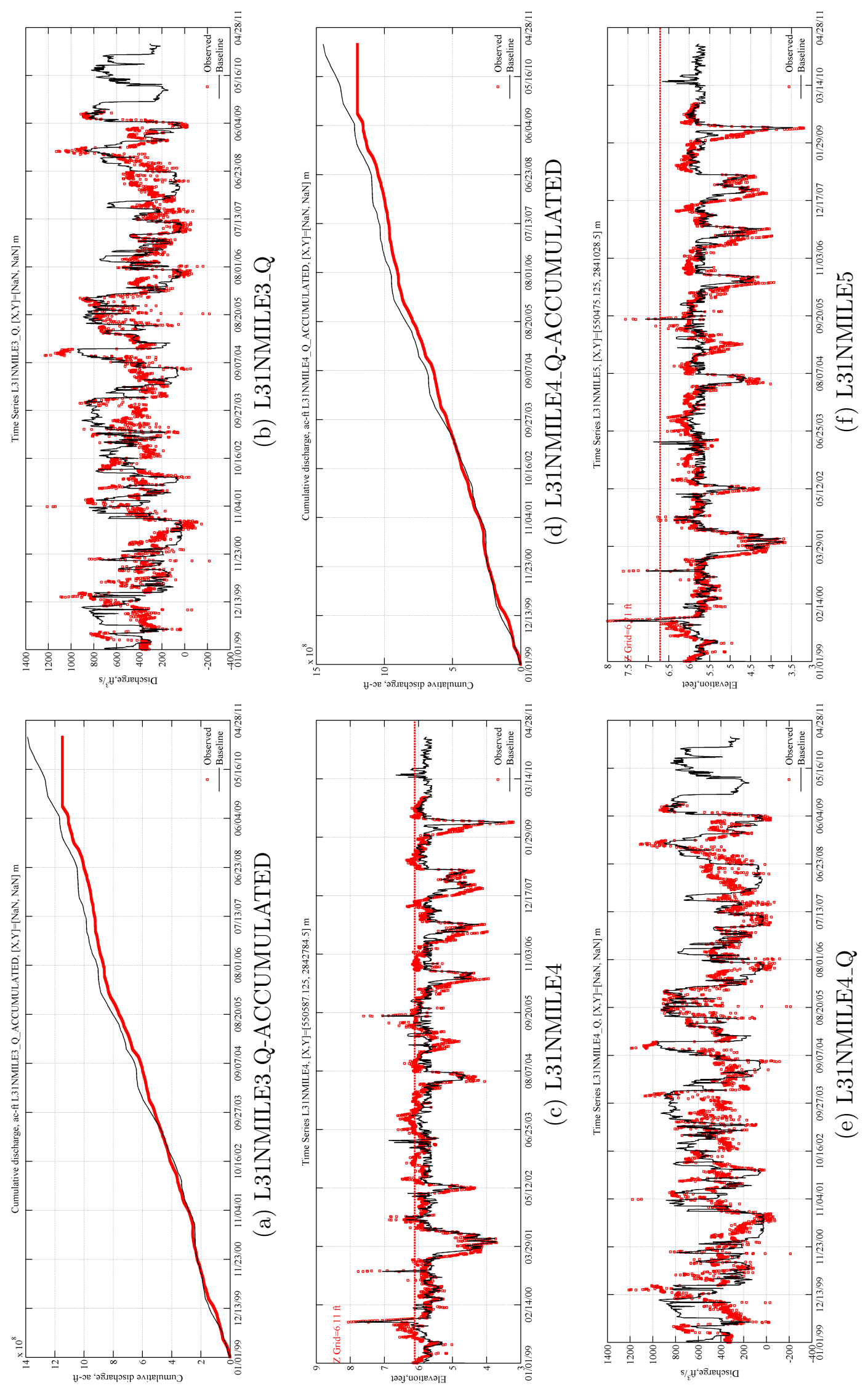

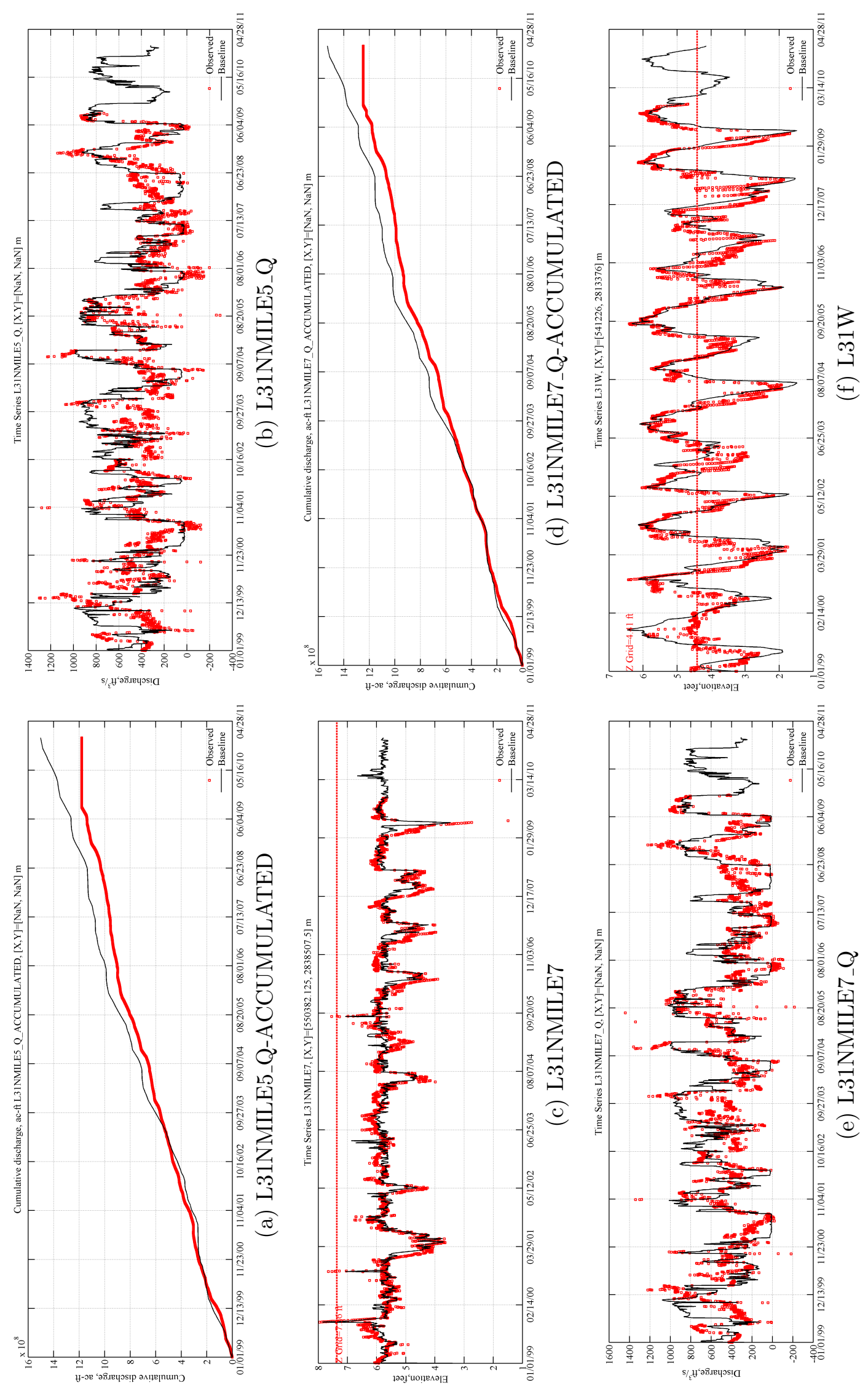

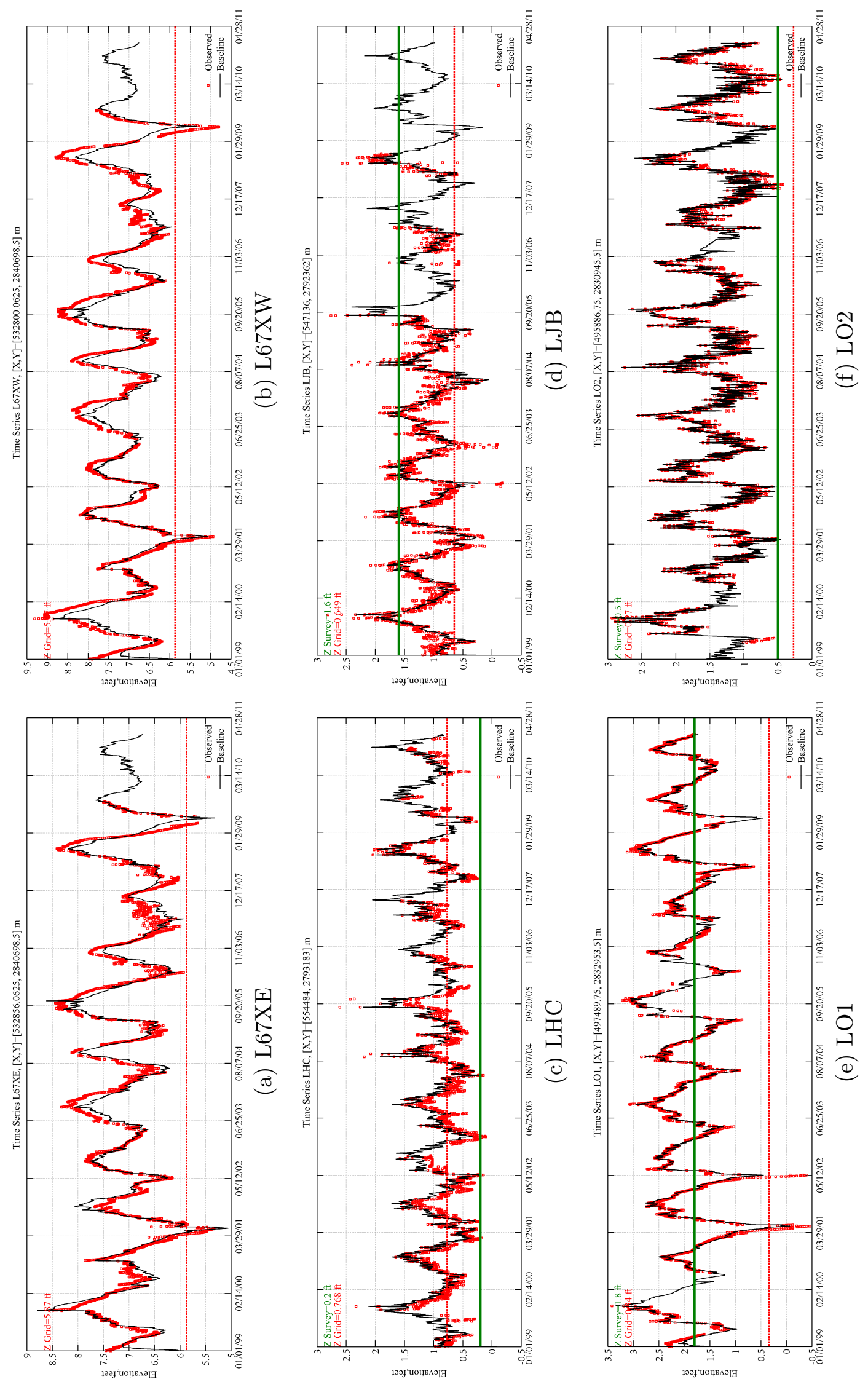

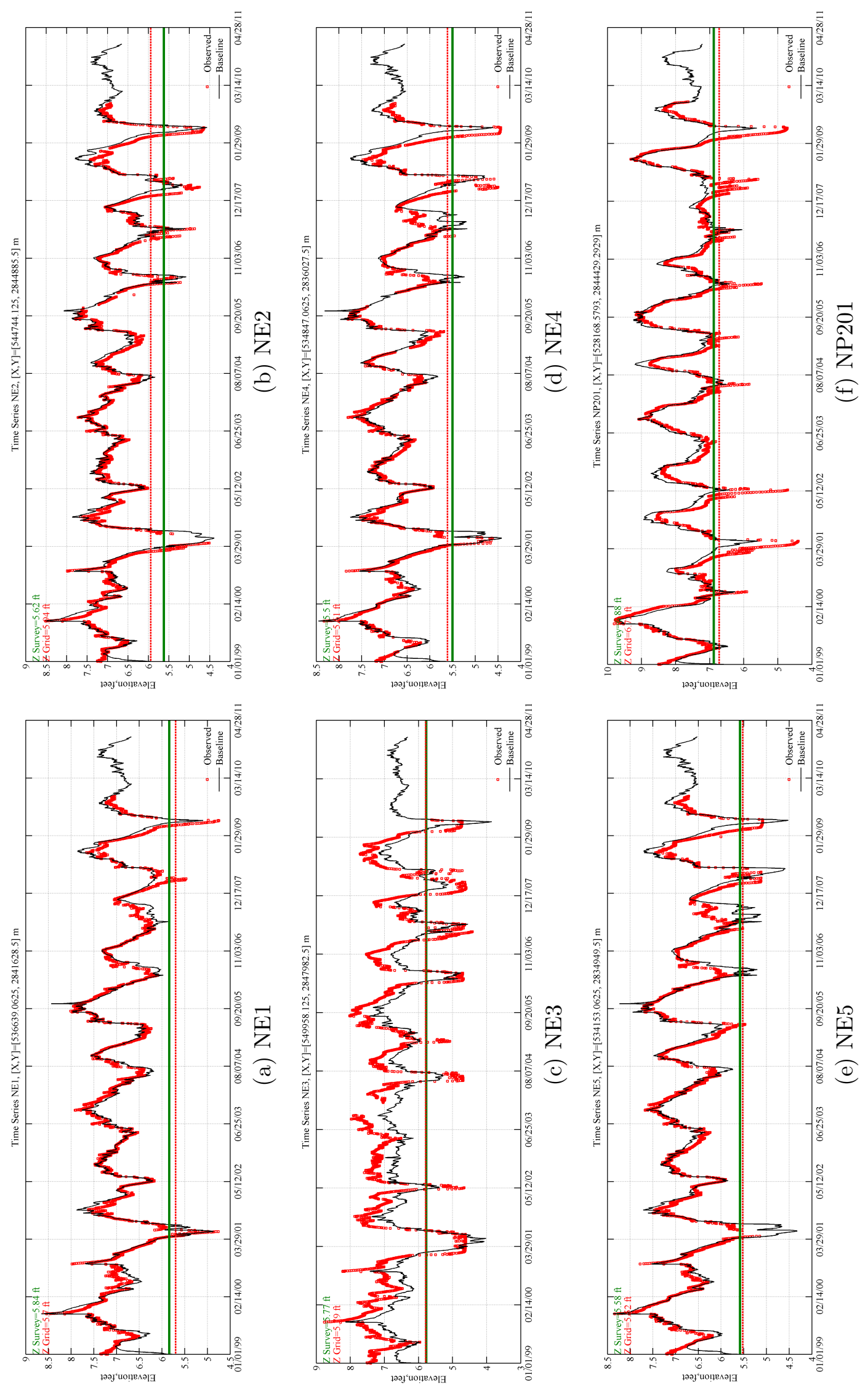

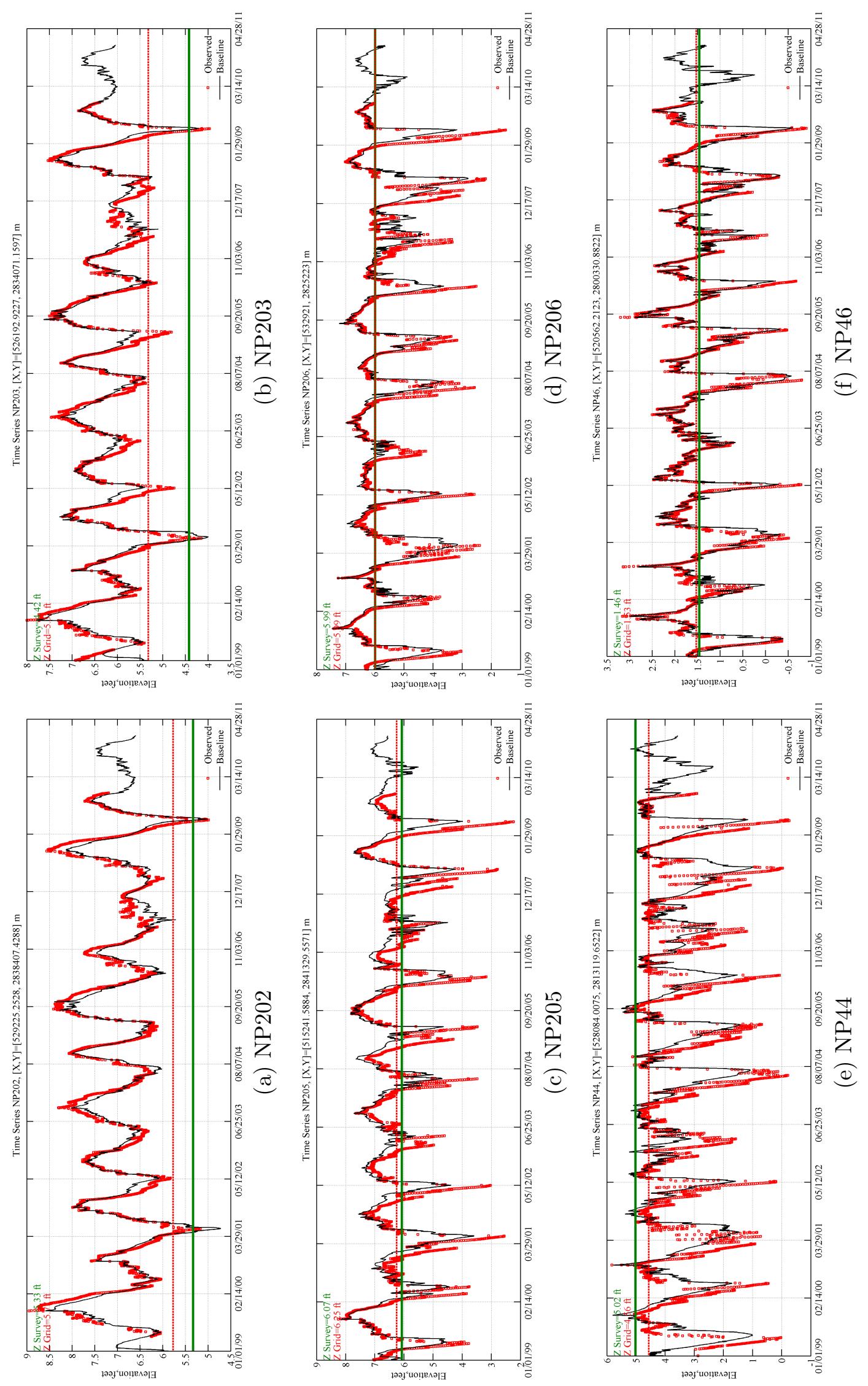

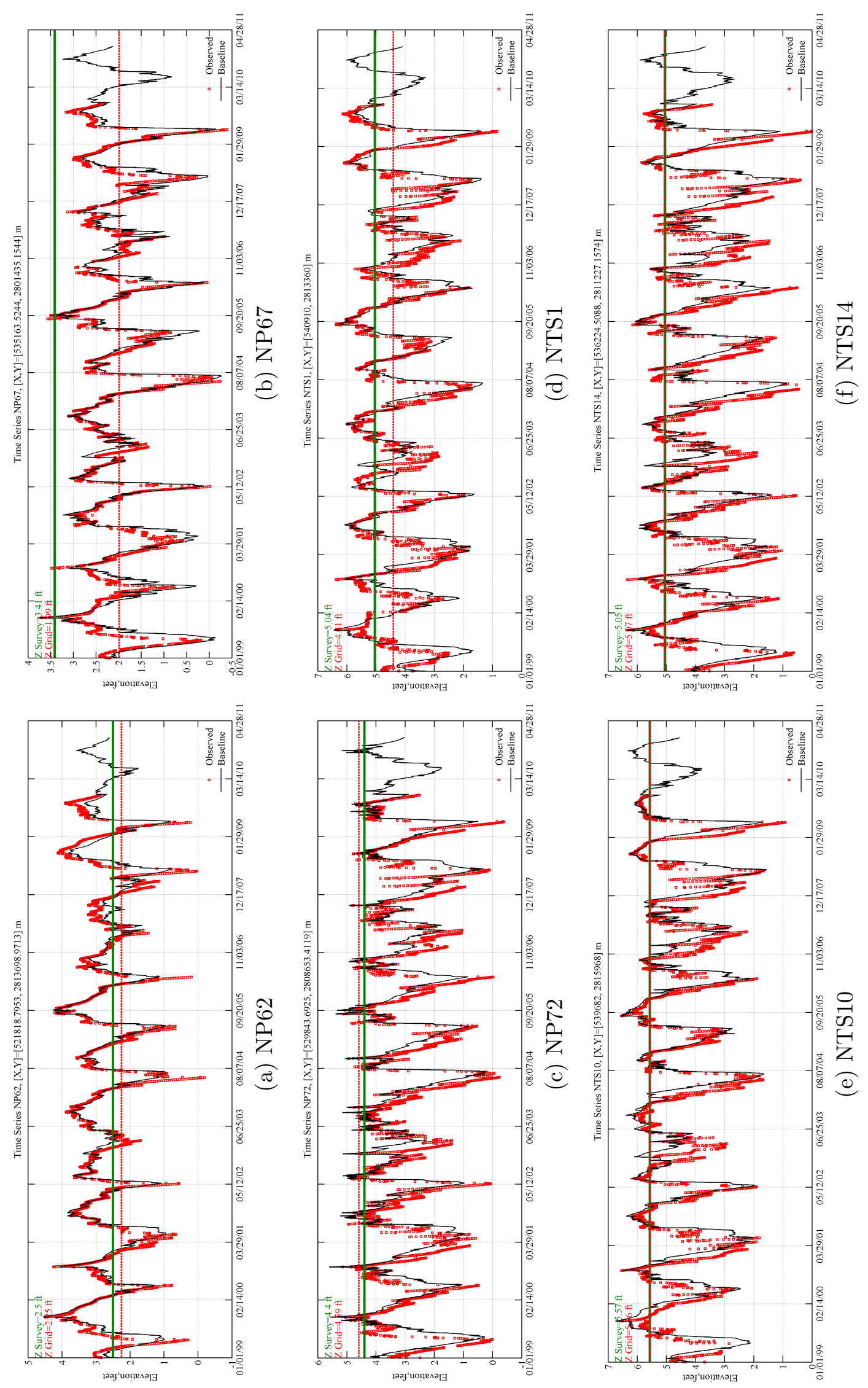

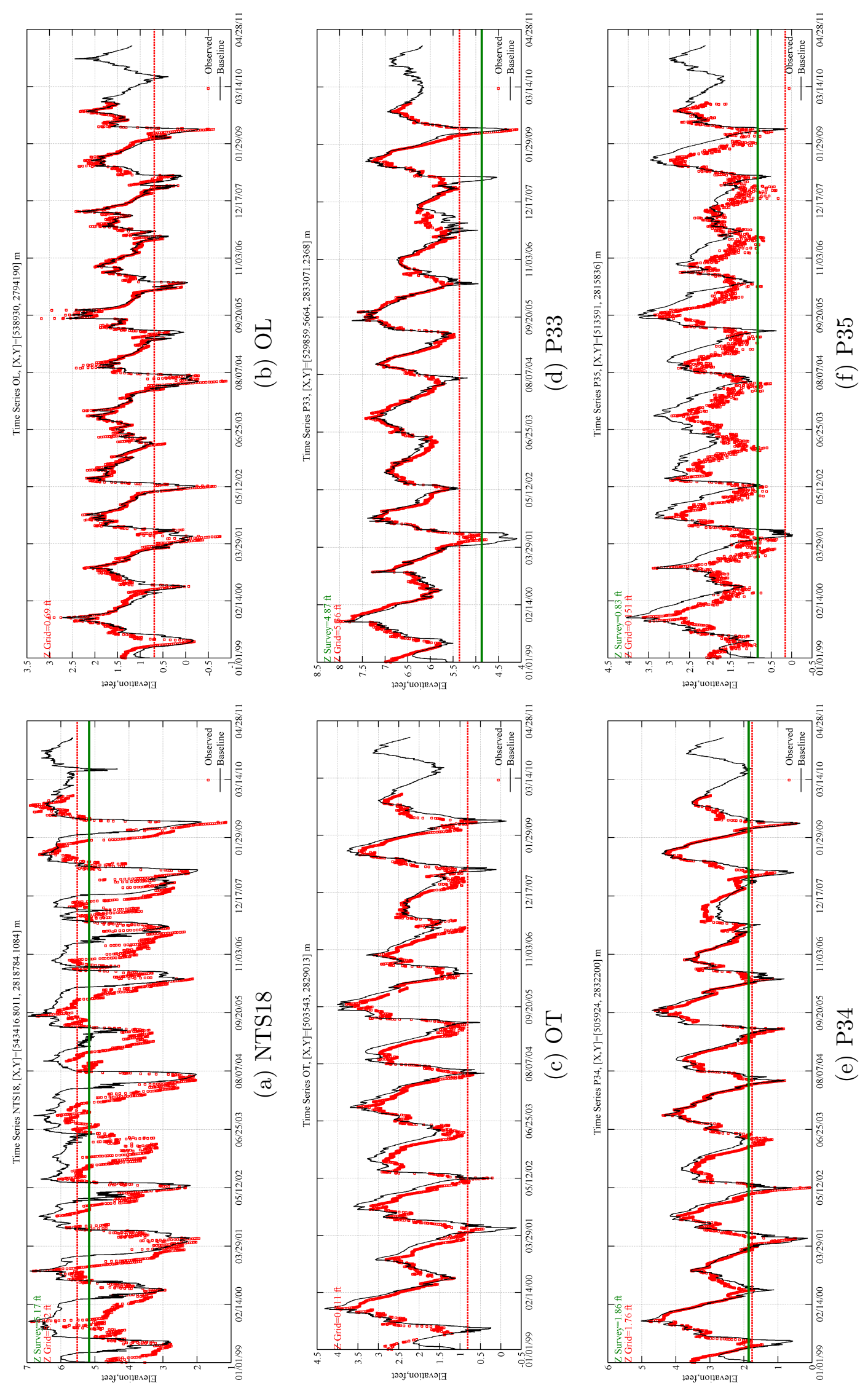

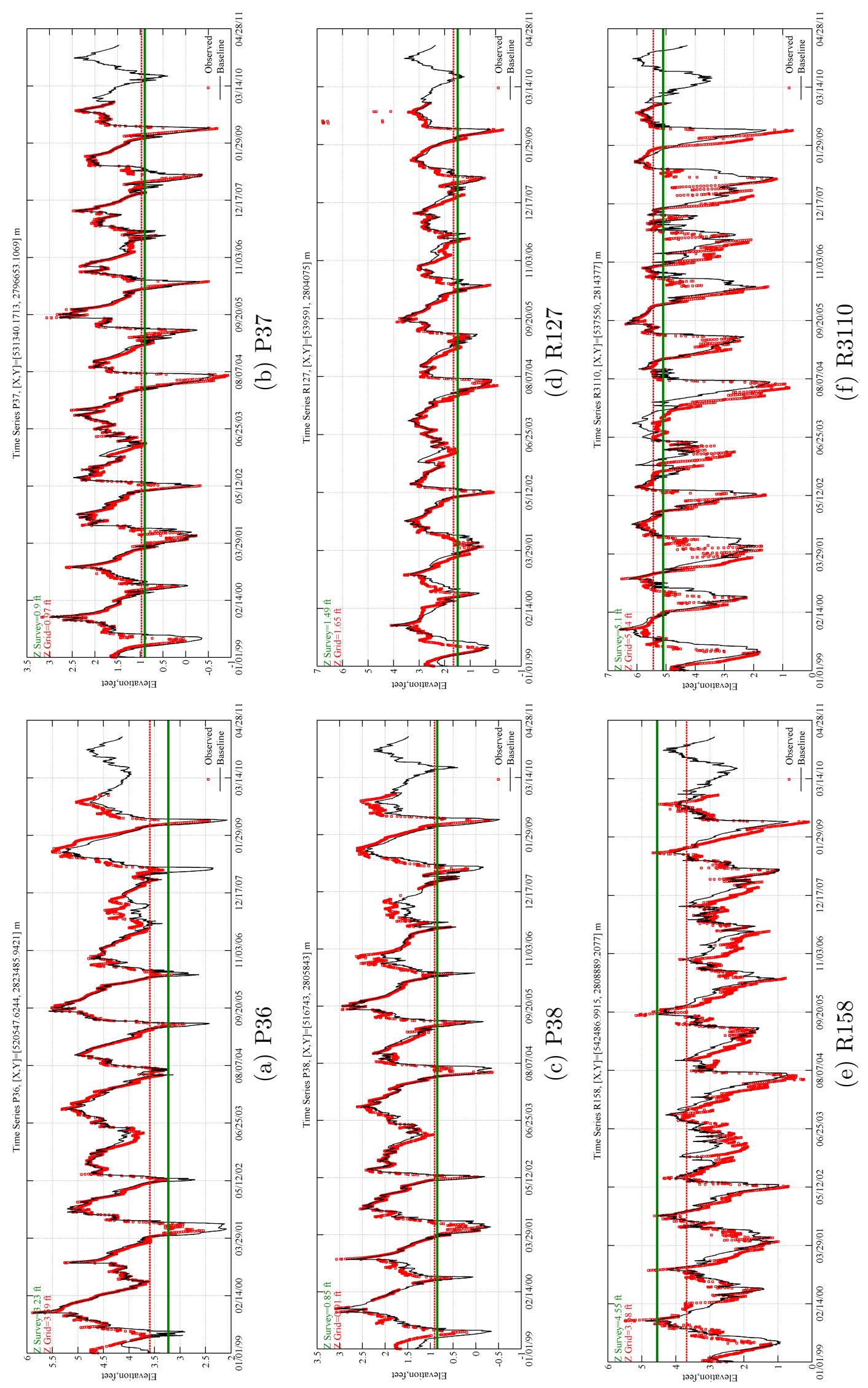

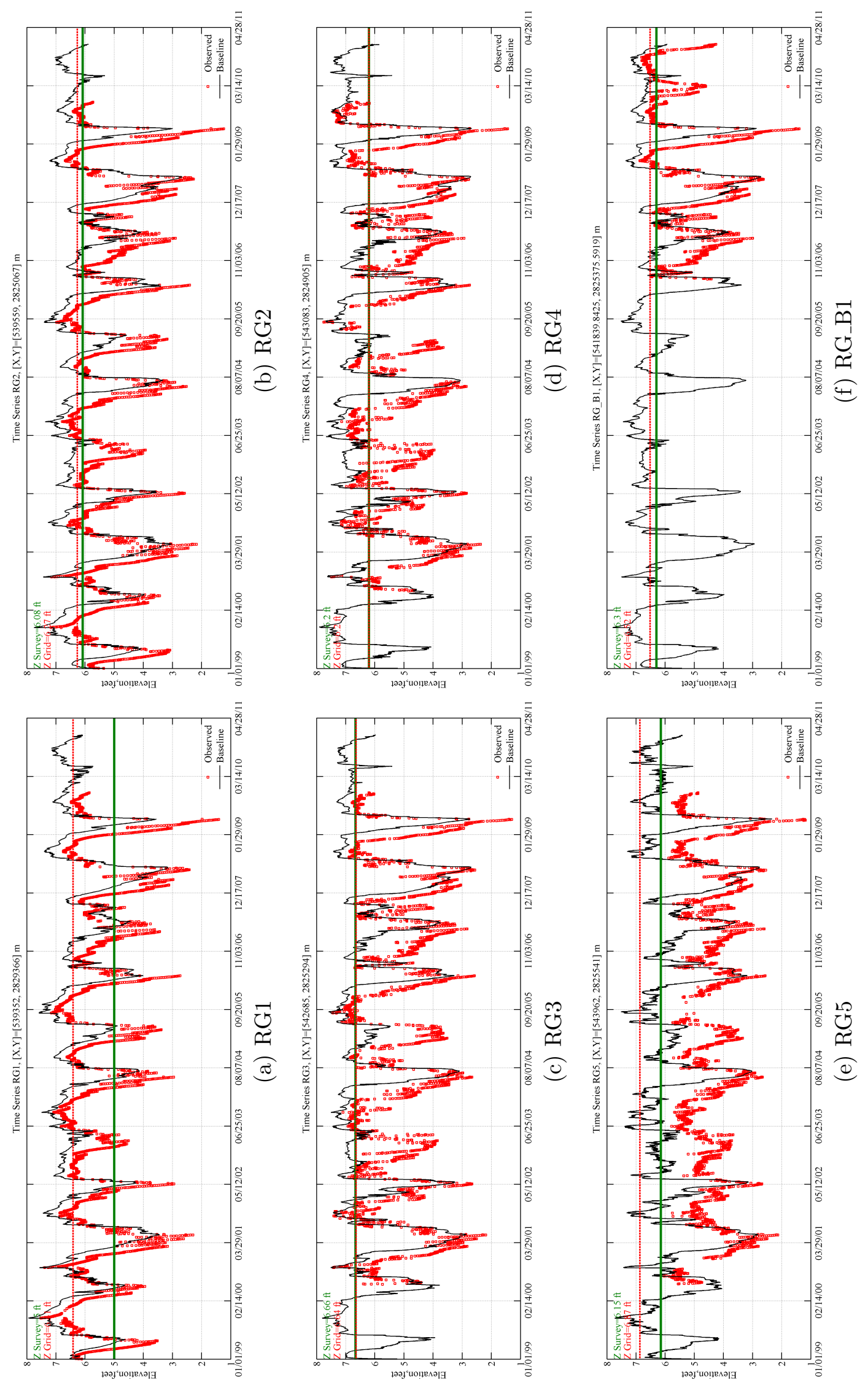

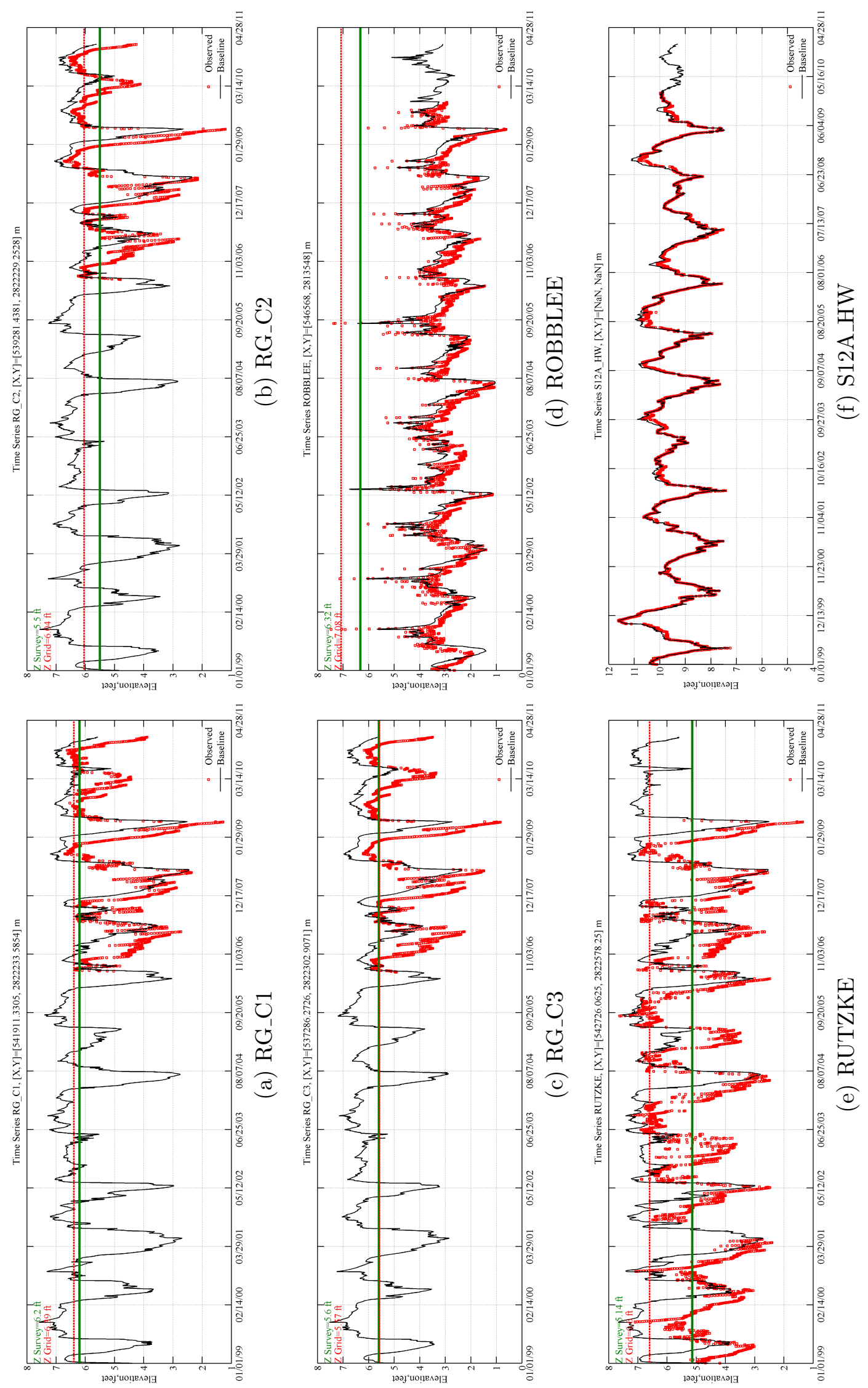

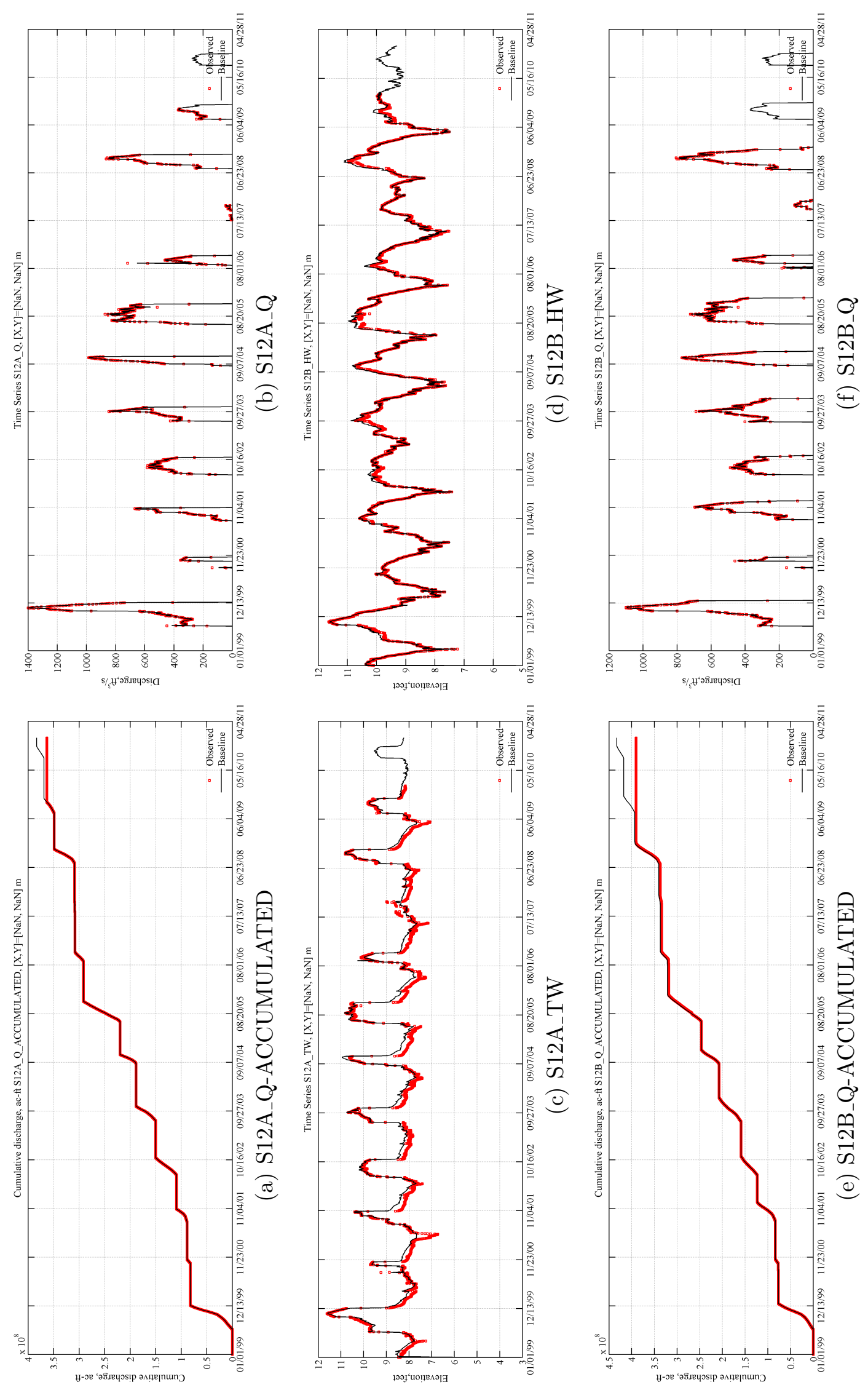

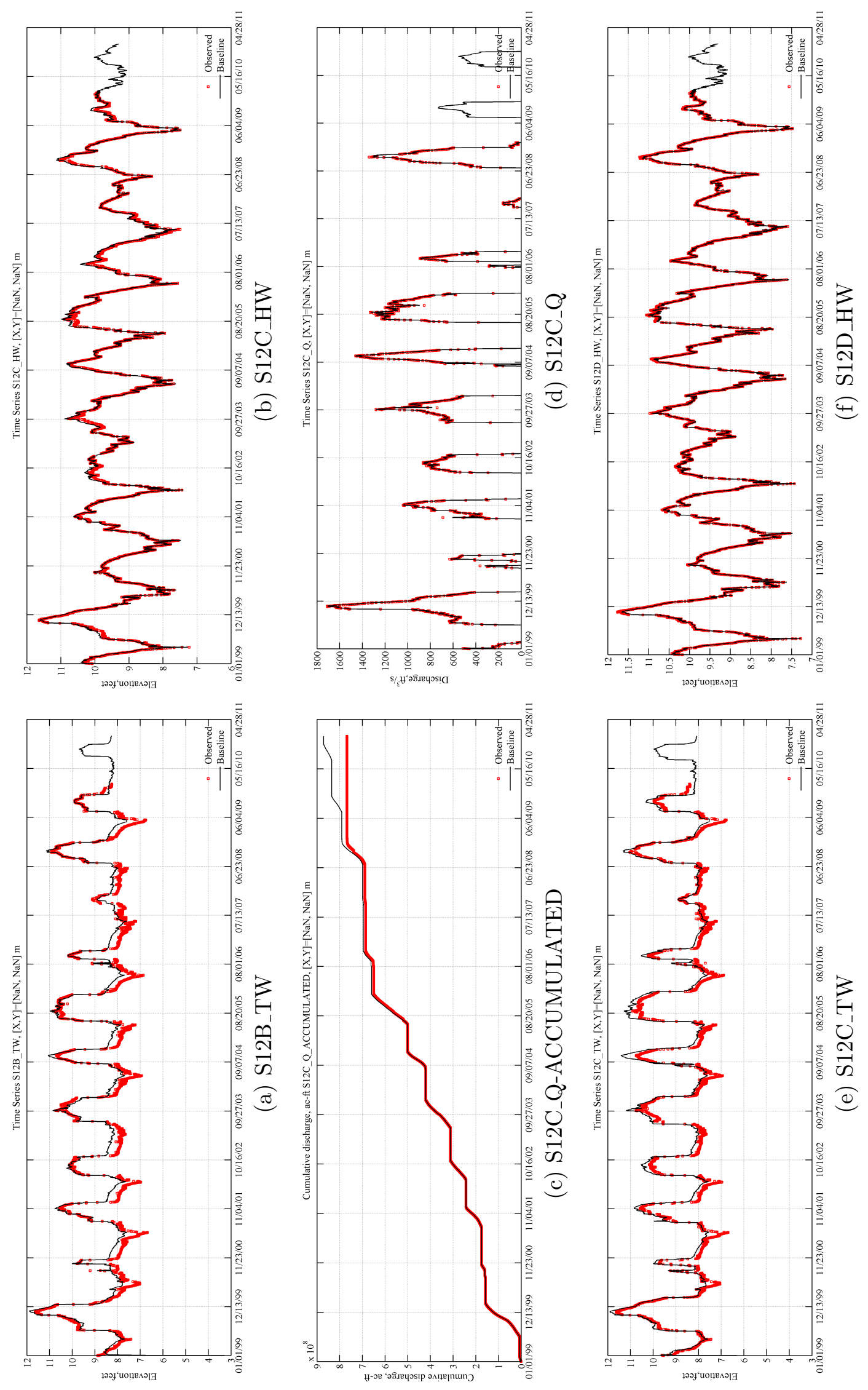

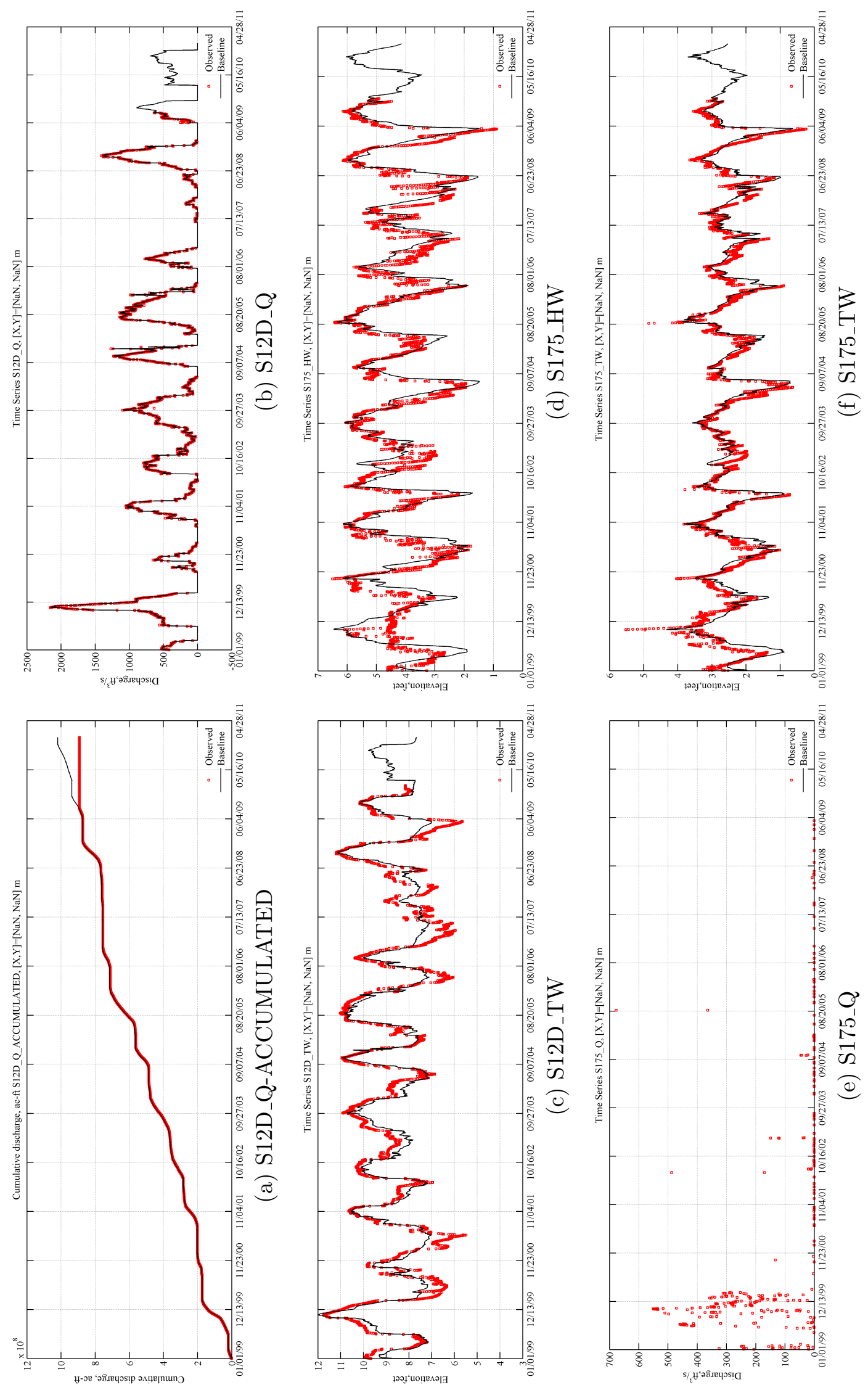

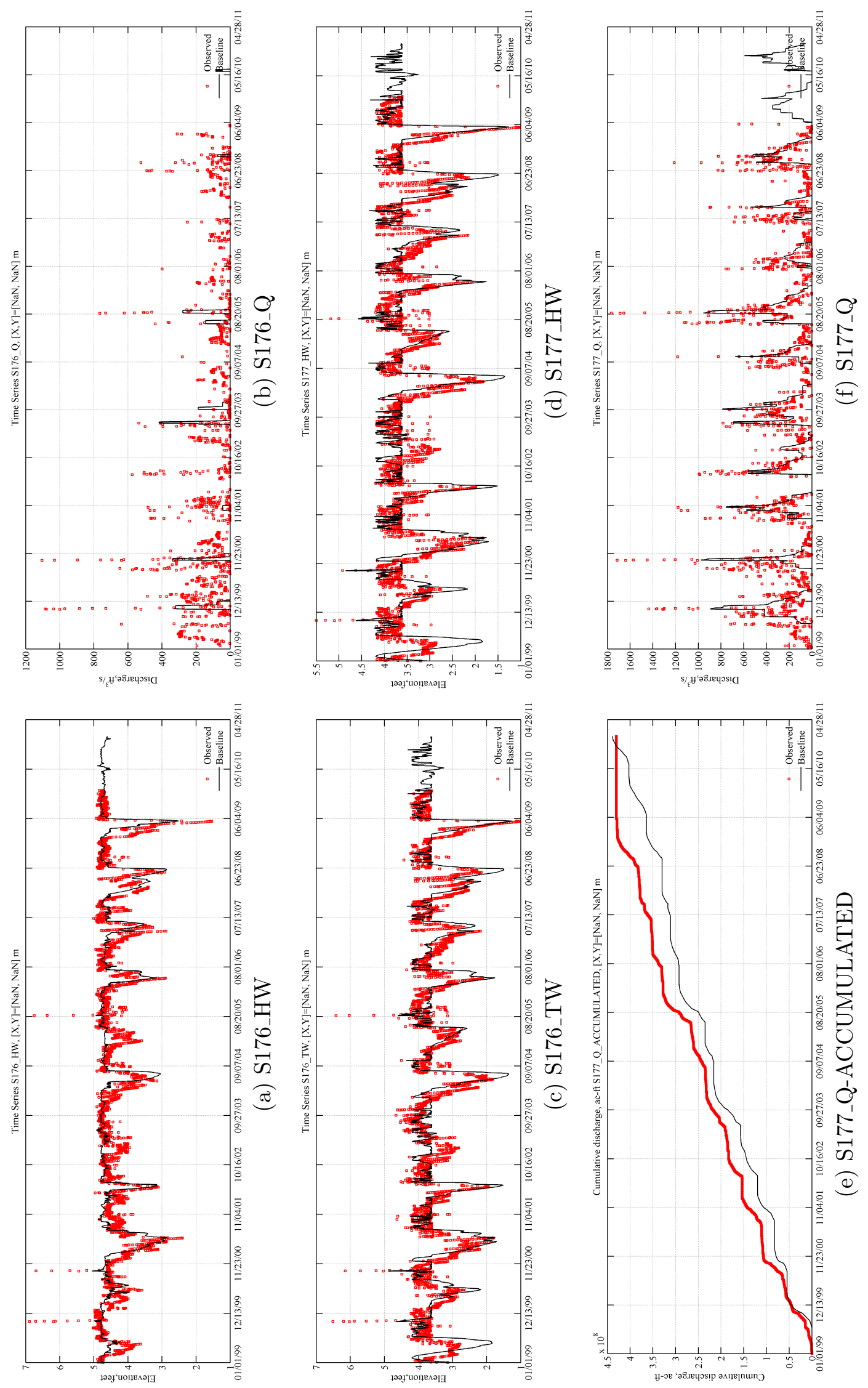

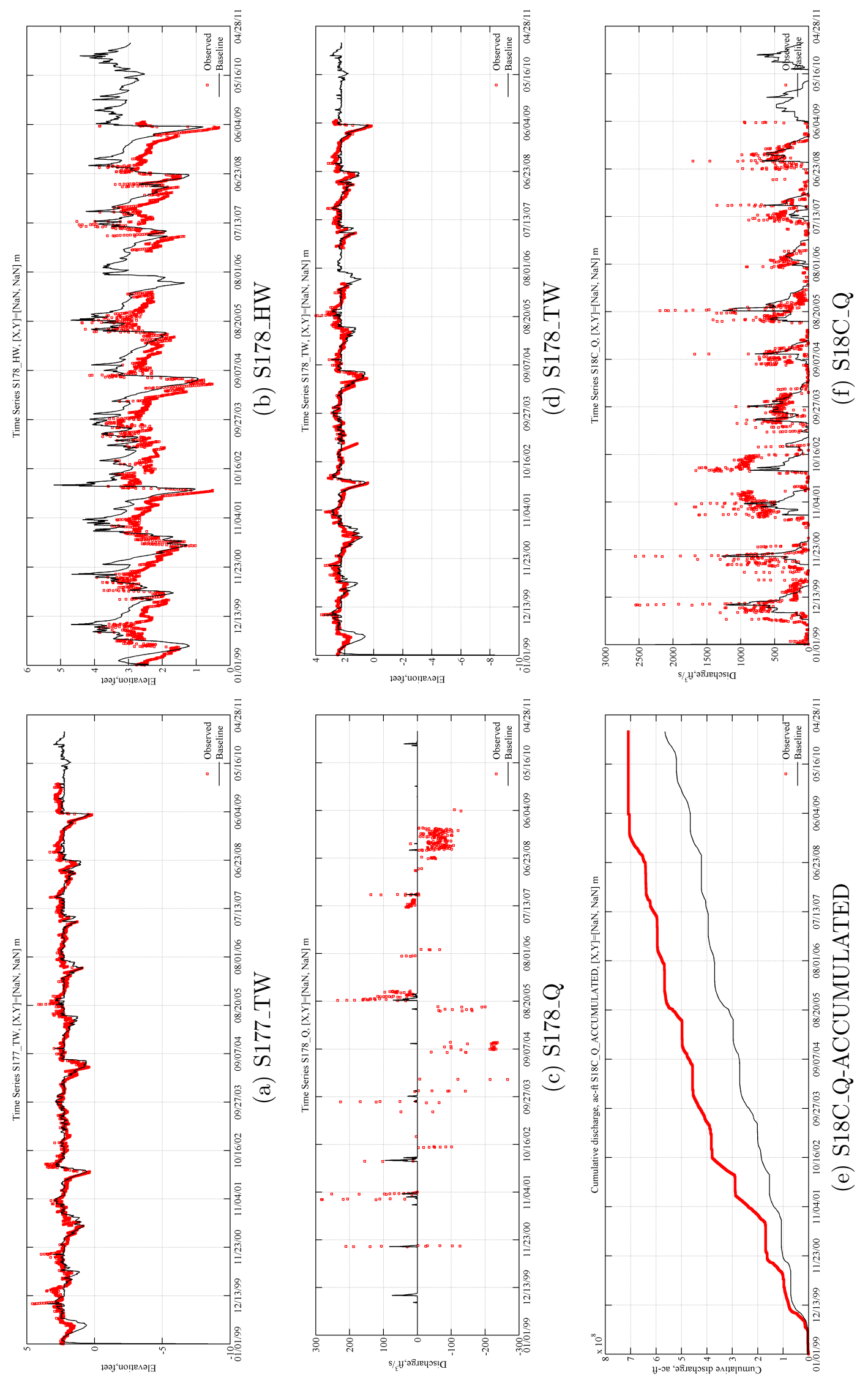

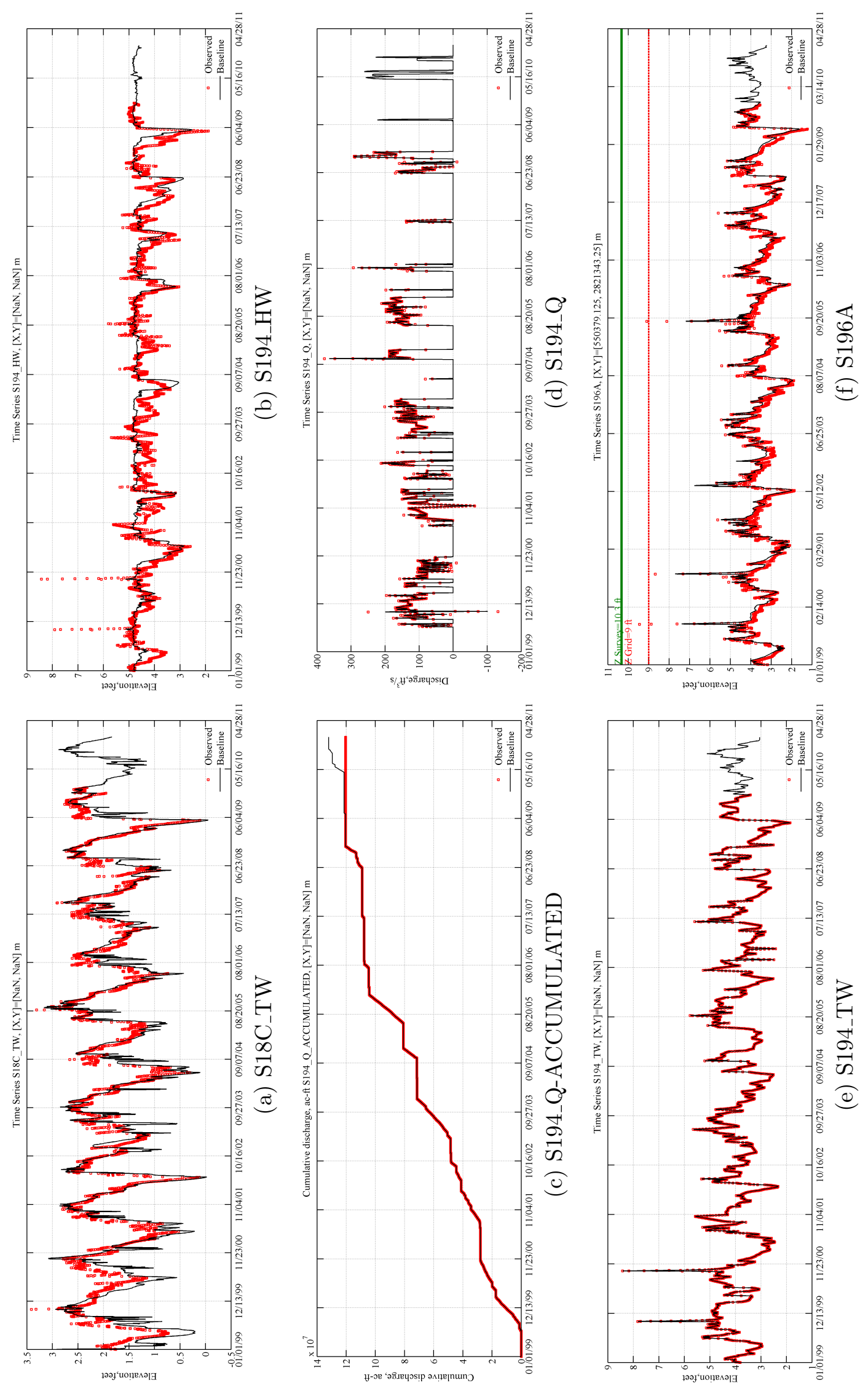

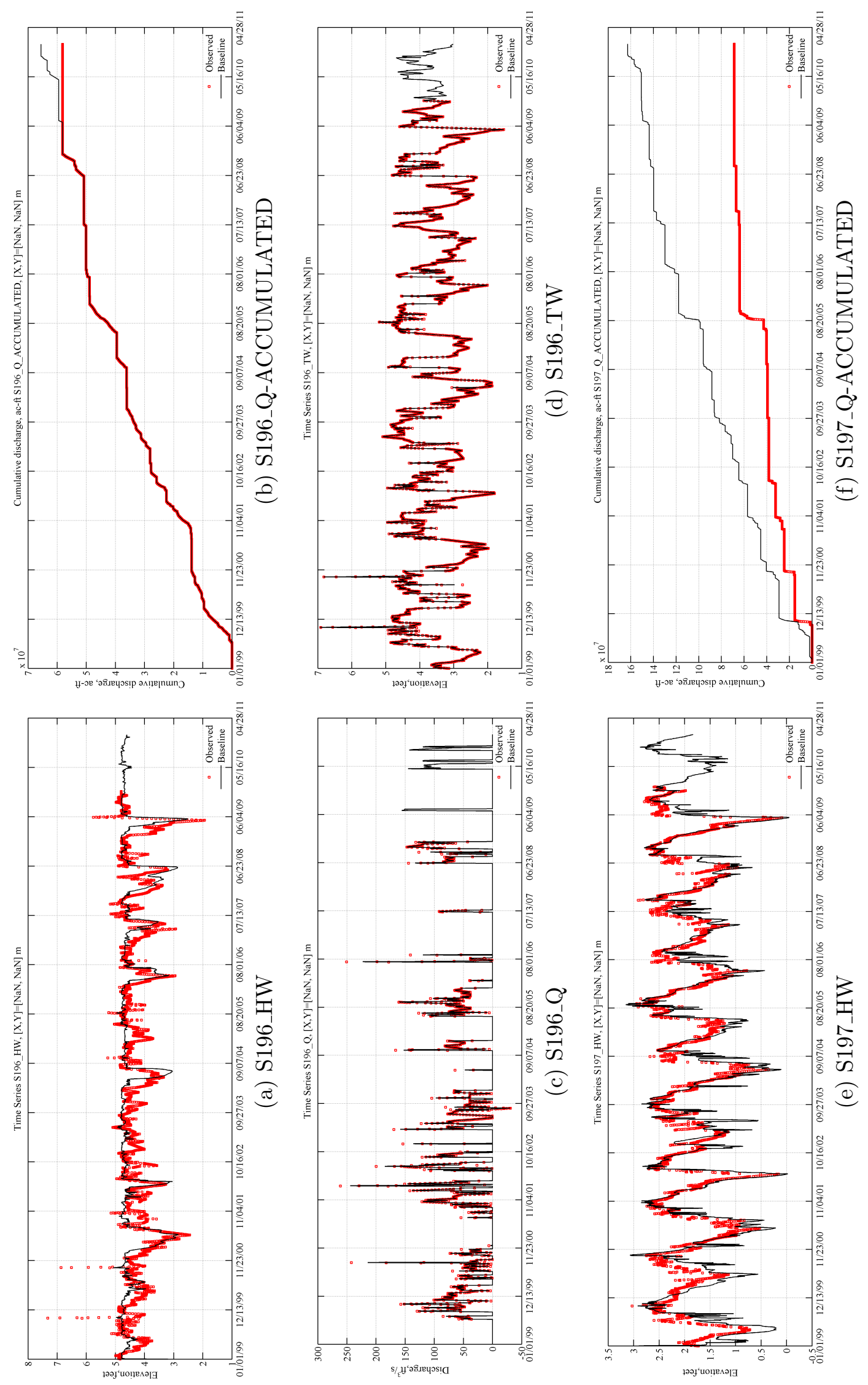

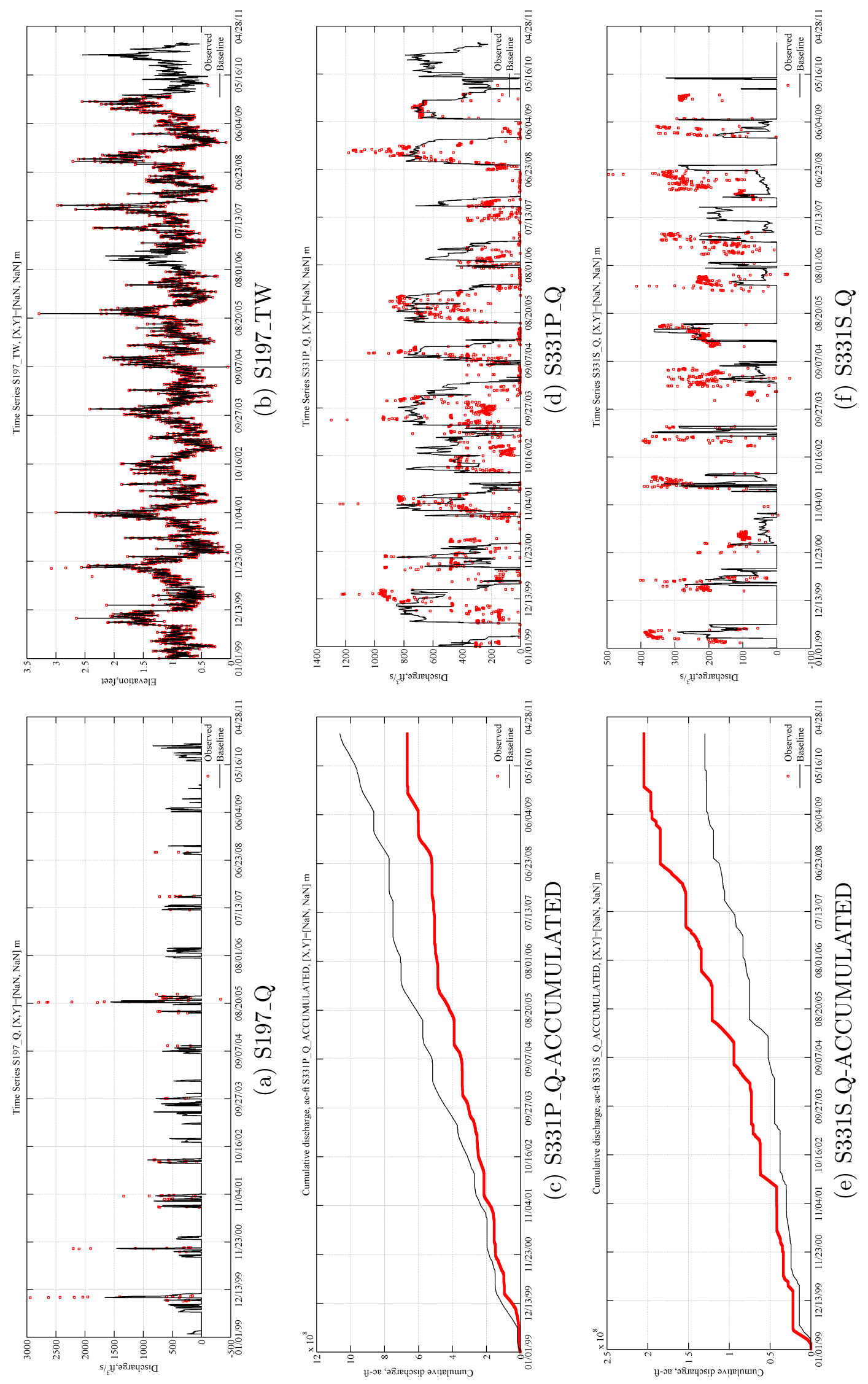

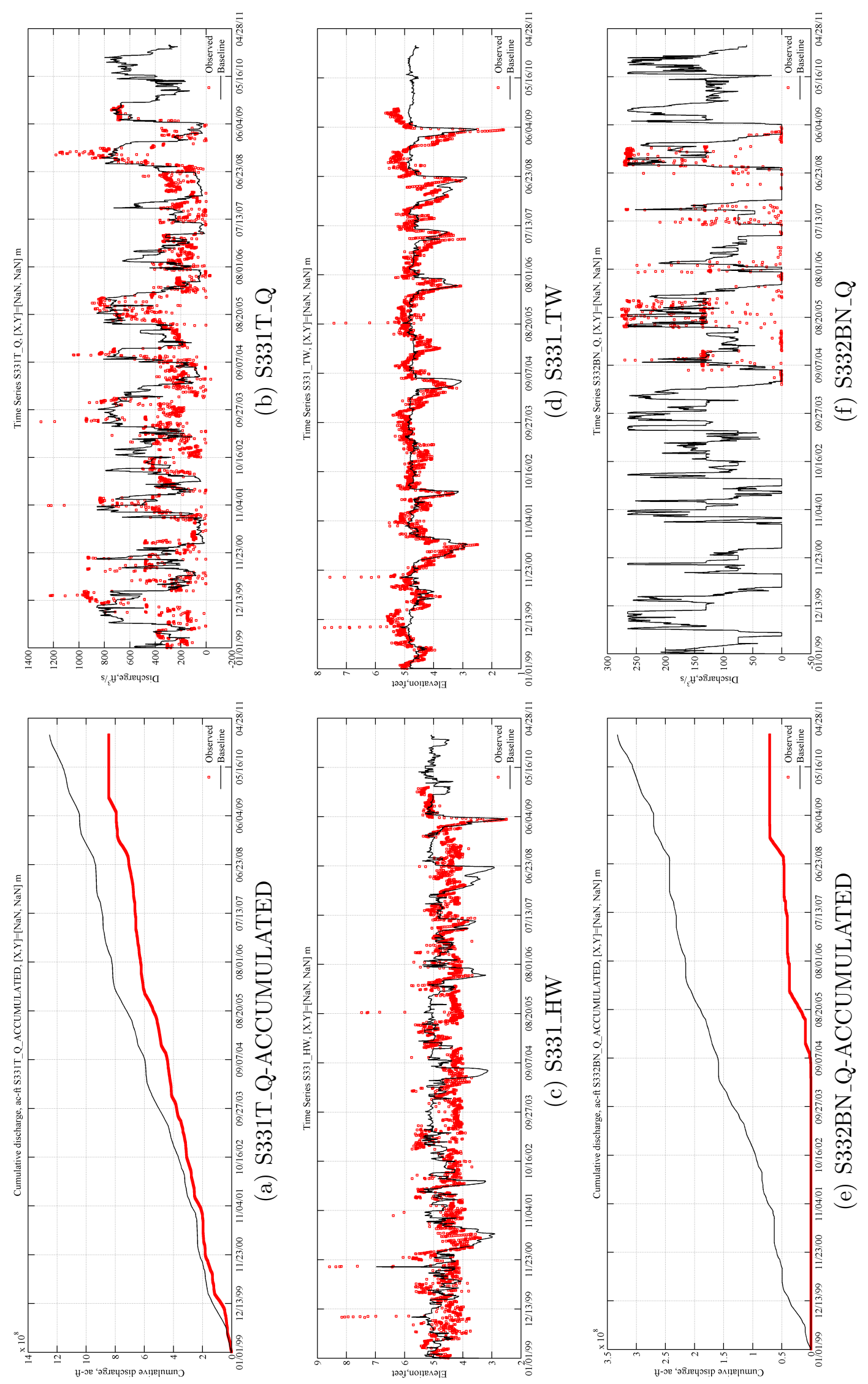

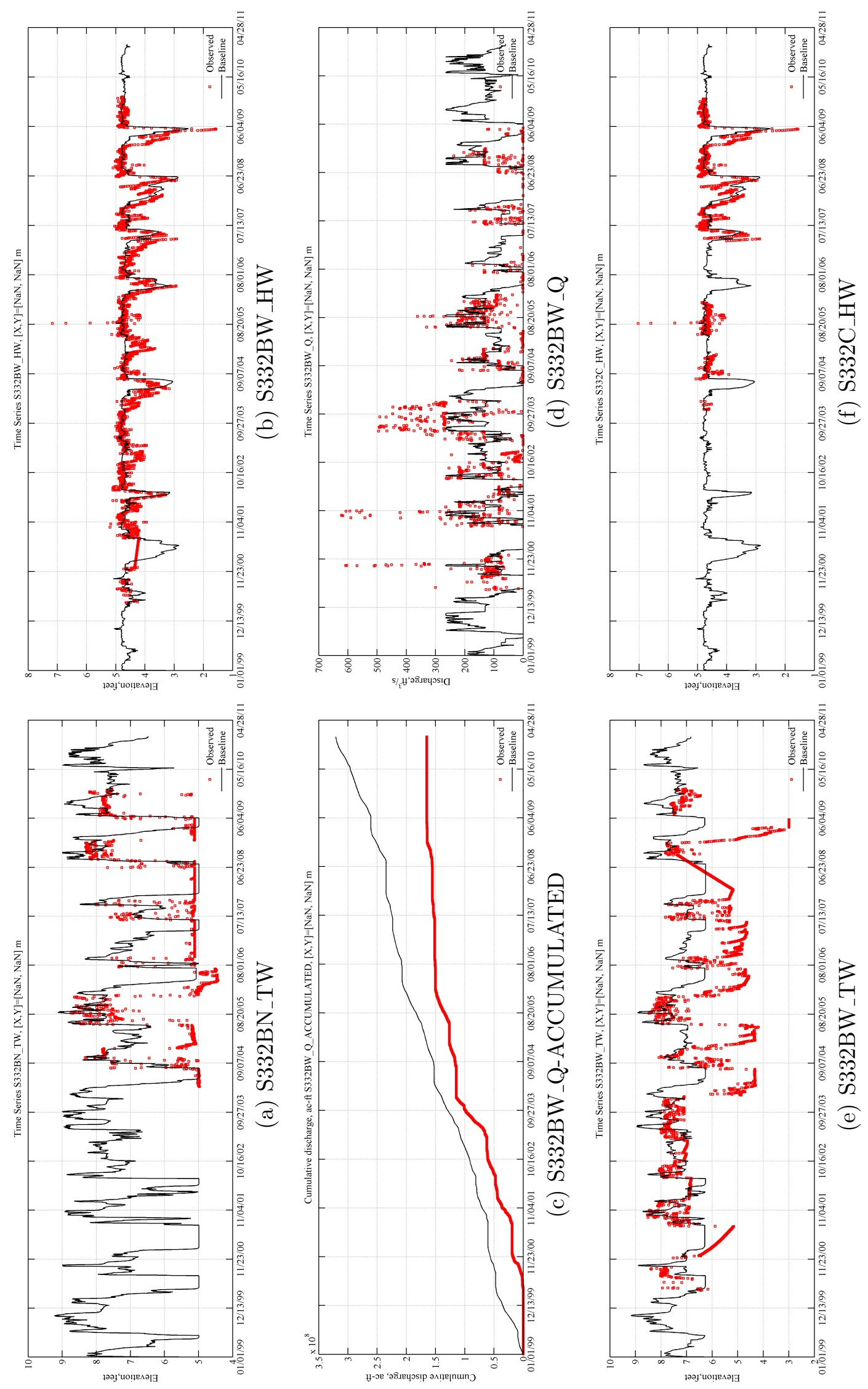

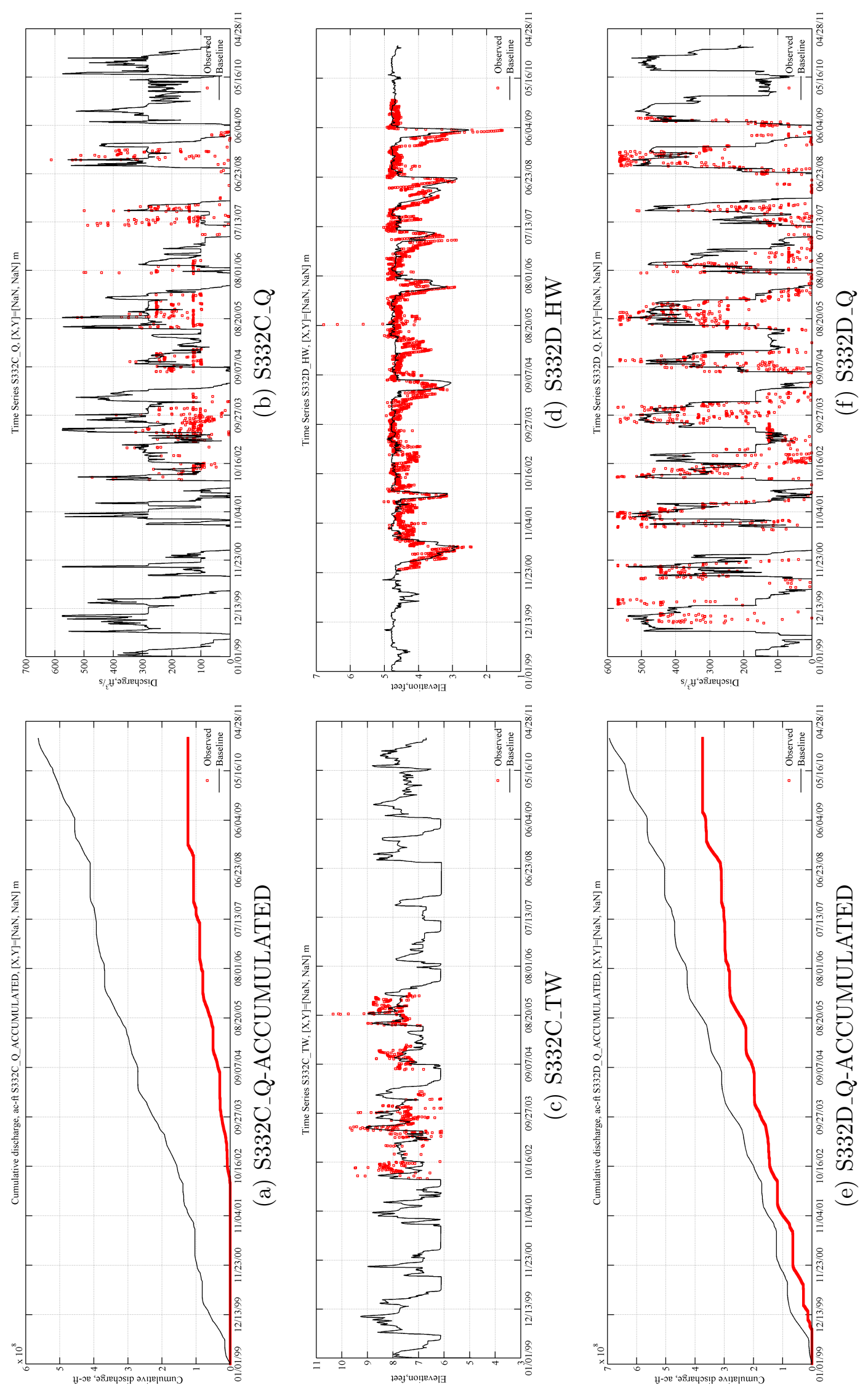

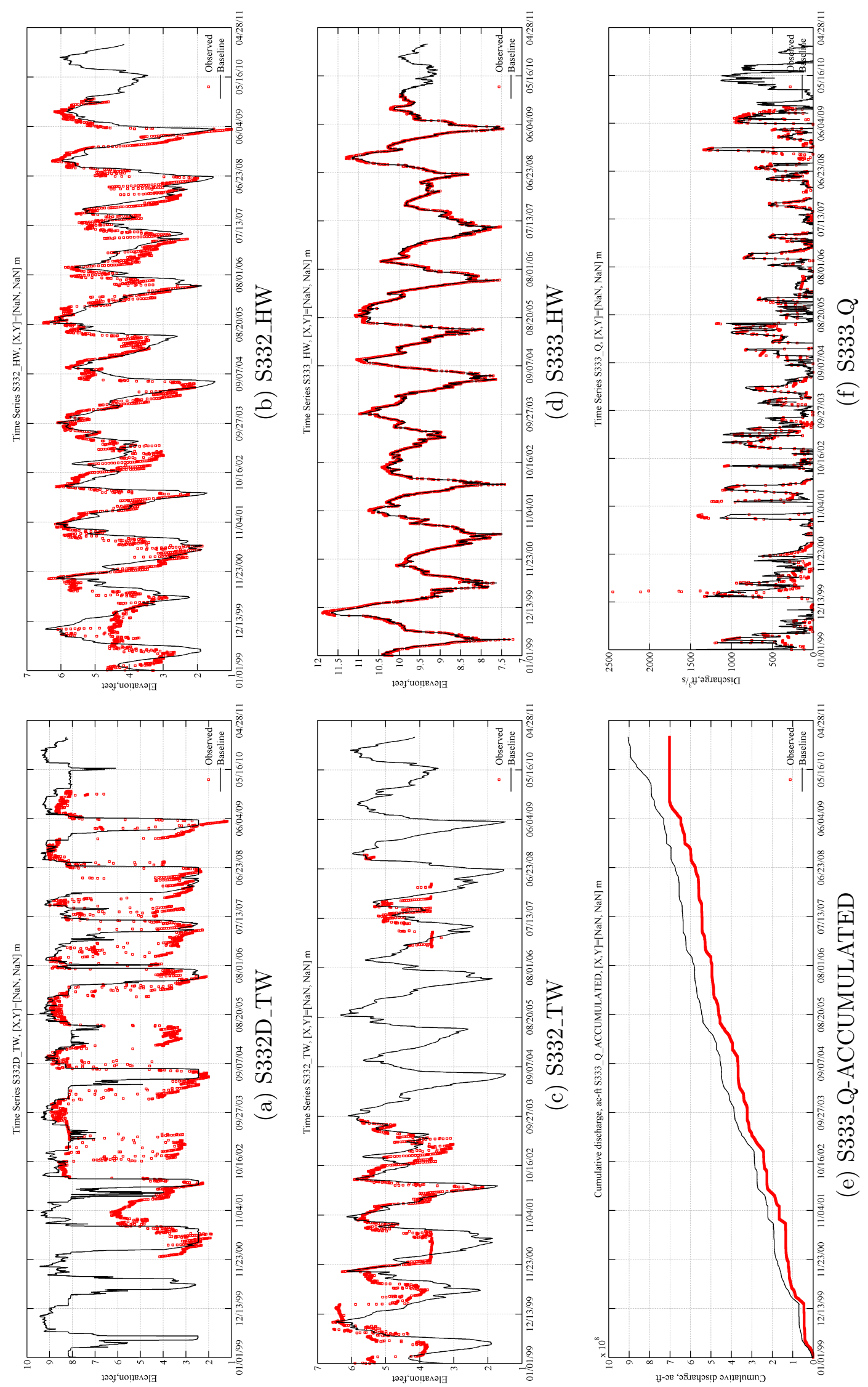

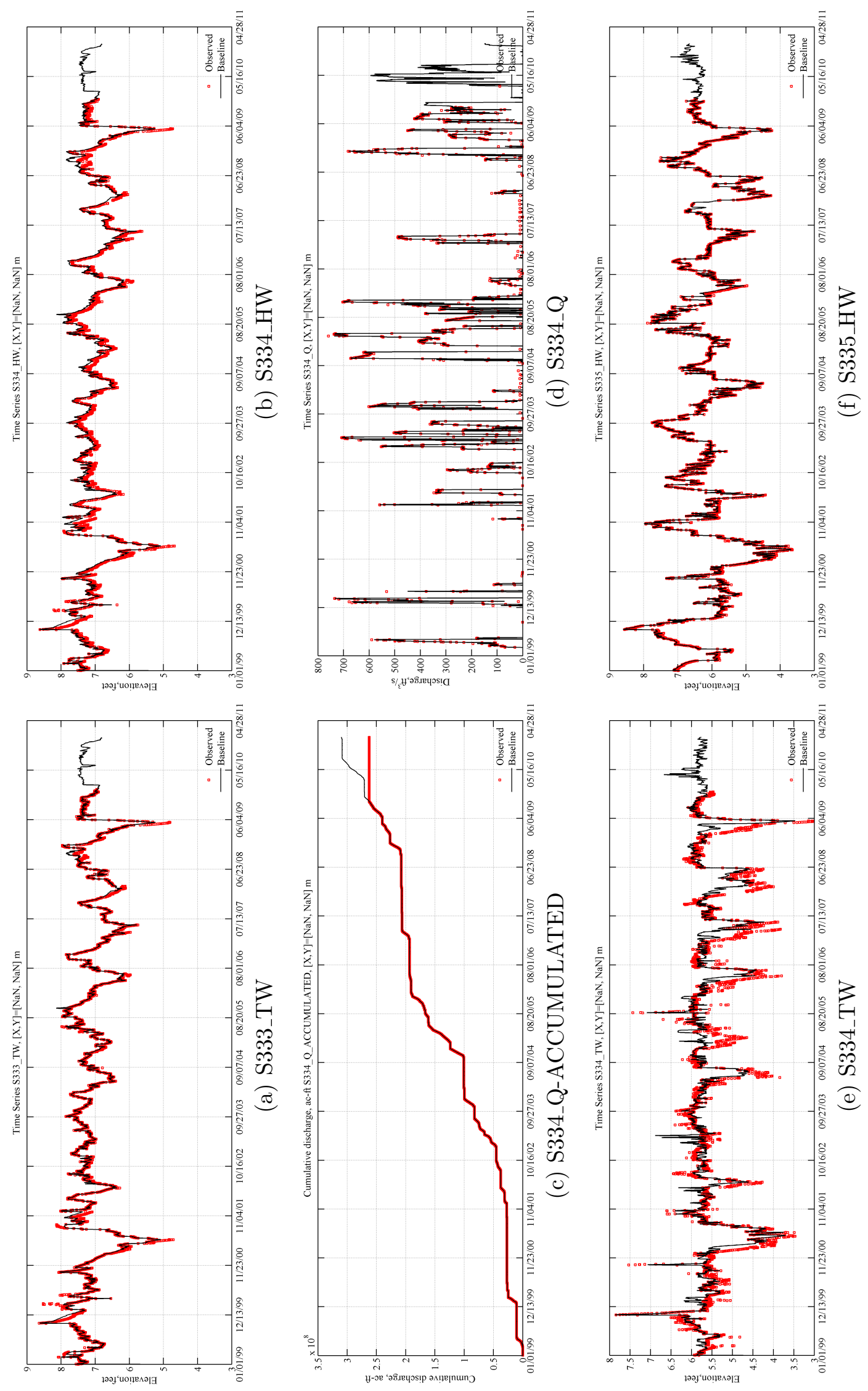

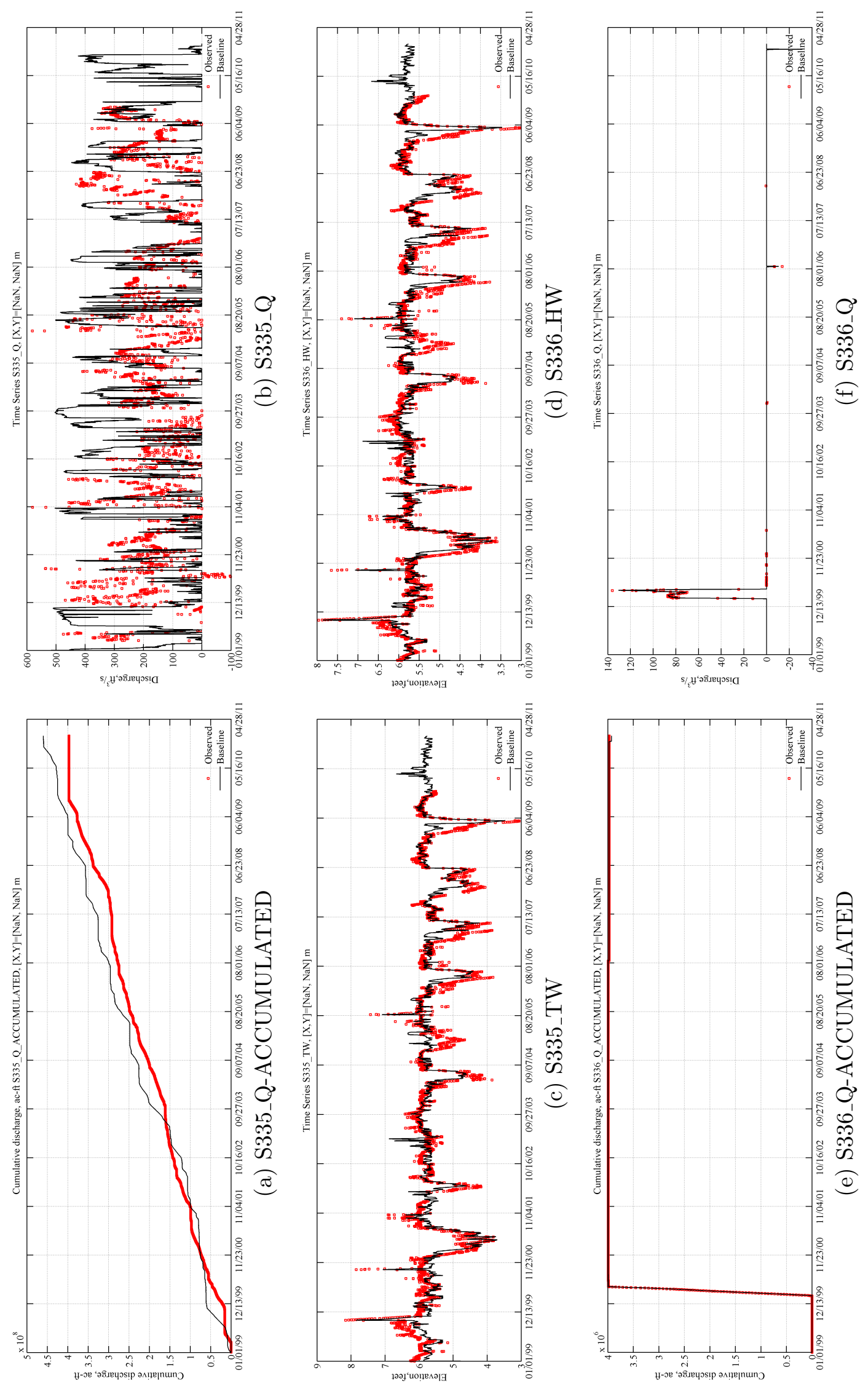

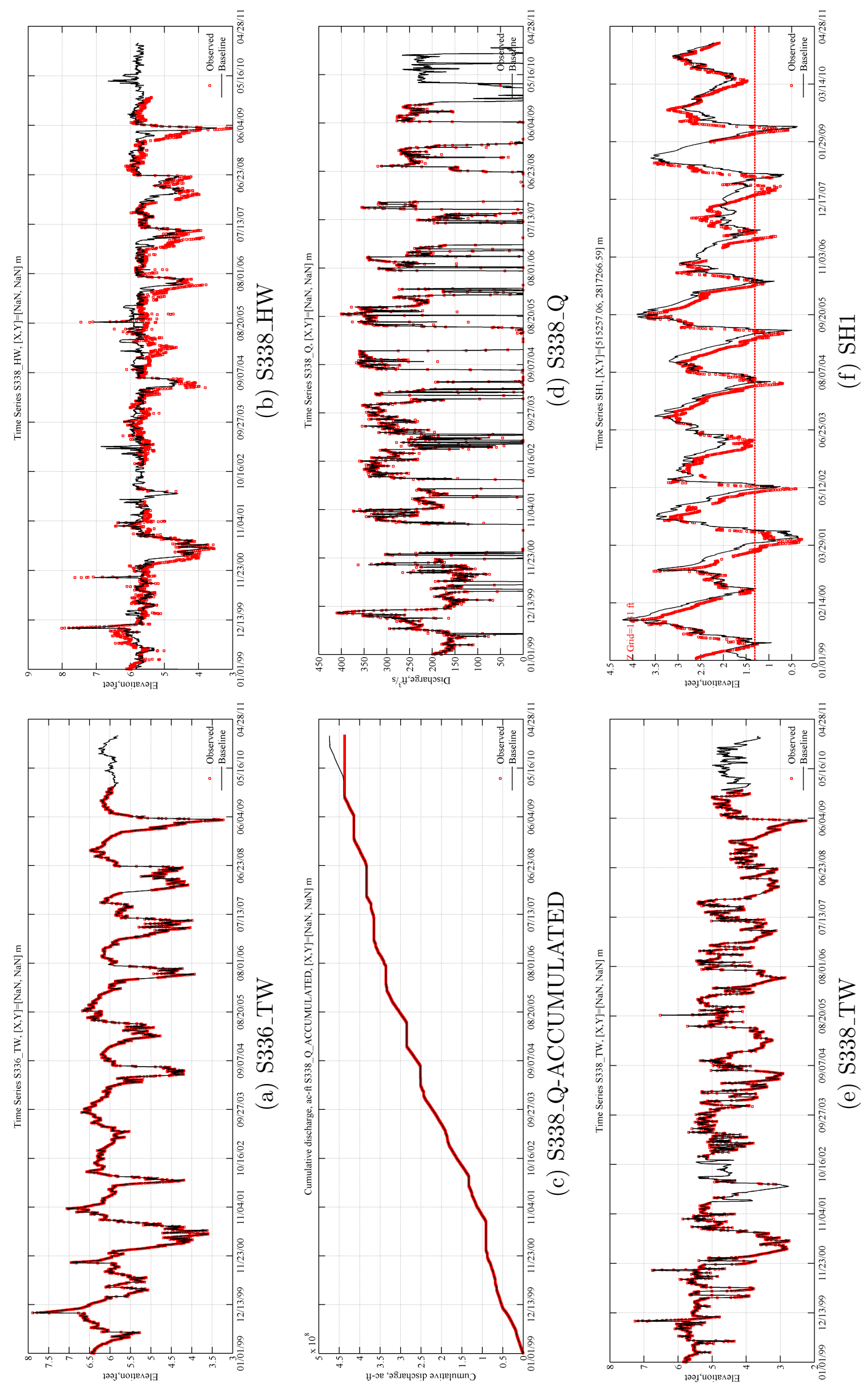

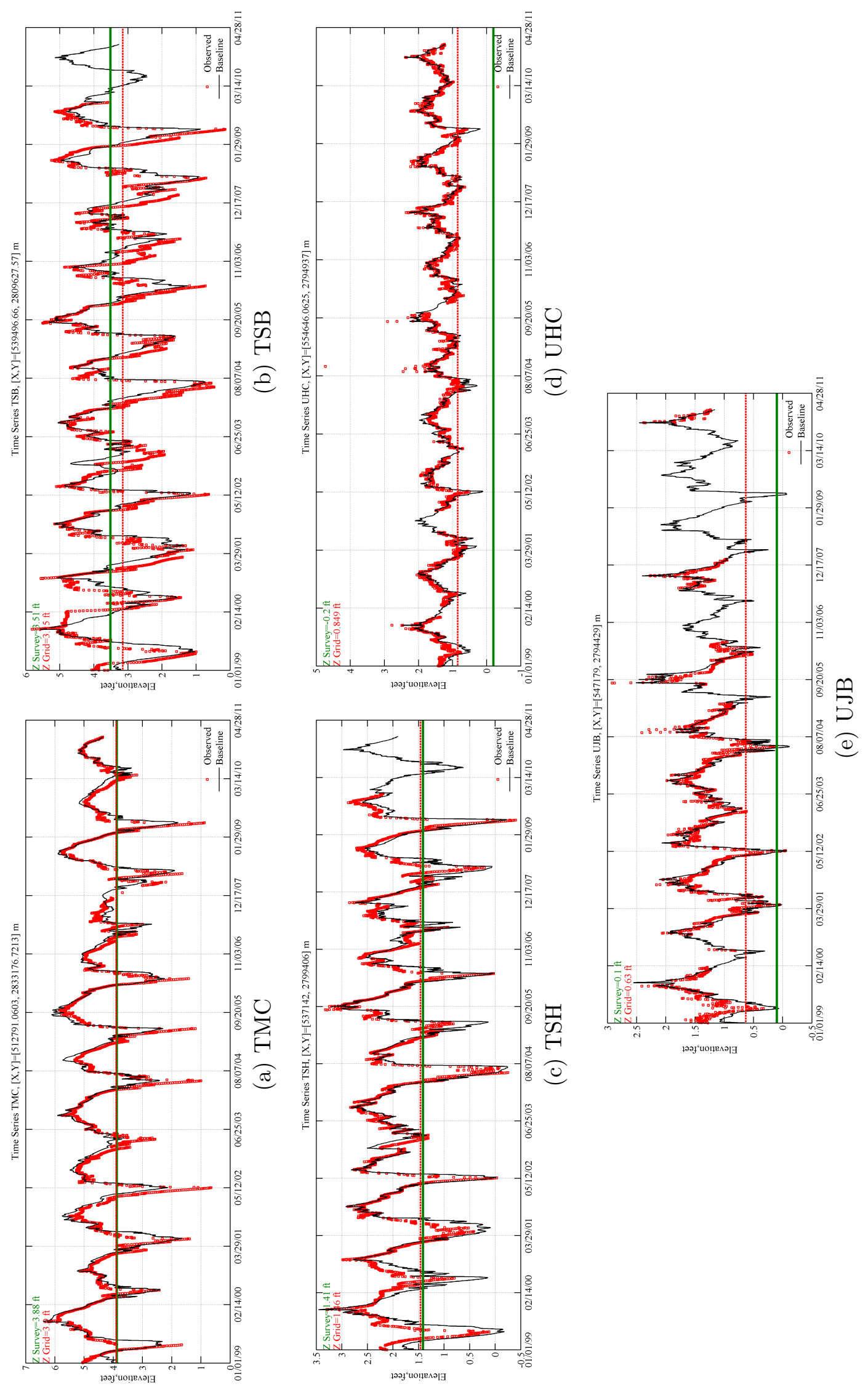

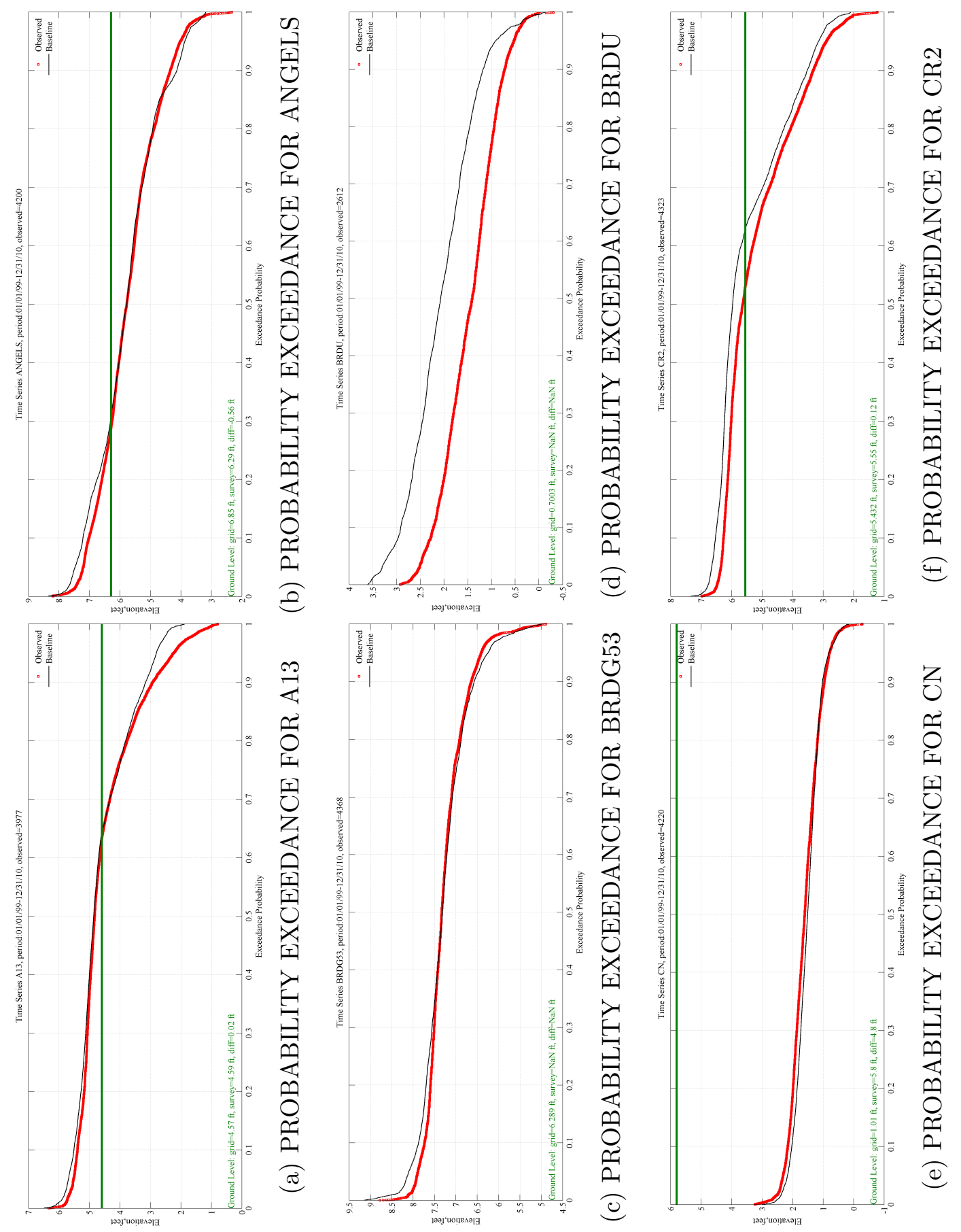

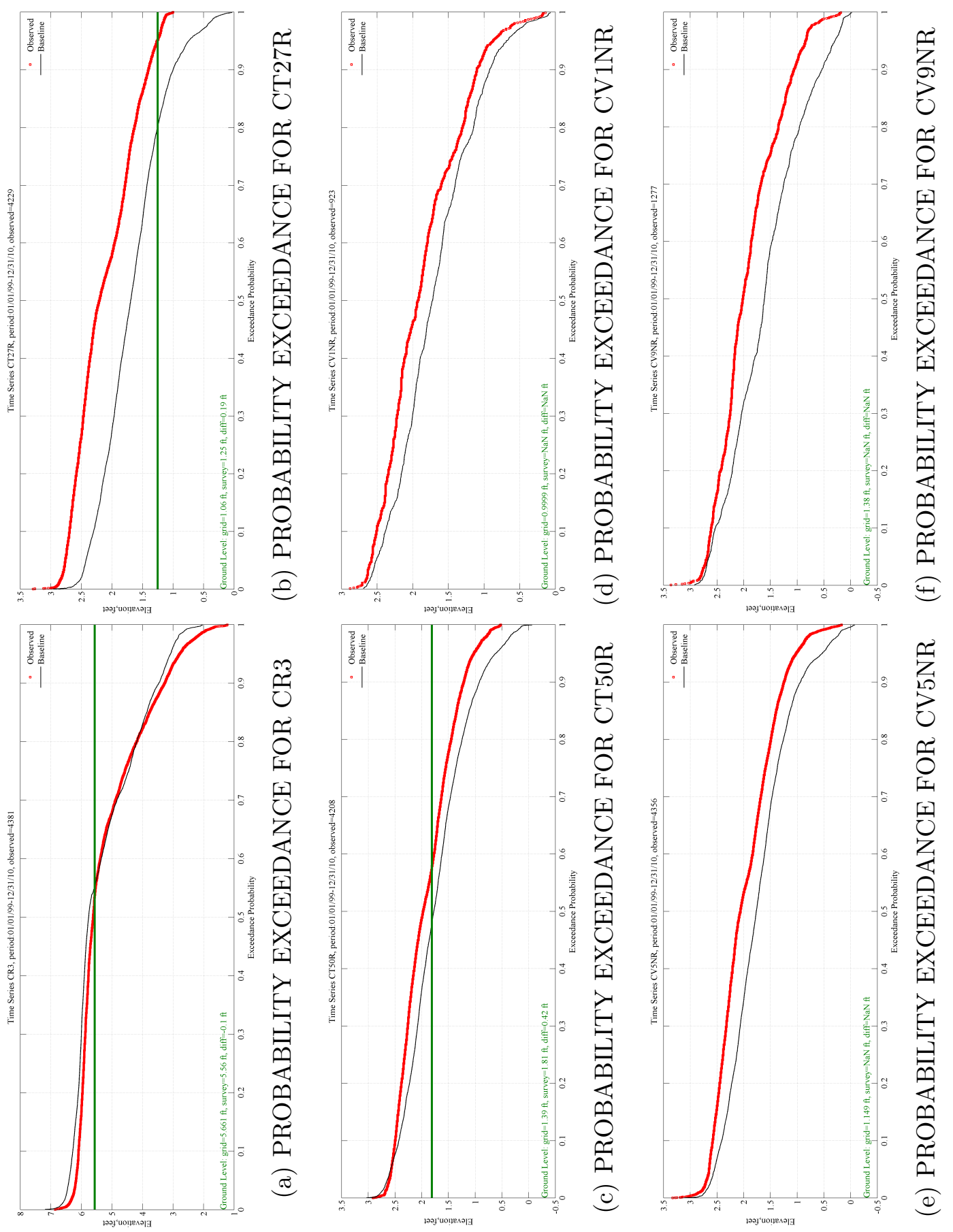

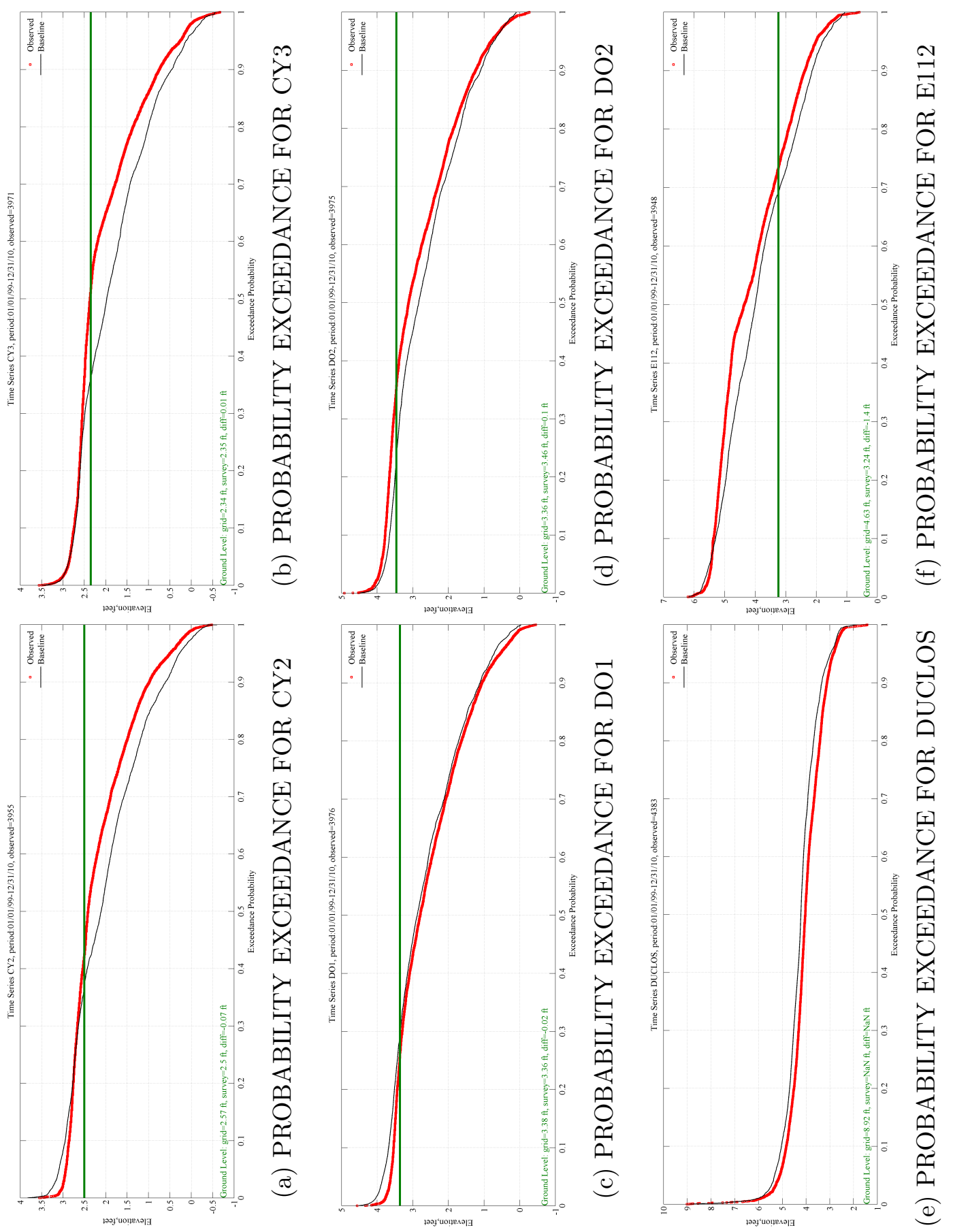

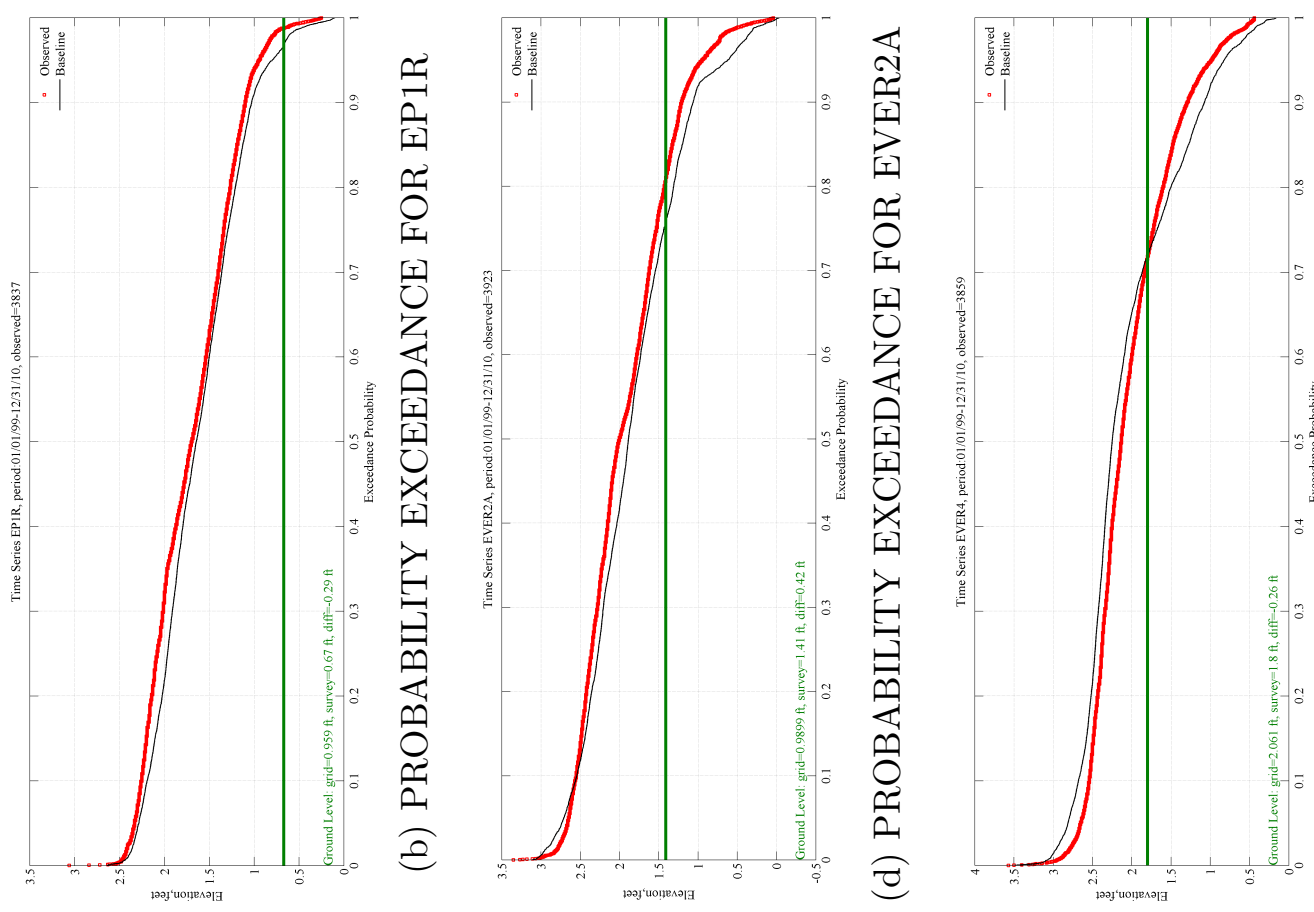

至
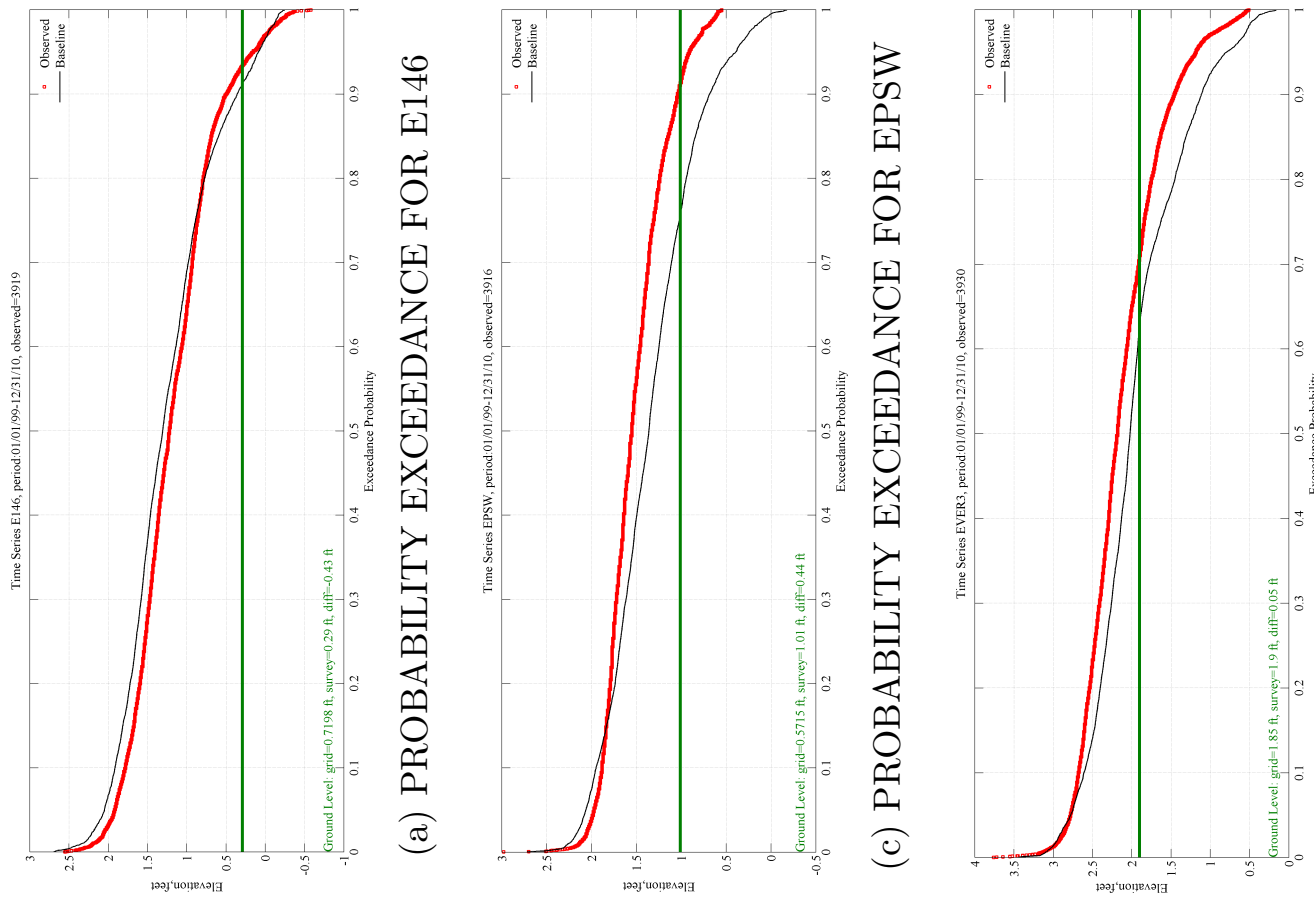

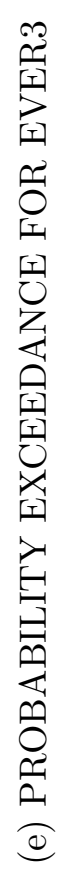




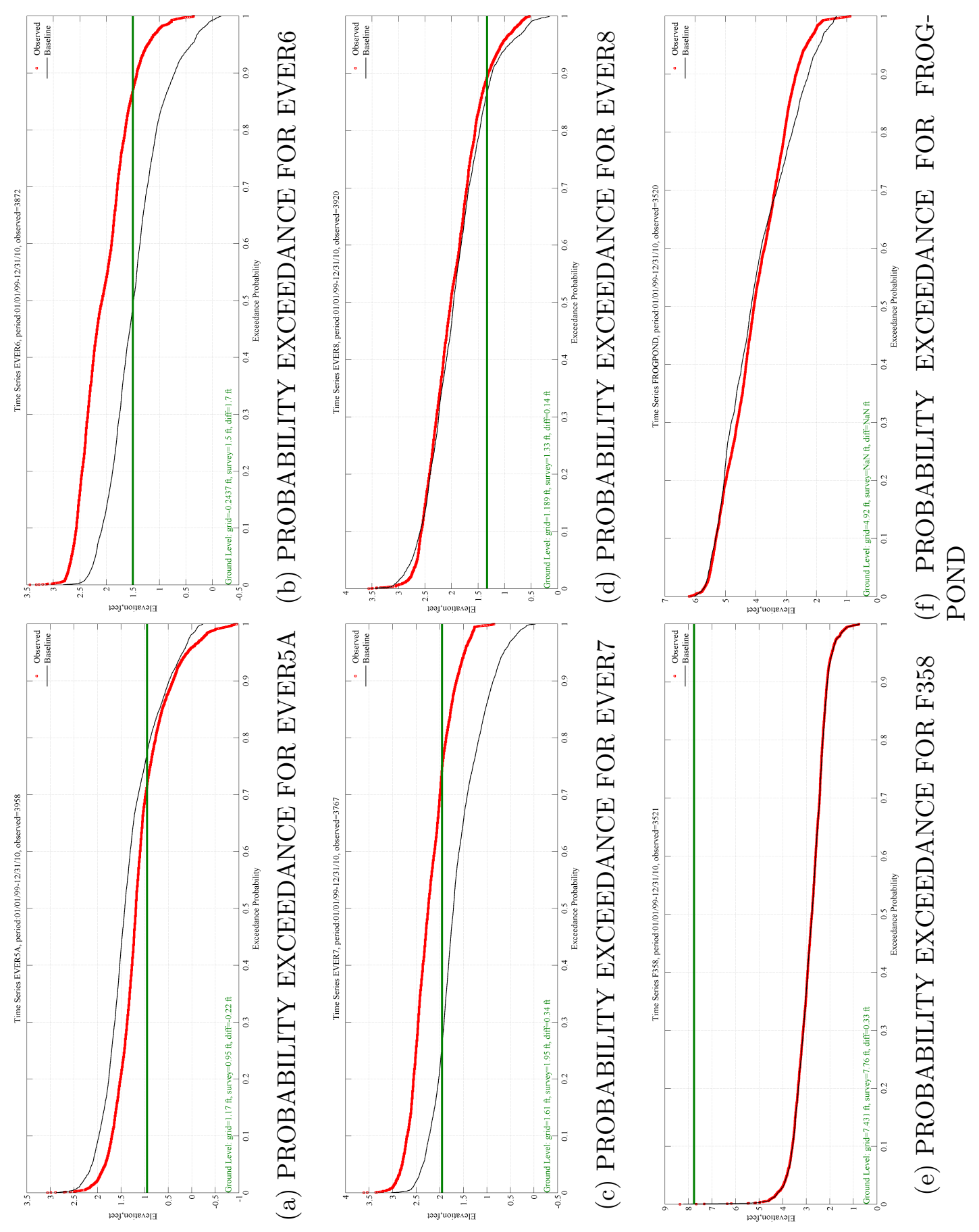




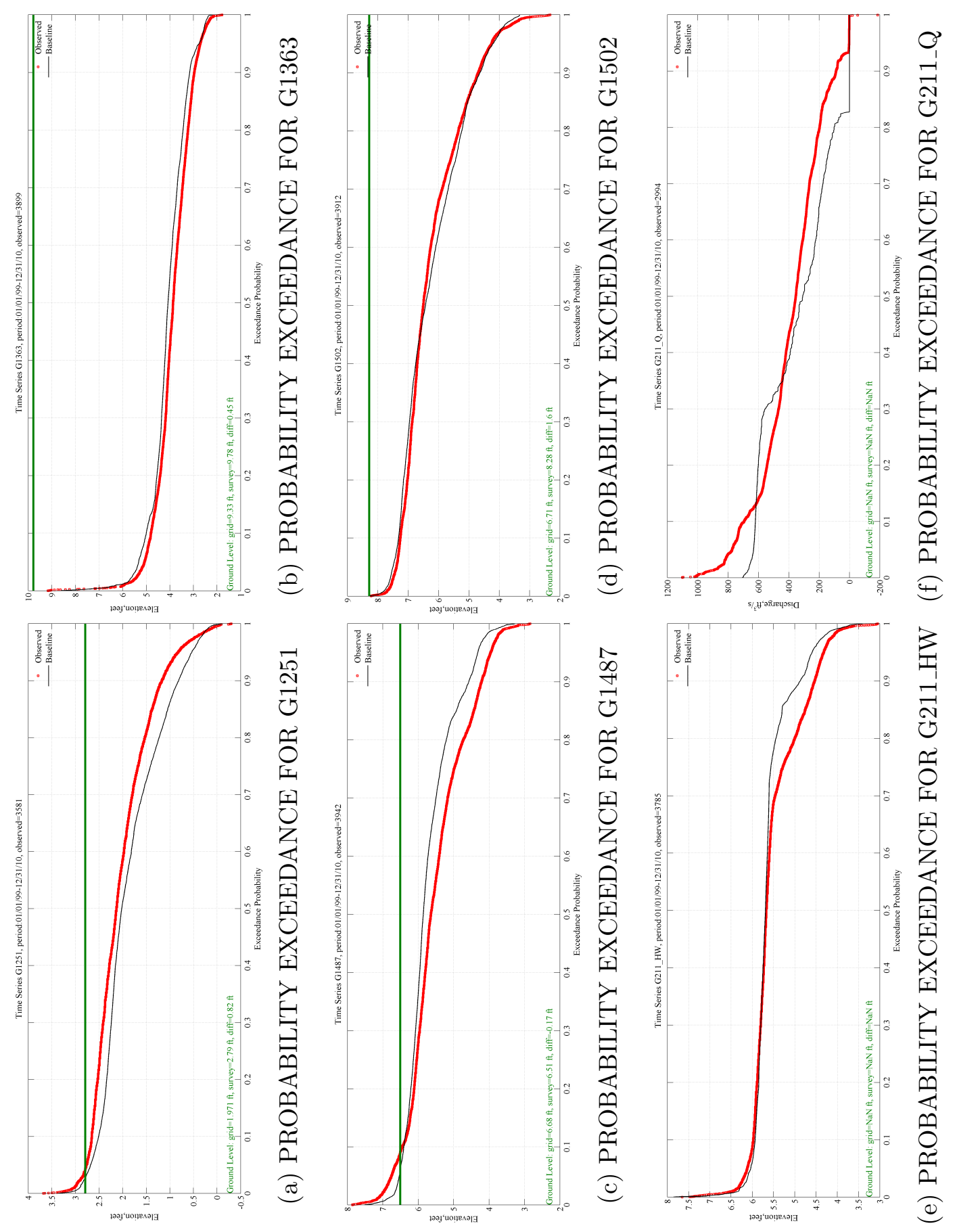



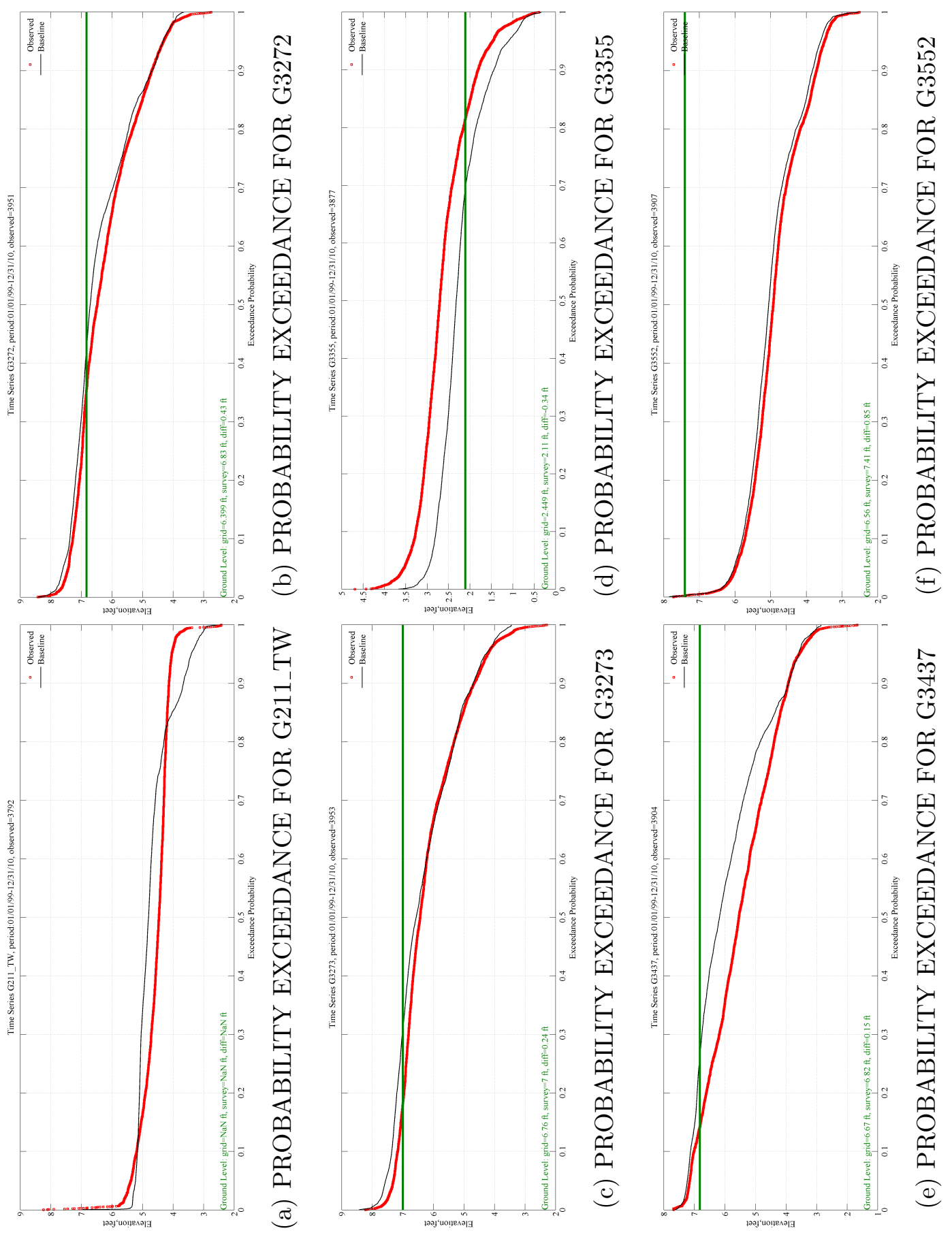

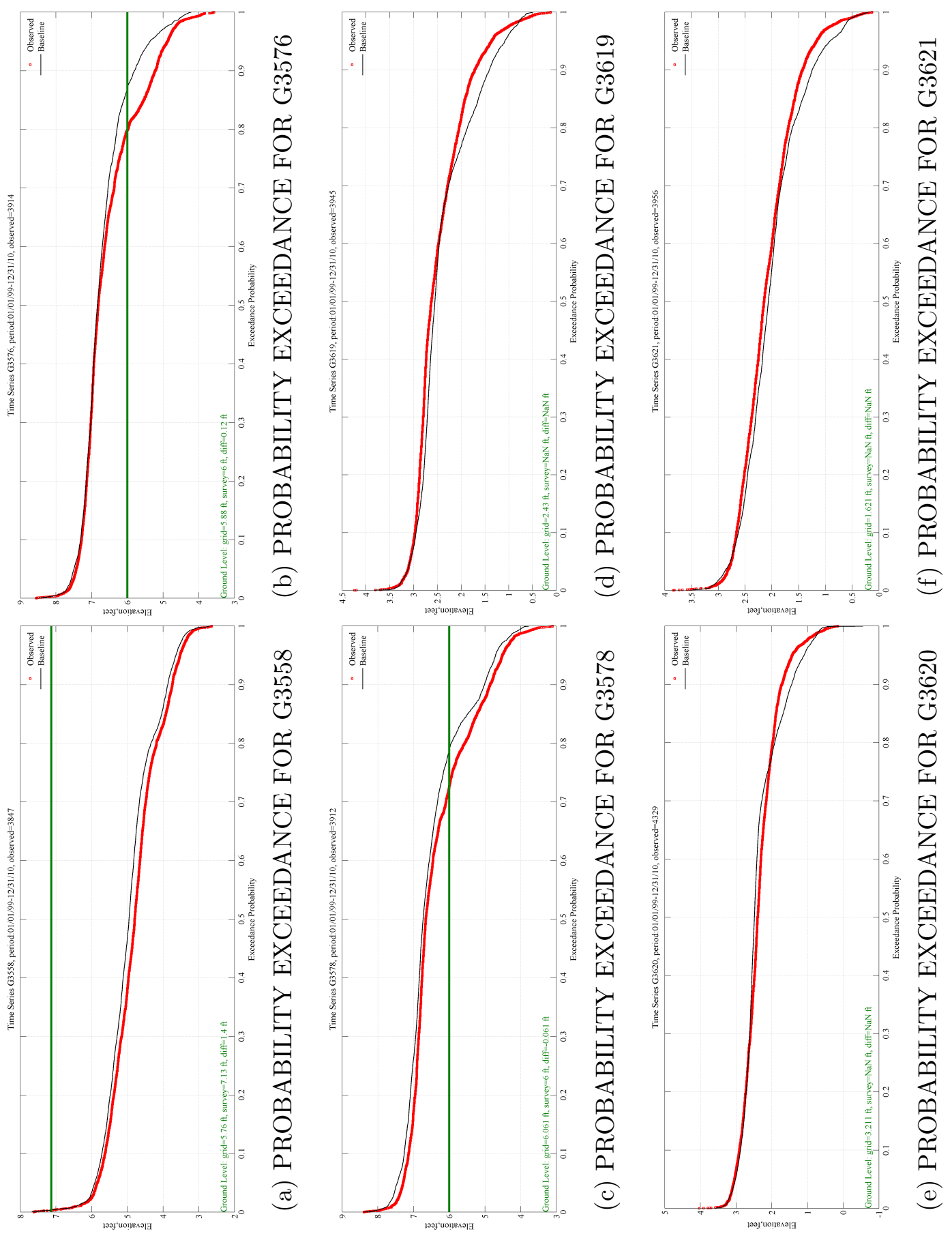

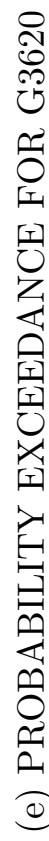



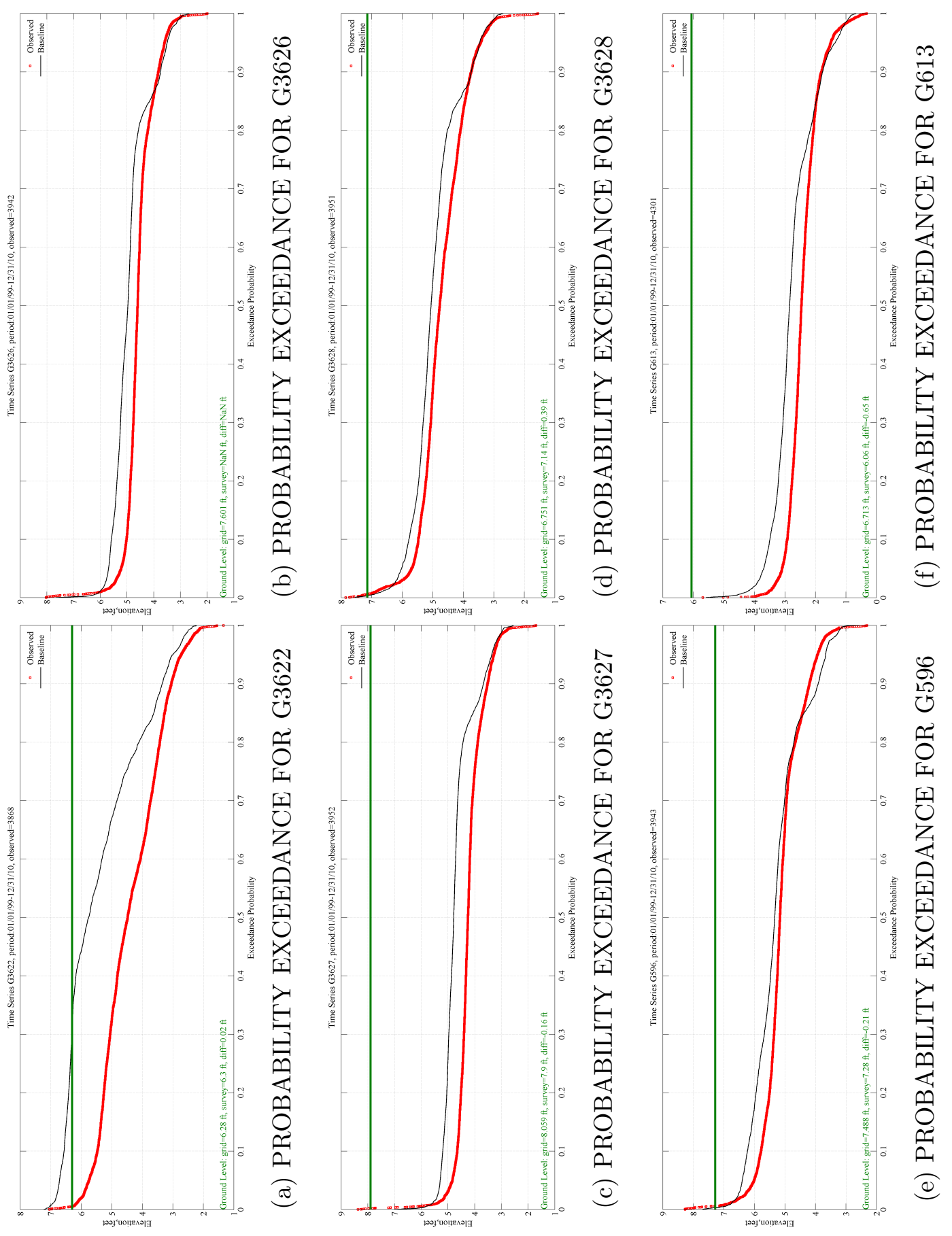

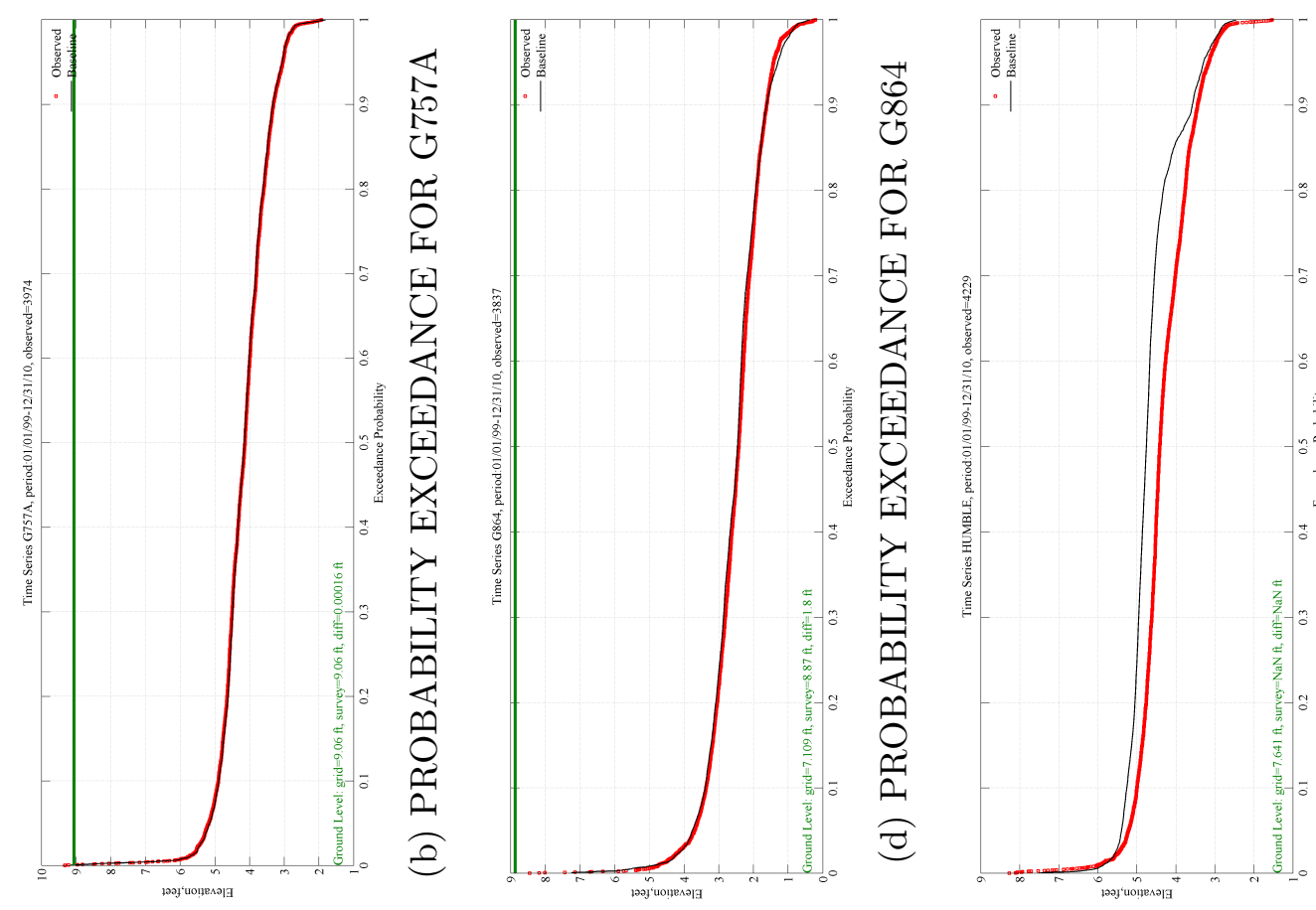


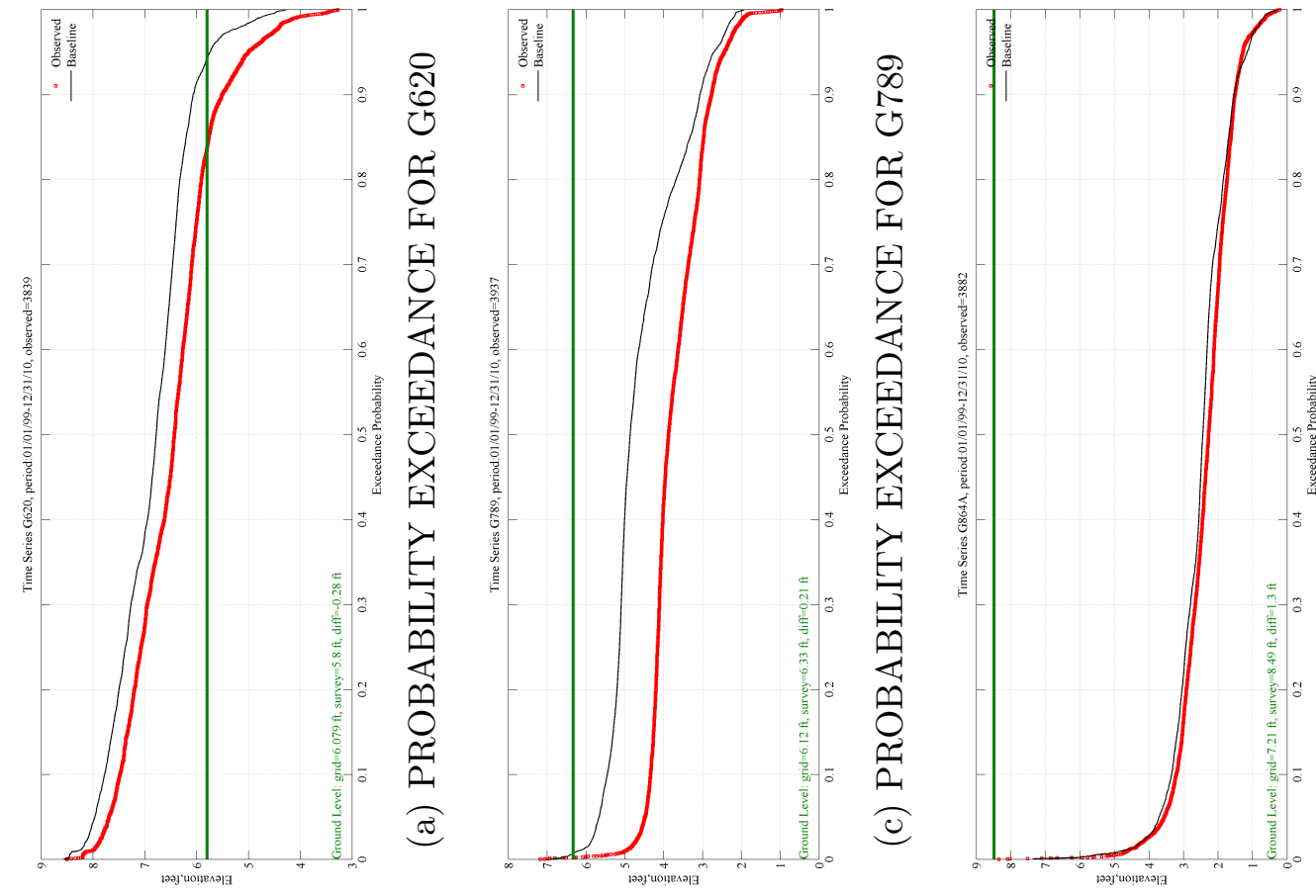

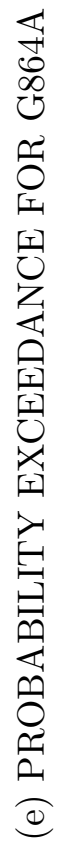



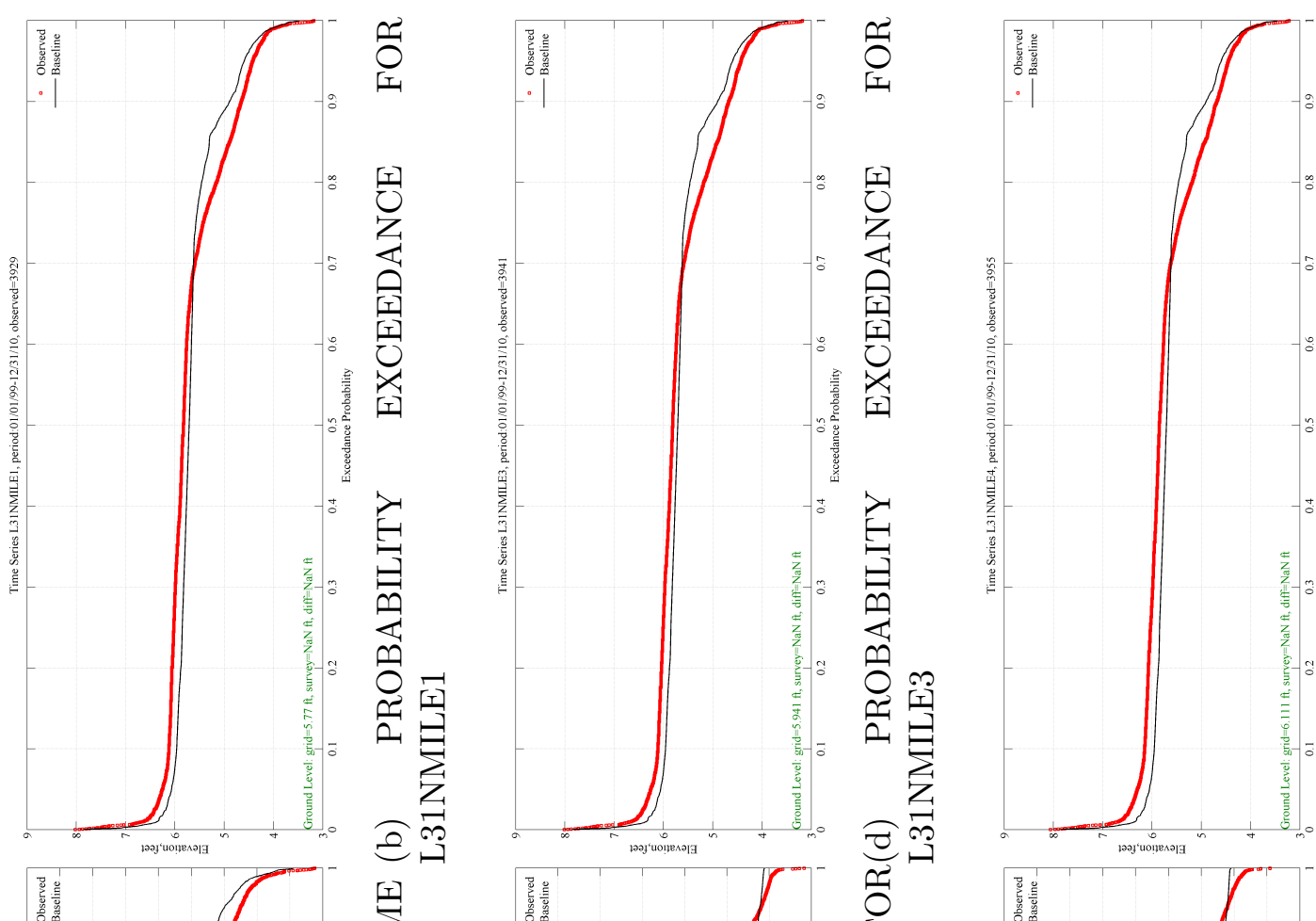

$0_{1}^{0}$
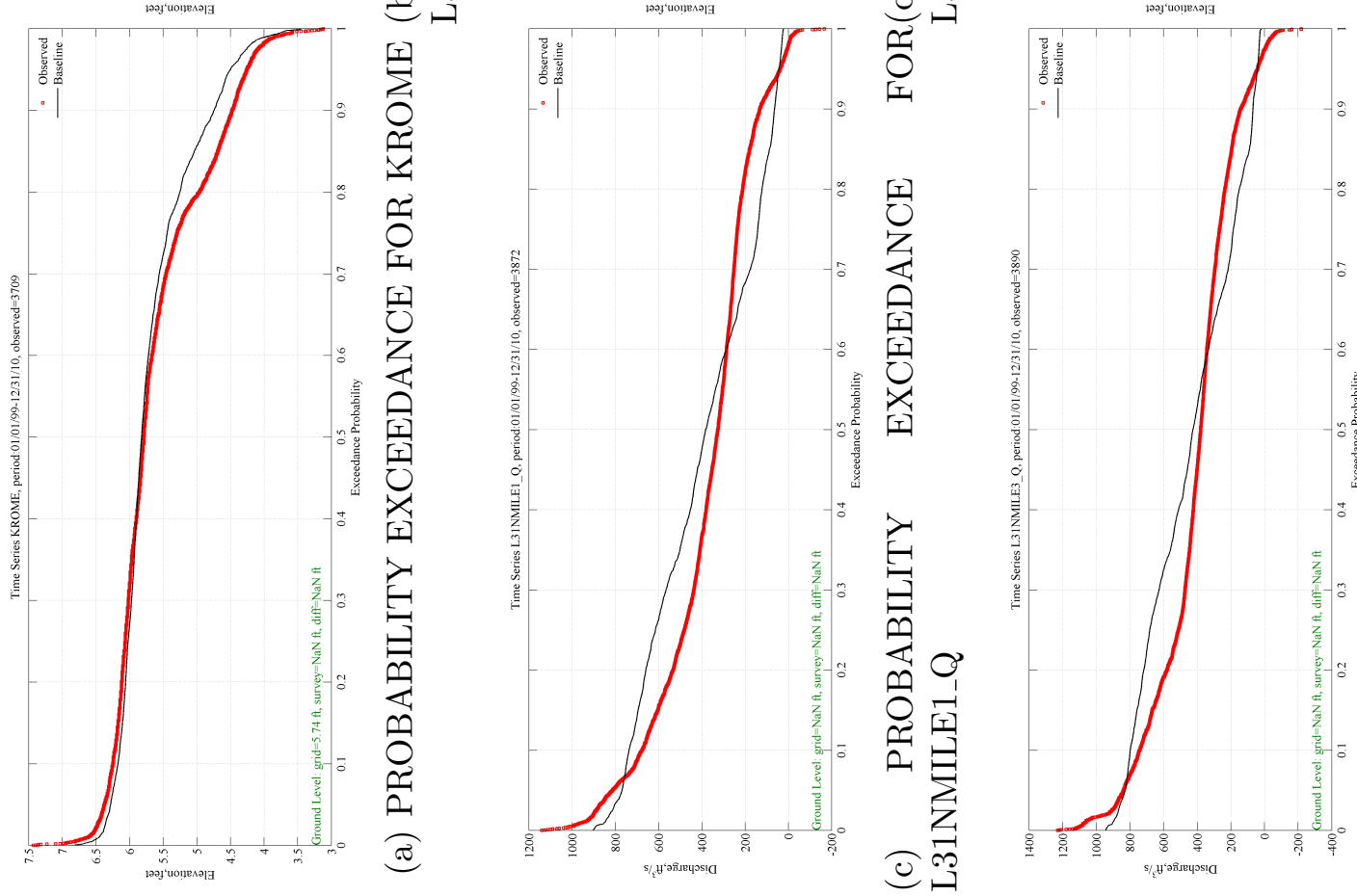

团

I

氜

号

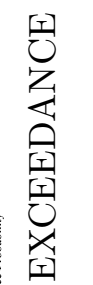

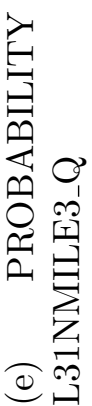




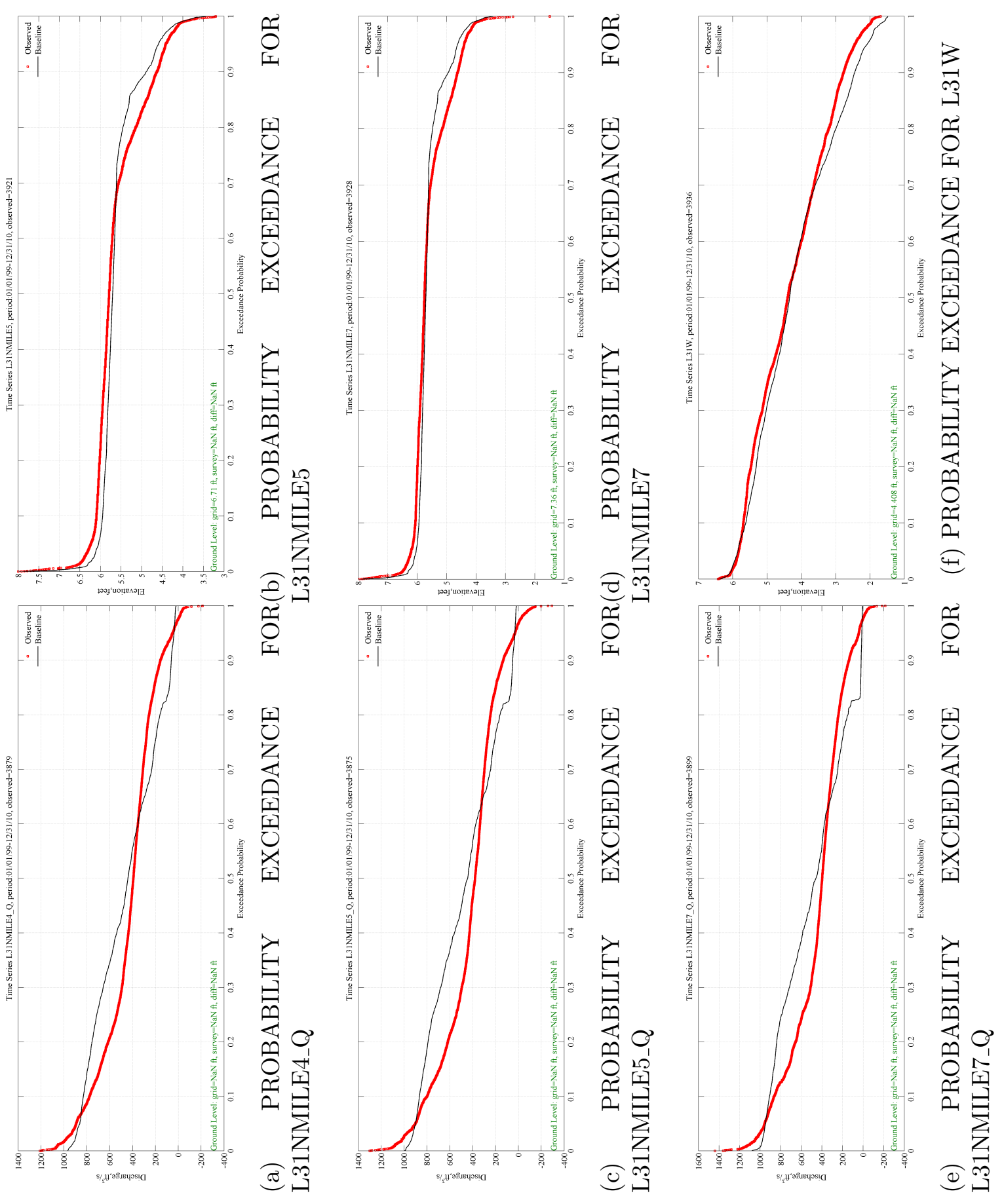



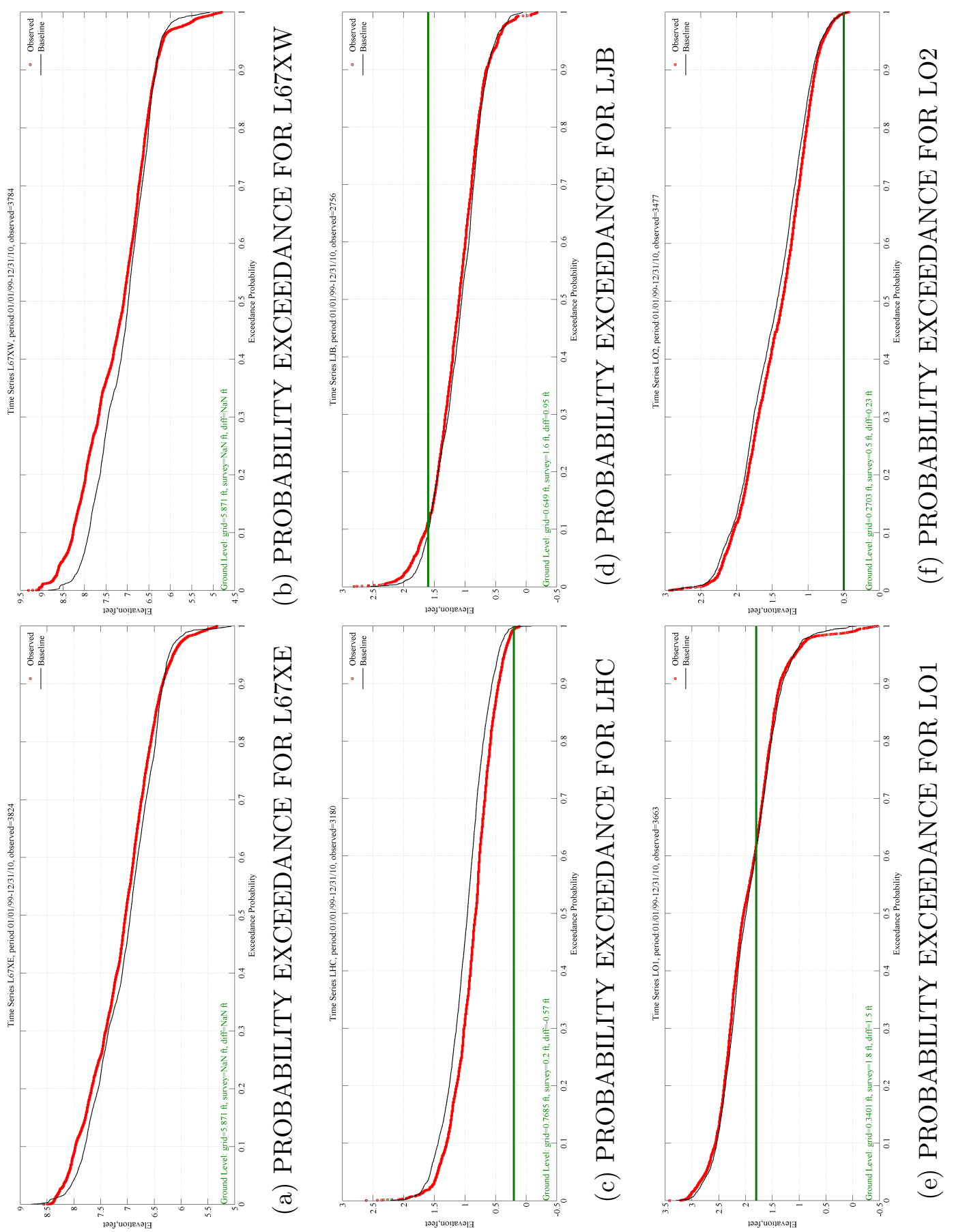

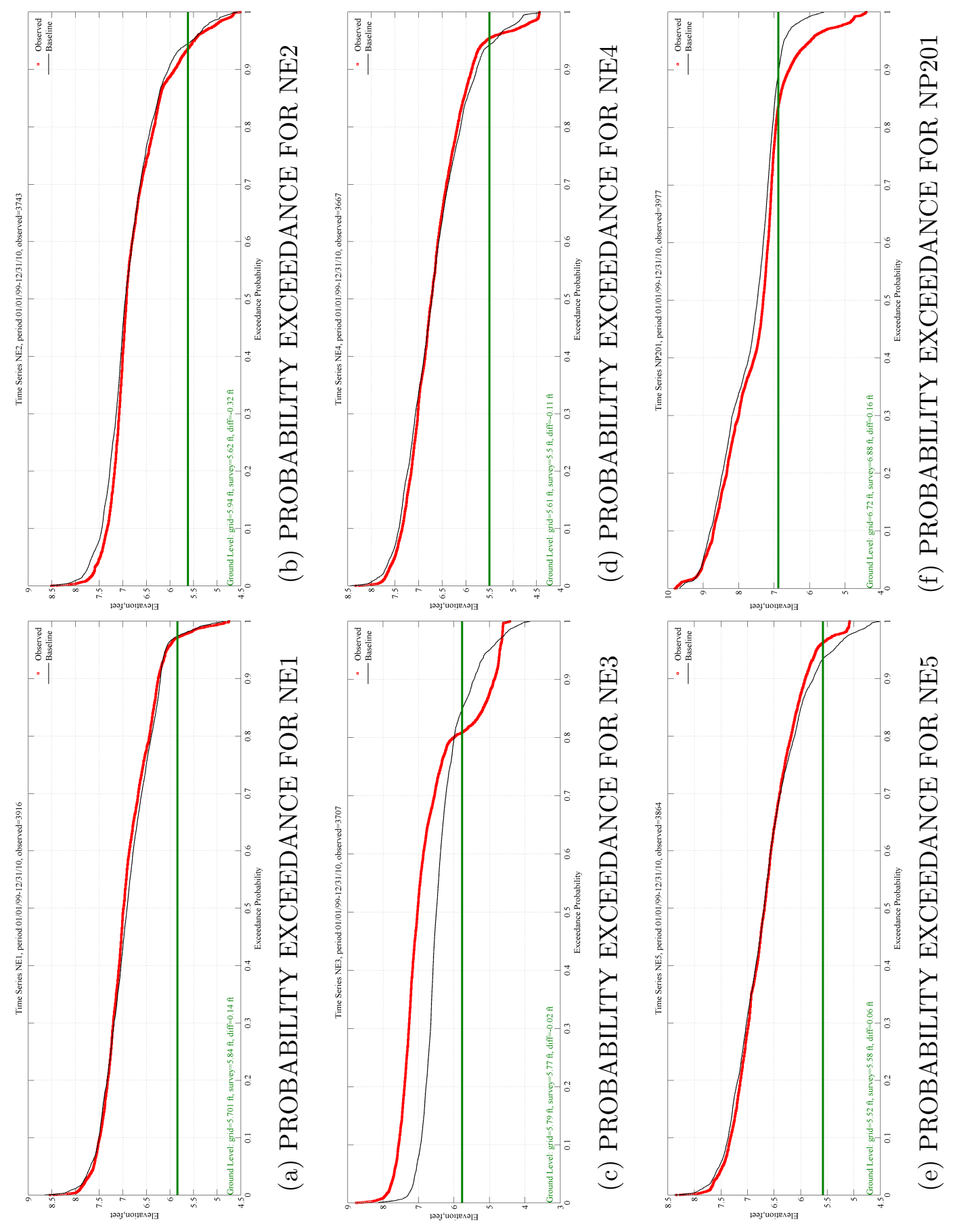

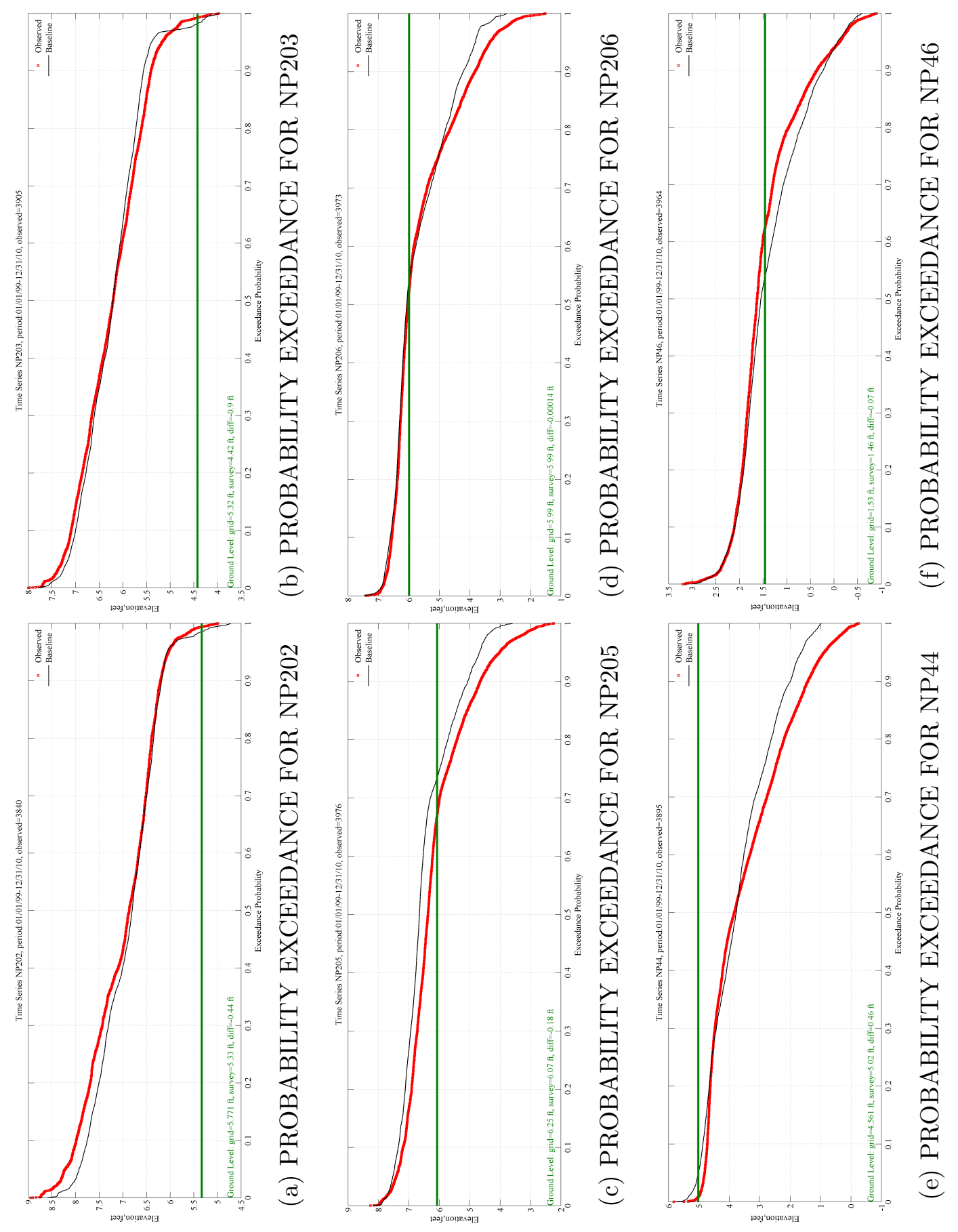

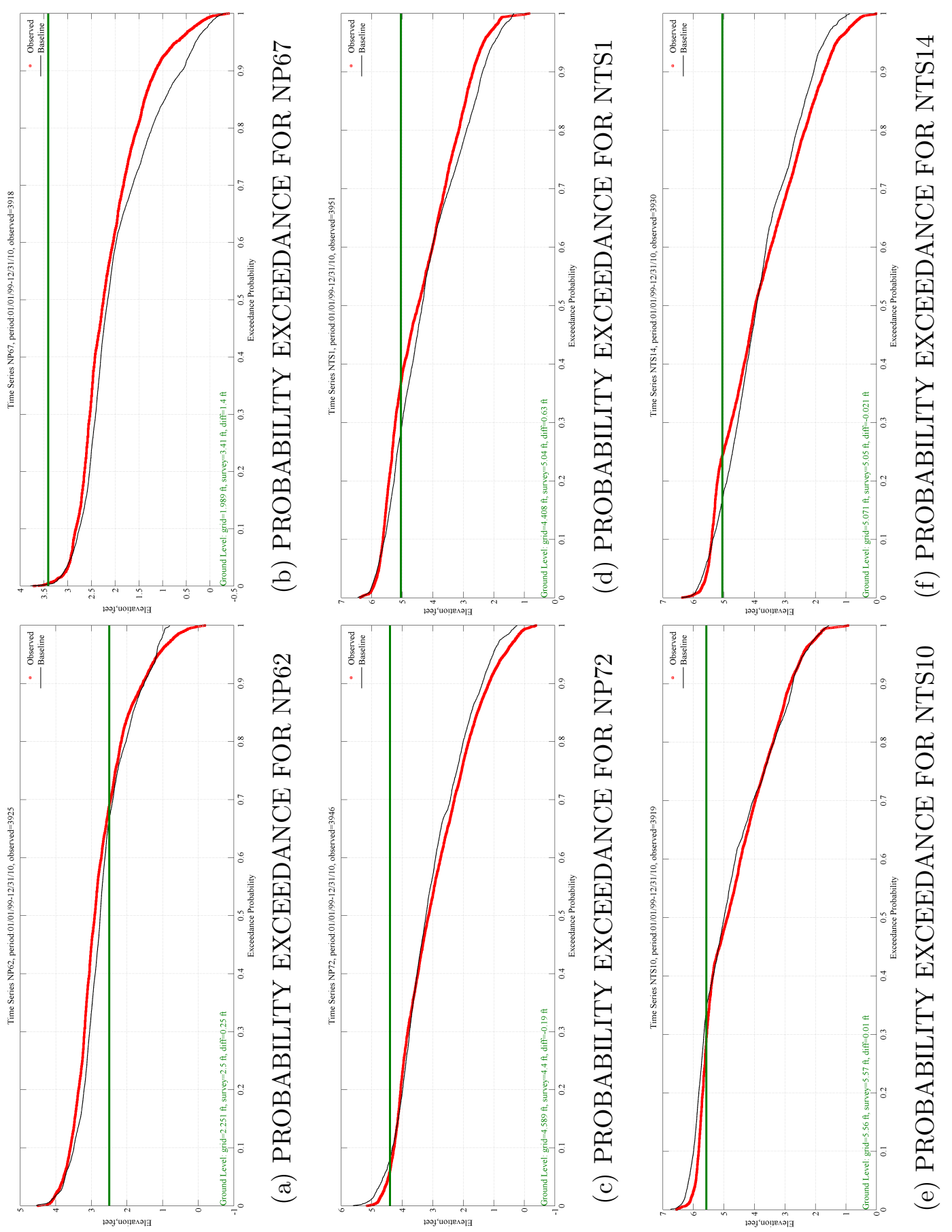

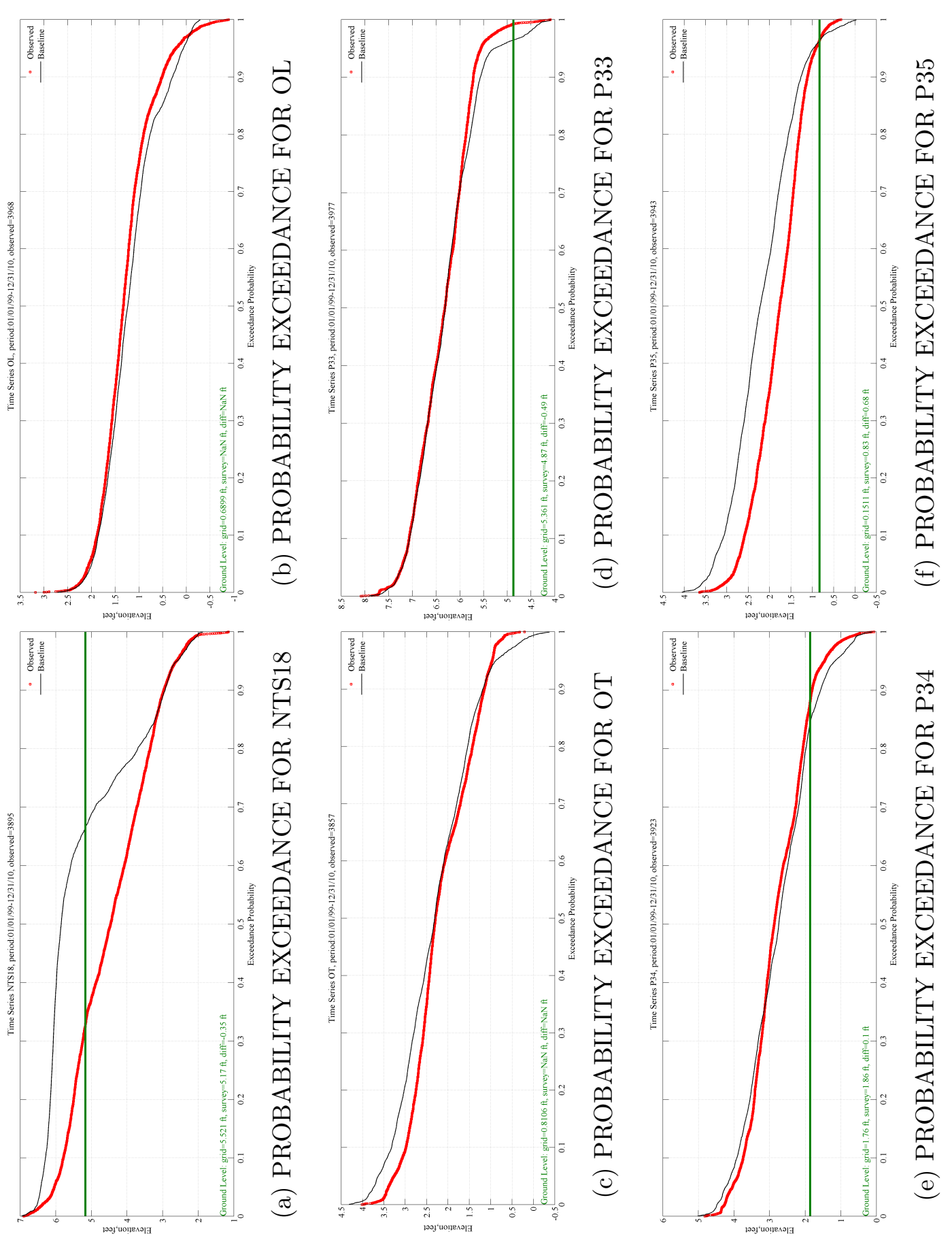

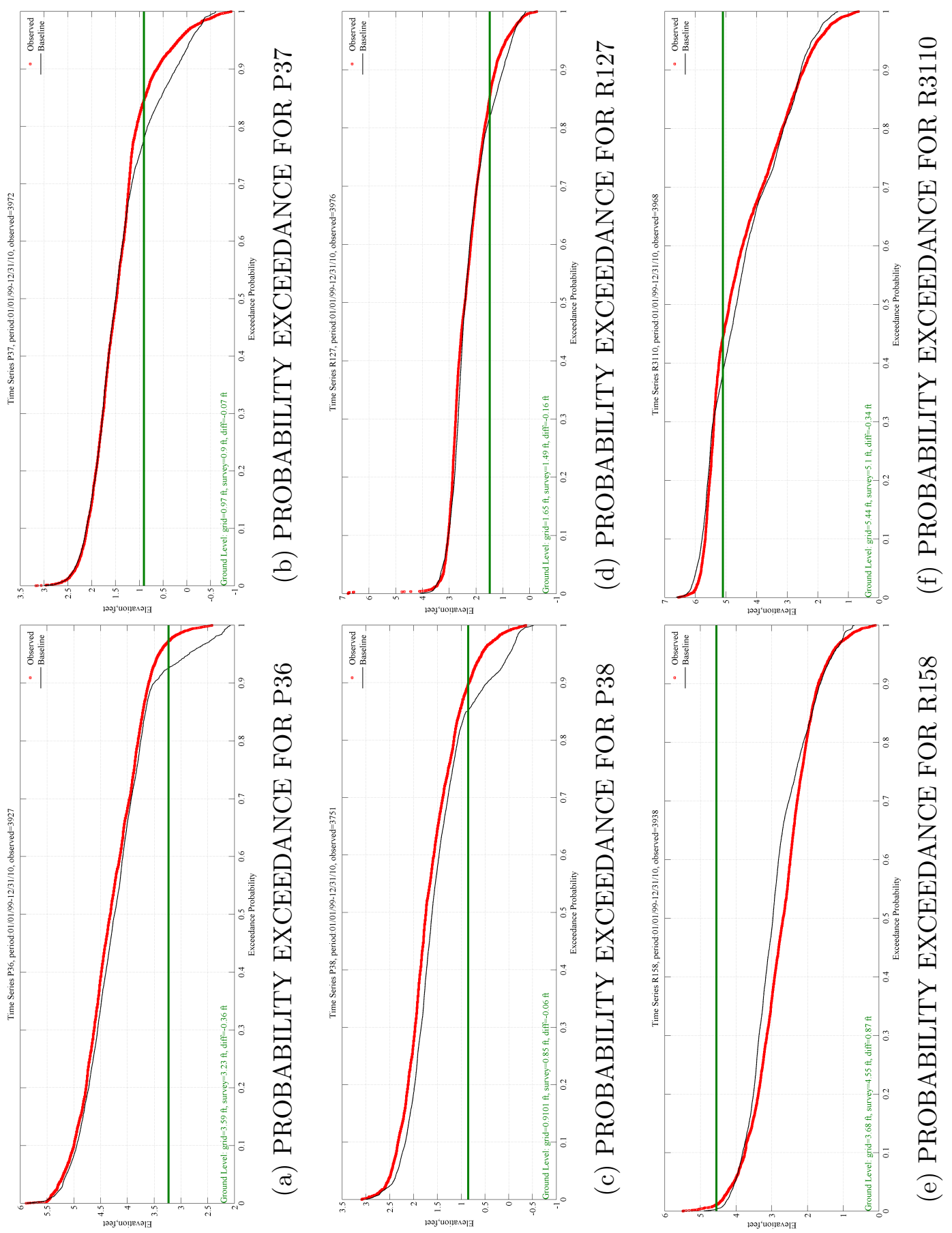


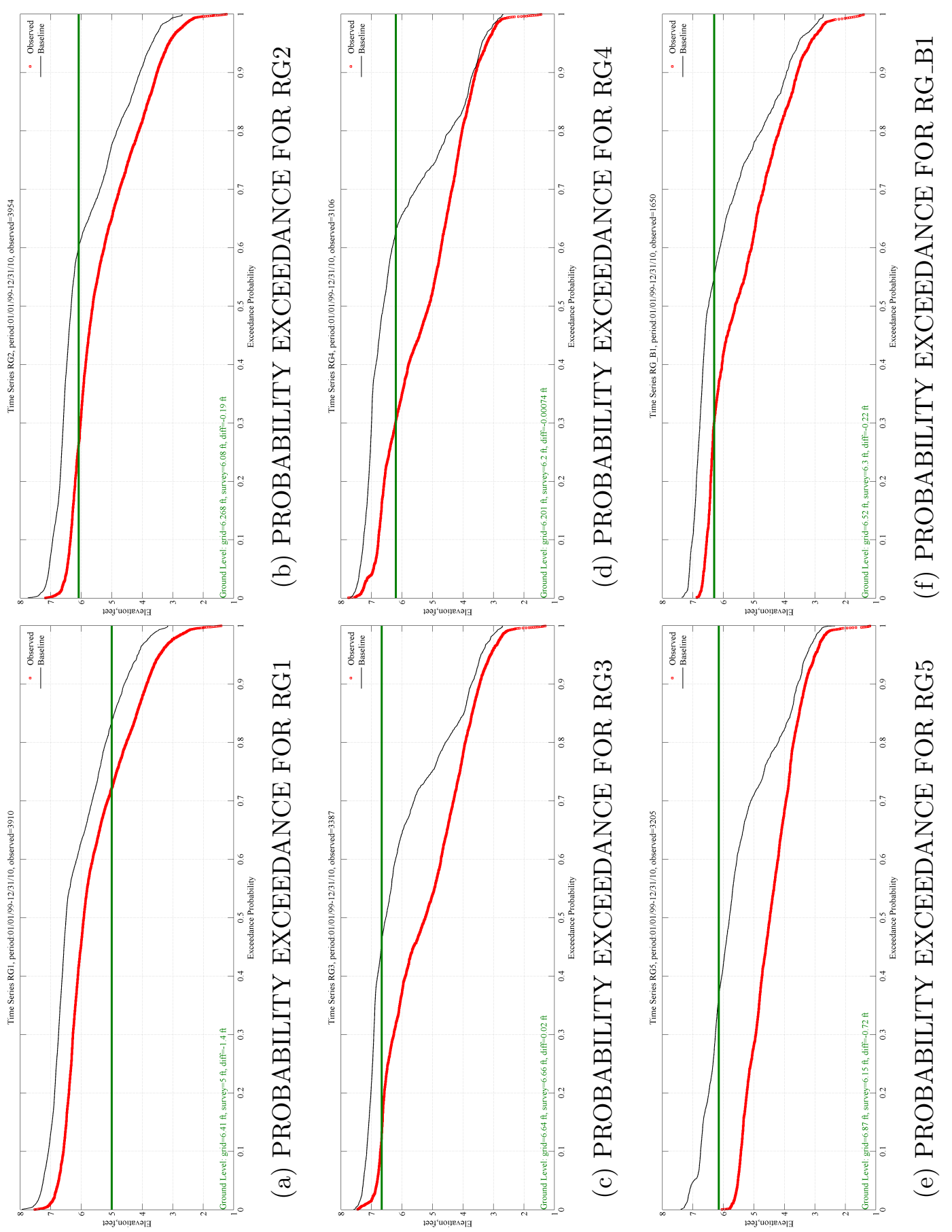




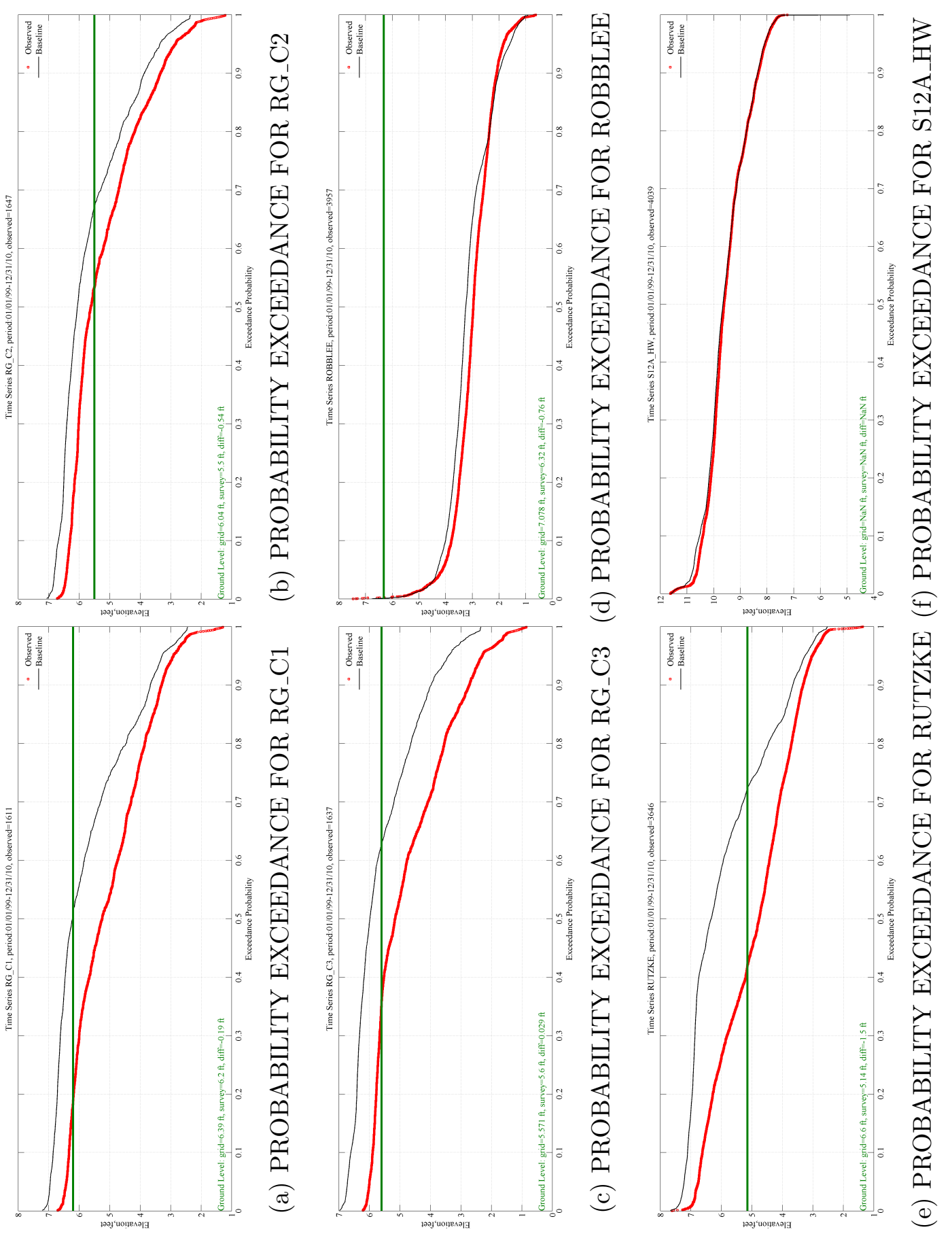



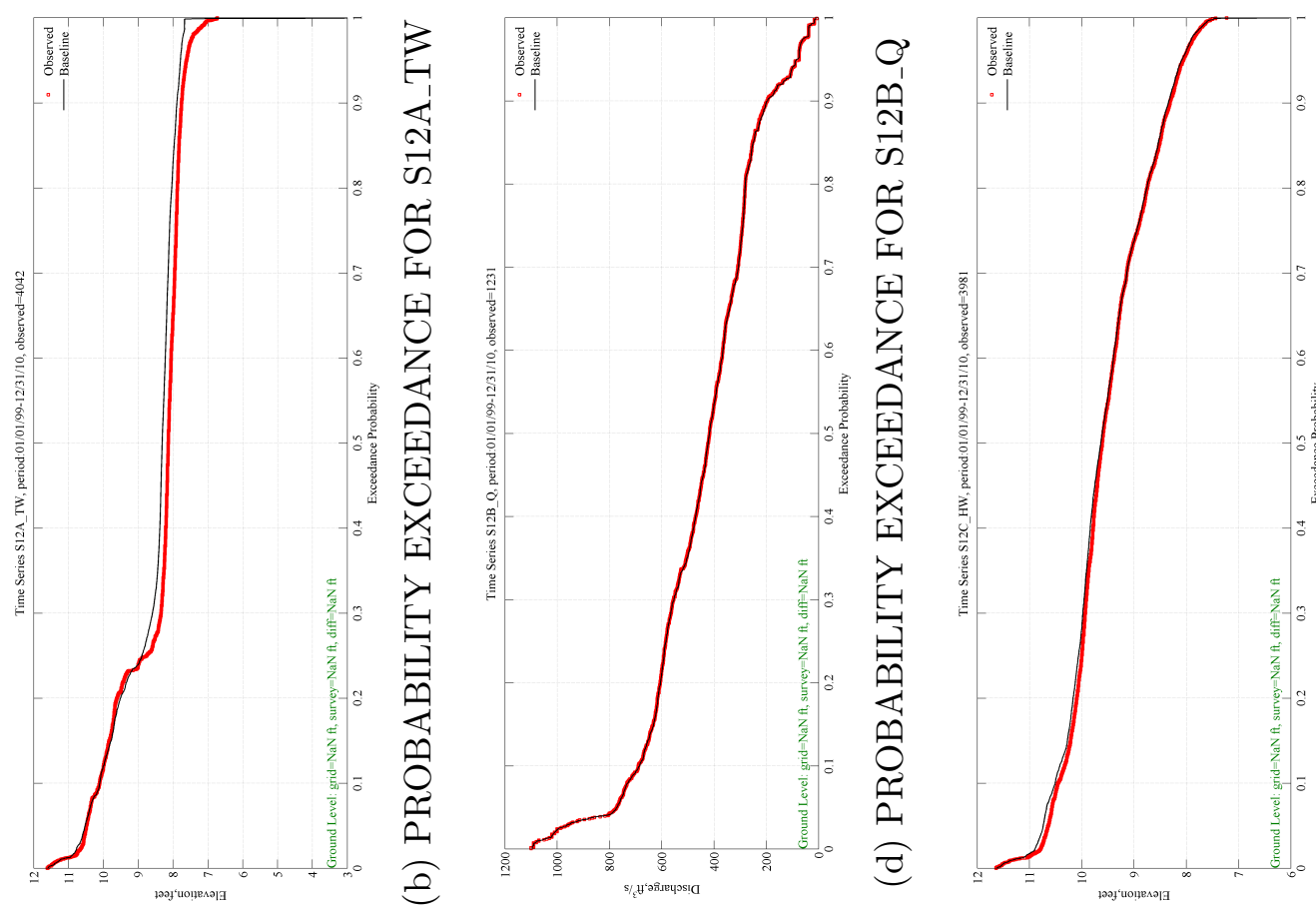

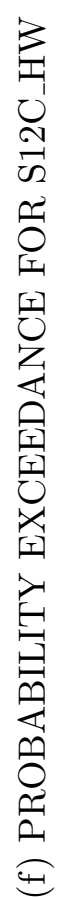
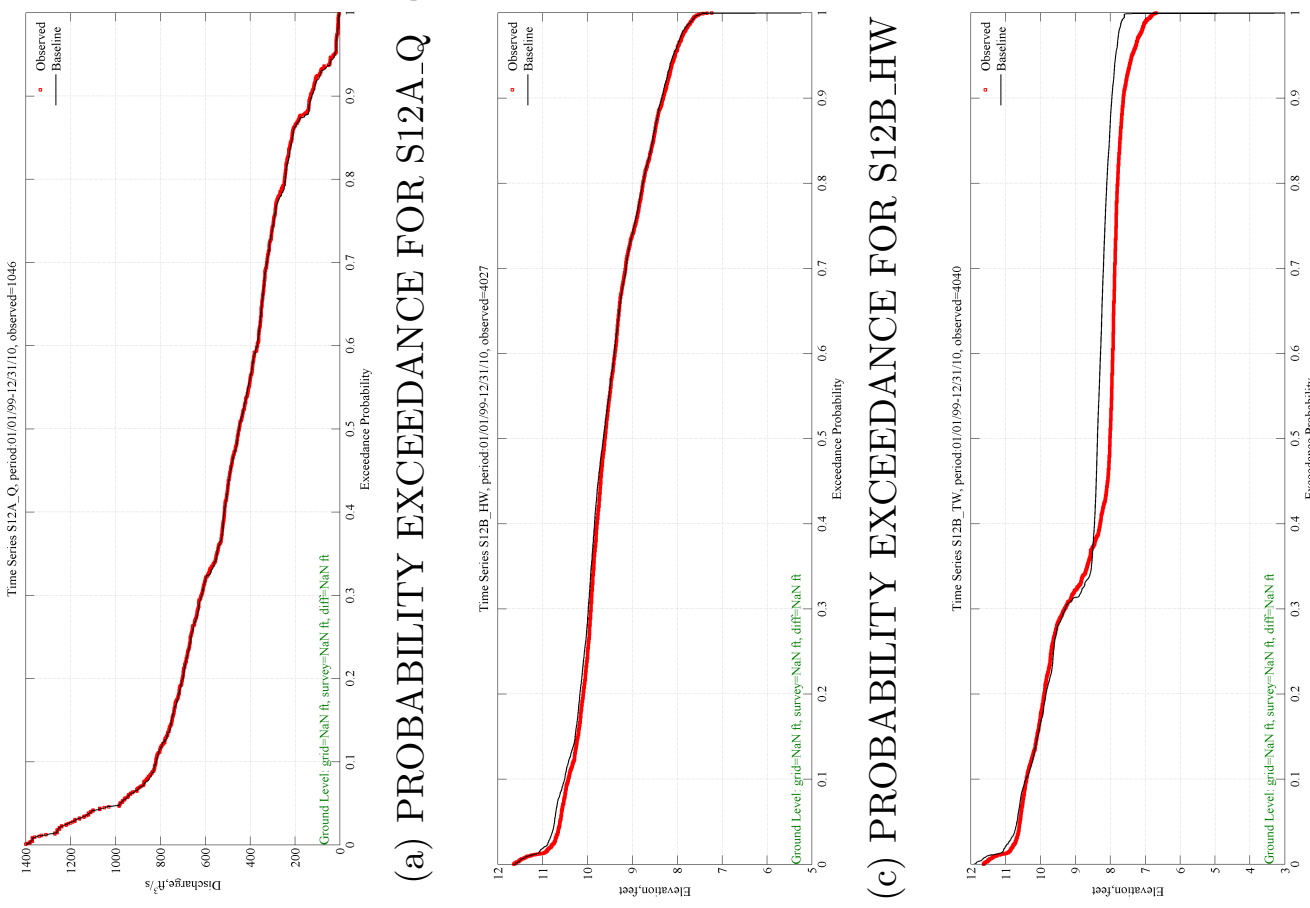

年 

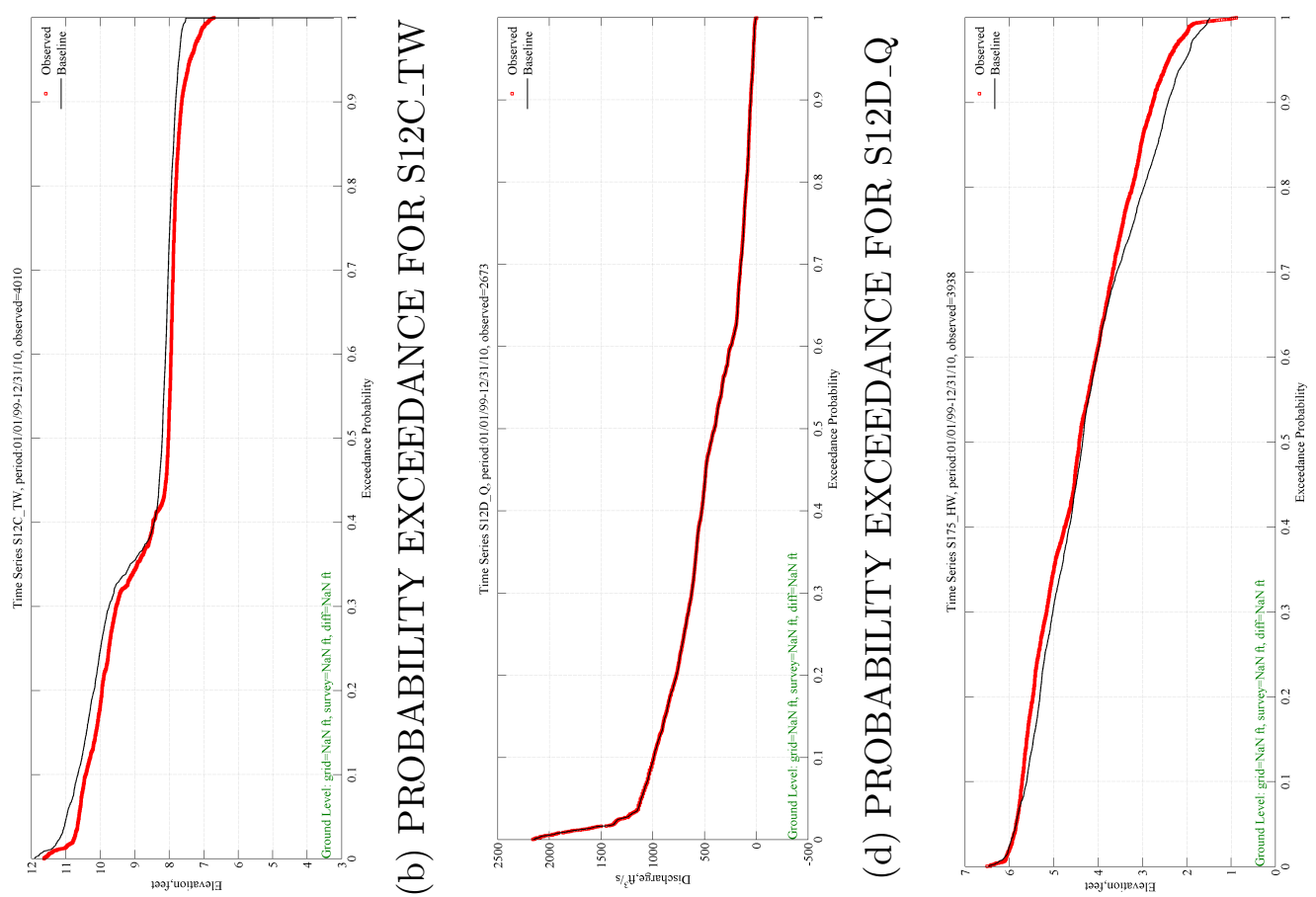

垔
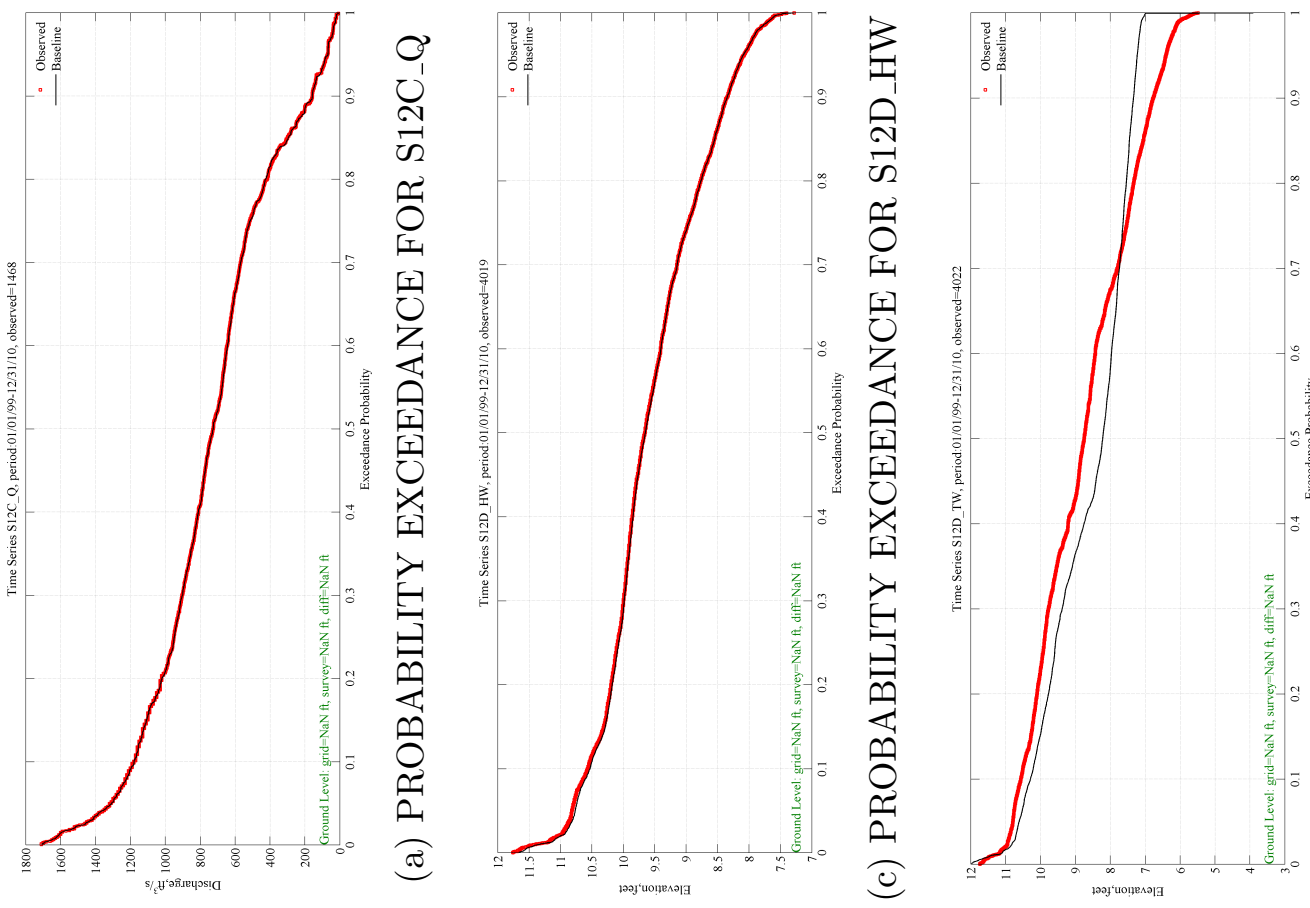

 

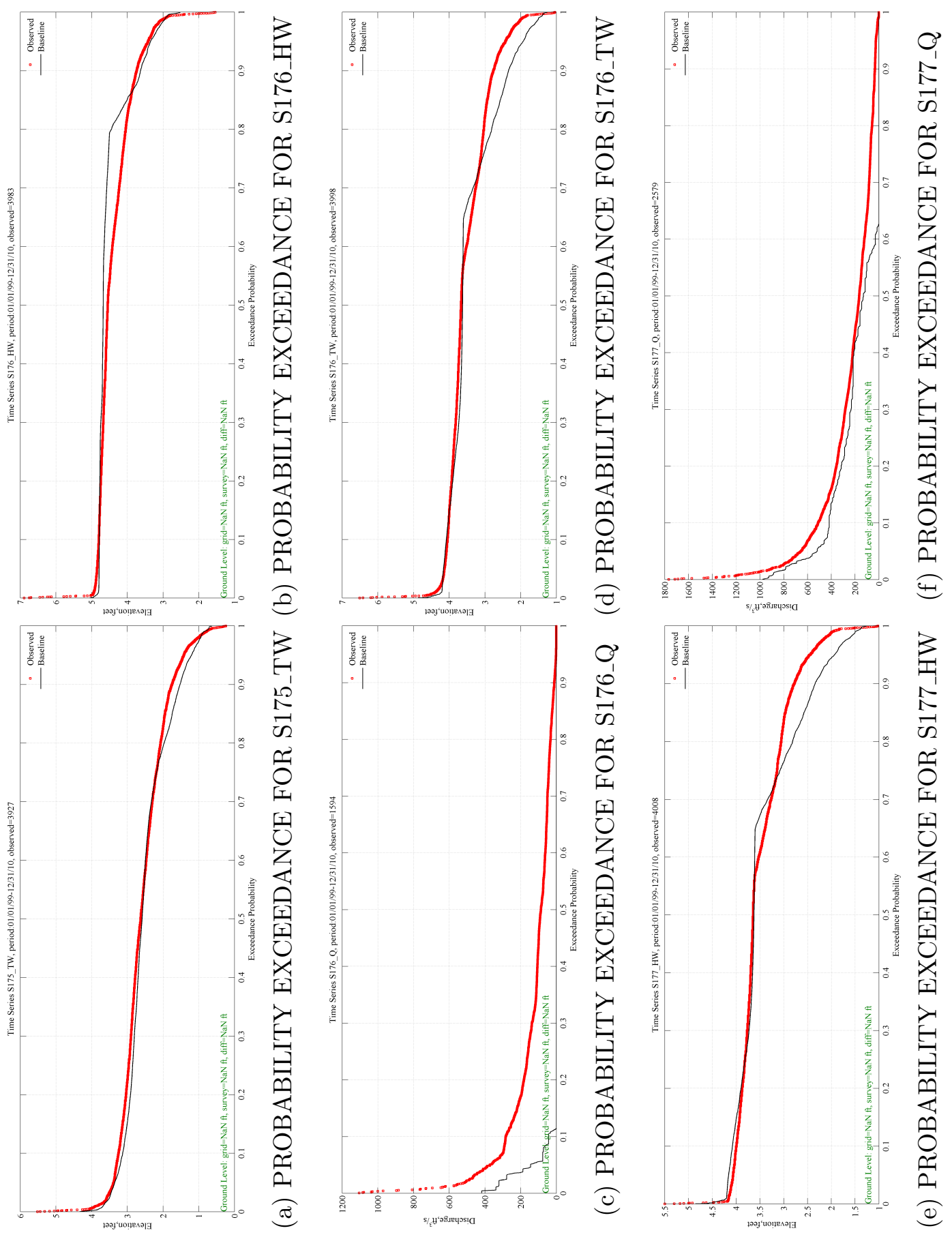


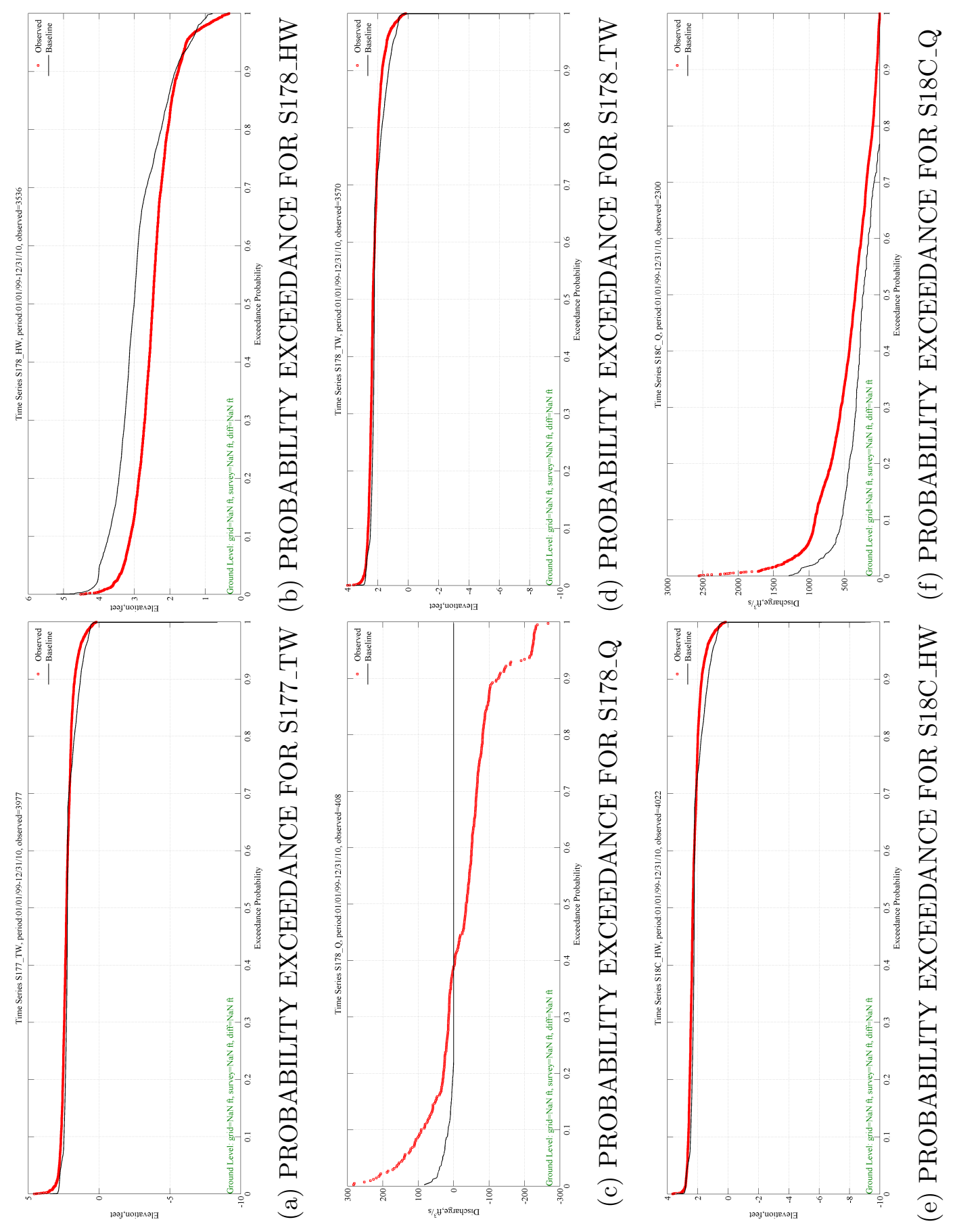




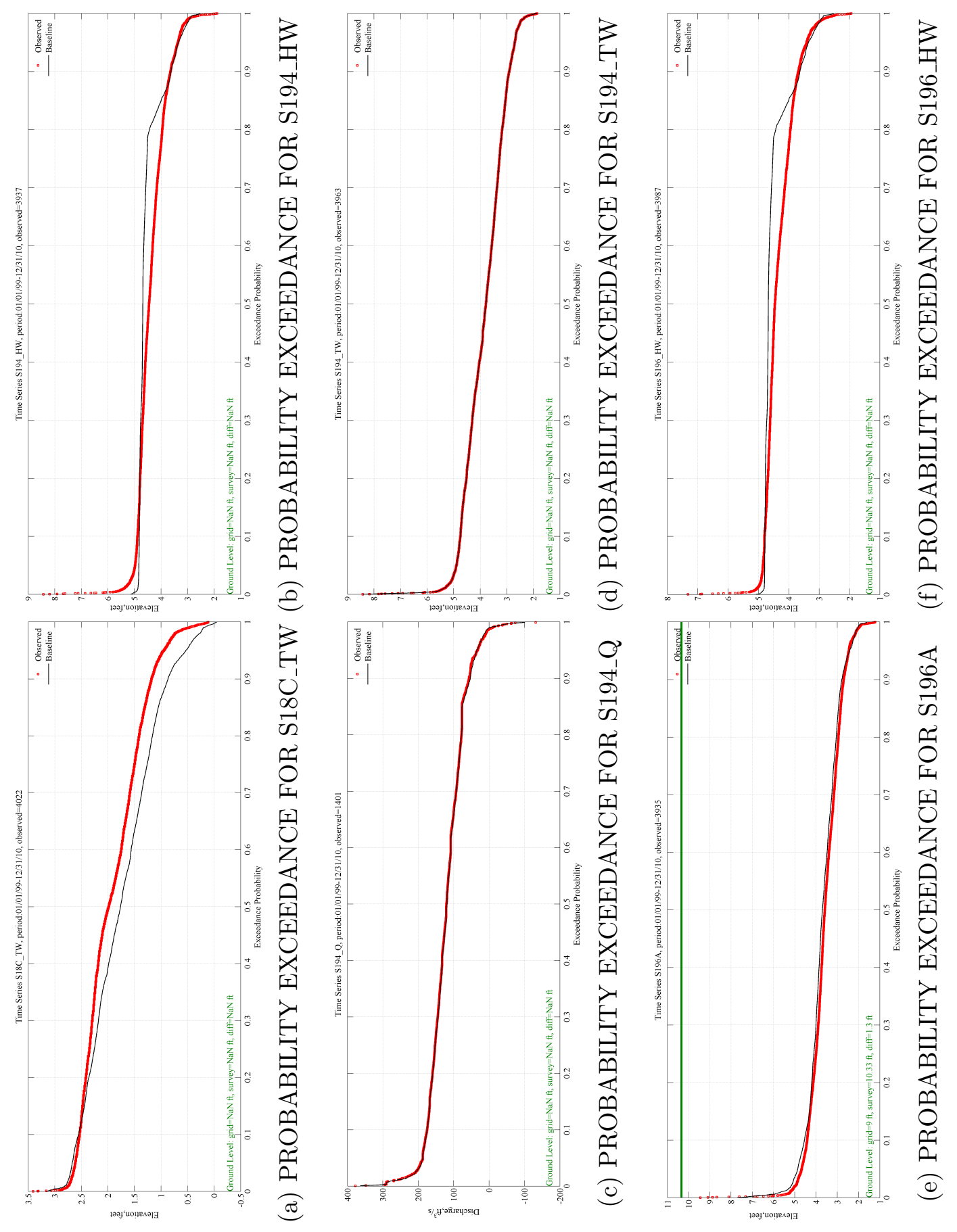



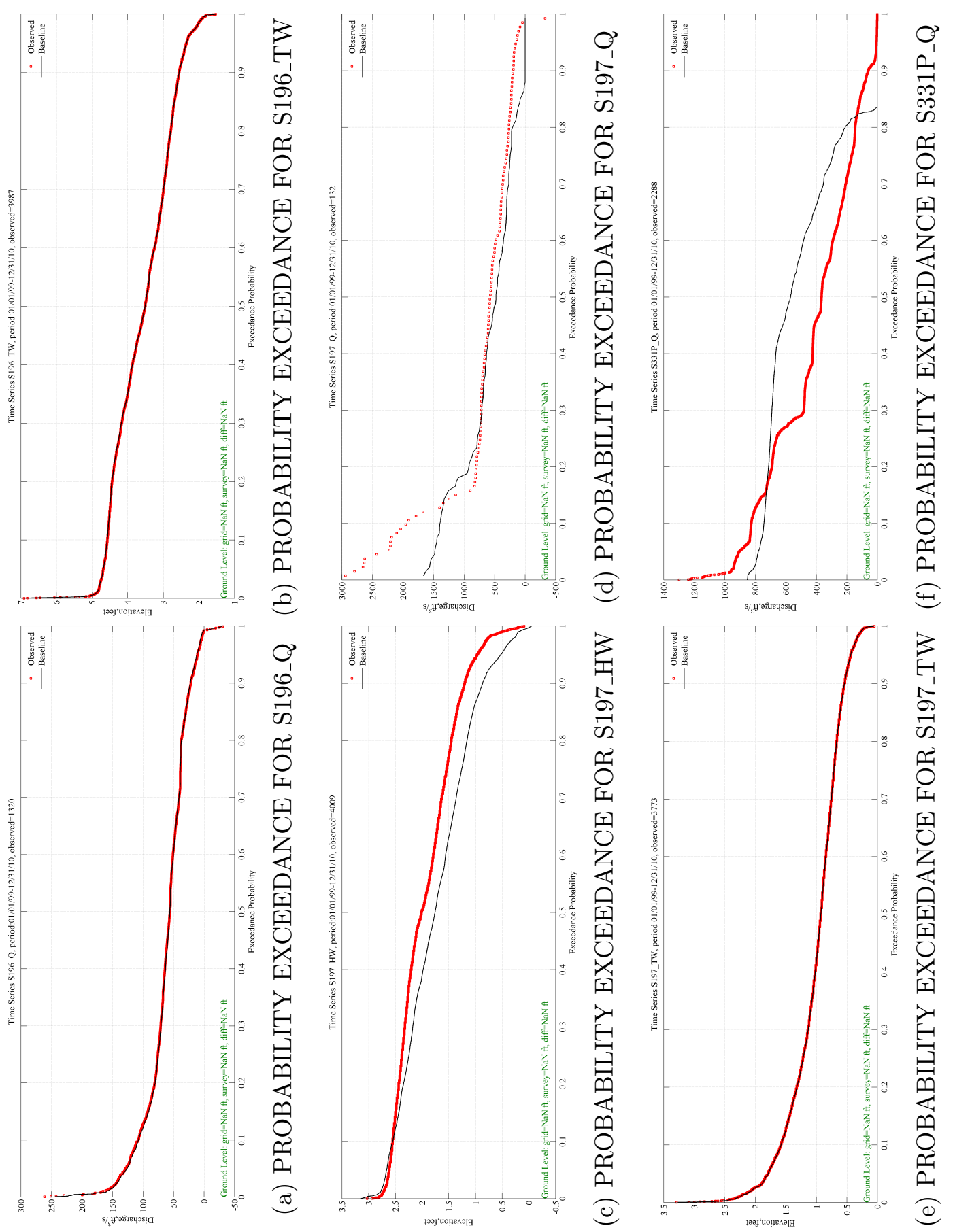

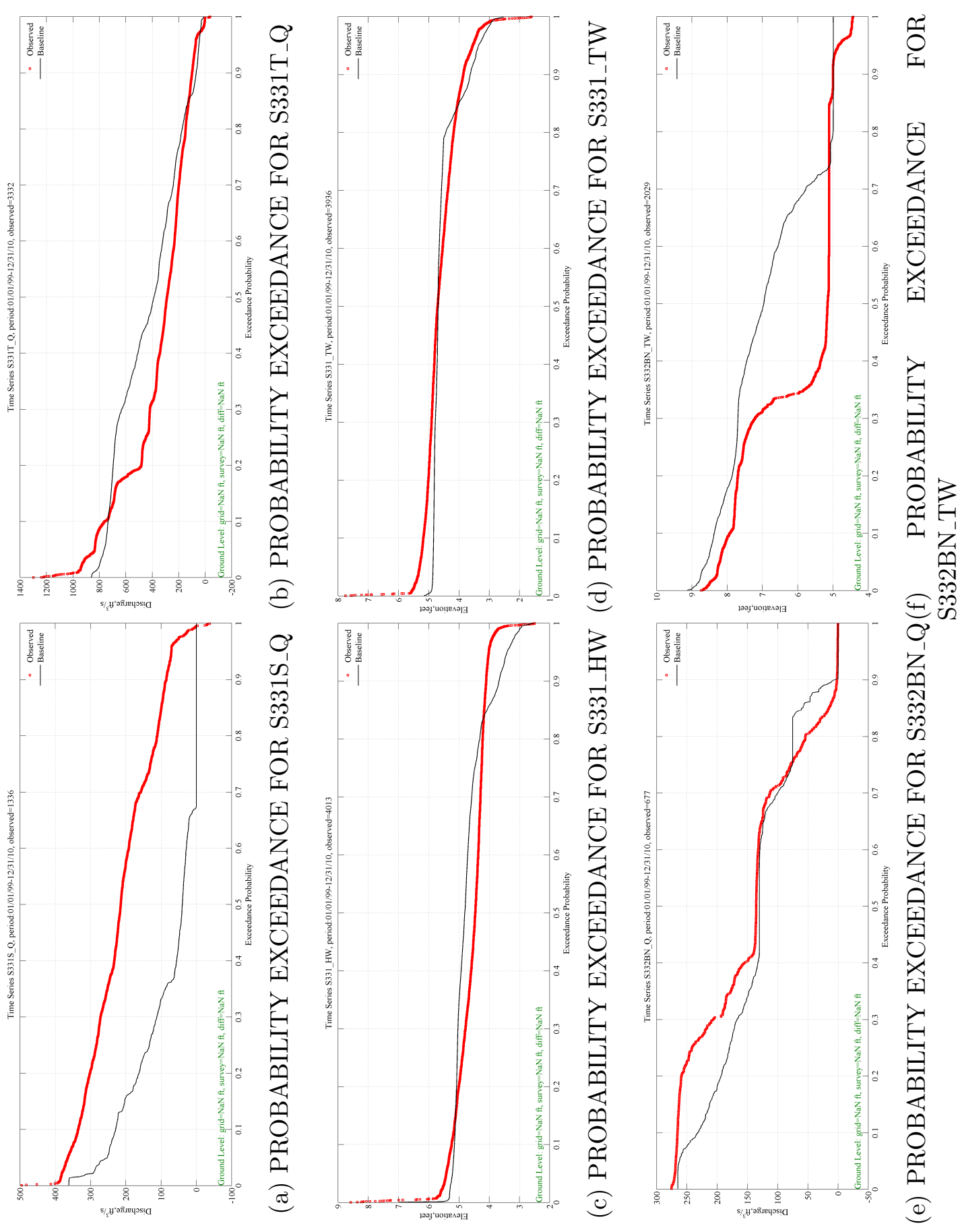


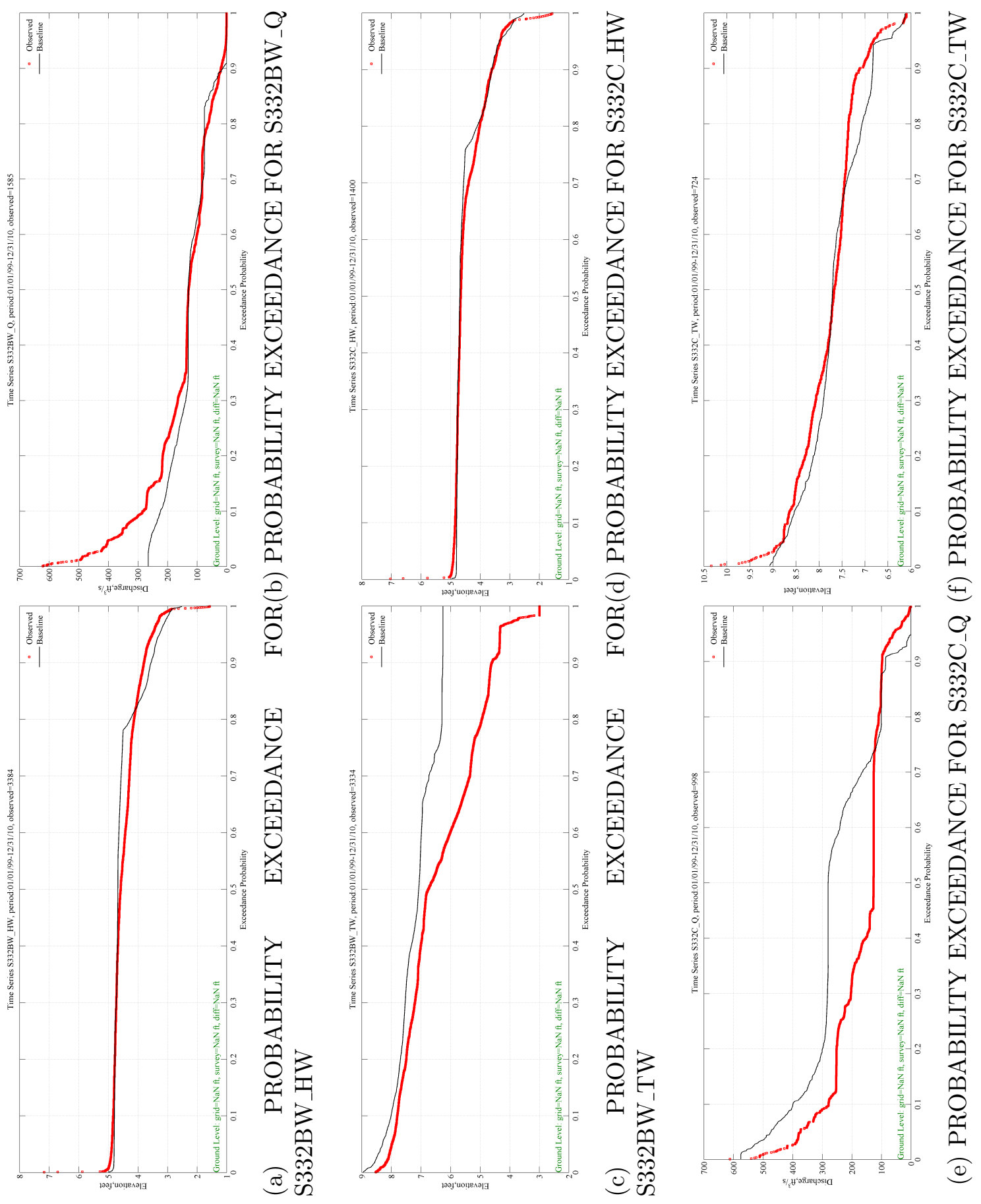



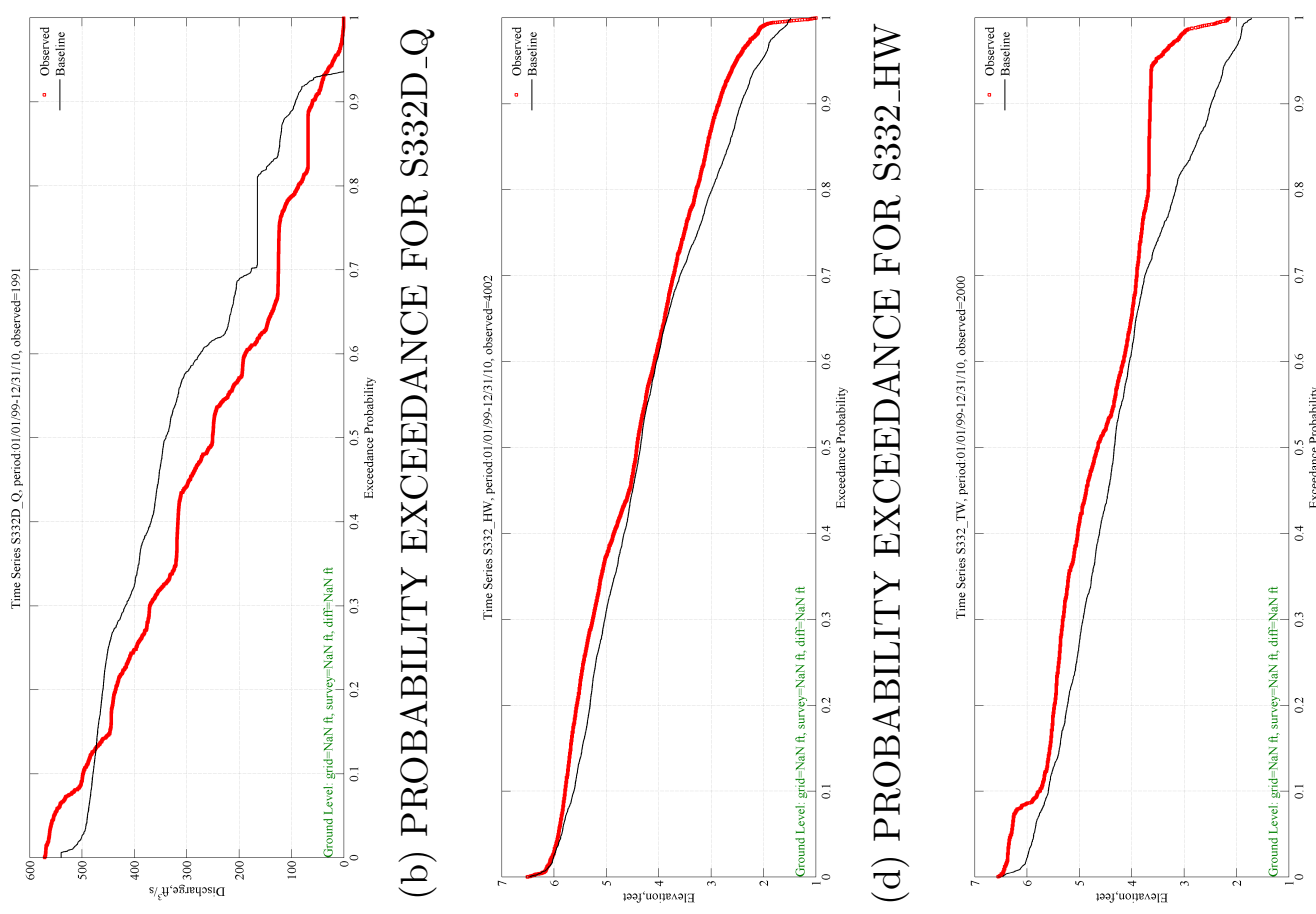

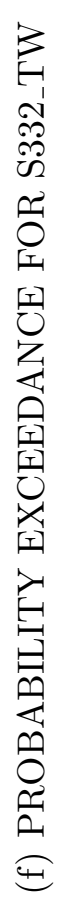
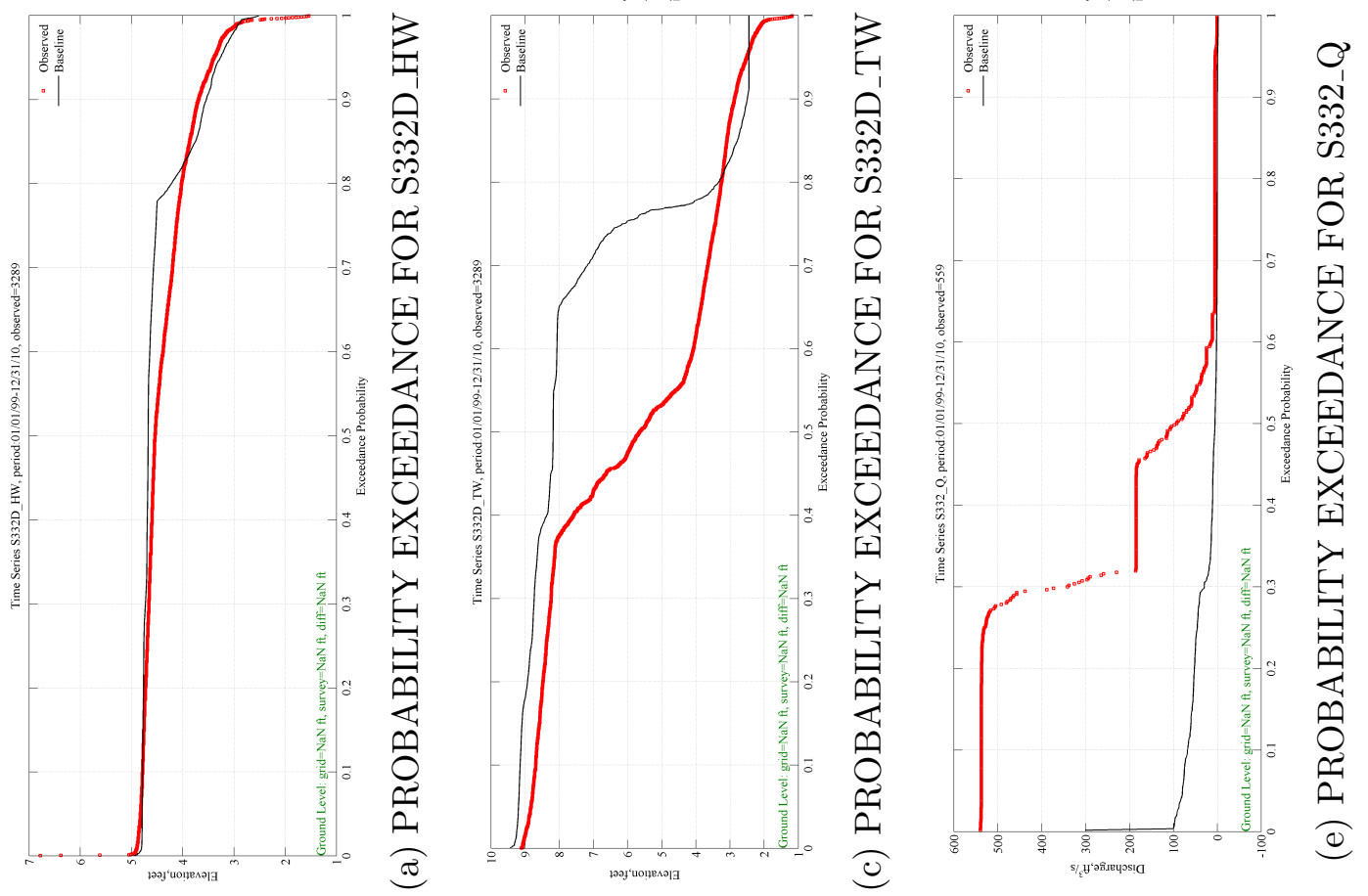


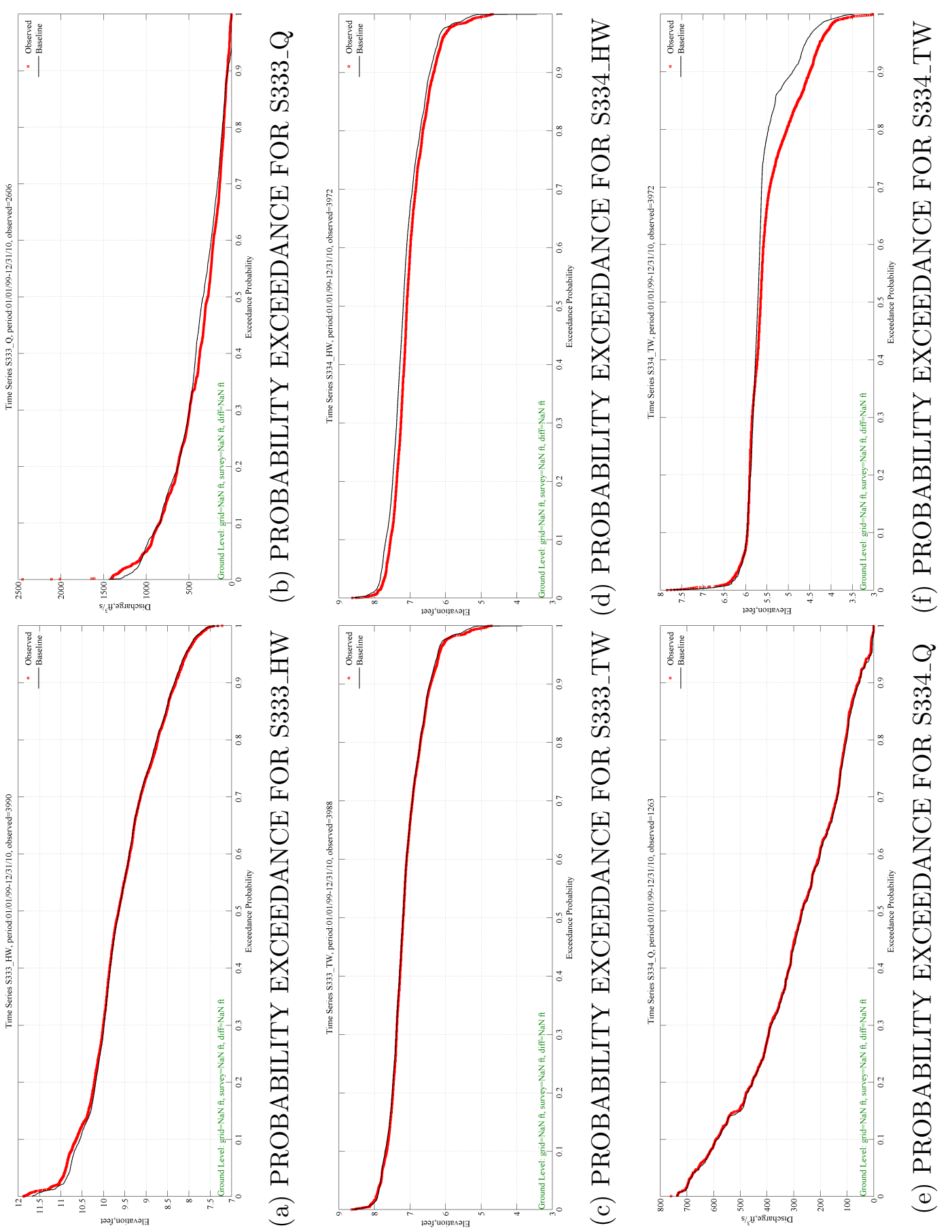



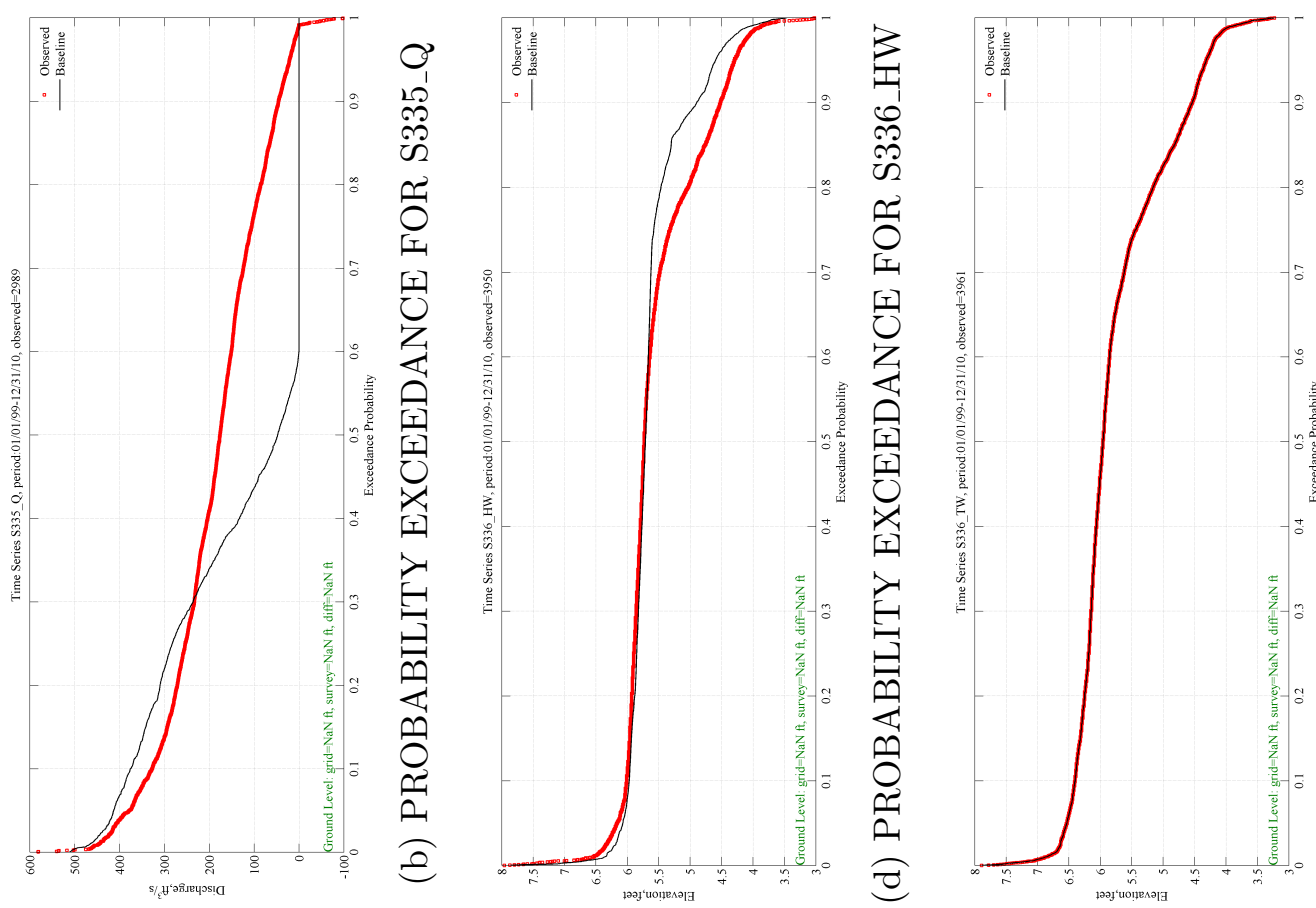

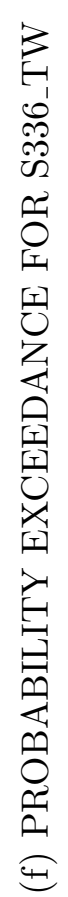
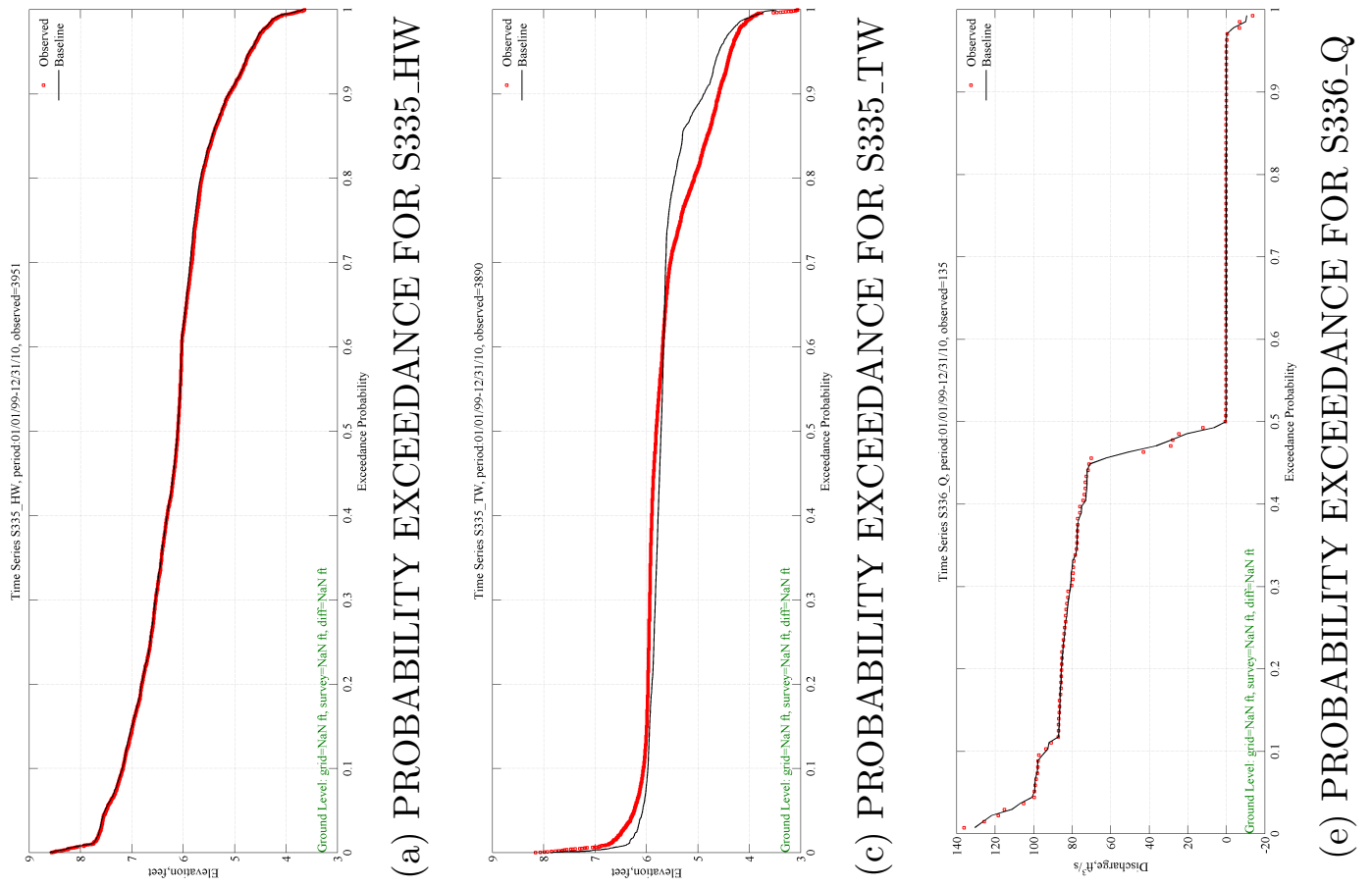

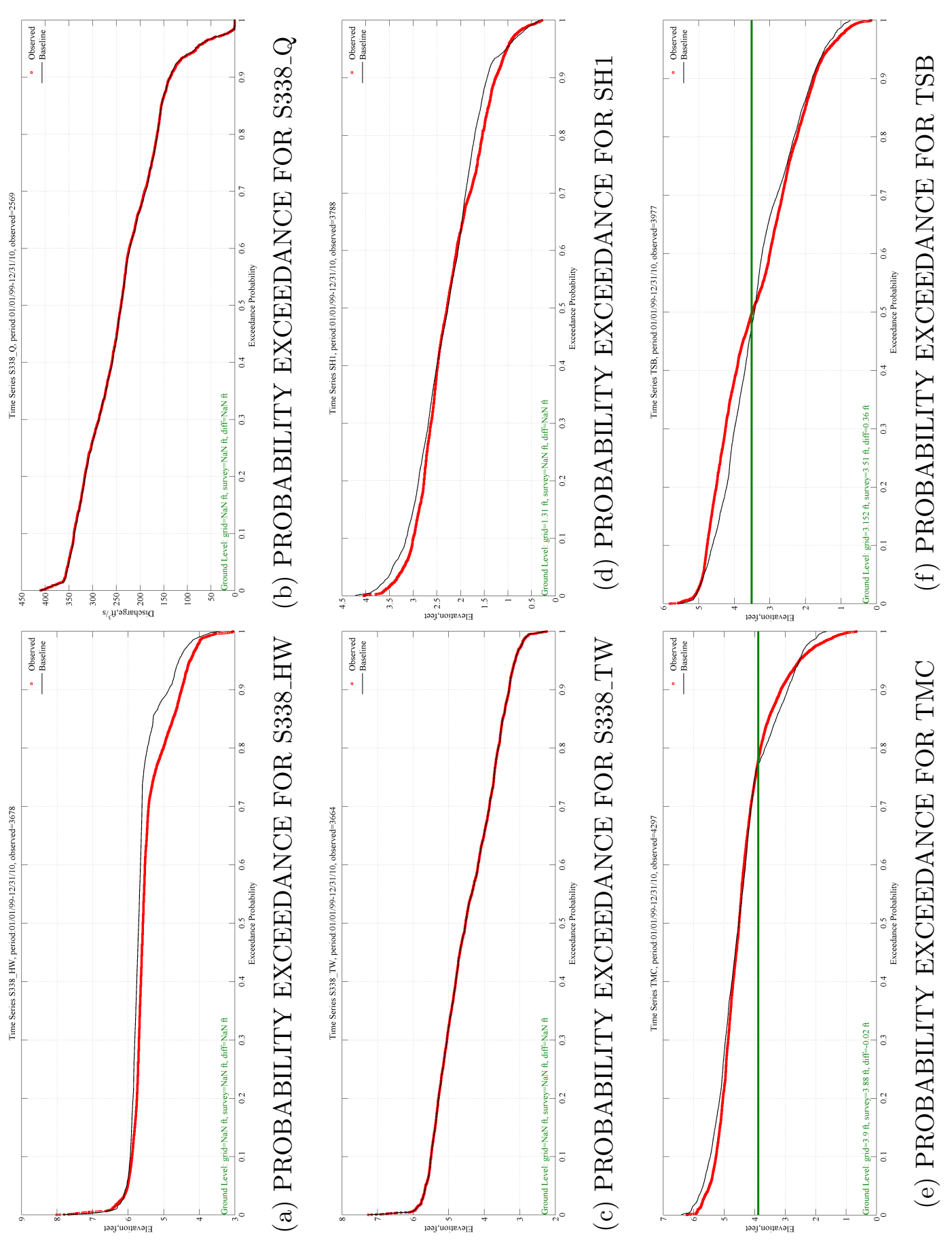


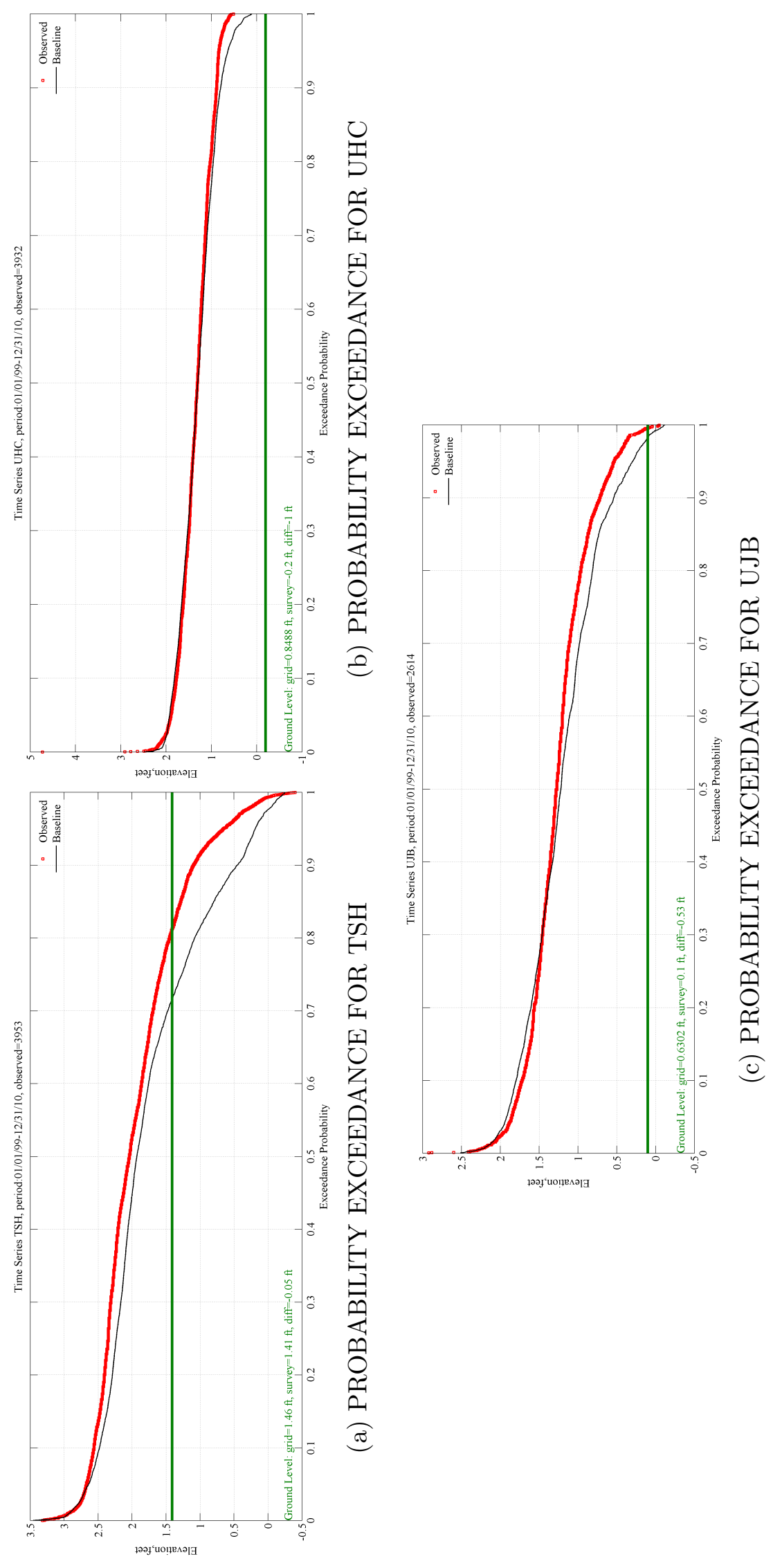




\section{Appendix B}

\section{M3ENP-AD Calibration}

The following figures provide a comparison of modeled and observed Total Phos-

phorus results at 4 additional water quality monitoring stations within Everglades National Park for the M3ENP-AD model (developed in Chapter 4). The figures show Cumulative Load, Daily Load, and percent exceedance over the simulation period. 

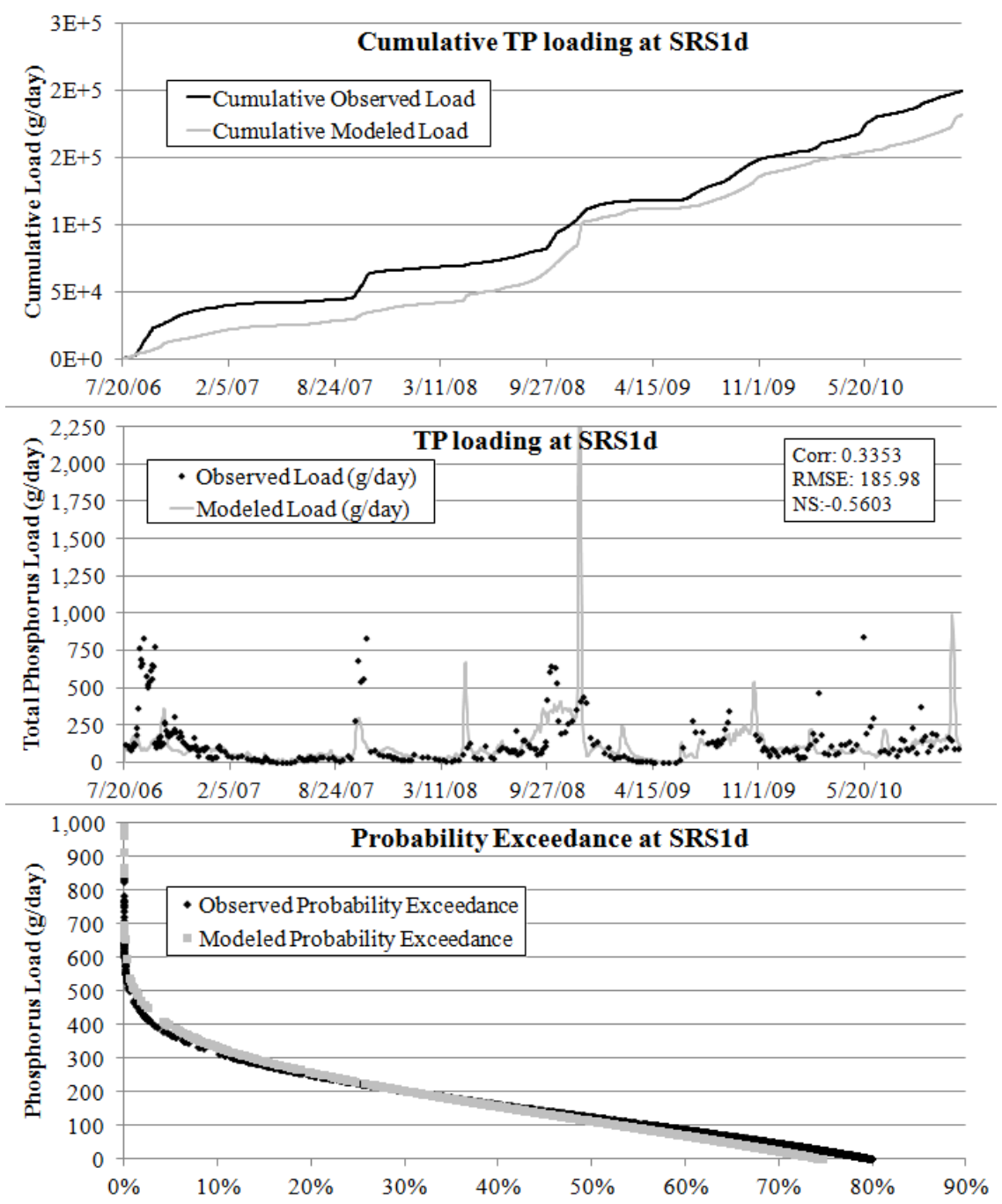

Figure B.1: Calibration results for the M3ENP-AD model at the SRS1d site in Shark Slough. 


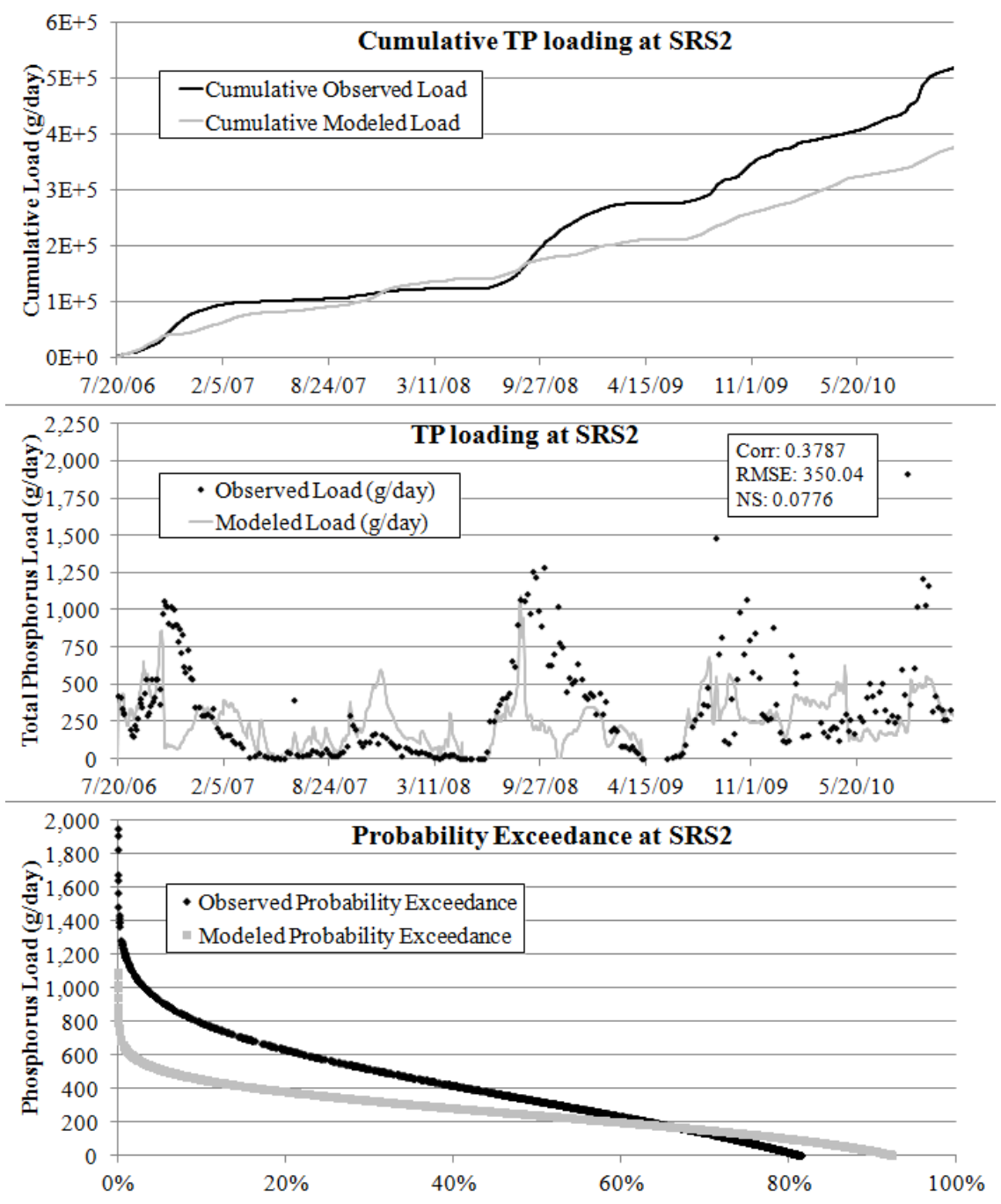

Figure B.2: Calibration results for the M3ENP-AD model at the SRS2 site in Shark Slough. 

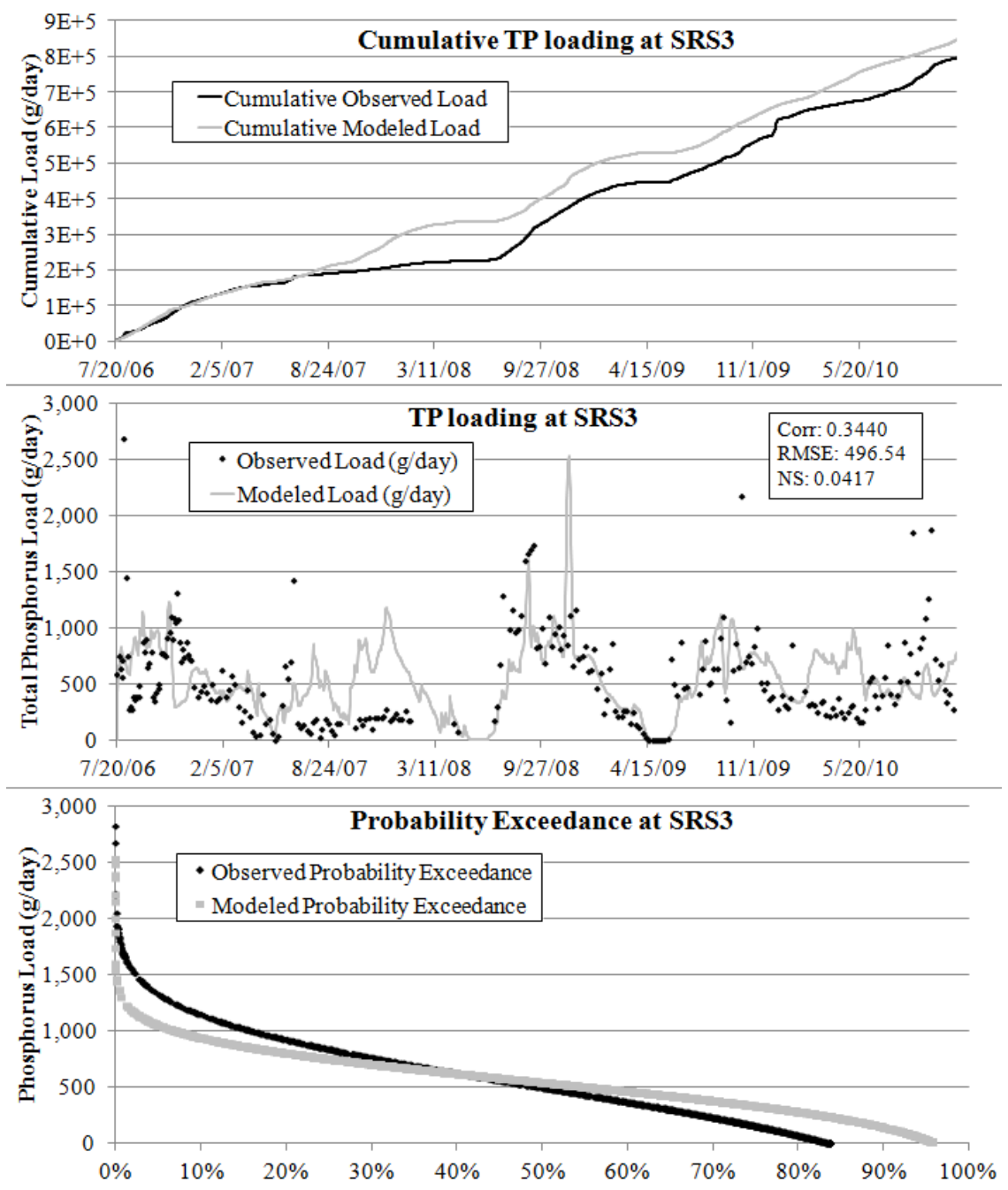

Figure B.3: Calibration results for the M3ENP-AD model at the SRS3 site in Shark Slough. 

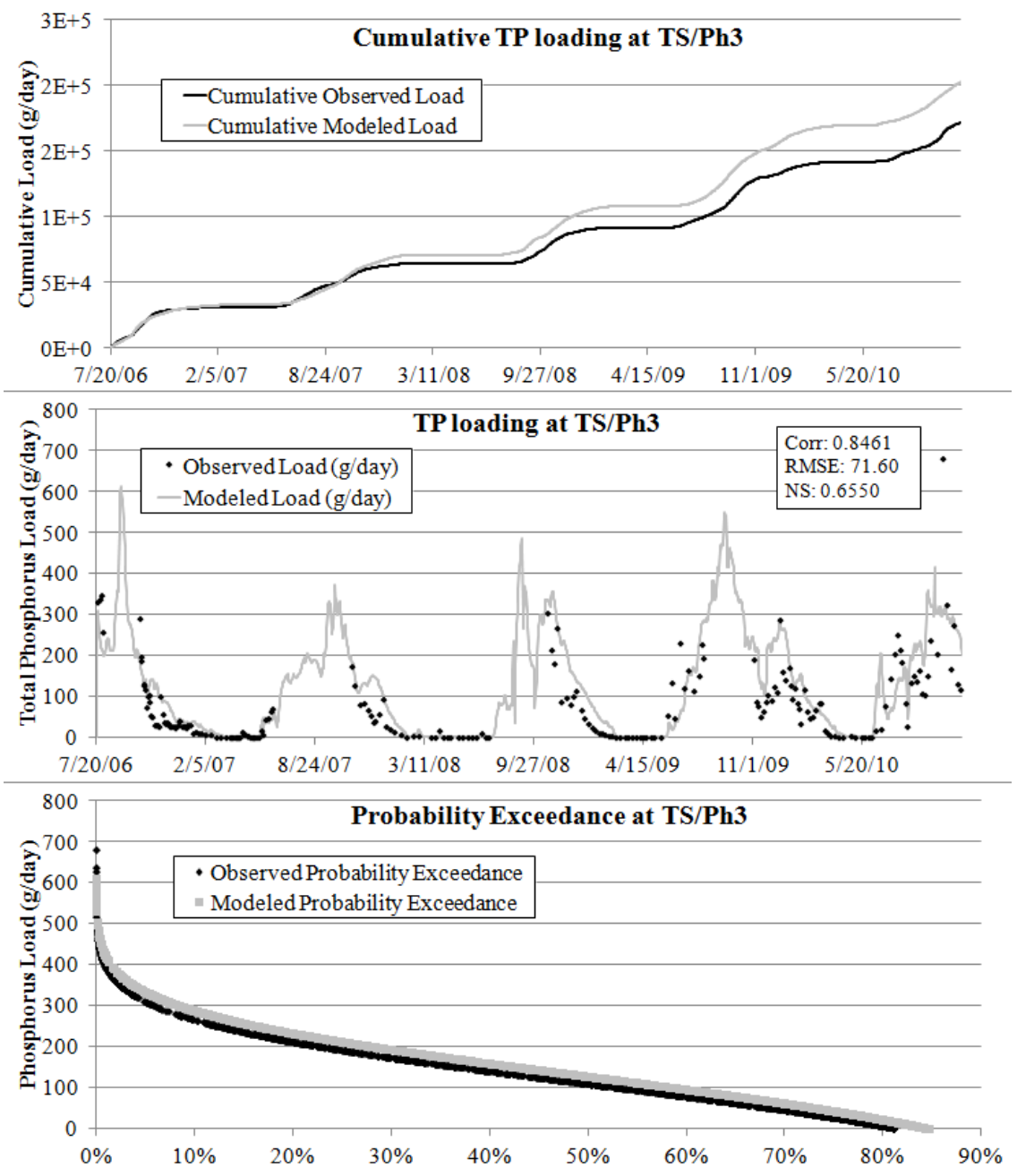

Figure B.4: Calibration results for the M3ENP-AD model at the TS/Ph3 site in Taylor Slough. 


\section{Appendix $\mathrm{C}$}

\section{M3ENP-MB Calibration}

The following figures provide a comparison of modeled and observed Total Phosphorus results at 6 water quality monitoring stations within Everglades National Park for the M3ENP-MB model (developed in Chapter 5). The figures show Cumulative Load and Daily Load over the simulation period. 
Figure C.1: Comparison of observed versus M3ENP-MB model results for two stations.

(a) SRS1d Daily Load

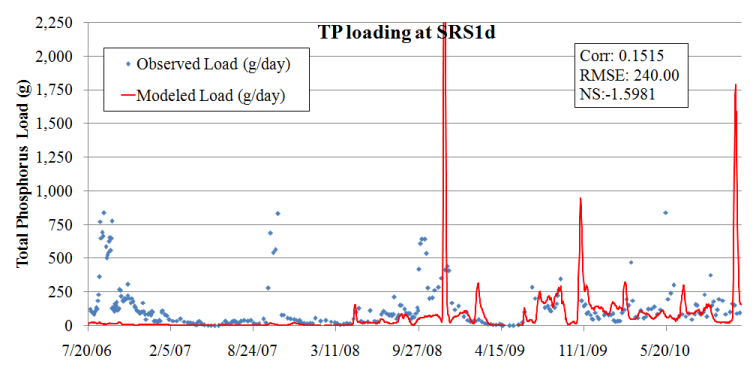

(c) SRS1d Cumulative Load

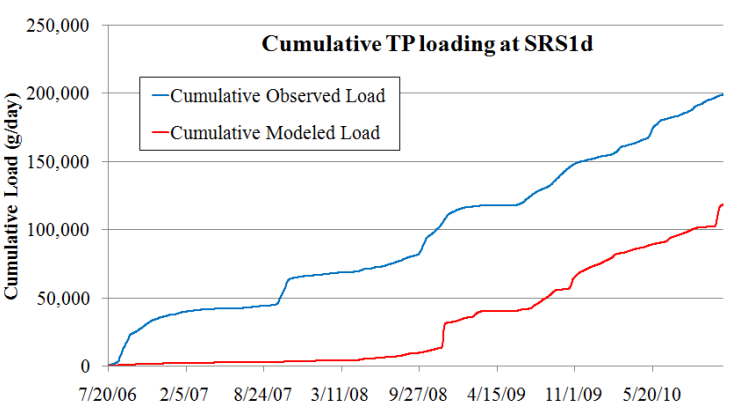

(b) SRS2 Daily Load

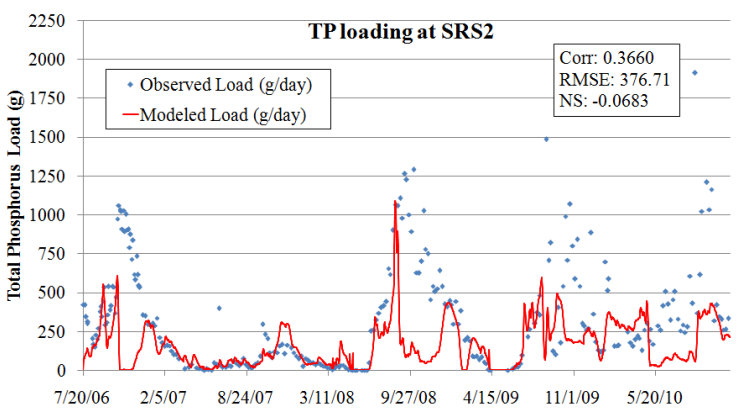

(d) SRS2 Cumulative Load

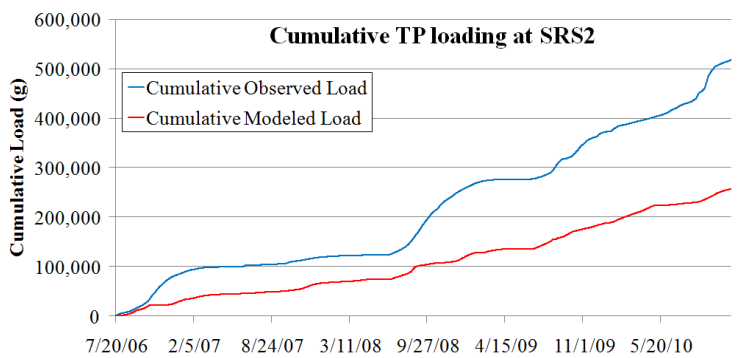

Figure C.2: Comparison of observed versus M3ENP-MB model results for two stations.

(a) SRS3 Daily Load

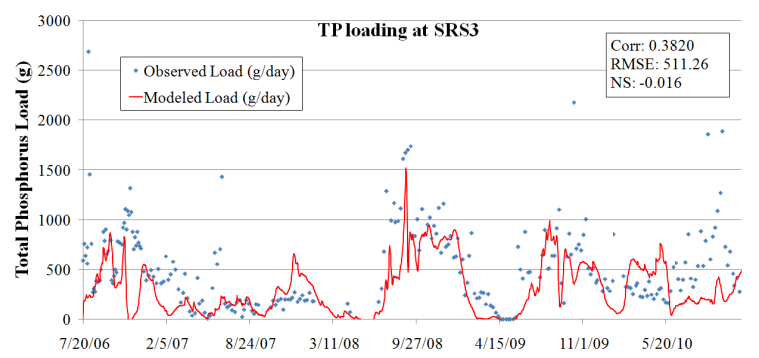

(c) SRS1d Cumulative Load

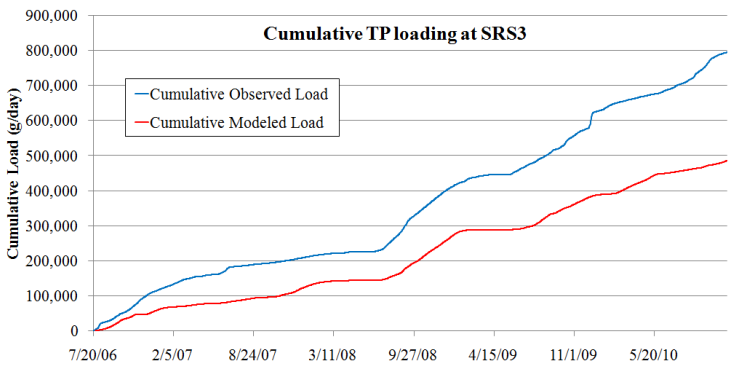

(b) TS/Ph2 Daily Load

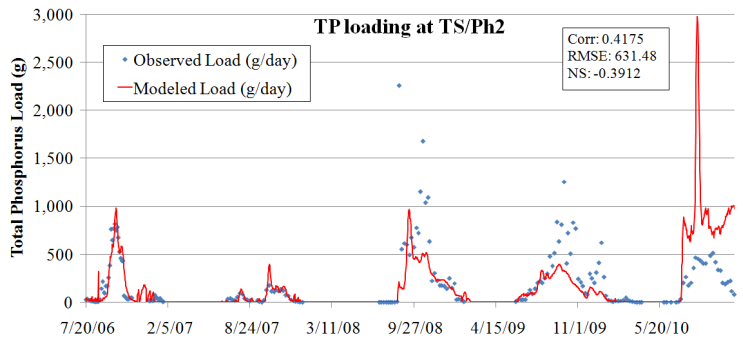

(d) TS/Ph2 Cumulative Load

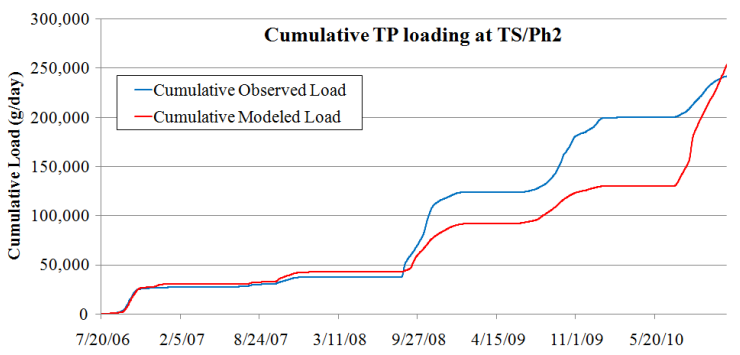


Figure C.3: Comparison of observed versus M3ENP-MB model results for TS/Ph3.

(a) TS/Ph3 Daily Load

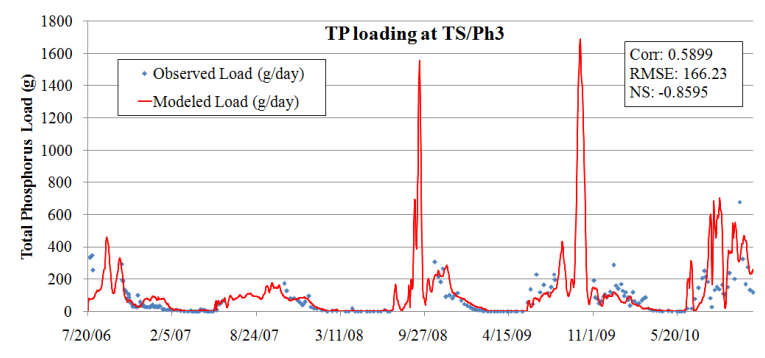

(b) TS/Ph3 Cumulative Load

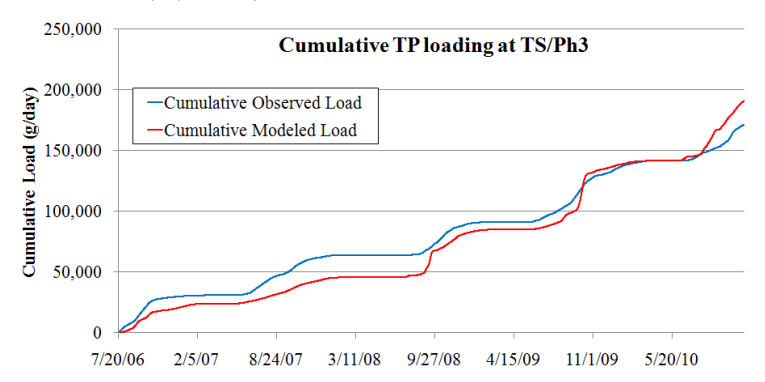


VITA

\section{STEPHANIE A. LONG}

May 18, 1984

2004-2010

2006

2009

2010-2014

2014
Born, Sarasota, Florida

Research Assistant

Applied Research Center, FIU

Miami, Florida

B.S., Civil Engineering

Florida International University

Miami, Florida

M.S., Environmental Engineering

Florida International University

Miami, Florida

Research Assistant

Department of Earth and Environment, FIU

Miami, Florida

Ph.D., Geosciences

Florida International University

Miami, Florida

\section{PUBLICATIONS AND PRESENTATIONS}

1. Long, Stephanie (2009). An Integrated Flow and Transport Model to Study the Impact of Mercury Remediation Strategies for East Fork Poplar Creek Watershed, Oak Ridge, Tennessee. FIU Electronic Theses and Dissertations, Paper 141.

2. Long, Stephanie, Karl F. Huemmrich (2010). Relationships between plant gas exchange and reflectance spectroscopy. AGU Fall Meeting 2010. Presentation Number: B31B-0305

3. Long et al. (2011). The Effect of Sea Level Rise on Freshwater Flooding, the Human Population, and Natural Forest Communities of Miami-Dade County. The Asian Conference on Sustainability, Energy and the Environment: Official Conference Proceedings 2011. pp 82-106 
4. Long, Stephanie A., Temilola E. Fatoyinbo, Fritz Policelli (2011). Simplified change detection method for flood extent mapping using SAR. AGU Fall Meeting 2011. H14C-05

5. Long, Stephanie, Amy M. Cook (September 26, 2013) M3ENP - MIKE-SHE and MIKE 11 Model of Everglades National Park. Environmental and Water Resources Institute Meeting, Miami, FL.

6. Long, Stephanie (March 31, 2014) Analysis of bridge construction as a hydrological restoration technique for Everglades National Park, FL, USA using hydrological numerical modeling. FIU Scholarly Forum.

7. Long, S., T. E. Fatoyinbo, F. Policelli (2014). Flood extent mapping for Namibia using change detection and thresholding with $S A R$. Environmental Research Letters, 9(3), 035002 doi:10.1088/1748-9326/9/3/035002

8. Long, S, A. M. Cook, R. Fennema, G. I. Tachiev, V. Villamizar, K. Kotun, F. Miralles-Wilhelm (Submitted 2014). Analysis of bridge construction as a hydrological restoration technique for Everglades National Park, FL, USA using hydrological numerical modeling.

9. Yaari, G., G. Tachiev, T. Dean, D. Betancourt, S. Long, (2007). Destruction of Aspergillus versicolor, Penicillium chrysogenum, Stachybotrys chartarum, and Cladosporium cladosporioides Spores Using Chemical Oxidation Treatment Process. Wiley Periodicals, Inc. 